

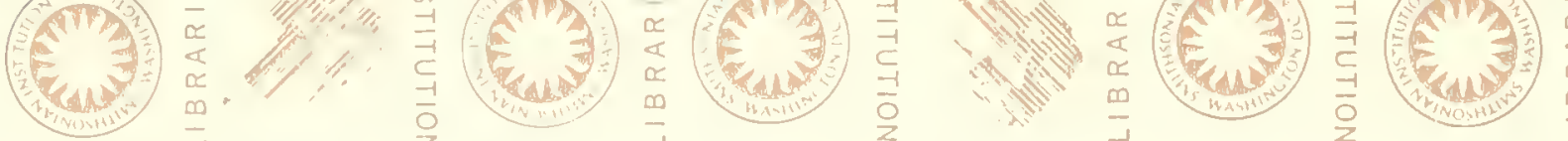

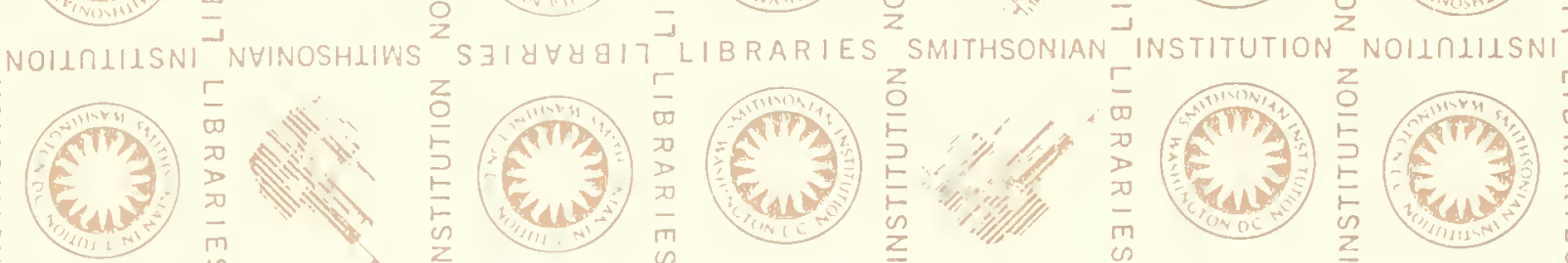
$=\frac{1}{2}=2$ RARIES SMITHSONIAN NOILILILSNI LIBRARIES ${ }_{n}^{\text {NOILOLILSNI NUINOSHLIWS }}$ L (ybarate (E)

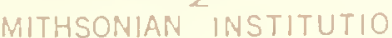

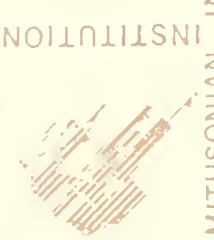
NGINOSHLIWS
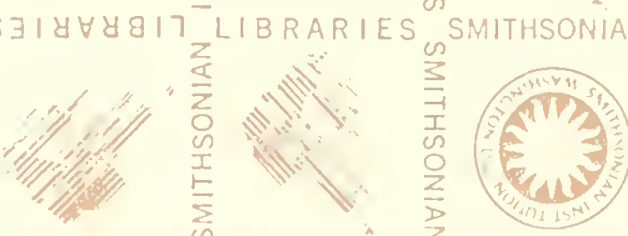
NHINOSHLIWS in SIIYYY817 LIBRARIES SMITHSONIAN

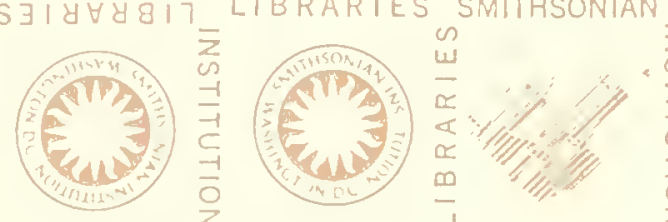
INSTITUTION NOILOLILSNI MITHSONIAN<smiles>c1ccc2ccccc2c1</smiles>

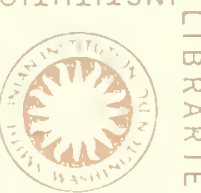
anding $\left.\left(C^{2}\right)^{2}\right]^{2}=$
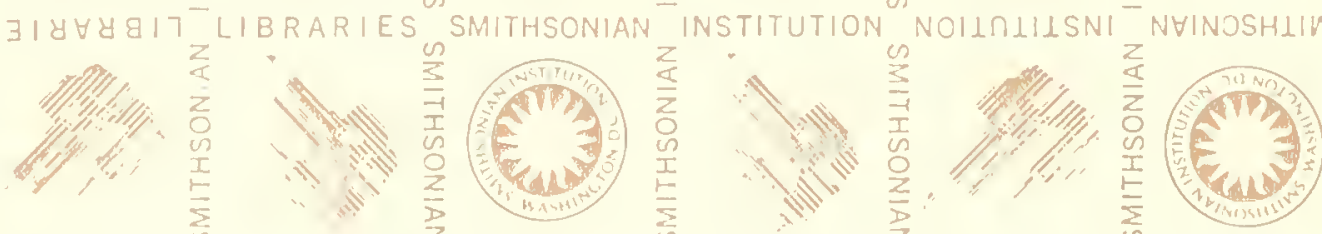

N

NOILIIISNI NHINOSHHIAS
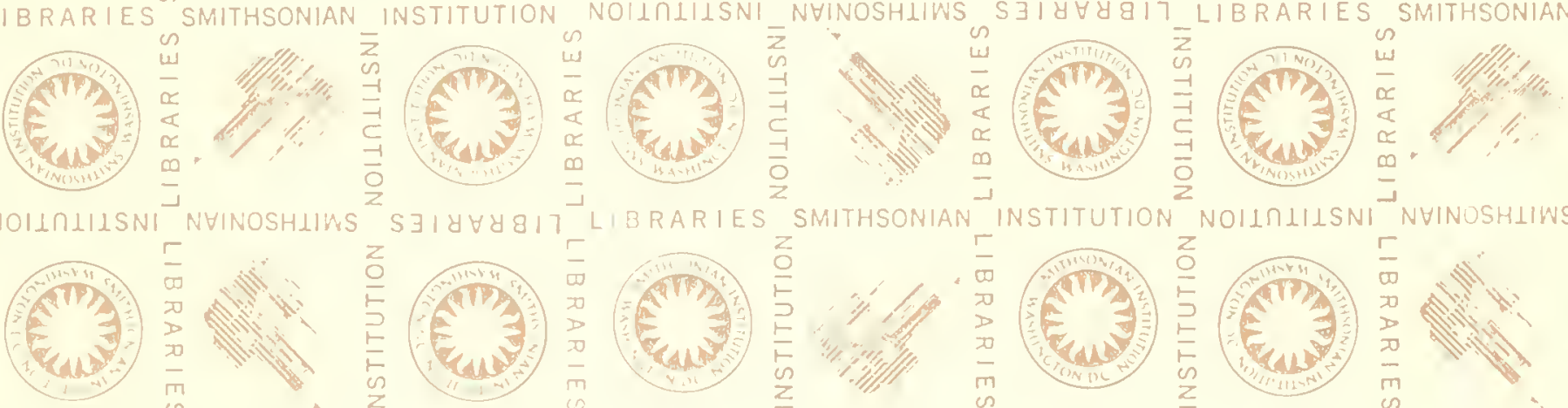

$z^{L}$
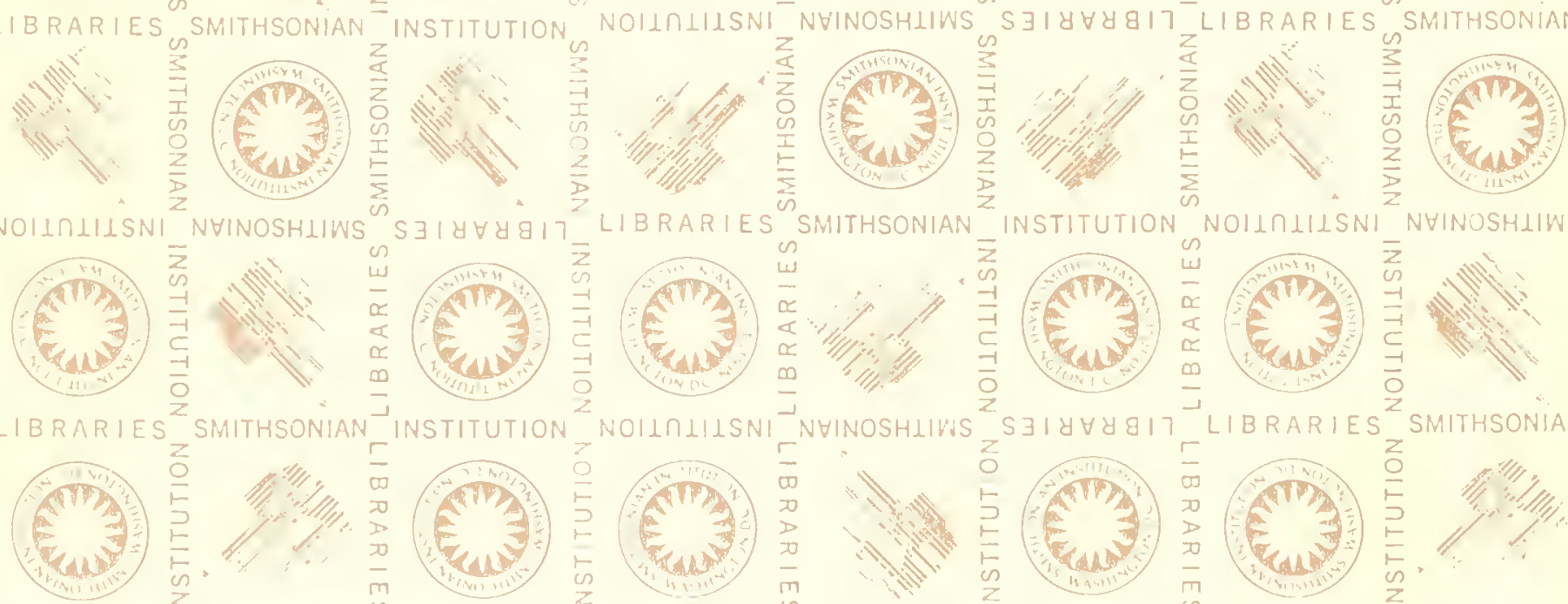
$N(3)=3$
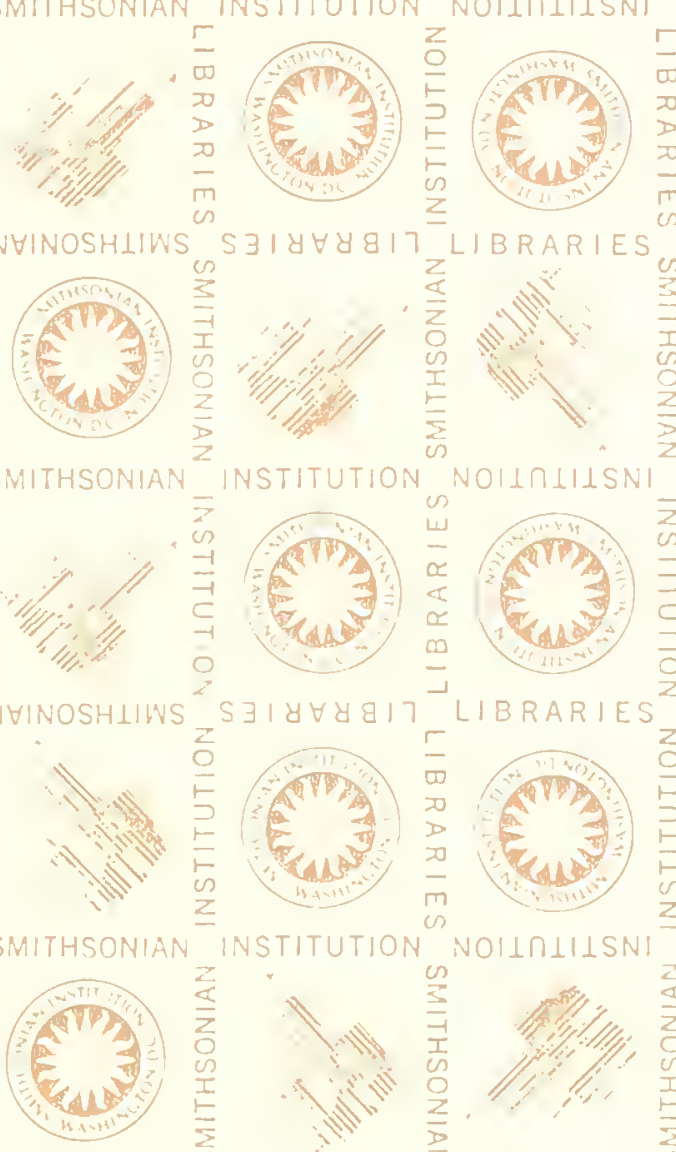
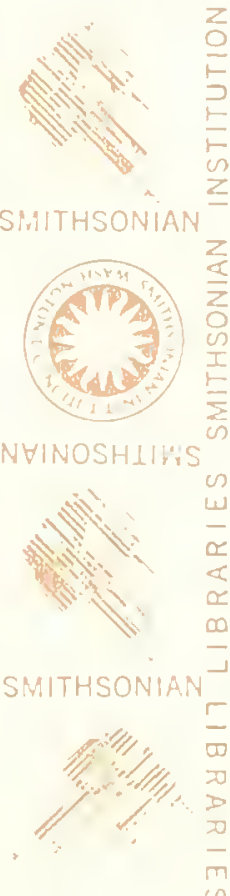

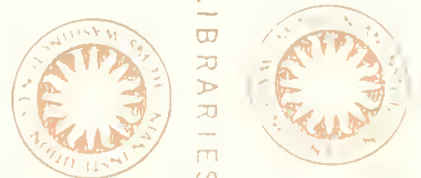

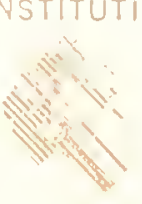

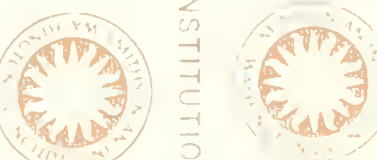

(R⿴囗十)

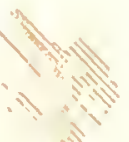

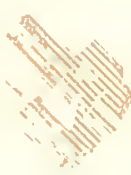

(coves
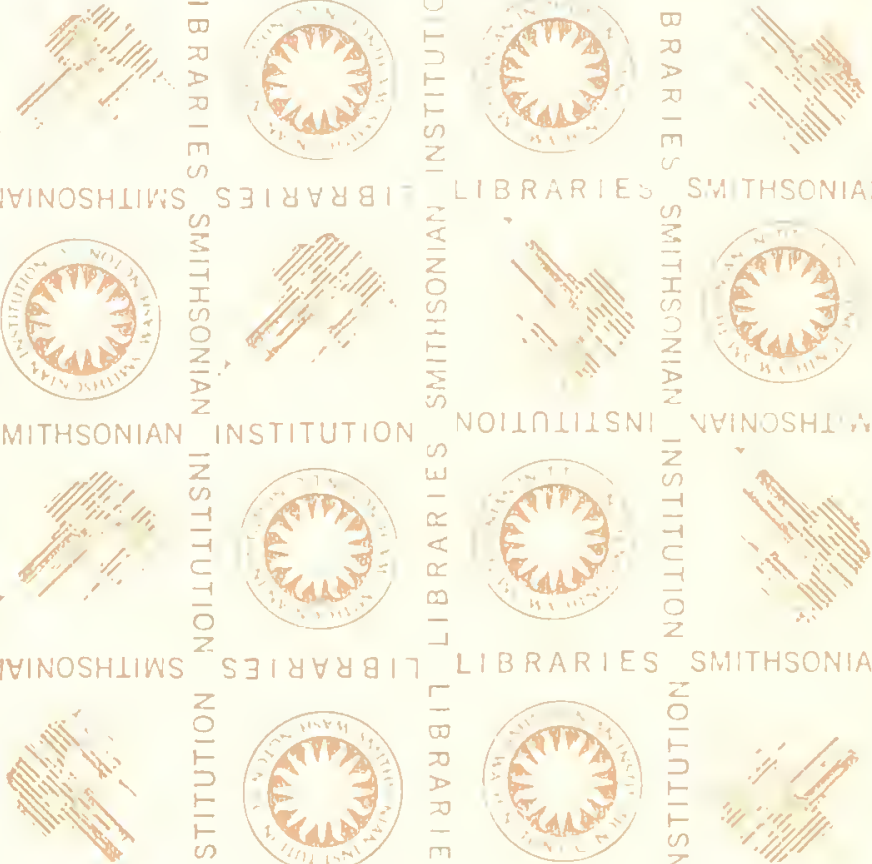

E(d)
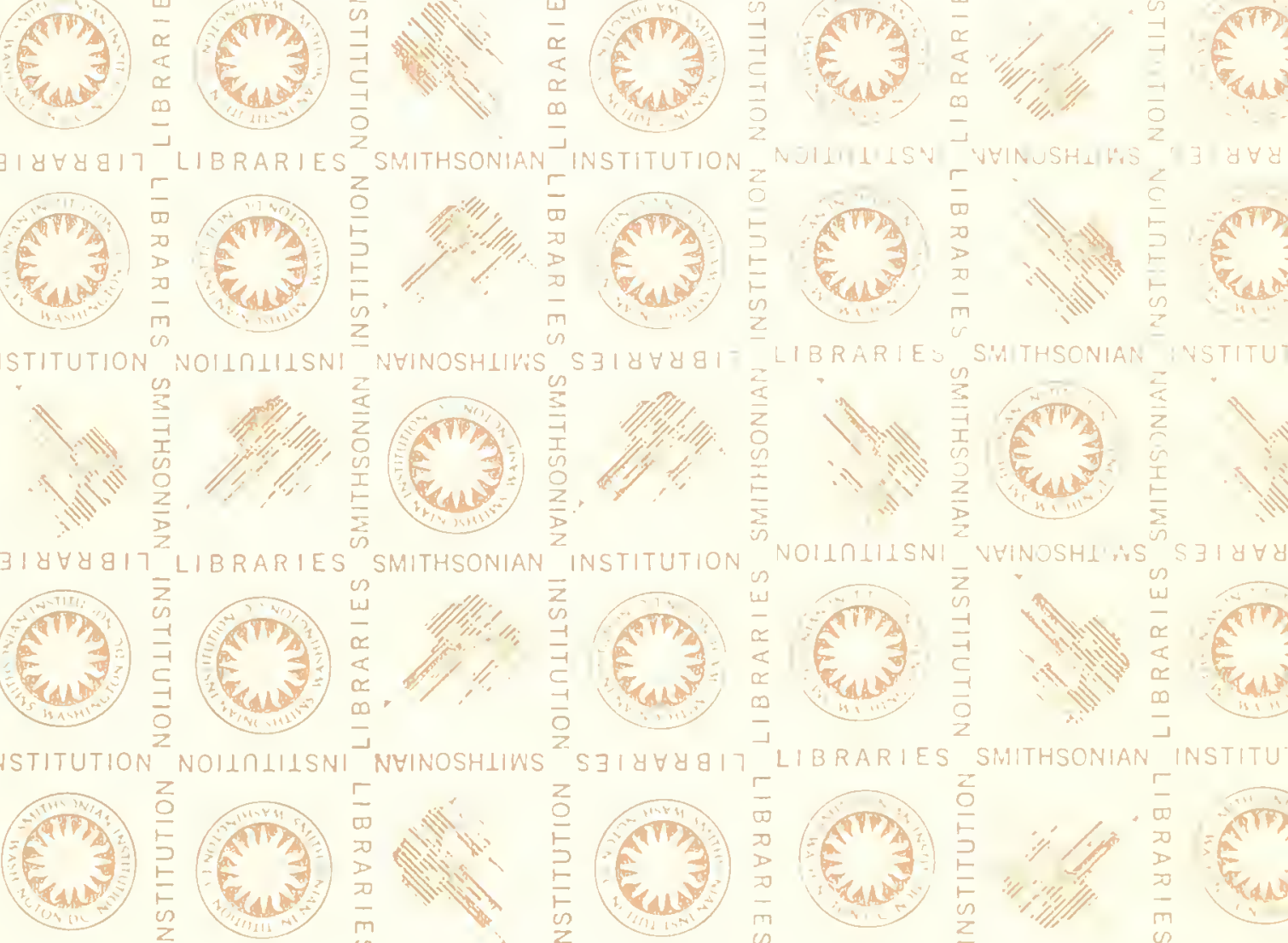

(N)
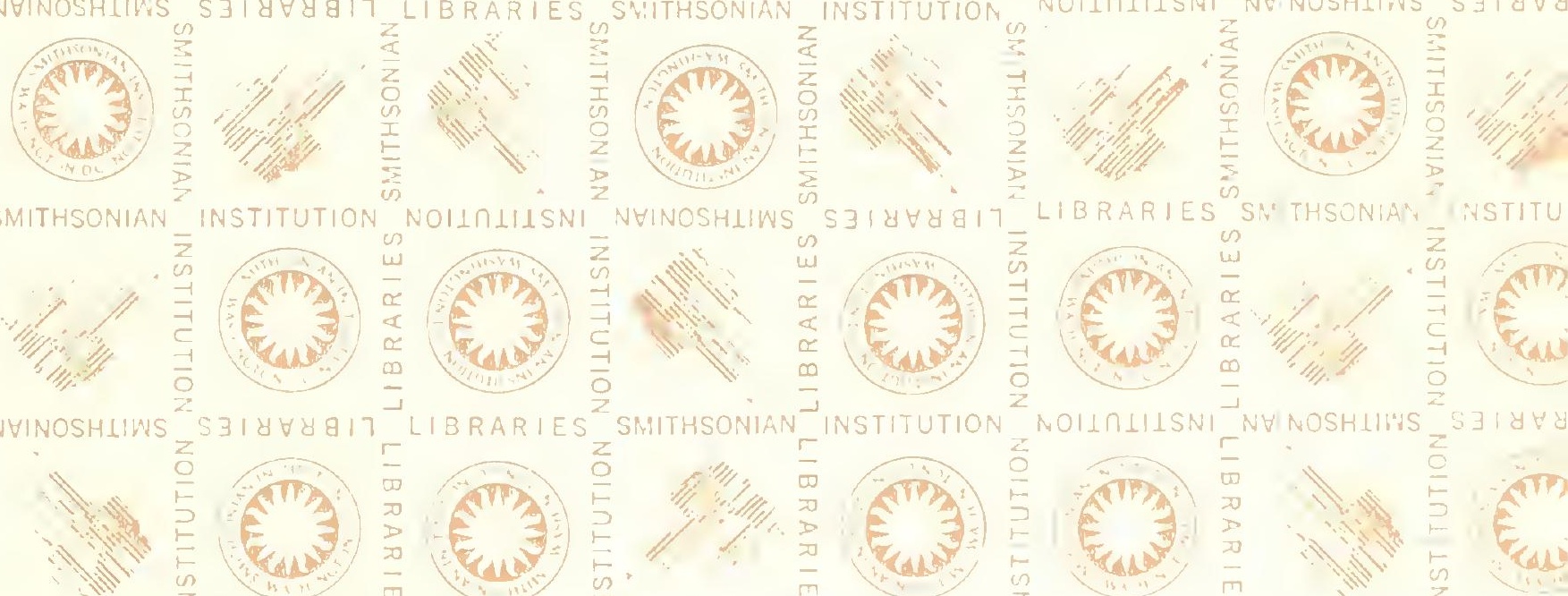

$$
\text { ( }
$$
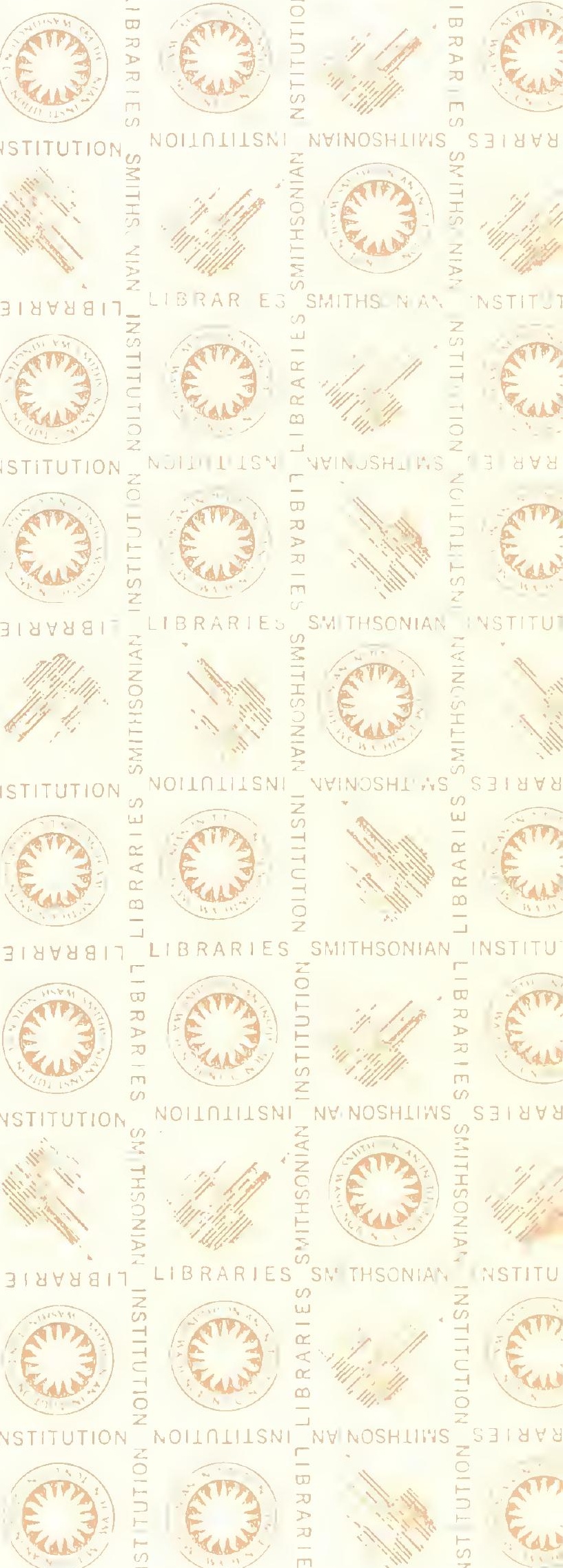





\section{ÉTUDES ZOOLOGIOUES}

SUIH LU:

\section{GRUSTACES RECENTS}

DE LA FAMILE IES PORTITIESS

M. ALPHONSE MIL NE ED IV ARDS

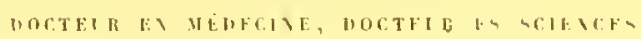

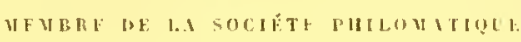

\section{PARIS}

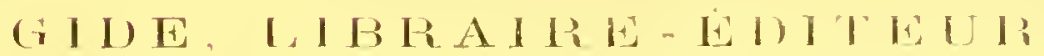

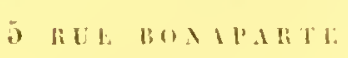

$1 \$ 61$
CRUSTACEA LIBRARY SMITHSONIAN INST.

RETURN TO $K-119$

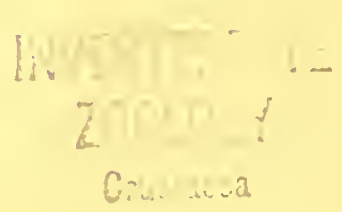

4 \& 8

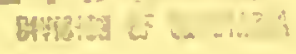
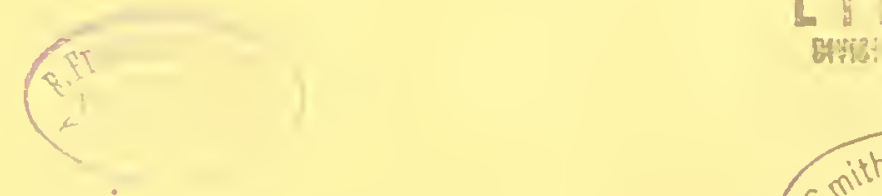



\title{
ÉTUDES ZOOLOGIQUES
}

\author{
- I'li 1.1.: \\ CRUSTACÉS RECENTS \\ UE W PAMLLE HES PORTEYIEN
}

M. ALPHONSE MILNE EDWARDS

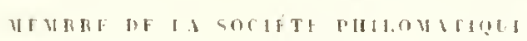

\author{
PARIS

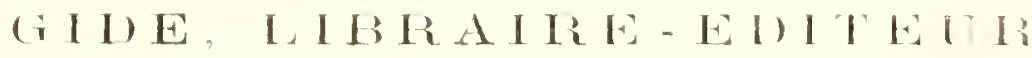

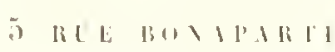 \\ 1861
}

212425 



\title{
ÉTUDES ZOOLOGIQUES
}

\author{
SLE LE \\ CRUSTAGÉS RÉCENTS
}

DE LA FAMILLE DES PORTLYIENS

PAS

M. ALPHONSE MILNE EDWARDS

Les recherches patéontologiques que jai entreprises sur les Crustacés lossiles m'ont conduit a laire une étude altentive des amimaus de cetle etasse, qui anjourd'hui penplent nos mer's; car il m'a paru nécessame d'établir une romparaison rigonreuse entre les espreces éleintes el les espres actuelles. do laçon il hes faire toutes

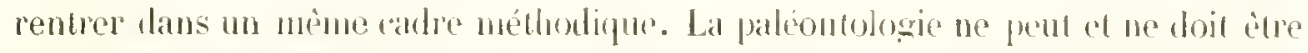
considérée que comme une branche de la zoologrie; at parce que le squetedte, soil intérieur soil extérienr des atres vivants. contiendra plus ou moins de matiere

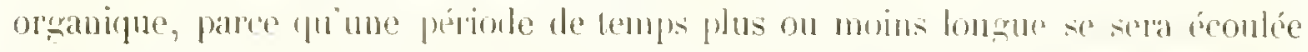

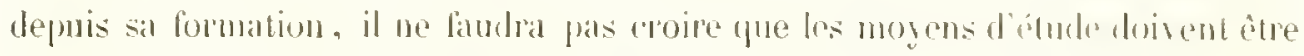
diflérents el que le point de départ ne soit pas le mème. En próparamt la mono-

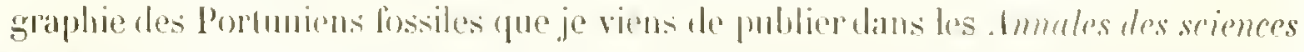

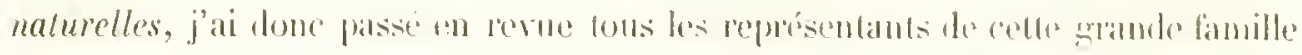
zoologique qui se louvent soil daus la bello collection carcinologique du Mustum Archives do Mleses. T. $\mathrm{X}$. 


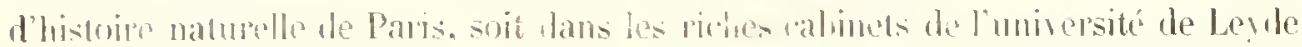
el du Vuso britamnique à londres, que j’al visiles lans ce bul. Beaucoup de res

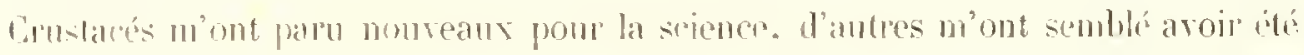

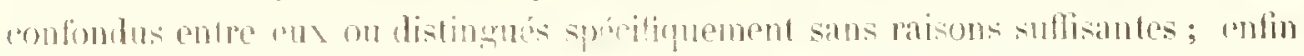

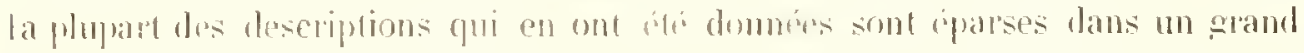

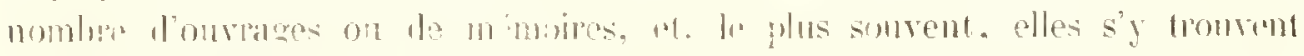

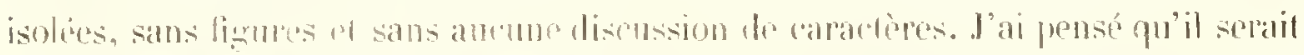

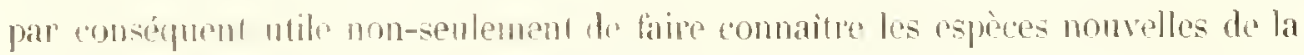
famille des Portuniens que jai pu rommailre. mais d'entrepremdre me révision

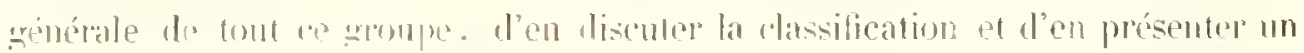
bablean ansi complot que posilde.

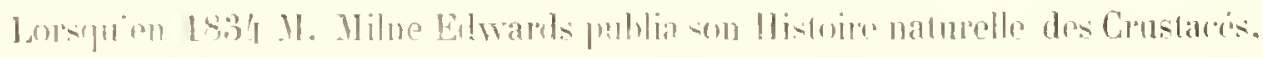

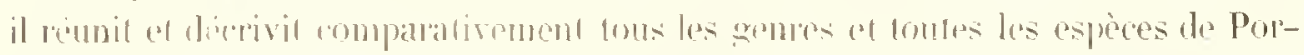

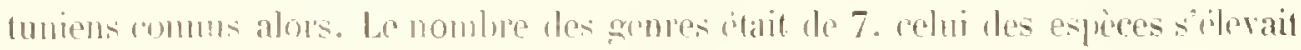

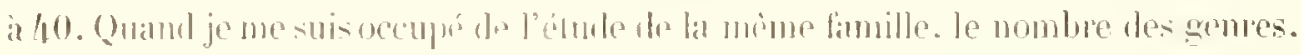

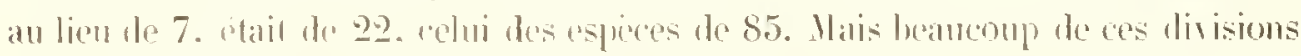

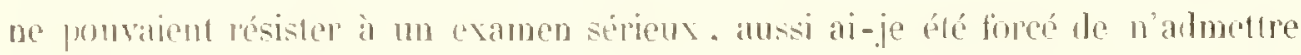

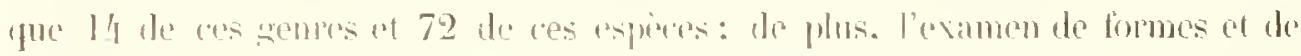

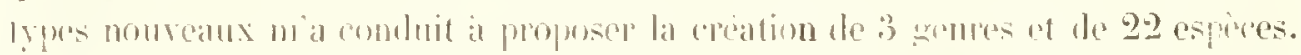

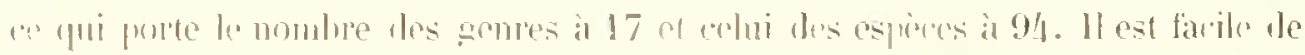

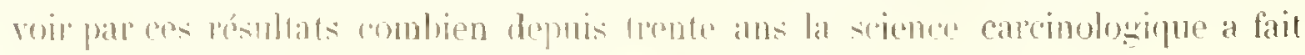

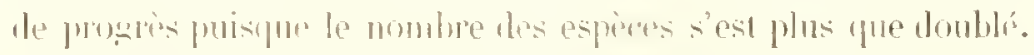

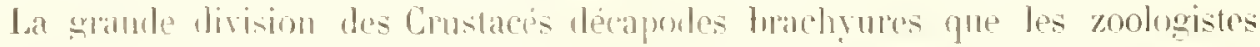

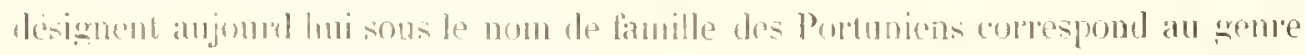

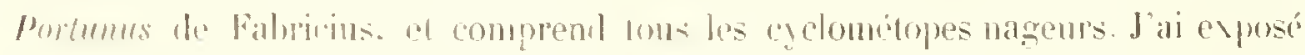

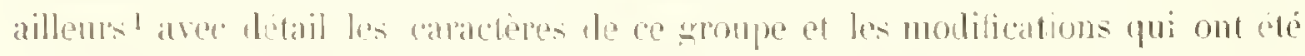

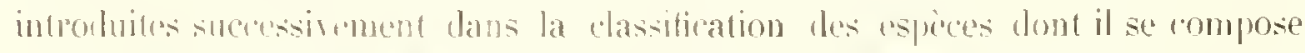
par Late?. Lalleille. M. Milne Erwardo, de Haan. at M. Dana. Je ne crois pas

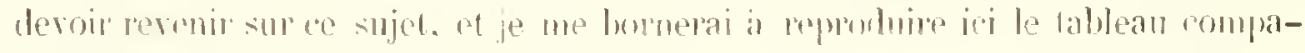
ratio des crentes tels que je les ai adoptis.

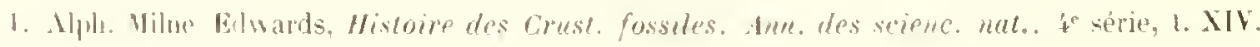
p. 2010 a - - 


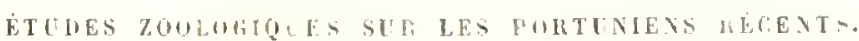

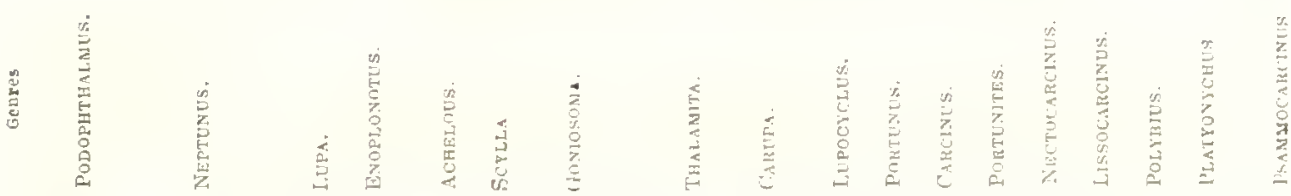

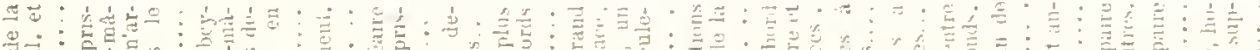

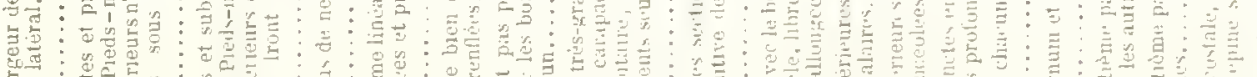

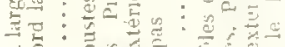

9

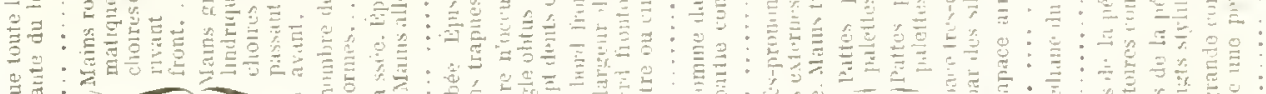

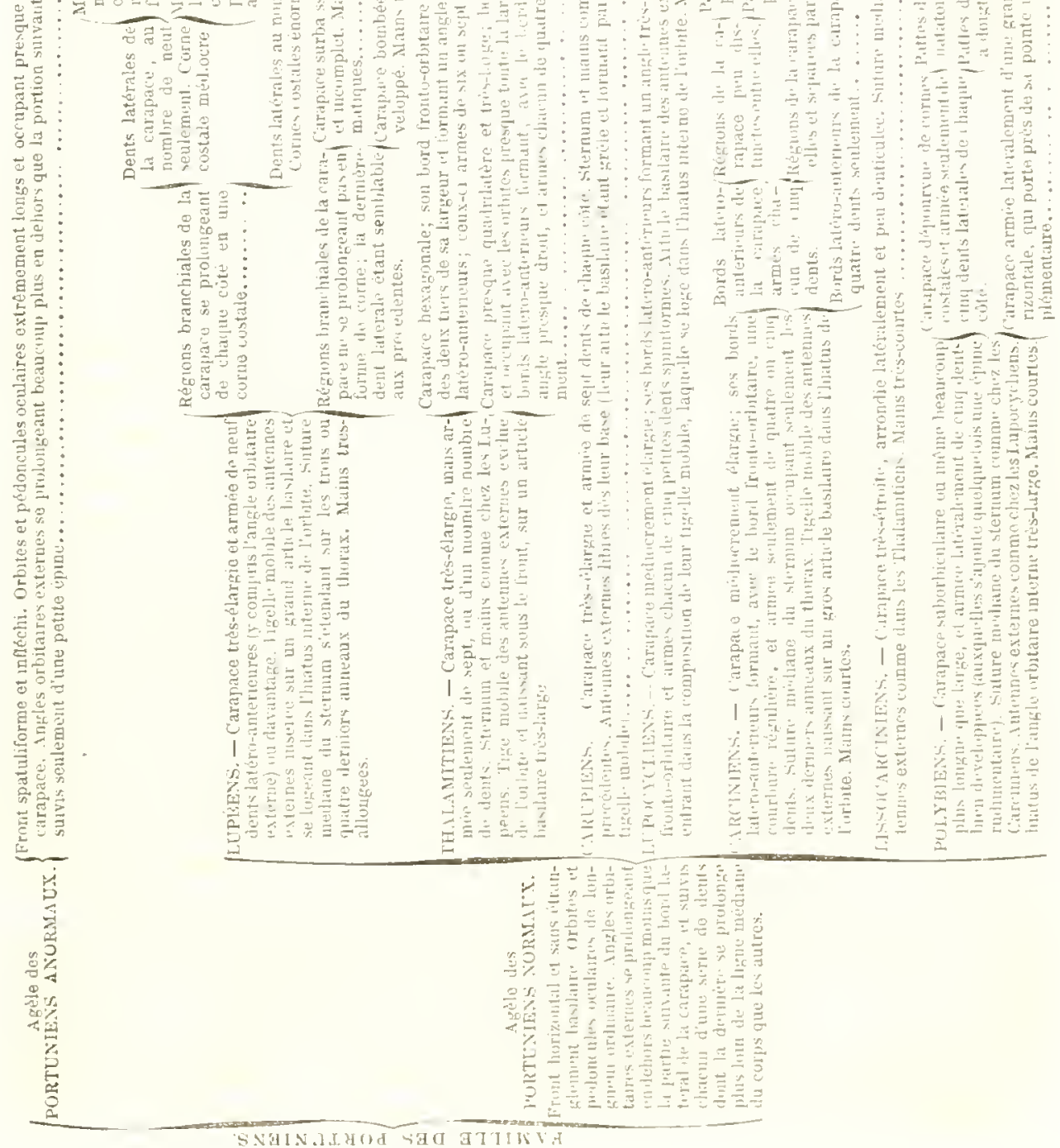




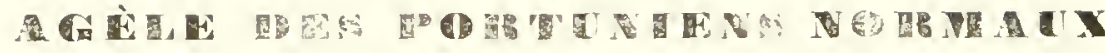

Front horizontal et sums étrantenent hasilaile. ordites et pridoncules oenlaires de longnenr ordinare, angles orthtames evernes se prolongeant en delrors beaucoup moins que la prortion suivante du bord latéral de la carapace, et suivis d'une série de dents domt la derniepe se frolongre a une distance pho grande de la ligne uniliane que ne le fint les antres.

\section{GROLPE DES LUPENS.}

En 1815, Learh sépara du genre Portumus de Fubricius les espoces à carapace

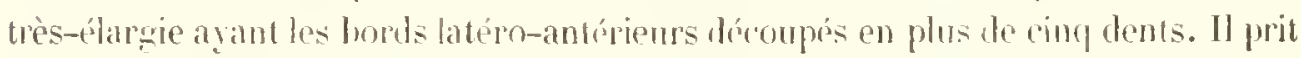
pour type de cette nouselle division le Portumus pelagicus et le l'. forceps (Fahricius) et lui donna le nom générique de Lupa. En 1829. Latreille ell sépara les es-

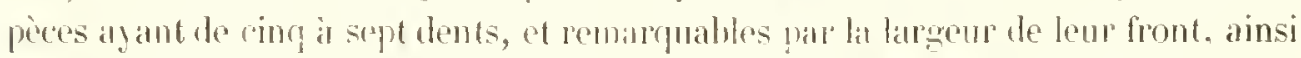
que par la forme tronquée de leur carapace. En 183/. 11. Milne Elwards adoptil

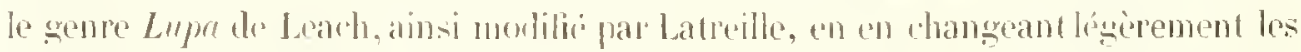
limites ef les arartives, el il y fit rentrer toutes les especes a carapace dargic

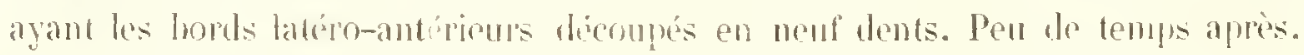

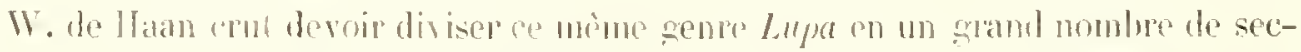

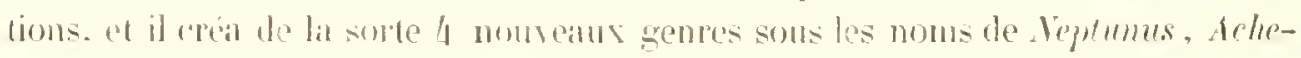

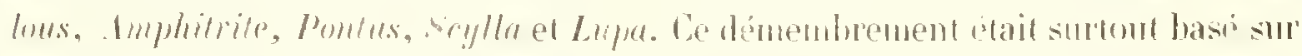

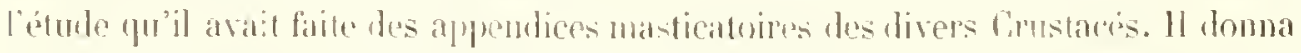

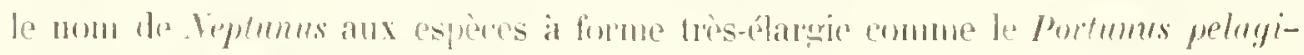
cus et lo Portunus sungumolentus de Fabricius. dent la dernière dent latérate ou

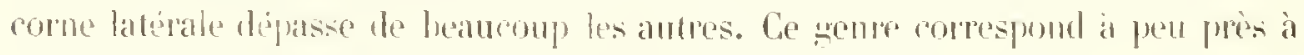
la division des Lupies nageuses de M. Milne Edwarils.

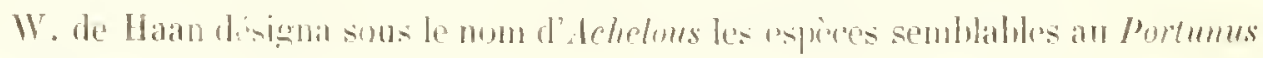

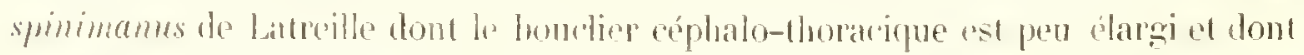
la dent postérieure est a peu de dhose près semblable à celles qui la préèdent.

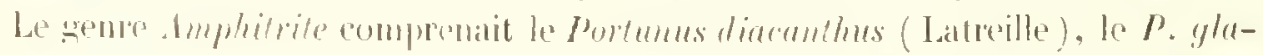

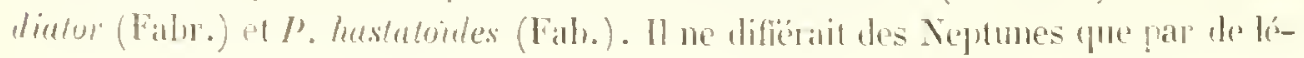




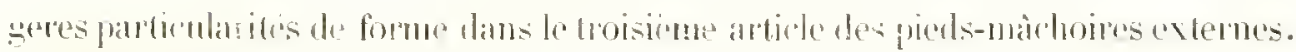

Le geme Pourus liut cró par le naturaliste hollandais pour mo espece nouvelle

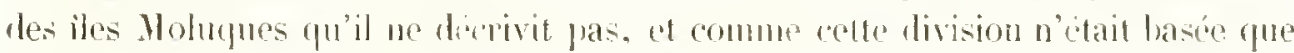
sur la forme des appendices bureanx dont la vateur est insignifiante. il est impossible anjourd'hui de savoir à yuor on peut la rapporter.

Le gemre Lapa ne comprenait plus qu'me espince, Je Portunus forceps de Fabricins caractivisé par ia forme du trobième andiele des pattes-màchoires extermes.

Le genpr Seglla, qui ne comprenait aussi qu'une seule espece, le Cancer serratus de Forshil, correspondait candement an soms-gente de's Lupues convexes de II. Hihne Elwands.

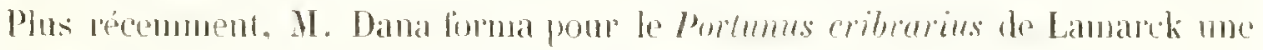
nonvelle division généripue soms le nom d'atrempus.

En 1851. M. Hephots, a Leyde, en suivant la methode de classilication de

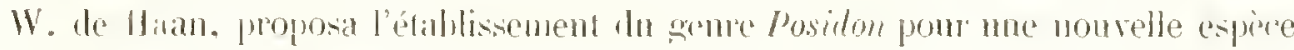

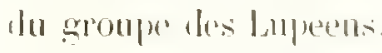

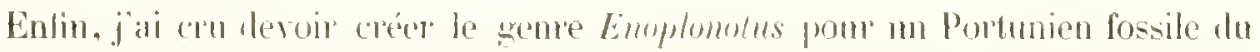
terrain nummulitique de Honte-Boka. qui se rapporte ausst à la division dont nous nous occupons.

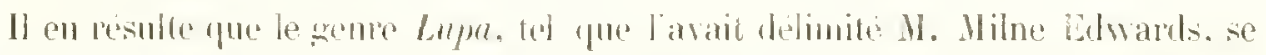

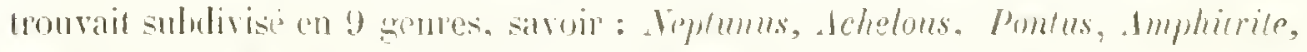
Lupa. Secylla, arencers, Positon et Emophlonolns.

Une telle muliplication atait foin dètre nécessaire. et, pour des ratisons que j'ai exposées ailleurs, j'ai aru deroir supprimer les genres lontus, amphitrite,

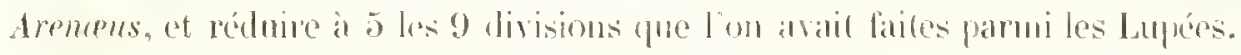

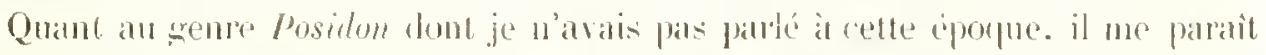

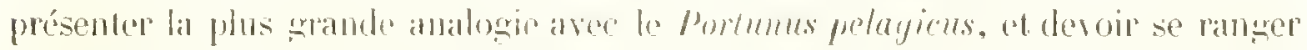

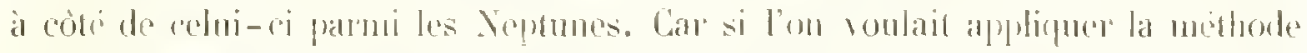

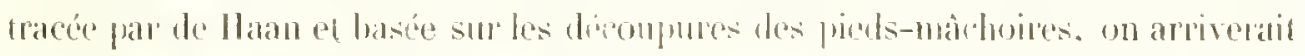

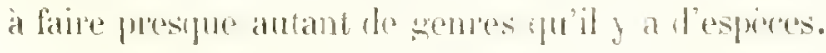

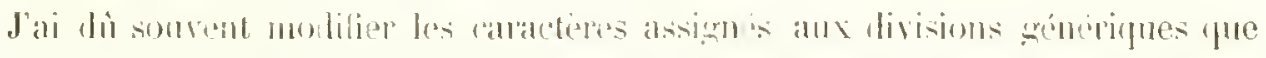

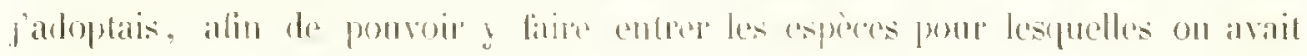

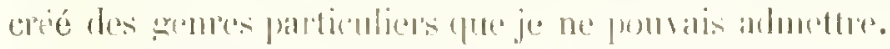

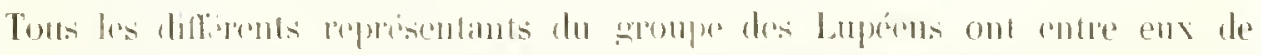

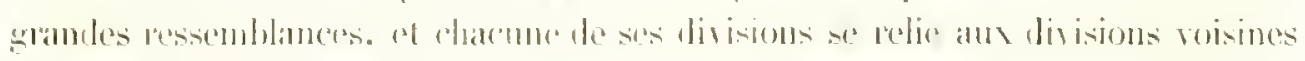

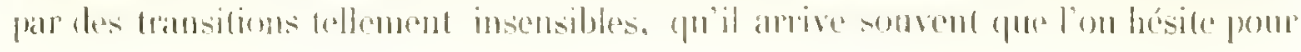




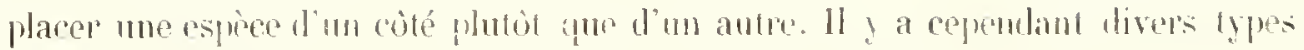
yue l'on pent regarder comme autant de centers d'attraction at antour desquels viennent se grouper un reptain nombre d'especes : ce sont as rentres que jaa

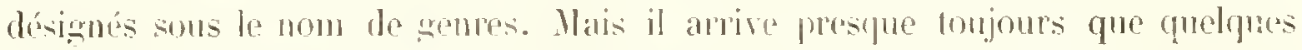

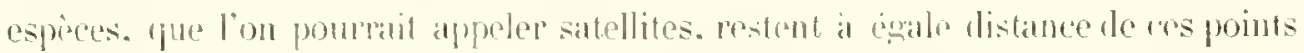
centraus, et servent de flasige entre ens. Vème entre le groupe des Lupécns el le grompe des Thalamitiens. noms aumens l'oceasion d'obserser le ces transitions.

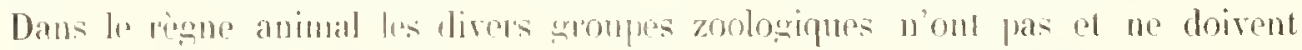
pas avoir des limites anssi nettes que eelles gur fuelques zonlogistes on souvent

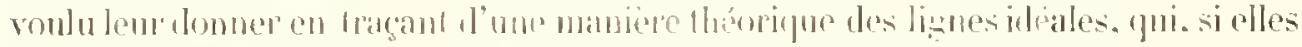

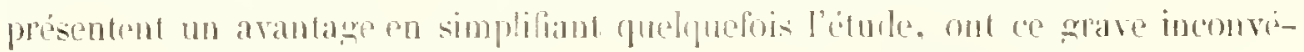
nient te mas juer les viritables allinités que les dilférents attros ont entre eux.

\section{Genre NEPTUNG.}

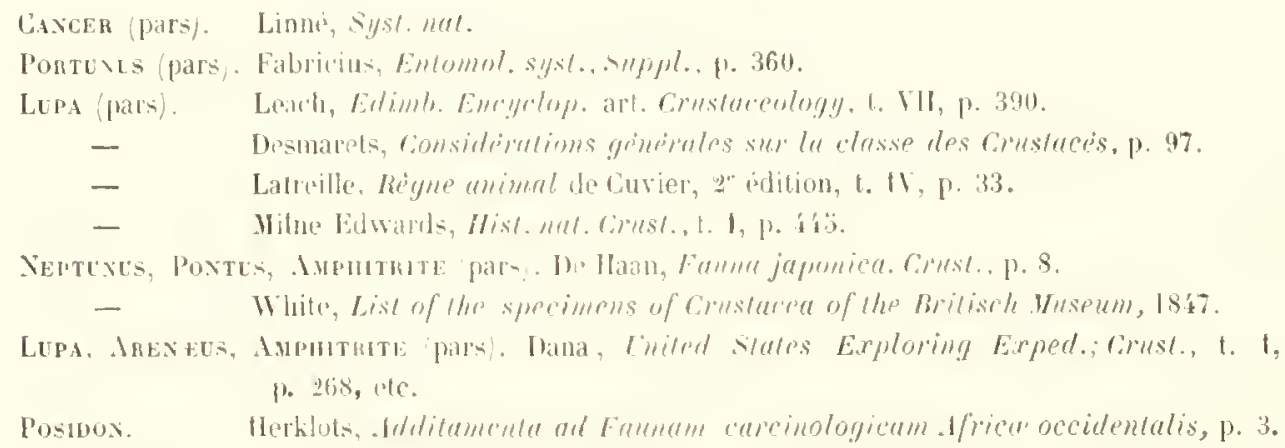

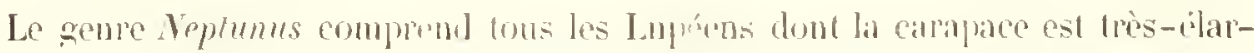
gie, et porte de charque còré une corne latírale trìs-longue; dont les pieds-mâchoires externes sont dehordants. el hout las sufures du sterum se continuent jusque sous l'alutomen; mais or iemier caractere peut mancpuer.

La earapace est ro gquéral traversie far du lignes raillantes granuleuses. L'une se roit sur la région gastripur. c'est la ligne éphigastrique; an-dessons il en

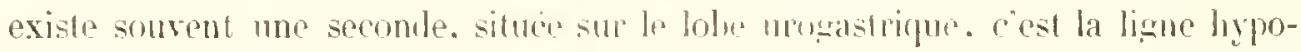
gastrifue; enfin vers la farlie antirieure de thateune das rigions branchiales,

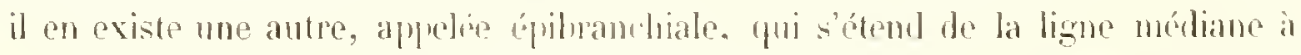
l'extrénité des cormes latérales. Antlessous de celle-ri, sur la partie postíricure des regions iranchiales. on voit qualquefois d'antres lignes phus petites. Le front 


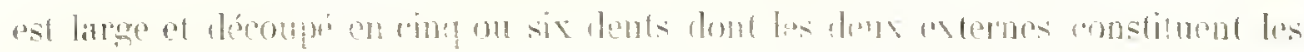
angles ortitaires supérieurs internes. Le planher de lindite s'avance heanconpl

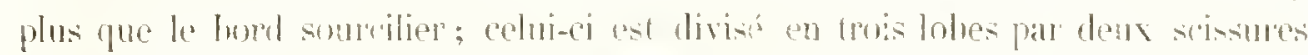

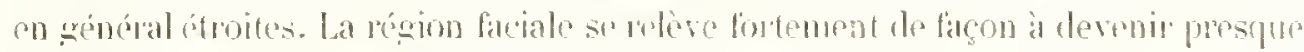

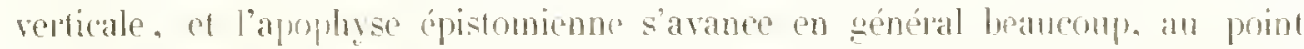

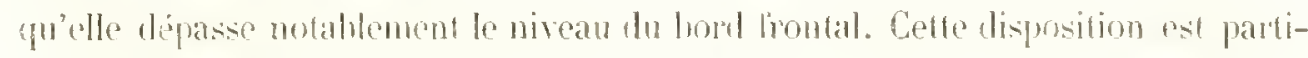

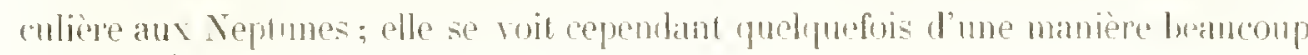
moins makrfui chez gurelques antres Lupéens.

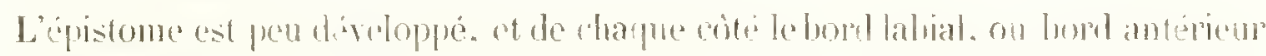

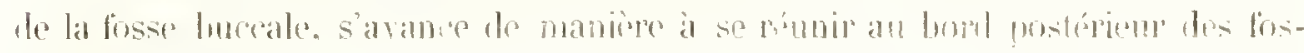

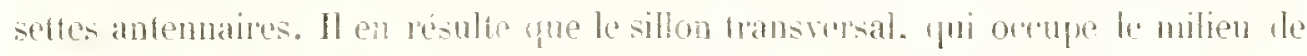

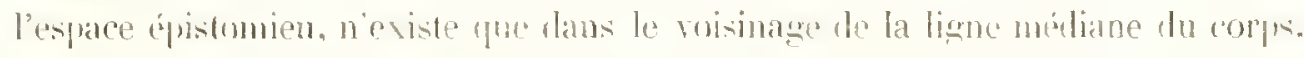

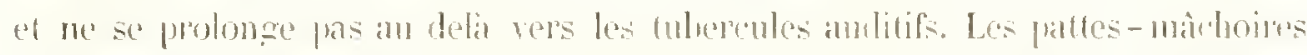
externes sont courles ef feur portion operenlaire ne su prolonge pas sur l'ipistonte. comme nous le rerrons dans le gonde Lupa proprement dit. Lindostome est prescue

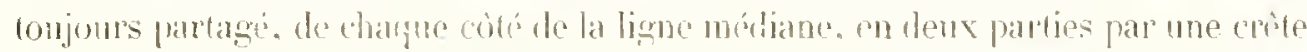

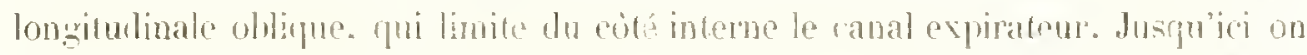

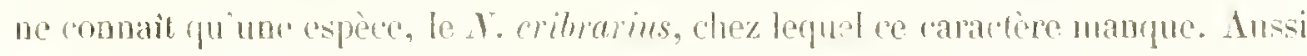

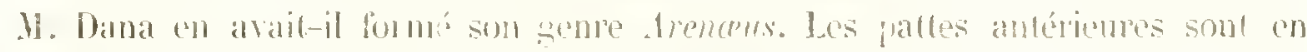

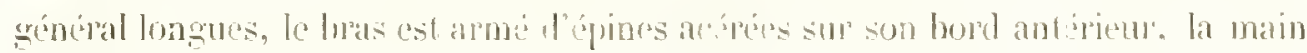

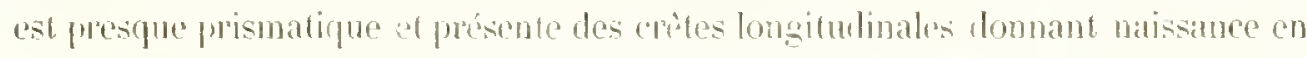
dessus a des prolongements spiniformes. La cuisse des pattes natatoires est ordinairement lisse sur son lemel inférieur; il est extrument rare d'y roir une épine aigue comme cela existe unjours chez les Thatamiliens. Enfin la suture módiane du plastron stemal s'atemel sur les trois demiers anmanx du thorax.

Co genre est tris-bombrou on esperes. qui pour la fupart se rescmblent beatcoup cutre elles. Anssi est-il tres-dílicile d'y atahlir des serdions conme on pent le faire parmi les Thalamitiens.

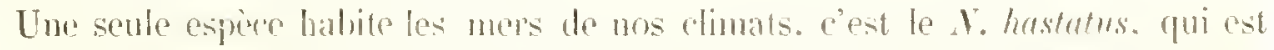
rommun dans la Bróliterranes toutes les autres sont exoliques. Quelques-mos atteignent nne taille tres-onsidirable. d'autres au rontraire ne dépassent pas quelques millimintres.

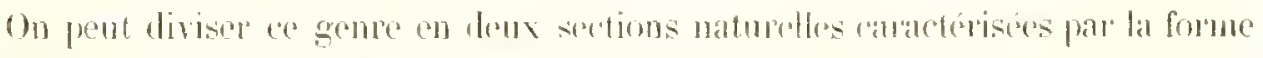

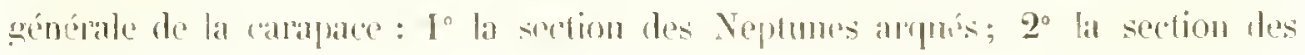
Neptumes ansulares. 


\section{\$1. NeprTEes ArQués.}

Front el bords latero-anterieurs disposés sur une ligne courbe à grand rayon et dont le centre se trouve sur la ligne mediane, pres du bord postérieur de la carapace.

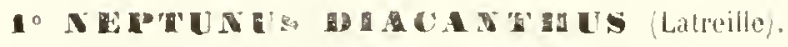

Pt. XXX, fin. 1

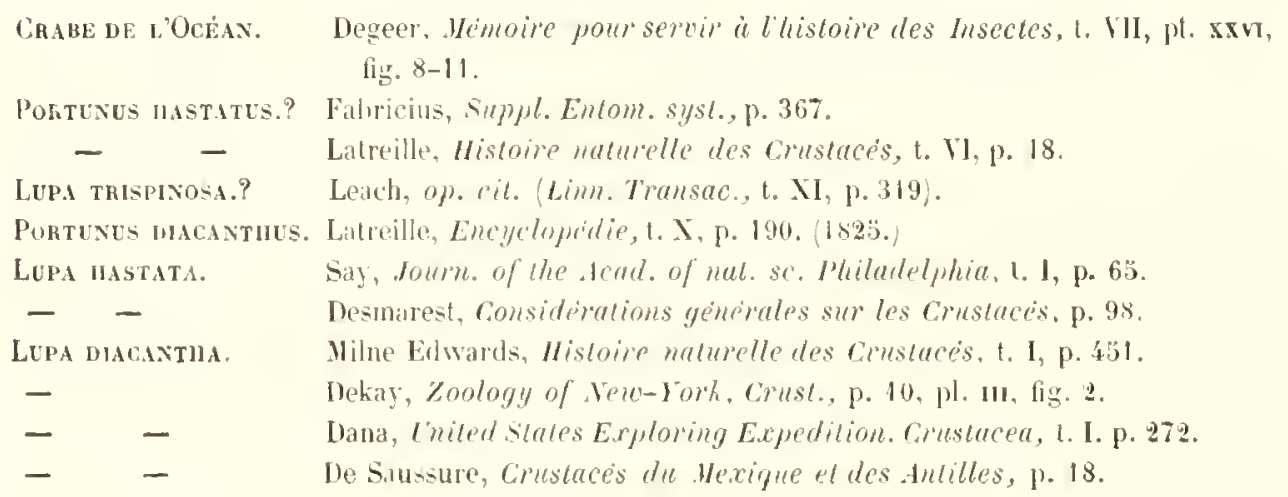

Carapace très-élargie (Io diancetre transversal plus lu double du diamètre longitndinal ), peu lombée. finement granuleuse. Lignes épirastriques et épibranchiales hien marquées. Bonds latéro-anterieurs à peu près égaux aux bords latéro-postérienrs; neuvieme dent longrue et aigué; les autres semblaliles entre elles. larges ì la base, dirigées en dehor's et non en arant. Front découpé en six dents; les deux medianes trè-petites, les mitovenues plus larges et plus aigrues, les externes obtuses. Bord sourcilier divisé parr deux scissures étrontes. Apophyse épistonicune tres-longne ef dífassant heauronp le front. Troisieme artiele des pattes-màchoires externes Irés-échancrés en haut et en dedans. I'attes antérieures assez robustes. Bras armé sur son hord antérieur de trots ćpines, et à l'extrémité du bobl postéreur d une autre épine. Irant-hats portant sur sal face externe un tubercule sfinilorme. Mains traversées par des crêtes très-légèrement granuleuses et armés de deux épines l'une au-dessus de l’artirulation de l'avant-bras. l'autre à la partie interne au-dessus de l'articulation tu ponce. 
Abdomen du mâle se resserrant brusquement à partir du quatrieme arlicle, de façon à ressembler à la leture T renversér (I).

Cette esprice peut aciunirir une taille ansez considérable. On en rencontre souvent des individus dont la carapace a environ 14 centinètres de large sur 6 de lon.s.

IIabitation: Toutes les còtes de l'Amérigue.

Cette espece pent offrir certaines modiliealions de forme tres-importantes à noter. On en voit des individus dont les dents midianes du front ont complétement avorté, de façon 'pu'an lien de six on n'en comple que quatre (Toy. pl. xxx. fig. 1. et $1^{a}$ ), et si l'on ne tronvait pas fons les pasidgos entre ces denc rariélés. on serait tenté d'en faire deux especes distinctes.

Collection du Mluséum.

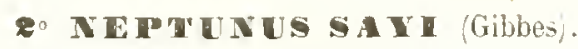

PI. XXIS, fir. 2.

Portuxus pelagicus. Bose, Misloire naturelle des Crustaces, t. 1. p. 220, pl. v, fig. 3.

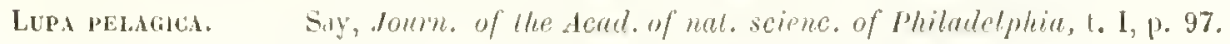

- - wokay, Zool. of New-York, Crust., p. 11, pl. Wi, fig. 8.

Lup.i Sax. Gibhes, citreinological colleclions. Proceed. Americ. 1ssociat., 1830 , P. 178.$)$

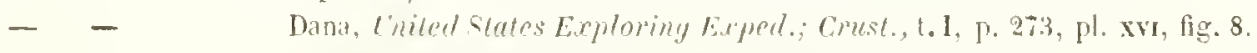

- - Stimpison, Prot. Descripl anim. peperteb. proceed of the Acad. of nat. scienc. of Heiladelphia., 1835, p. 30.)

Carapace plus hombie et moins élargie que dans l'usprece prócródente. Les lignes épibranchiales et épigatsuligue sont à peine saillantes. Front divisé en six dents dont les deux módianes sont presique égalles anx laterales. Trobieme articte des

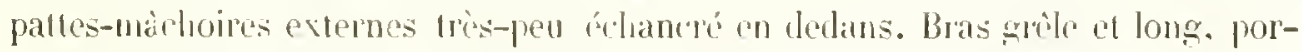
tant sur son bord antérieur quatre dphines, landis qu'il n'en présente pas à l'extré-

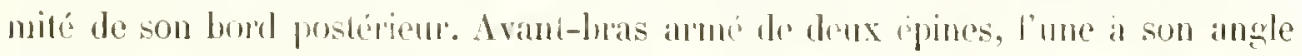

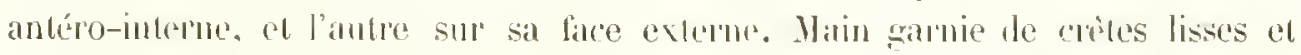

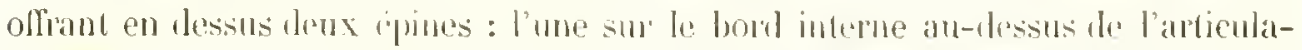
tion du ponce; la seconde sur le bond exteme all-dessils de l'articulation de

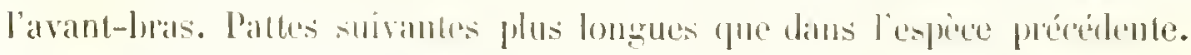

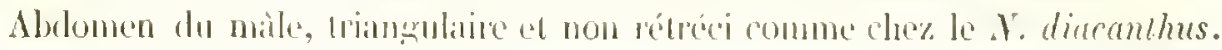
Anchives be Mrét:M. T. X. 
Taille. - Jamais relte espèce n’atteint les dimensions de la précédente; cu général, la carapare présente 0 "',050 de large sur $0^{\mathrm{m}} .025$ de long.

Uabite l'océan Mllantique sur les còtes de l'Inérique.

Pendant longtemps on a confondu cette espère avec te $\boldsymbol{N}$. diacanthus. Elle peut cependant s'en distingner par la forme de la carapace phus hombée et plus lisse; par les quatre ćpines qui se trourent sur le bord antíricur du hras, landis que le bord postérieur en est dépourru; enfin par l'existence d'une épine à l'angle antéro-iuterue de l'arant-bras. La forme de l'ablomen ne peut être d'un grand secours, car chez le diucanthus elle varie avec làge d'une manière considérable.

Collection du Musćum.

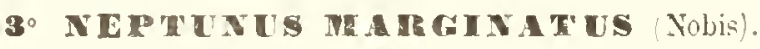

Pl. XXX, fig. 2.

Carajace ilargeic marquée lle pelites granulations pasfaitement nettes. Lignes épigastrique et épilurancliales lien distinctes. Dents du hord latéro-antérieur larges à leur base el dirigées en dulors. Corme latérale on úpibranthiale de longneur médiocre. Front à six dents et borde d'un petil bourrelet marginal, les deux dents mádianes rulimentaires. In deux mitoyennes plus longues, les doux externes courtes el tronquées. Bord sonreilier droil et divisé en trois loles par deux scissures. Apoplusse épistomienne saillante. Troisiome article des palles-màchoires externes fortement échanclé en dedans. Pátles de la première paire comrles. Bras armé de trois épines aịzuès sur son bord antéricur cet d'un tulnereule spiniforme à l'extrémitú de son bord postélieur. Avant-bras portant me seule f́pine sur sa face externe. Hain fortement carrube à carènes linement granulés, et olliant une épine au-lessus de larticulation de l'avant-bras, et un tubercule spiniforme au-lessusde l'arliculation du pouce. Palles suivantes couples. Ahdomen du mâte triangutaire.

Largeur de la carapace, $0^{\mathrm{m}}, 052$ longuenr, $0^{\mathrm{m}}, 024$.

Ilabitation. - Cote du Gabon.

Celte espèce présente une srante ressemblance avec le $X$. diacanthus des côtes de l'Amérinue, mais son ablomen est triangulaire chez le male; le troisième arlicle des palles-màchoires est phus fortement chancré en dedans; enfiu, les régions de la caraprace y sont plus fortement indipuées.

Collection du Museim. 


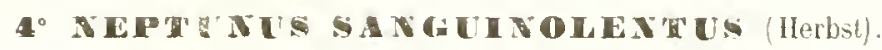

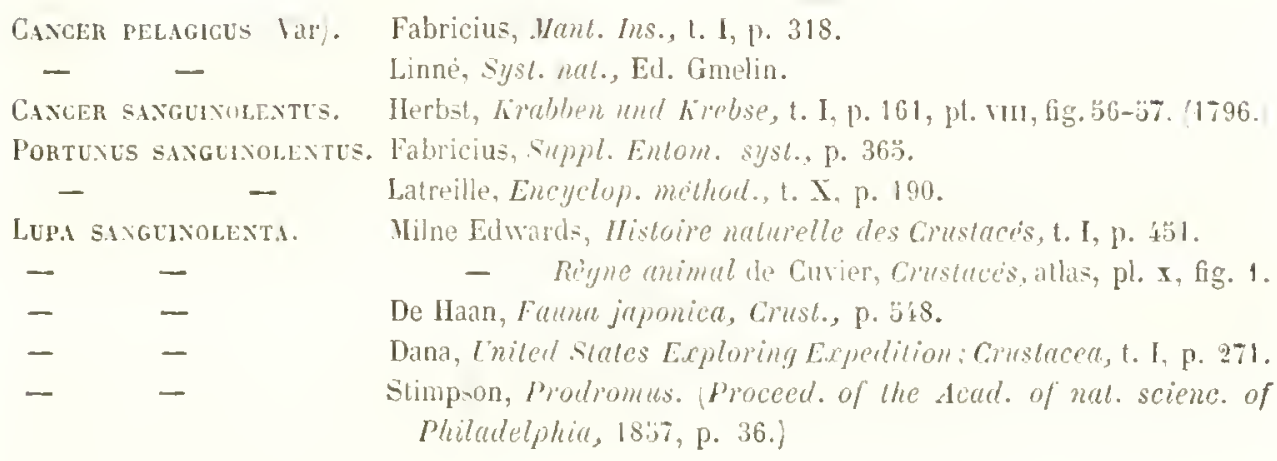

Carapace jeu lombée. tris-large, finement granuleuse, traverséc par des lignes épigastrique et épibranchiales peu saillantes, et portant en arriere trois grandes taches circulaires d'm rougre de sangs: l'un me miane, placce sur la régrion cardiaque, les autres latérales sur les régions branchiales. Bords latéro-antérieurs très-obliques et tres-longs, amuis de neuf dents dont les huit premieres ì peu près égales et dirigíes en dehor's, la dernière on corne épiluranchiale tris-longne et très-aiguë. Front à six dents, les denx médianes très-petites, les nitoyennes plus longues et aigueis, les externes courtes et obuses. - Bord sourcilier droit ef divisé par deux petites scissures. Apophrse épistomienne saillante ef dépassant le front. Troisieme article des pattes-màchoires externes, long et peu ćchancré en dedans. Pattes antirienies longues et griles. Bras dont la longrneur excède de beancoup le diamitre antéro-postéricur de la carapace, et ami sur son bord antérieur de trois on qulatre épines, mais n'on prósentant pas ì l'extrémité de son bord postérieur. Irant-liras crarni d'une petite épine sur sal fare externe et d'une plus graude à son angle antéro-interne. Mains trés-carénés ef portant deus épines en dessus, l'une an bord introne an-dessus de l'articulation du pouce. l'autre au bord evterne de la face supérienre ante-sons de l'articulation de l'avantbras. Doigts longs, armés de dents tranchantes qui s'engrement partement. Pattes

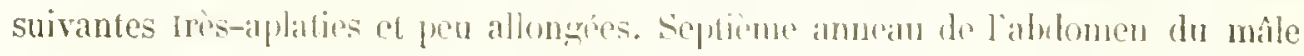
court; sixième trés-long et quadrilatere; cinduiène et quatrième s'dargissant leaucoup.

Couleur d'un jaune rosé aree des taches d'un rouge ril, trois sur la carapace 
et d'autres sur les pattes, surtout ì la hase des épines et aux condyles articulaires.

Larzenr de la carapace. en grénéral, 14 inntinètres sur 5 1/2 de longueur.

Ilabitution. - Toul l'océan Indien : Bombay, Singapour. Java. Samarang, Chine, Japon, îles San?wich.

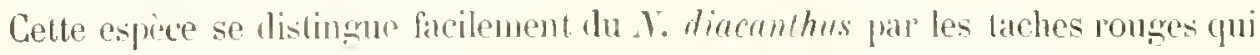

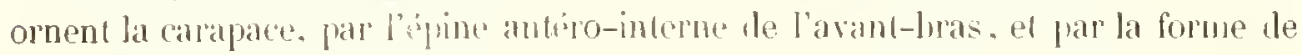
l'abdomen. Les laches el la forme aplatio de la carapace empechent de la confondre avec le $\lambda$. saryi, dont lus pattes antérieures sont ronformées sur le même plan.

Collection du Muséum.

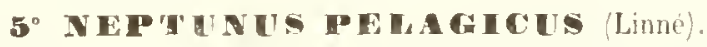

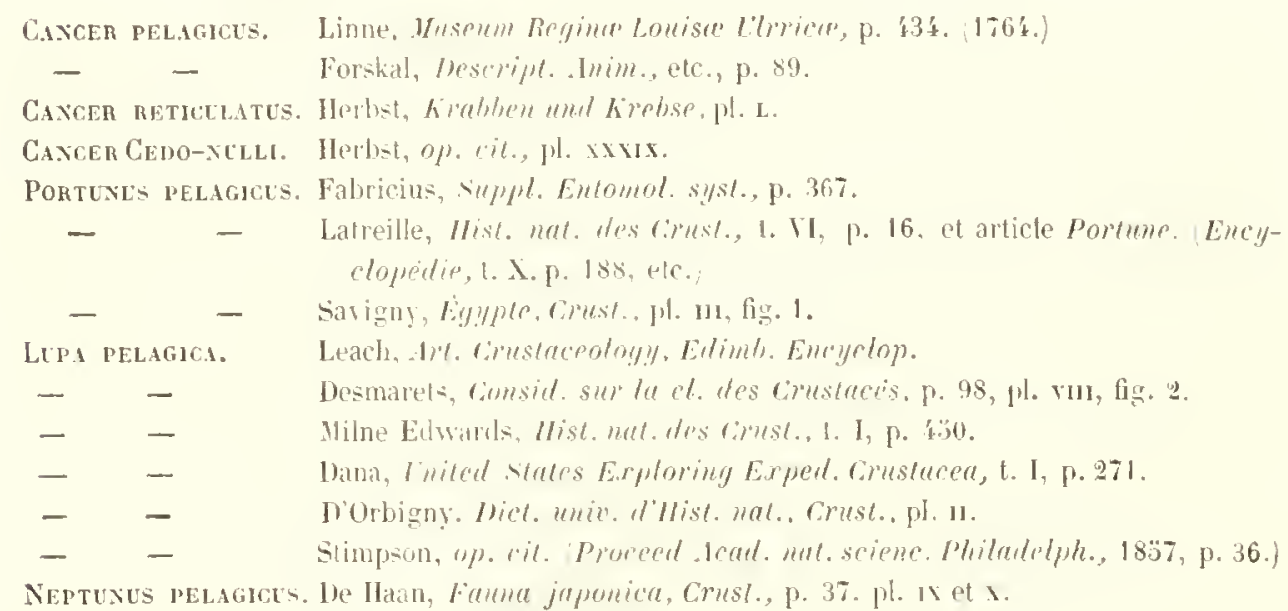

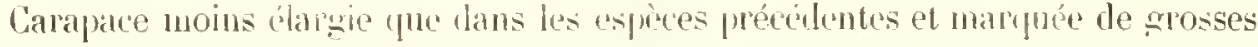
granulations. Dents des bords latíro-anterieurs courtes et dirizeres en dehors. La premicre, qui forme langle onditaire externe, beaucoup plus longue que les antres. Corne épibranchiale lougue el pointue. From à six dent.s. les deux médianes rudimentaires, les unitogennes plus longues ot plus aigues. Bord sourcilier divisé en trois lohes par deux scissures profondes; l'angle externe du lohe módian se terminant par un prolongentent spiniforme. Apophyse épistonienne dípassant beaucoup le front. Troisiime article des pattes-màchoires externes très-long et faiblement échancré à son bord interne. Pattes antérienres très-longnes el grêles. Bras portant sur son bord antéreur trois épines, et à l'extrémité de son borl pos- 


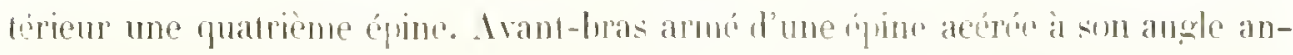

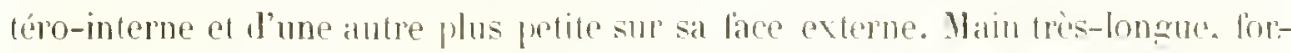
tement carénée et portant trois épines : denx en arant an-desists de l'artieudation du prouce, et une antre en arrire an-desins de l'articulation de l'anant-bras. Pattes suivantes fris-longuges ef flates. Alulomen du mate un pen triangulaire.

Cette espèce présente dillírentes variélís de coloration; tantot elle cat blene aver

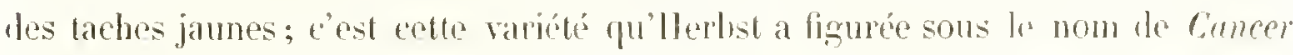
cedo-mulli; tanicit elle est rouge avee des taches jaunes; cest lo Cancer reticulatus dı même anteur.

On troure souvent das M. polugicus d'me taille considiratule; le diamitre transtersal de leur cardace a partiois 22 centimetres te le diametro antéro-poslépieur. 10 centimètres.

Ilubitution. - Les côtes de la mer Romge, les eòtes des Indes, Bombay. Pondichéry, Singapour; les mers de Chine. Macao; les iles Philippines. Bormén. les Iloluques. Nacassar; Java, Balavia; Samarang: la Nourelle-Hollande, PortJaelison.

Le Neptune pélagrique ne peut se confondre avec le $\mathrm{K}$. diucanthus dont il se distingue non-sentement par la forme de l'abulomen du mâle, mais eneore par les dents externes du front, qui sont aiguis. par l'ípine qui arme l'angle antéro-interne de l'avant-bras et par les trois épines de la main. Les mènes caraclères. a l'exeftion de celui tiré de l'avant-lras, peurent faive distinguer le Y. Pelagiens du X. sanguinolentus et du Y. sayje.

Collection du Muscum.

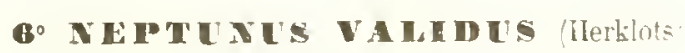

PI. XXIX. fig. 1.

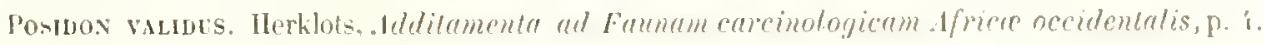

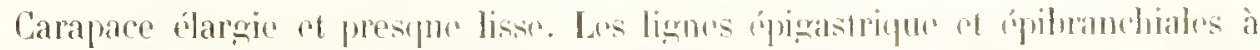

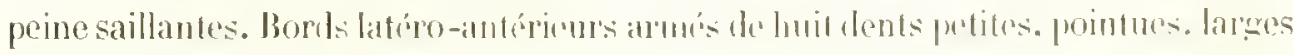

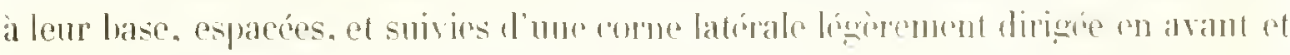

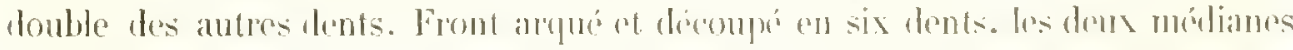

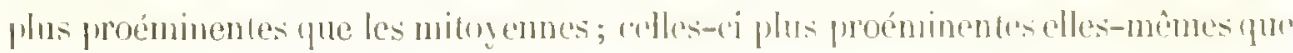


les externes qui sont pointues. Bord sonrcilier troit et divisé par deux seissures. Apophyse épistomienne courte ol ne lípassant pas le front. Troisiome article des pattes-mâchoires externes peu échancré en dedans. Pattes antérieures longues et fortes. Bras armé de trois épines sur son bord antérieur el de deux à l'extrémité de son bord postérieur. Avant-bras portant denx épines, l'une à son angle antéro-interne, l'autle sur sa face externe. Main très-large, carénée el arméc de deus épines, l'une au-dessus de l'artienlation de l'avant-bras. l'autre au-dessus de la hase tu ponce. Doigts longs. forts, comprimés et garnis le dents tranchantes. Pattes anbulatoires longues ef très-aplaties. Ablomen du màle triangulaire.

Couleur d'un mse jannâtre avec une lache blanche sur elaque région branchiale an-dessus de la hase des palles natatoires. La taille de ce Yeptumus est souvent considérable; on en voit dont la carapace a, comme largeur, 18 centimètres. et comme longneur, 9 centimitres.

IIabitation. - Cote-l'Or' (Afritue occidentale).

Cette esprece, qui par la forme générale se rapproche des $N$. pelagicus, $\boldsymbol{N}$. sanguinolentus et $\boldsymbol{N}$. diacanthus, s'en distingue par la disposition du front, où les dents médianes sont les plus avancées, et par les deux épines qui sont situées à l'extrémité du bord postérieur du bras. L'individu figuré ici appartient au Musée de Leyde.

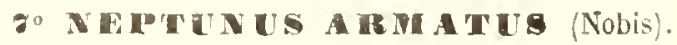

\section{Pl. XXXIII, fig. 2.}

Carapace extrêmement allongée et finement granuleuse, bords latéro-antérieurs de la carapace frarnis de huit dents à peu près égales, dirigées un peu en avant, et d'une corne épilnranchiale énorme. Front à six dents; les deux médianes petites, les mitoyemnes longues et aignïs, les externes obtuses. Apophyse épistomienne dépassant trés-pen le front. Pattes antérieures fubles. Bord antérieur du bras garni de quatre dents. Bord postérieur terminé à son extrémité par une épine. Avant-bras portant deux úphes, l'une à son angle antéro-interne, l'autre sur sa face externe. Mains à trois éphes, deux an-dessus de l'articulation du ponce, et une autre au-dessus de l'articulation de l'avant-bras. Pattes suivantes grêles. Abdomen du màle triangulaire. 


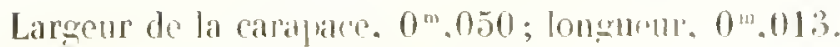

Inabitation. - Anstralie. Starkbay.

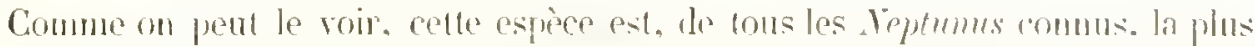
abargie; elle se distingue tu Y. pelugiens par la forme du front. oì les dents

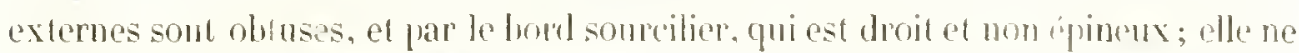
peut se confondre arec le $Y$. diucanthus, à camse de lit forme de son ablomen. tle l'úpine qui arme l'angle antrín-iuterne de l'arant-bras. of des trois ápines dont

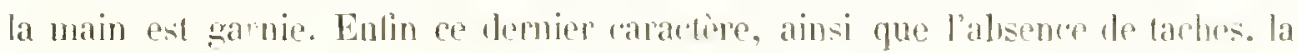
séparent du Y. sanguimolentus, ainsi que du .Y. Sayj.

Collection du Musée Britunniqque.

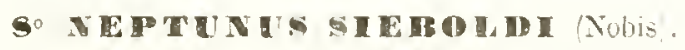

P]. XXXY, fig. 5 .

Carapace élargie fmement granuleuse; lignes f́pirastrifue et épiluranchiales hien visilules. Bobls latíro-antrpieurs à huit dents semblables entre elles, pointoes, dirigées en avant. Corne latérale lirigée avant, courte, ayant rnviron une fois of demie la longneur des autres dents. Front i six dents placéps à pen pues sur le même plan; los quatre módianes semblables entre elles. les evtornes olutuses. Bord sourcilier droit el divisé par deux scissures. Apophyse épistomienne courte et ne dépassant pas le front. Troisiome articla des pattes-mâchoires extermes larg̣e et peu échancré en dedans. Pattes antérimes robustes. Bras offiant sur son bord anté-

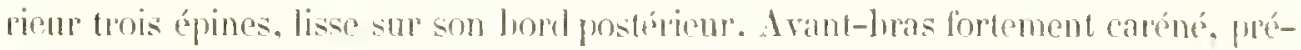
sentant à sou angle antéro-interne une fipho longue ef fine. et une petite spinule

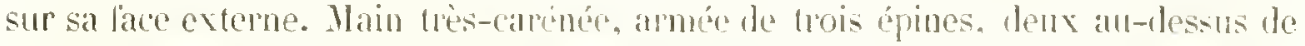
la base du ponce, et une an-dessus de ladtienlation de l'avant-bras. Pattes sui-

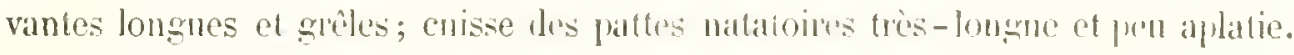
Ablomen du màle triangulaire of tris-pointu. Couldne d'un janne rosé.

Largene de la carapace, $0^{\mathrm{m}}, 045$; longroure, $0{ }^{\mathrm{m}}, 025$.

Ilabiation. - lle llaurice.

Cette espece ne peut se confublre avec aucun autre leptums. La forme du front. la lnieveté des cornes laterales et l'absence d'ipine sur le hord postérieur du blas la séparent de tontes les esireces connues.

Collection du Huséun. 


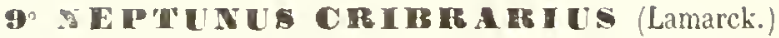

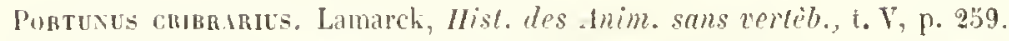

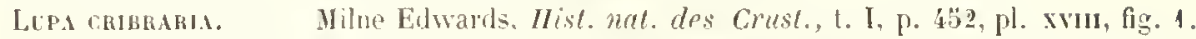

Arex.eus cribranes. Dana, Ćnited States Exploring Expedition, Crust., t. I, p. 290, pl. xuII, fig. 2.

Carapace élargie presque complétement lisse; les lignes épigastrique el épibranchiales sont a puine visilles chez les jeunes et s'effacent par le progres de l'àge. Dents des hords latéro-antérieurs pointues et larges a leur hase. les antérieures un pen plus petites tue les postórieures. Cornes latérales dirigées en dehors. Front découpé en six dents, les deux médianes minces el longues, les mitoyennes trèscontes, actolies aux jréródentes, dont elles semblent deêtre qu'un dédoublement, les externes olutuses el séparées des précédentes par une éthancrure large et profonde. Bord sourcilier divisé en trois lobes jar deux scissures larges; le lobe median plus proéminent que les autres. Apophyse épistomienne courte et clépassant trés-pen le front. Endostome lisse et privé des crêtes que l'on remarque chez tous les autres reptumus.

Paltes antéricures courtes et robustes. Bras armé de trois ćpines sur son bord antérieur ef d'une sur son bort postérieur, un preu en arriere de l'extrémité. Arant-bras portant deus épines, celle de l'angle antéro-interne presque aussi courte que reble de la face exlerme. Nain gamie de carines un peu granuleuses et armée de deux épines courtes. l'une au-dessus de l'articulation de l'avant-bras, l'autre au-dessus de la base du pouce. Nybumen triangulaire à borls un peu simbers el tres-pointu.

Couleur faure ou losée avee une multitude de petites taches circulaires blanchâtres.

Lingeur de la carapace, 11 centimetres; longueur, 5.

Ilabitation. - Les cótes du Brésil, la Guateloupe, le golfe du Mexique, VeraCipuz, New-Tork.

Cette esprece, dout II. Dana avait formé le genre Arenceus, se distingue de tous les teptums commus par l'alsence de crètes endostomiennes, et par quehues autres carkteres ghus visibles, tels que ceux tirés de la forme du front.

Collection du Musium 


\section{NETURES ITELAHES.}

Front et borls latero-intérieurs de la sarapace, disposes sur une ligne coutbe a petit rajon dont te centre se trouve sur ha ligne médiane, vers te milien de la réggion cartiaque.

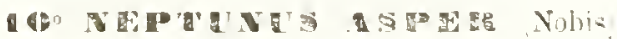

Il. XXX, fig. 3 .

Carapace bombée el élargie; ligms transversales granuleuses el très-saillantes. Il en existe deux sur la rigion gastriqu el deux à la partic postérienre des rógions

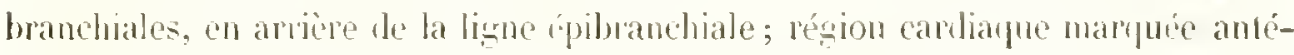
riemrement de granulations; entre ces différentes lignes la carapace ost completement lisse. Dents du bord latero-antirieur semblathes entre elles. Corne latínale longue et pointue. Front divisé en six tents; les deus médianes aigneis et plus avancées; les miloyennes ígalement aiguës, les externes contes, obuses, tronquées au sommet de facon a paraitre bilides. Bord sourcilier droil ol divisé en trois lobes par denc scissures profonder. Troisiome articte des pattes-mindoires externes

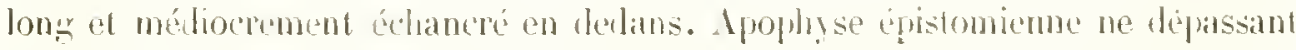

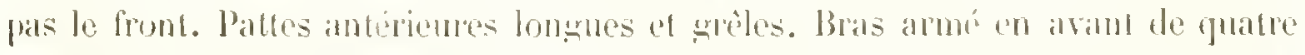

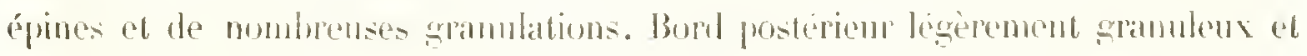

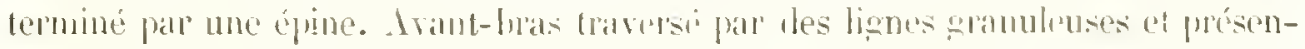

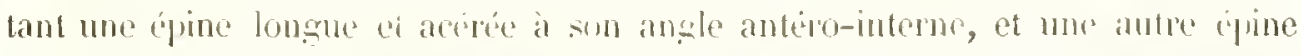

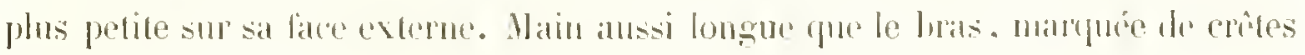

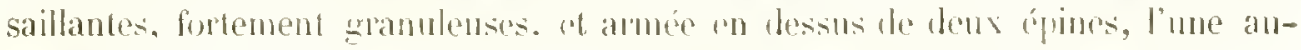

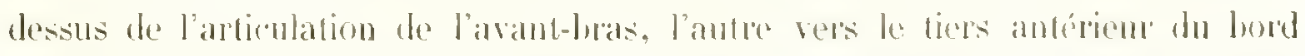

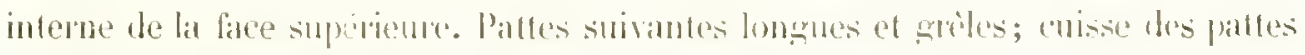

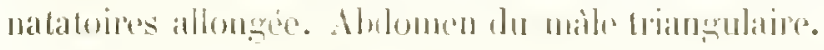

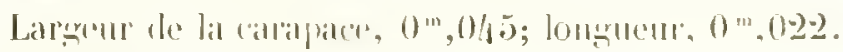

Mabilation. - Colle du Cihili.

Colleretion dh Museur. 


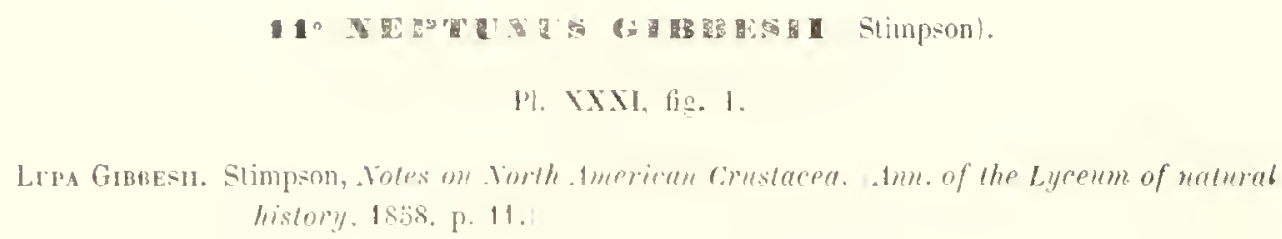

Carapace granulense markméc lo lignes transversales pen saillantes. Dents du

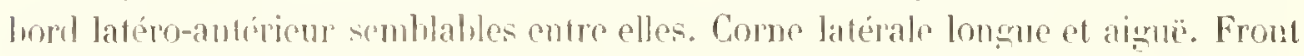

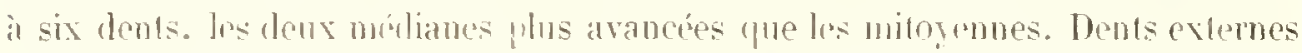
compes of tromequens. Bord sommerilier drnit at divise en trois lobes par demx scissures. Apoplyse bjustomicme ne dépassant pas le front. Pattes antérieures bonques. Bras portant quatre f́pines sur son horl antérieur et une à l'extrémité de son bord postérieur. Une longue ćpine à l'angle antéro-interne de l'avant-bras. et une autre plus petite sur la face externe du mime artick. Mains tres-apla-

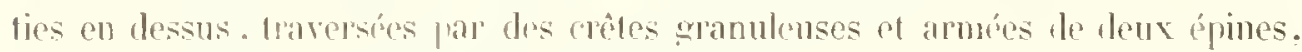
l'une an-dossus de l'articulation de l'avant-hras. l'antro vers le tiers antérieur du hord interne de la face supéricure. enmme chez lo Vephums asper. Pattes suivalues

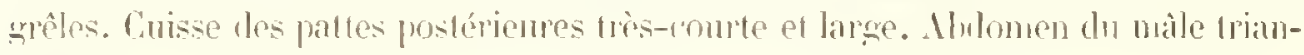
grulaire.

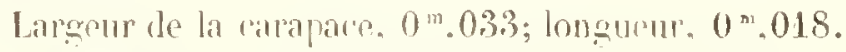

Ilabitution. - La Ciaroline du Sul at la Flonide.

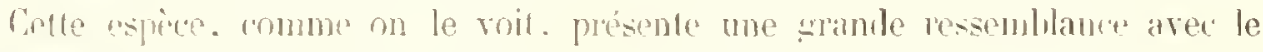
1. asper spui habite le Chili; elbe s'en distingne rejentant an premier aspert par les nomberenses gramulations dont la carapace ost converte, tandis que cliez.

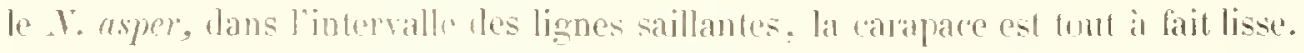

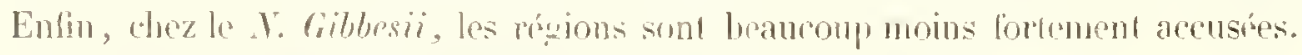
La cuisso des pattes matatoires est beauconpl plus courte, etc.

Collection du Huseum.

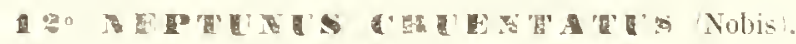

P. XXXl, lig. 2.

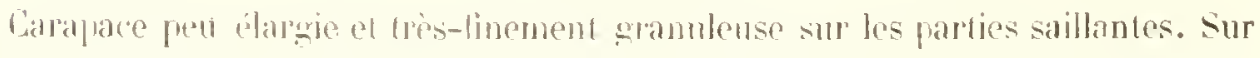
la région gastrique, vers la jartie médiane, an-dessus de la lig̣ne épigastripue, 


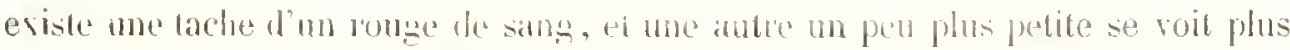

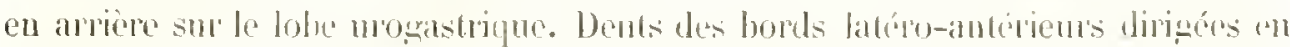

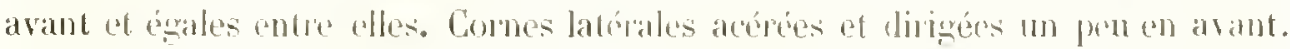

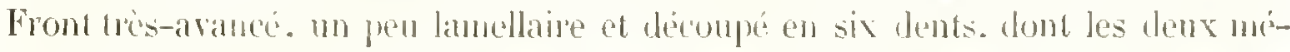
dianes sout les plus proénuinentes. Entre les dents mitoyennes of les evternes

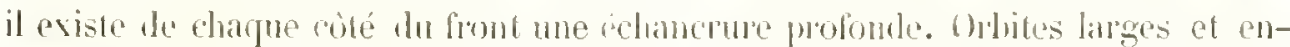

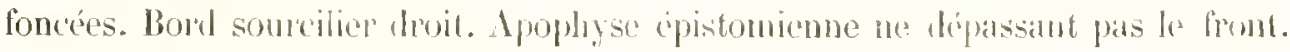

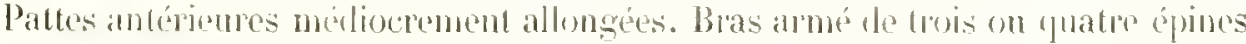
sur son bord antérieur, of d'une antre plus petite a l'extranite de son hord postérienr. Arant-bras portant une ringe longue et line a son angle antéro-interne.

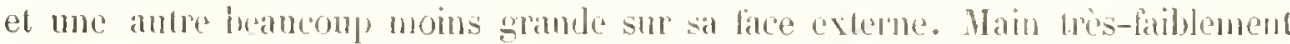
rarenée et presentant deux épines. l'une ant-dessus de l'anticulation de l'arantbras. l'antre rees le tions anteriem do hord interne de la firce supépienre. Pattes suivantes ladhetós de ronge. Aldomen du mile triangulaire at a bords sinneur.

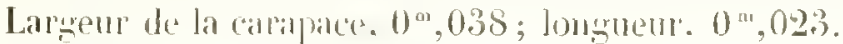

Ilabilation. - Les Antilles.

La forme trìs-avanctic du front ne permet pas de confomble cette espèce avec le $Y$. Giblesii ni aree te $Y$. asper.

Collection du lluree Britannituus.

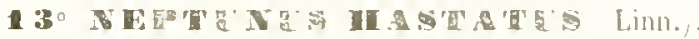

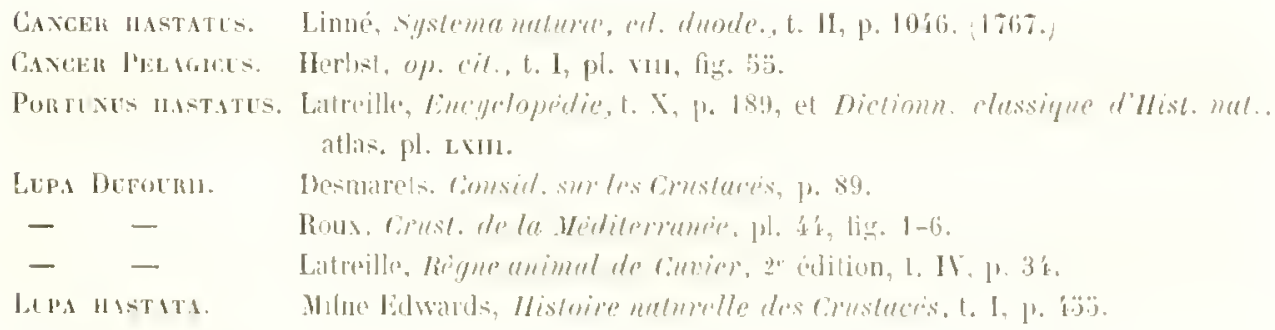

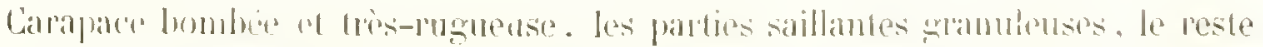

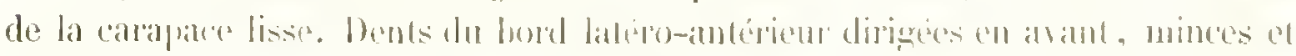

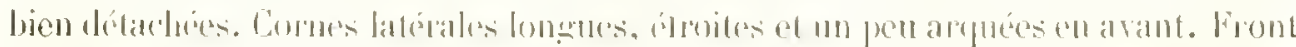

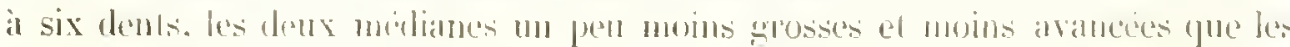

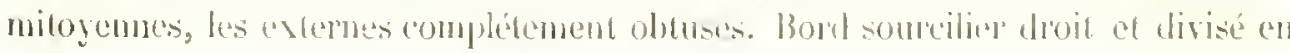


trois lohes par deux soissures átroiles. Apophse épistomienne ne tépassant pas le front. Troisirmo article des patles-màchoires externes pen éclancré en dedans. Paltes antérieures longnes ef grides. Bras armé de quatre à cinq épines sur son bord antérienr, et d'une a l'extrimite de son hord postériemr. Avant-hras portant deux épines pru développées. l'une i son angle antéro-interne. l'autre sur sa face externe. Mains aplaties ot léprimes en dossus, traversées par des crôtes granuleuses, amées on dessus de trois épines, l'une an-ulessus de l'articulation de

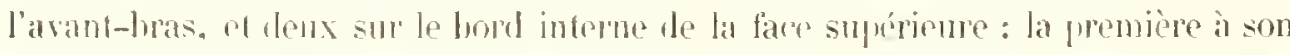
cxtrémité an-dessus du poure. l'autre un peu plus on arrière. Pattes suirantes tris-fongues. Ablomen du mile a pen pres triangulaire et à hords sinteux.

Laregeur de la rarapace, 6 cent..; longuenr, 3 cent.

Ulabitution. - La mer Méditerrance, à me assez srande distance des còtes.

La forme du front. combince aux denx épines qui earnissent lo bord interne de la face supéricure de la main. suffisent pour faire distinguepr cette espèce de toutes les prétridentes.

Collection du Vusẻum.

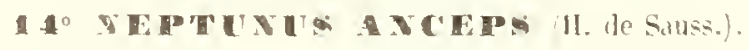

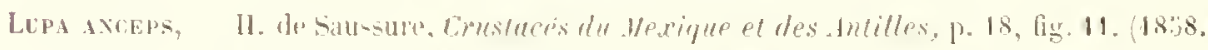

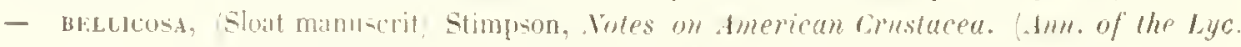
of nat. hist. Vew-5ork, is:i9, p. 11.)

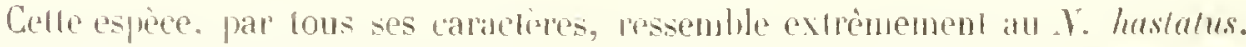
Cependant les dents mélianes du front sont un peu phus obtuses, les carines des dents moins gramulenses. el d'apres M. Stimpson. les denx derniers articles de l'abdomen th màle suratent plus délargis.

Largeur de la carilparce, $0^{\mathrm{m}}, 020$; longueur. $0^{\mathrm{m}}, 012$.

Ilabitation. - Les Antilles, le solle de la Cäilifornic.

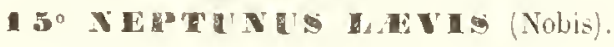

P. XXXI, fig. 3.

Carapace pen idaravie, presque complétrment lisse; c'ent at peine si on y aperçoit la trace des lignes épigastrinue el épilranchiales. Bords latéro-antérieurs plus 


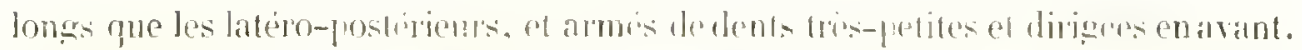

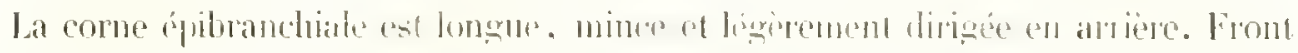

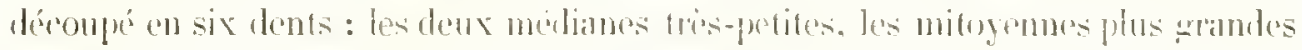

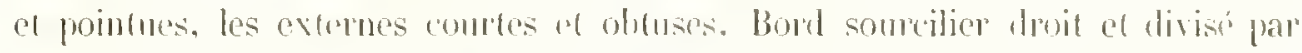

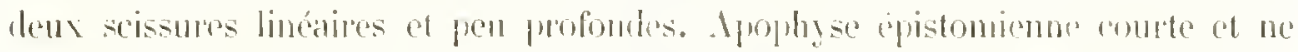

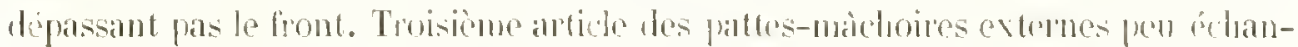

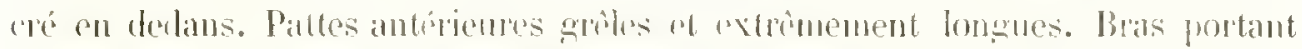

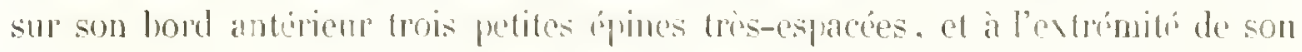

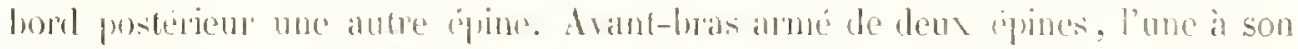

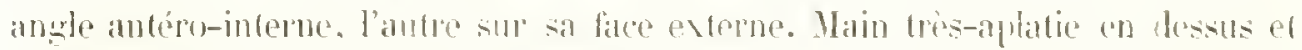

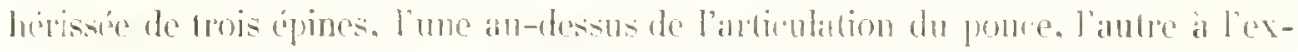
trimite du hord interne de la face supériente antedesins de la hase du proure; la

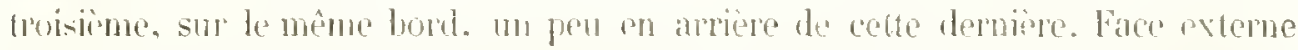

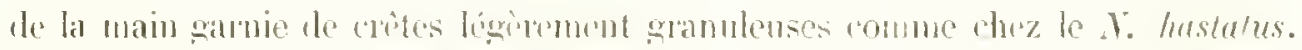

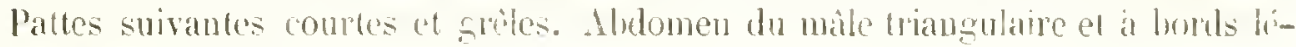
gèrement sinueux.

Largeur de la carapace, $0^{\mathrm{m}}, 034$; longucur, $0^{\mathrm{m}}, 012$.

labilution. - Océan Indien.

Cotte esprece, presgno semblahle an Tephums hastatus par la disposition du

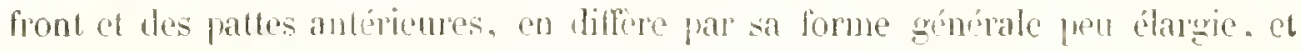
par sa carapare presque completement lisse.

Culfection du suséum.

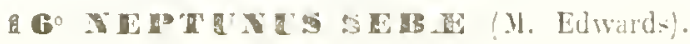

P]. XIVill, fig. ?.

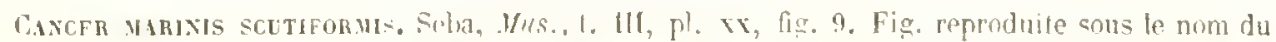
fontunus sumpminolenus, par Latreille dans l'Encyclopedie,

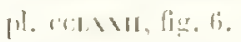

LUPA SEB.E.

Milne Edwards, Mistoire naturelle des Crustaces, t. I, p. iö:.
}

Carapace hexagonale presplue plate, marqune do quelques rares granulations

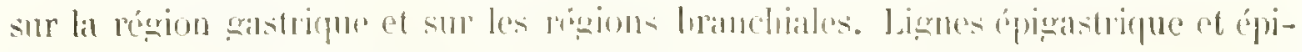

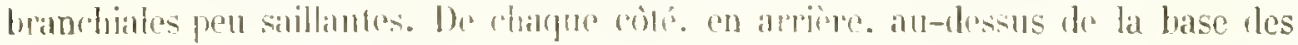

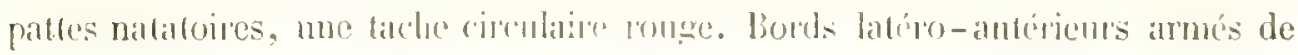


huil dents sensiblement égales et suivies d'unte tropue laterale aignè el recoundurs en arant. Front découpé en sis deyts aigués of tres-yrandes; les médianes phus avancées que les mitoyennes. qui sont séprarées des externes par une éelranclure

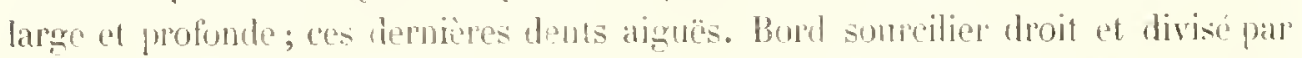
dens seissures. Apophyse éfistomienne ne dépassant fas le front. Troisieme article des pattes-mâthoires externes assez profondément échancré en dedans.

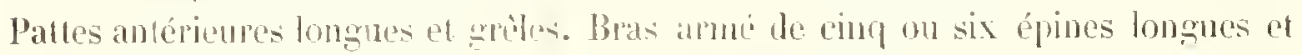
arérées sur son borl antérieur, et d'une autre épine a l'extrénité de son bord posterieur. drant-hras travers par des crètes saillantes et armé de deur épines. lime à l'angle antéro-internes. lautre sur la face externe. Bras garni de carènes

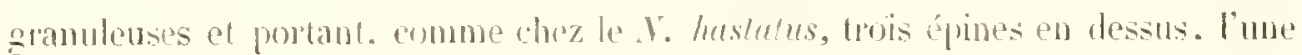
au-dessus de l'articulation de Javant-bras. les deus autres à l'extrémité du bord interne dr la lane suprérieme.

Pattes suivantes grites; une forte eppine dirigée en haut, au-dessus de la hancho des pattes natatoires. Cuisse de ces dernieres pattes garnie à l'extremité de

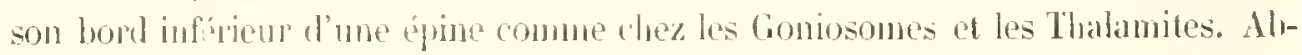
domen du mâte triangulaire.

Largeur de la carapice. $0^{\mathrm{m}}, 090$; longueur, $0^{\mathrm{m}}, 046$.

Ilabilation. - La Marinique, les coites du Brósil.

Cotte espexce remarquable est la seule qui prósente une épine au-dessus de l'articulation de la hanche. La forme de son front ex l'épine qui existe an bord inléricur de la ruise des pattes natatoires permettent de la distimgner facilement de la plupart des autres especes du mème genre.

Collection du Yuseum.

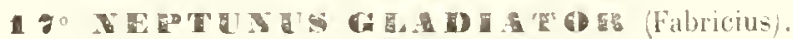

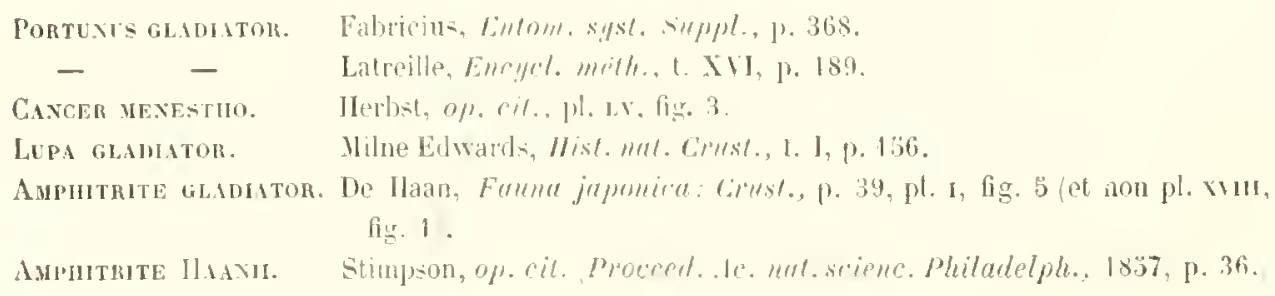

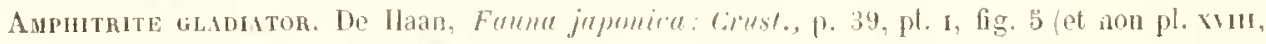
fis. 1 .

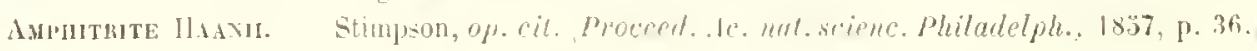

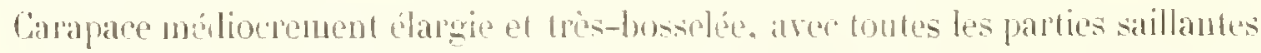
convertes de granulations. mais les parties rentrantes lisses. Les épines du bord 


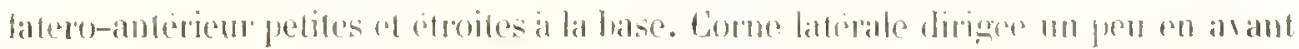

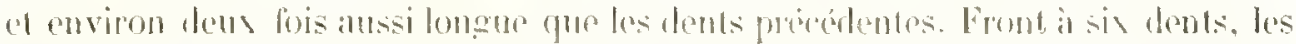

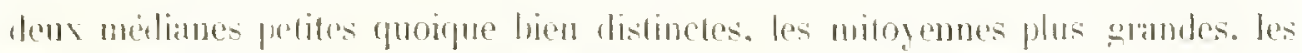

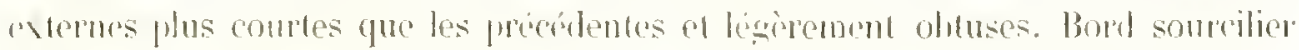

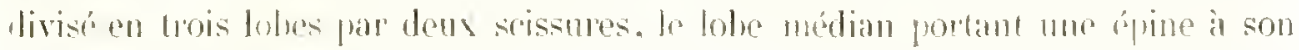

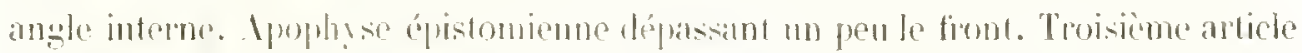
des pattes-mâc roires externes trós-échancró en dedans ot à angle supéro-externe

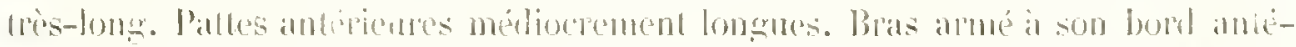

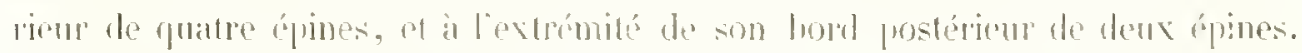

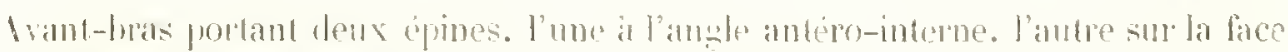

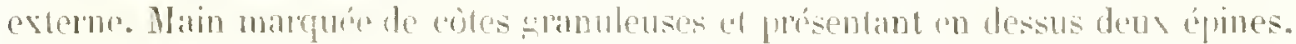

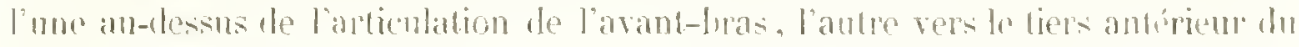
hord interne de la fare supépienre. Caisse des paltes natathipes presque ondiculaire. Abdomen du male à brods tres-sinuent.

Comleur. - Jaunatre arom des taches rouges.

Largeur de la caralate. (1) 076 ; Iongureur, $0^{\mathrm{m}}, 044$.

Mabilation. - Ner de la Chinc, du Japon, Sumatra.

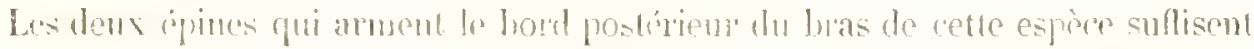

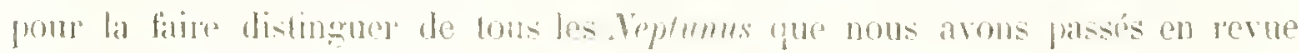
jusqu'ici.

Collection du Musium.

\section{C}

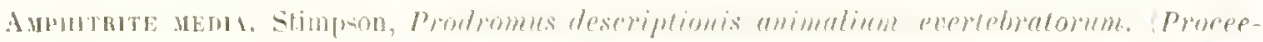

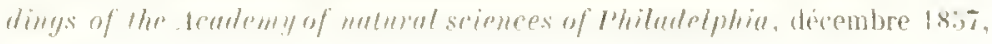
p. 33 .

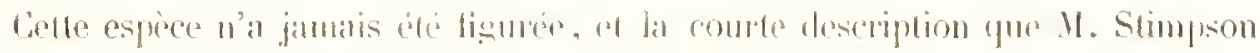

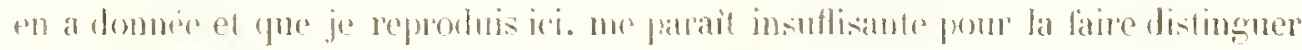
to Ja preverdeme.

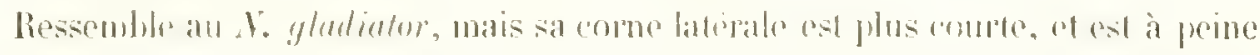

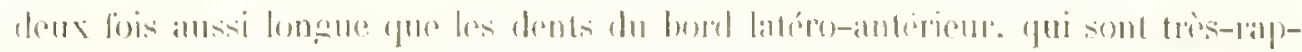

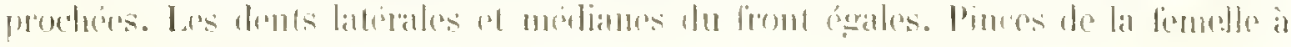
linets rourts of latreses. 


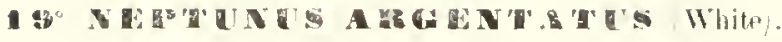

1. XXXI, fig. \&.

Amplithite argearata. White, List of the sprecimens of Cimestacen of the British unseum. p. 126 .

Carapace peu ́largie, hosselée et marquée de granulations sur les parties saillantes, mais lisse dans les intervalles. Dents des bords latíro-antírieurs courtes;

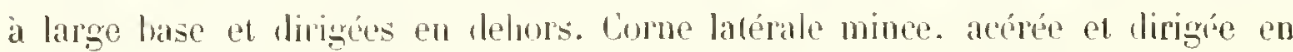
dehors. Front déwupé en sis dents; les deus médianes r'mlimentaires, les mitoyennes plus longues, les extermes obuses. Bort sour ilier divisé en trois lobes par deux scissures linedires. Apophyse épistumienne dépassant le front. Paltes anterienres médioxrement allongées. Bhas armé de quatre épines sur son bord anterienr. of de deux ipines a l'extrémite te son bord posterienr. Arant-bras portant deux épines. l'une ì son angle antéro-interne, l'autre sur la face externe. Main garnie de trètes saillantes, relle de la face externe surtout; deux épines en dessus, l'une an-dessus de l'articulation de l'anant-bras. l'antre vers le tiers antérienr du borl interne de la face supérieure. Palles suivantes longues et grèles. Abelomen du male triangalaire el a bord sinuenx.

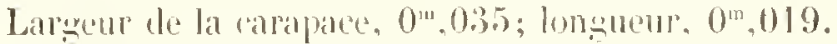

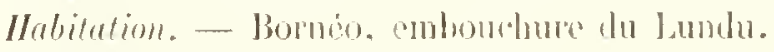

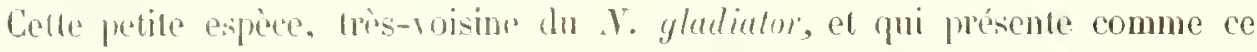
dernier deus épines à l'extrónité du bord postérieur du hats. s'en distingne par

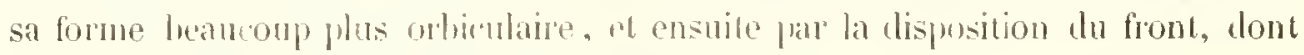
les dents mélianes sont presigue rulimentaries.

Collection da Musèe Britumique.

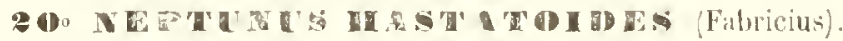

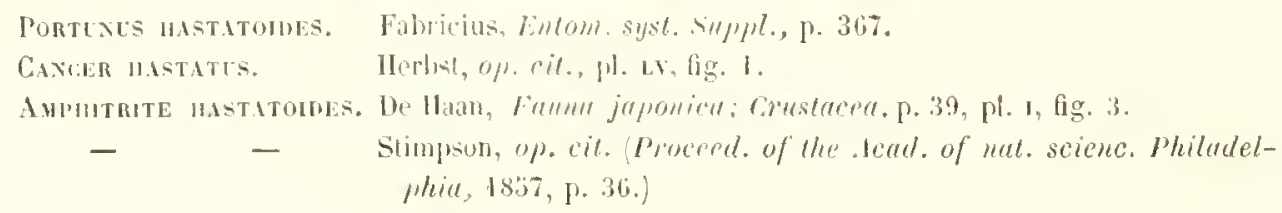

Carapace prespue complitement aphatie, légerement hosselíe; les hosselures seules couvertes de fines granulations. Bords latéro-antérieurs trés-longs et armés 
de petites dents bien détachées les unes des antres. Cornes latérales longues, trèsaiguës et un pen dirigées en avant. Angles postérieurs de la carapace, au lieu l'être arrondis, aigus et mème quelquefois terminés par une petile épine. Front divisé en six dents : les derr médianes trés-grôles, quoique aussi avancées que les mitoyennes qui sont beaucup plus larese; les externes obtuses. Bord sourcilier llivisé en trois loles par leux scrisures; langle interne du lobe médian terminé par une petite éphe. Apophyse épistomienne dépassant un peu le front. Troisieme

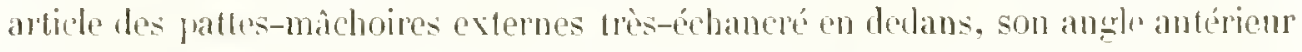
et externe se prolongant beaucoup en debors. Patles antérieures srèles. Bras armé de quatre épines sur son hord antérieur. el de deus à l'extrémité de son bord postérieur. Avant-bras présenlant une fipine à son angle antéro-interne, et une antre tris-aigue sur sa face externe. Nain traverste par des crites gramulenses of armée de deux épines. l'une au-dessus de l'articulation de l'arant-bras, l'autre au-dessus de ha base du ponce. Cuisse des pattes nageuses plus large que komgue. Mrdomen du mâle trós-long ef étroil ; le sixième article deux fois aussi bong que large ì sa hase.

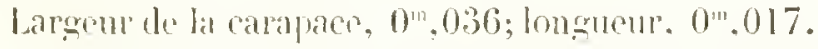

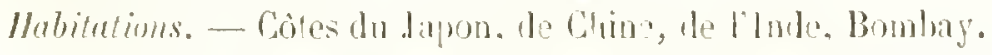

La formo aplatie de rette espece et les angles postipienrs de la tamapace qui sont spiniformes ainsi que la longnenr da sixieme article de fablomen du màle la font immerdiatument distinguer des Yeptunes que nous renous d'étudier.

collection du Muséum.

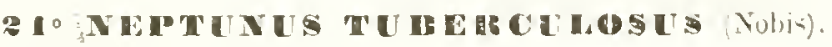

Pi. XxxI, fig. $\ddot{3}$.

Carapace aplatie, très-large en avant, très-rétrécie en arriere, extrîmement bosselée, the tolle manirre que, sur la rigion cardiafue, on pouprait croire a l'existence de tuberenles. Tomtes les parties saillantes comertes de grambations.

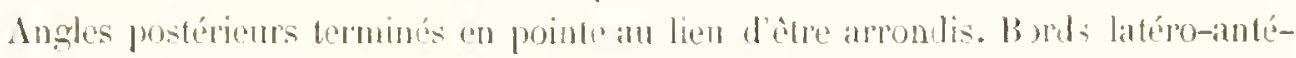

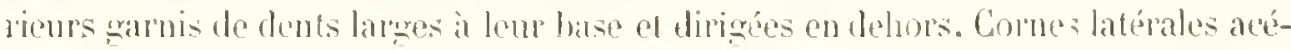
rées. Bord sour ilier droit el divisé par deux scissures. Gront a vancé el découpé en sis dents : los deux midlames plus próminentes que les mitogennes, et eelles-ci phos proéminentes pur lese externes qui sont olutuses. I pophyse épistomienne courle 


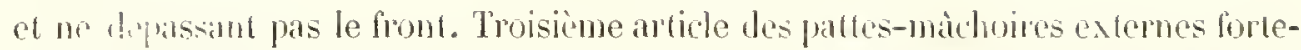
ment friancré en dedans. Pattes antéricures assez fortes et très-linenent granuleuses. Bras armé de trois épines sur son borl antérienr et al'une í l'extrimité de

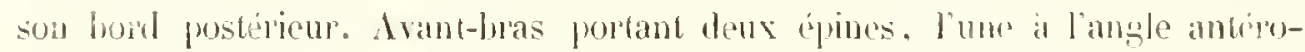
interne, lautre sur la face evterne. Main armée en dessus de deux épines. l'une an-dessus de l'articulation de l'aramt-bras. l'antre au-dessus de la base du poure. Paltes suivantes grèles. Abdomen du màle allongé.

Larecur de la carapace, $0^{\mathrm{m}}, 008$; longueur. $0^{\mathrm{m}}, 005$.

Ilabitution. - Iles Sandwich.

Cette espèce. rui se rapproche du X. hashatudess par la forme générate de la rarajace, dout les angles postérieurs sont remines en poince. s'on distingrue prat la forme du front, dont les dents midianes sont kn pus avancies. et parlesistence d'une seule épine a l'extrémitri du bord postérieur du bras.

Collection du Hurexum.

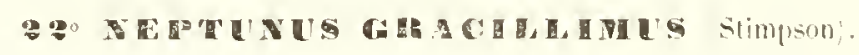

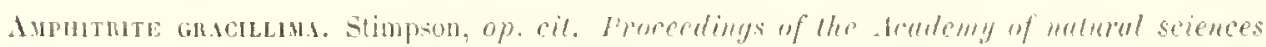

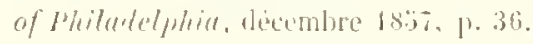

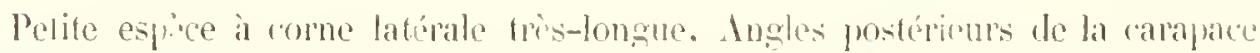

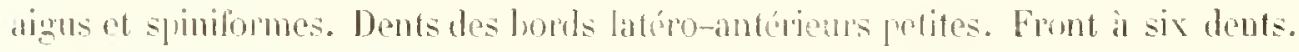
les deux mólianes moins procumineutes que les mitosennes. Bord sourcilier por-

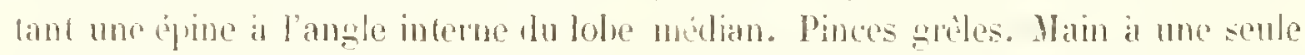
fpine placéc an-dessus de la hase du pouce. Palfes ambulatoires longnes comule lece le X. Irmmipes.

Inelitution. - Jles Bonin.

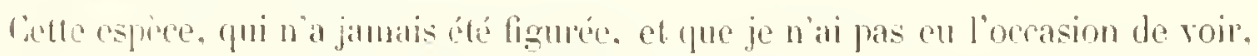
n'es comnur que par la courte description qui pricide. Par la forme des angles

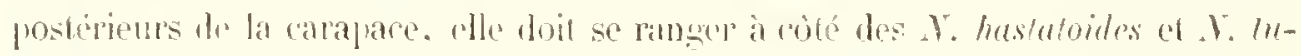
berrulesus; elle differe du prenier jar l'existence l'une senle épine sur la main. el du second par la forme da front dout les dents módianes sout plus courtes que les mitoyennes. Il est impossible de la confondre aver le r. rugysus, dont le front noflre que cinq deuts dont une midiane. 


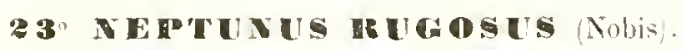

P. XxxII, fig. 3.

Garapace très-fortement hosselée, les parties saillantes granulenses, les parties

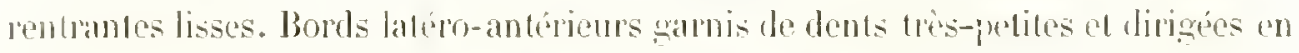

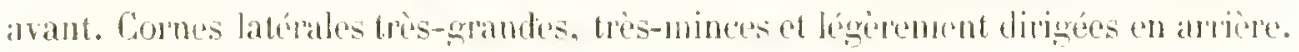
Angles postirieurs de la carapace aizurs el spiniformes. Front ì einq dents. la médiane pointue et un pen flus courte que les milogemnes, les externes rourtes et obtuses. Ophites tresprobondes. Yeus tris-gros. Apophyse ipistomienne ne depassant pas le fronl. Paltes antérieures courtes. Bras porlant trois épines sur son

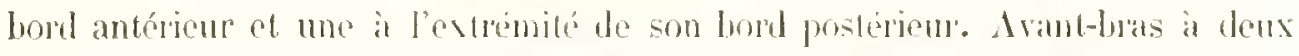
épines. l'une à l'angle antiro-interne. lautre sur la face externe. Nain armée de deux ćphes. l'me au-dessus de l'arliculation de l'arant-has, l'aulre an-dessus de la base du ponce. Paltes suivantes grèles. Abdomen du mâle triangulaire el à bords sinueux.

Latrgentr de la carapace, $0^{\mathrm{m}}, 03.35$; longucur, $0^{\mathrm{m}}, 016$.

Inbitation. - Anstralie.

Cinte espive, qui se rapprom, par la forme de la carapace termince en arrière

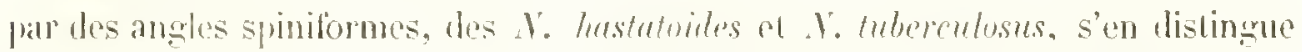
par un caratere de prentier ondre liré de la disposition du front découjú en eing

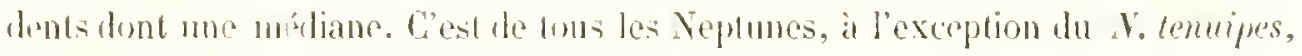
te seul qui présule celle parlicularité.

Colfection du Musce Britantique.

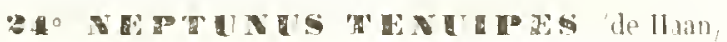

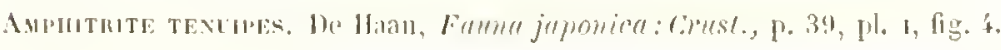

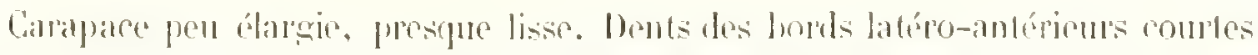

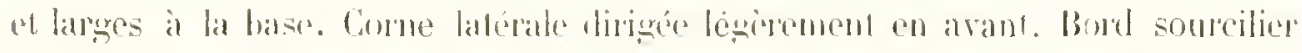

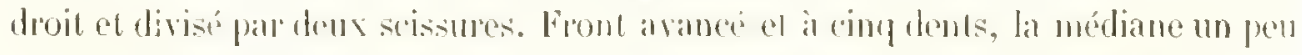
plus petite que les mitoyemues, les externes combes at obluses. Paltes antériemes 
longues et rugueuses. Bras armé de trois épines sur son borl antérieur el d'une à l'extrómité de son bord postérieur. Avant-bras portant deux épines, l'une à l'angle antéro-interne. l’autre sur la face externe. Main traversée par des crètes saillantes et armée de deux épines, l'une an-lessus de l'articulation de lavant-bras, l'autre au-dessus de la hase du pouce. Pattes snivantes longues et grêles. Abdomen du màle triangulaire.

Largenr de la carapace. $0^{\mathrm{m}}, 0.35$; longuenr, $0^{\mathrm{m}}, 01 \mathrm{~s}$.

Habilation. - Mer du Japon.

Cotte aspèce, de mème que la précédente. présente un front à cinq dents; mais elle s'en distingue par la forme de la carapace, dont les angles postérieurs sont arrondis an lien d'etre aigus el spiniformes.

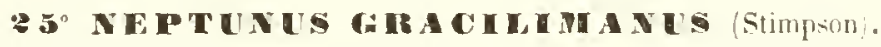

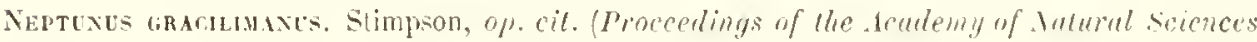
of Ihiludeluhir. dicembre 1837, P. 36.)

Carapace convere, poilue of ormé de sis lignes transwersales élevées, granuleuses, interrompues. Bord latéro-antérieur armé (comme d'ordinaire) de neut dents; la dernière (ou corne épibranchiale) double des antres. Front a six dents. les dents médianes un peu phs próminentes que les latérates. Youx grands, globuleux. Pinces du male allongres. poilnes. Bras large, gros, squammeux en dessus. portant quatre dents sur son bord antérieur, ef deux a l'extrémité de son bord

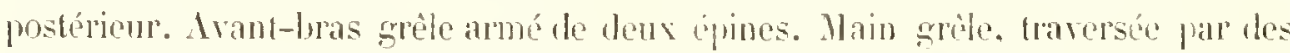
coites longitudinales et armóc en dessus de trois ápines. Doights un peu plus courts que le poignet, très-griles. comprimés. Paltes ambulatoires grètes, les troisièmeun peu phus longues que tes quatriènes. Abromen du male triangulairo el grite.

IIabitation. - Mer de Chine.

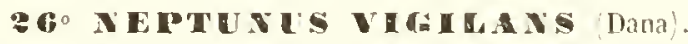

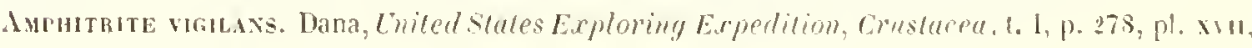
fig. 3 .

Cette espèce parait n'itre encore qu'imparfaitement conue. M. Dana l'a décrite comme n’ayaut que sept épines au bord latéro-antérieur; nais a ant eu l'oc- 
easion d'en examiner un grand nombre d'individus réunis an Husée Britami que.

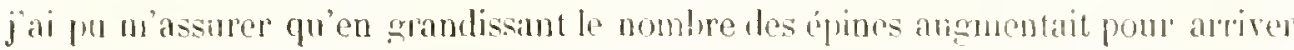

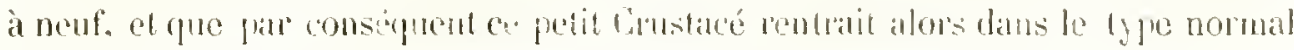
des Noptumes.

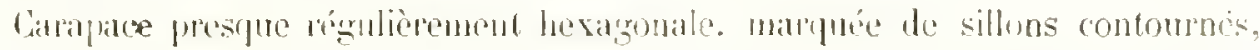
d'ailleurs lisse. Bords latéro-anterienrs presque droits, armés de cing, six, sept

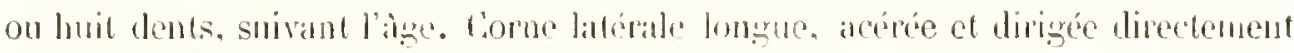

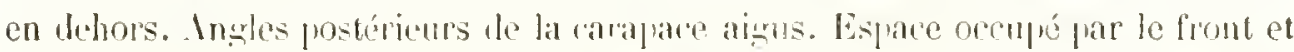
les orbites très-large. Front à luatre dents; les médianes rudimentaires, le's lantérales trimgulines, pointues, lamndleuses at tris-grandes. Les anglos onditares internes qui ordinatrement forment la tonsième paire de dents frontales, se

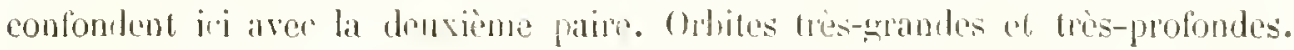
Yeux tres-gros. Apophlyse épistomienme non sallinte. Patles antipieures longues

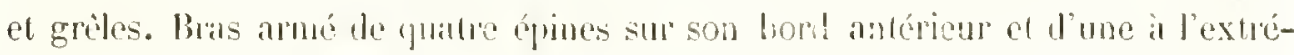
unté de son bord postérient. Arant-inas portant deux épines. l'une à l'angle an-

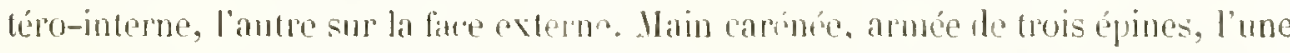
ant-dessus de l'articulation de l'arant-bras, les deux autres un peu en arriore audessus de la hase du poure.

Conleur jaunitre, aree des tarkes d'un vert beu.

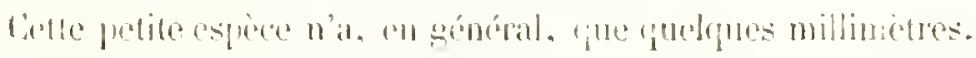

Imbitalion. - Irchipel Viti.

La forme géncirale de la carapare, unir ì la disposilion des dents frontales. ne

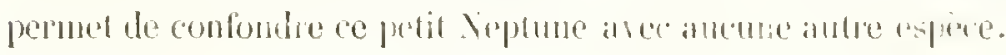

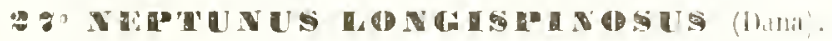

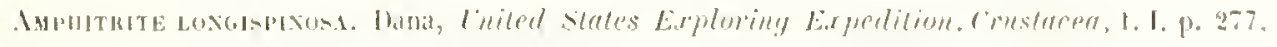
1). vist, lig. $\because$

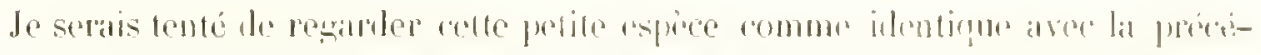

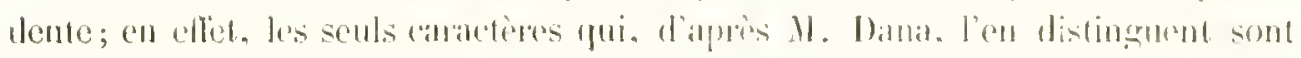

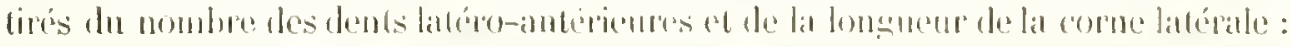

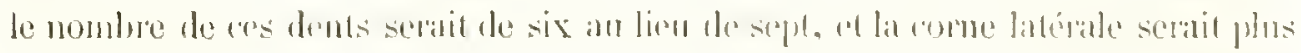

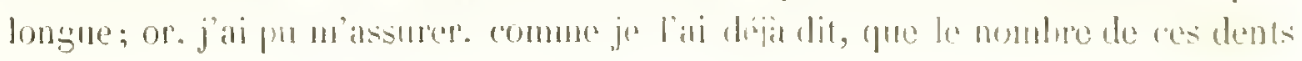


augmentai arec l'age pour arriver au type normal, qui est de neuf. Quant à la longueur de la corne latérale, elle varie aussi avec les mêmes circonstances.

Ilabilation. - Archipel Tili.

\title{
ESPECES FOSSILES :
}

\author{
Neptunis Mosepeliexsis (A. Edw.).
}

Alph. Milne Edwards, Mistoire de's Cousurés fossiles. (Ann. scicnc.nal., f́ série, 1. XIT, pl. IV, fig. 1.)

\author{
Neptoxes lanteti (A. Edw.
}

Alph. Milne Edwards, loc. cit., p. 237, pl. v, fig. 2.

Neptunes Vicentixus /. Ediv./.

Alph. Milne Edwards, loe. cit., p. 238, 1.. vi, fig. I.

Neptunes arceatus (A. Elw.).

Alph. Milne Edwards, loc. cil., p. 210, pl. Ix, fig. 2.

Neptexts granulates (A. Edw.),

Alph. Milne Edwards, loc. cil.. p. 2ḱ, pl. nil, fig. 1.

Neptuxes mertes (A. Edw.).

Alph. Milne Edwards, loc. cit., p. 2if, pl. v, fig. 3. 
ÉTIOES ZOOLOGIQUES SIR LES PORTLYIEXS TRECEXTS.

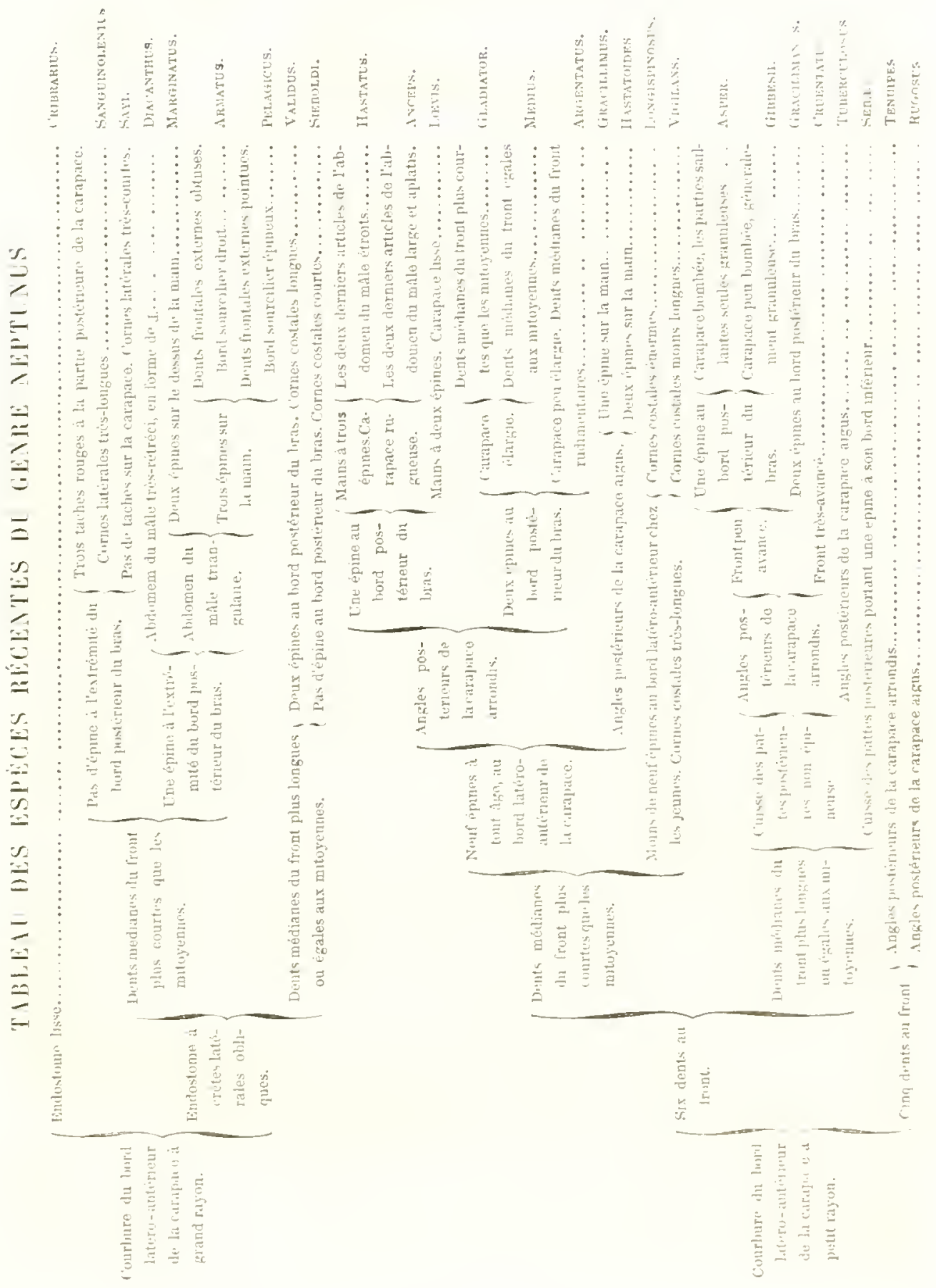




\section{Genre AGHELOUS.}

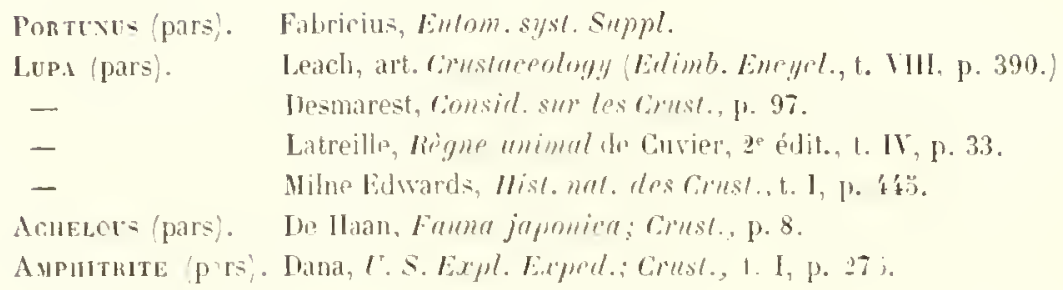

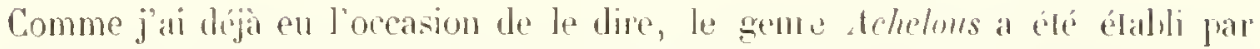
W. de Maan. II ne comprenait d’alworl qu'une seule espece. le Jortumes spinimanus, ef les caractères sur lesquels il élait hasé étaient surtoul tirés de la forme des appendices luceaux. Aujourd'hui. lel que je l'ai moditie, il se compose de sepu espices, el comprend tous les Portuniens ì carapace armée latéralement de neul" dents sensiblement égales. la postérieure ne se prolongeant jamais en forme de corne comme chez les Neptunes. Il est vai que upuelquefois. dans le jeune àge, la neuvième lent présente me longueur considiralle (notamment chez l'A. spinimanus); mais, par les progreses de l'igre. elle s'amoindrit pour ne plus dipasser les autres que d'une longucur insignitiante. La rarapace, an lieu de se terminer en avant par une ligne régulièrement arquée forméce par le front ef les bords latéroantérieurs, offre une forme hexagonale, les hords se réunissant au front par un angle hien marefó. Le front presente de cion a huit dents. Quant aux autres caracteres, ils sont idenliquement les mimes que cewr du genpe Neptune. Aussi, la meilleure diagnose que l'on puisse donner des Achelous, peut se résumer ainsi : ce sont des Neplumus a carapace lexigonale. el dont toutes les épines des lrords latéro-antériours sont curales chez les alultes.

Quclyues especes. l'1. spinimumus par exemple, acquièrent une laille assez considerable; mais en gínéral les antres especes n'alteignent pas à de bien erandes dimensions. On n'en comnait ancun représentant dans les mers de nos climals. Ils habitent les còtes de l'Amérigue, de l'Isie ou de l'Océanie. 


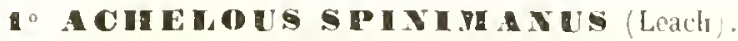

\author{
Pt. XXYII.
}

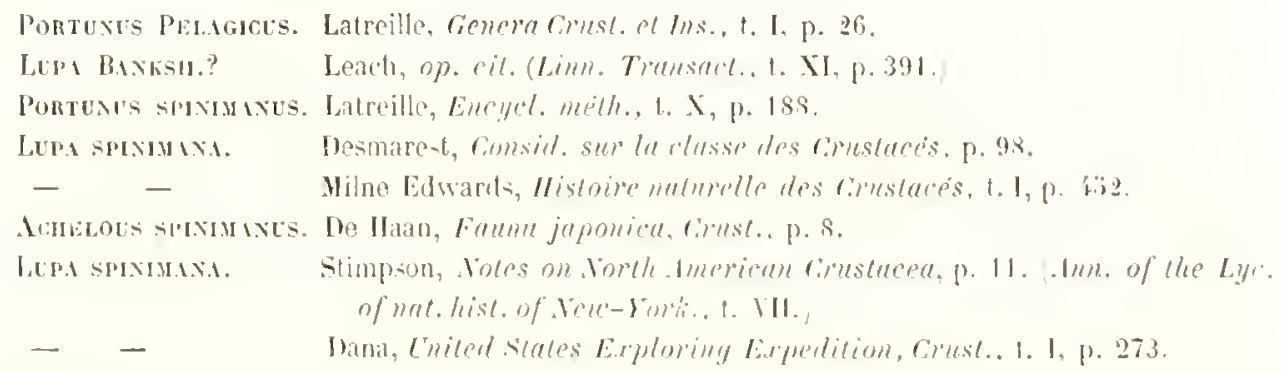

Carapace peu élaroic chez les rieur individus, plus large dans le jeune àge. bossdic, parties saillantes comertes de glamulations. Bords latélo-antérieurs armés de neuf dents sensiblement igales, sanf la dernière. qui. dhez les jeunes.

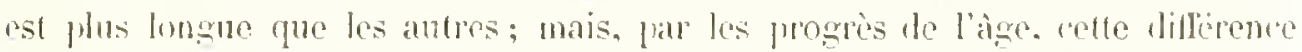
s'amoindrit de plus en phus. Front avancé el déconpé en huit dents. Ies deux

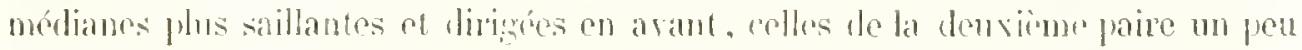
plus contes, dirigées en duhor's el séparées de celles de la troisiome paire par une

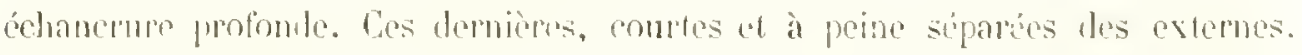
Borl sourcilice droil el divisé par denx scissures. Apophyse ápistomienne non

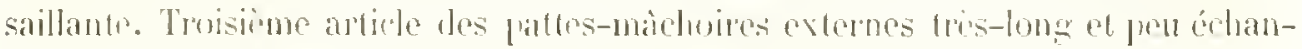

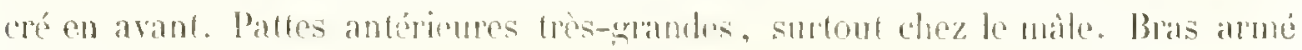

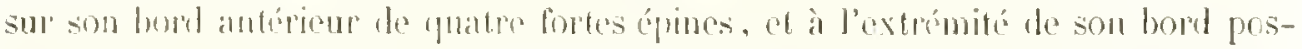

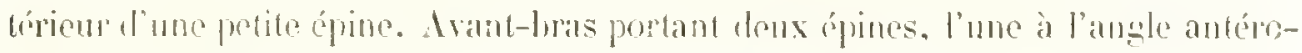

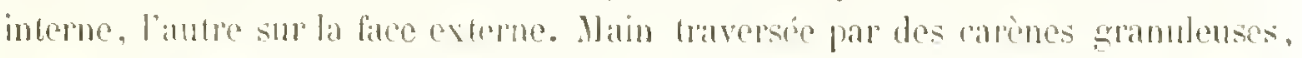
armén en desius de deus épines. l'une antedessus de l'articulation de l'arant-

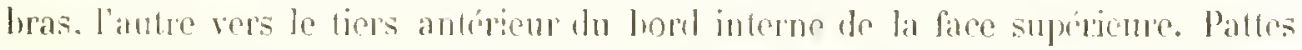

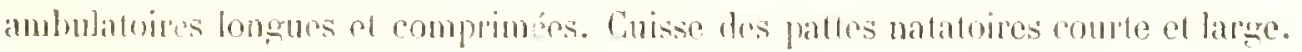

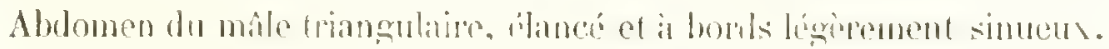

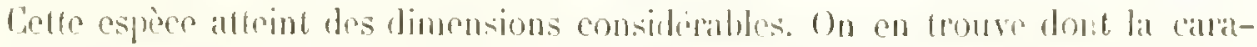

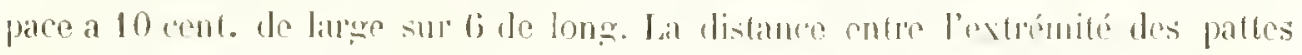

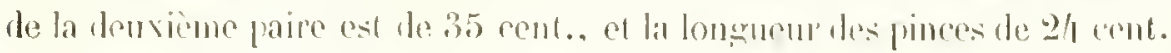

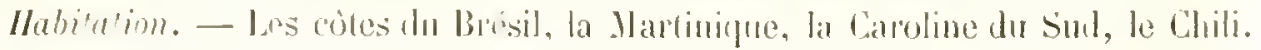
Collection du Masćum. 


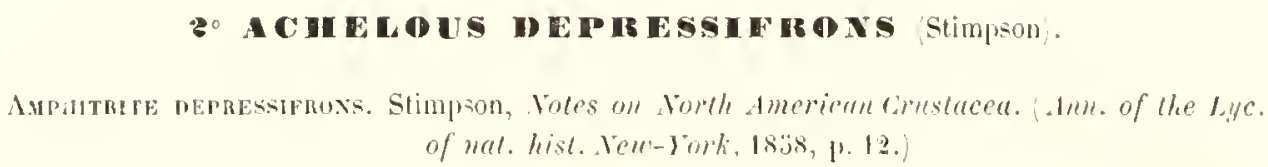

Carapace convese postérieurement et jusfu’an milieu, dépriméc vers le front et les bords latéro-antérieurs; surface finement wamulense. Bovds latéro-antríreurs diconpés en neut dents sensiblement ágales. Front ì six dents, les quatre médianes érales entre elles. Bord sourcilice divisé par denx scissures. liras armé d'une petite épine à l'estrémité de son hord postérinur et de cinq ápines en avant. Avantluras portant une épine longue, mince et aréréc à son angle antéro-interne. ef une petite spinule sur la face externe. Hain garnice on dessus d'une erête proéminente, armée de deur petites éfines, l'une an-dessus de l'articulation de l'arant-luras, l'autre au-dessus de la hase du pouce. Surface finement granuleuse. Pantes ambulatoires grôtes : la quatrieme paire beancoup plus petite que la troisieme. Abdomen du màle subtriangulate et à bords ligerenent sinueux.

La longueur est ì la lingeur comme 1 est i 1 1:2.

Mabilation. - Cóte de la Caroline du subl et de la liforide.

La forme du front découpé en six dents, ainsi que les cinq épines du bord antérieur du bras, ne permettent pas de confontle cette esprece avec l'A. spinimumus.

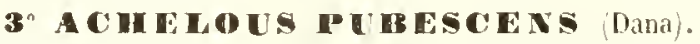

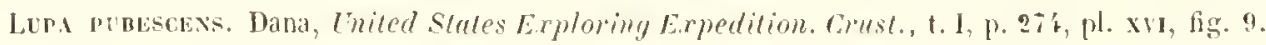

Carapace très-convexe, peu élargie. finement gramuleuse. Bords latíro-antérieurs découpés en neuf dents, dont la depnière est un peu plus longue que les autres. Front étroit divisé en sis dents, dunt les quatre médianes sont petites, lamelleuses, lien séparées et régales entre elles; les externes complétement obtuses et tronquées. Bonl sourcilier droit et divisé par deux seissures. Apoplyse épistomienne non saillante. Pattes antérieures courtes et grètes. lras armé de trois épines sur son bold antérieur, lisse sur son bond postérieur. Avant-bras à deux épines, l'une longue et mince située à l'angle antéro-interne, l'autre petite el placée sur la face esterne. Mlan armée en dessus de lrois épines, l'une an-dessus 
de l'articulation de l'avant-liras. Ies denx autres audtessus de lat base du poure.

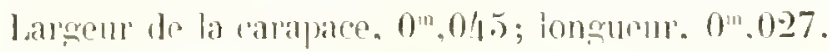

Mabilution. - Iles Sindwirh.

L'existence de trois épines sur le borl anteriem du brats. l'absence d'épines à son bord prestérirur. le nombre des f́pines de la main, ef enfin la forme du front. permethent de séparer facilement cetle espoe des f. spinimanus et depressifinns.

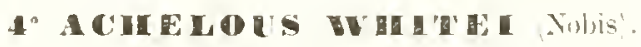

P. XXXI, fig. fi.

Carapace peu blargie, traversée par de nombreuses ligues granuleuses : trois sur la rógion gastrigue, une sur la région carliaque, teus en arriere des liggues épibranchiales à la partie postériente des régions branchiales; le reste de lia carapace, sauf la hase des éphes latérales. est lisse. Bords latéro-antérieurs à neuĺ dents dirigés en arant. Dent posterieure dipassint tres-pen les précédentes. Front découpe un is dents à pou près égales. les médianes un pen plus avanefós que tes autres. Ophites tres-profondes. Yeur tres-gros. Bord sourcilier droit et divise par deus scissmes. Apophyze épistomienne combe th ne lépassant pas le front. Pattes antérieures longues of greles. Bras armi sur son hord antrieur de quatre it six ápines. et sur son bord postérieur de denx épines. l'ume terminale. l'autre

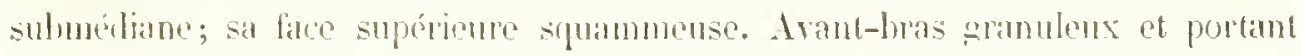
deux épines. l'une à son ande antiro-interne. l'autre sur sul fice externe. Jain trè-bongue, gride. garnie de carènes longitudinales tress-granuleuses, et armes en desius de trenis épines. deus sur la mème lighe, un peu en arrière de la base du proun, lautre an-dessus de l'articulation de l'arant-bras. Doigts longs comprinés latéralement, la pointe du pouce un peu polerée. Pattes ambula-

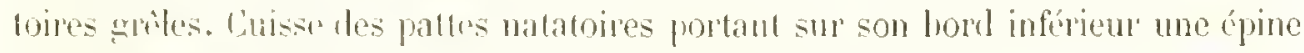
atérée. Abdumen du mâle triangntalairr et tris-pointu.

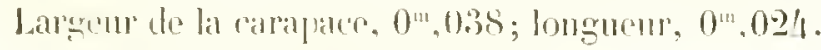

Intrikation. - Ciotes de Bornéo.

De tons les lchelons, cette espece est la sente aver l'a. meber. qui porte une épine sur le hort infériour des cuisses des pattes nageuses. Ce cantciere, uni à la forme des pattes antérieures, la rent tres-facile à distinguer. 


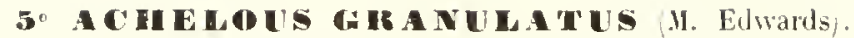

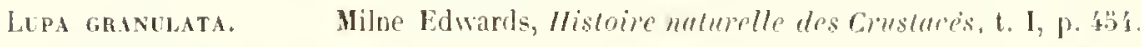

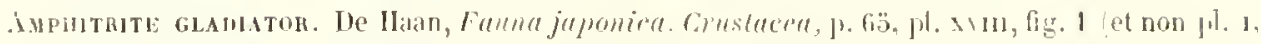
fig.

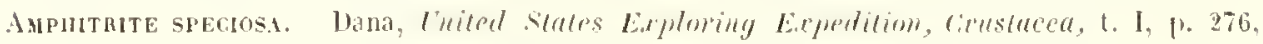
pl. xiı, fig. 1 .

Carapace très-peu élargie, tres-bosselée. el ayant loutes les saillies granulenses. Bords latéro-antérients tris-longs, peu olliques, técouprés en neul dents. pretites. aignës, diriges con avant, sensilhement égales entre elles, a l'exception de la neuvieme qui, chez les jennes individus, est un pen plus longue, ef de la premiere on angle orlitaire externe, qui est beancouj plus grosse. Front plutôt lobé que découpré en dents; les deux divisions mádianes, tris-petites, sont sonders sur la ligne médiane. pour n'en former qu'une seule, au milien de lacpulle on apercoil cependant une depression indiquant la lace de leur síparation; les dents (ou lokes) mitoyens larges, obuses el arancíes, lesexterues courtes. Bord sourcilier droit ef divisé par

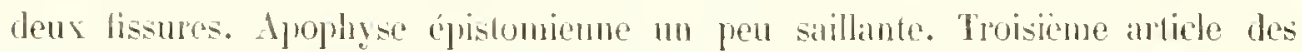
paltes-màchoires externes tres-íchlancré en avant. Patles antérieures longues el reaflées. Bras armé de quatre ou cinq pelites épinces sur son lmol antérieur ed de

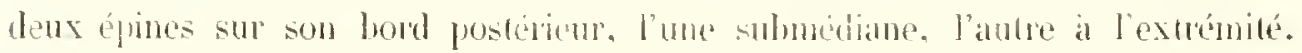

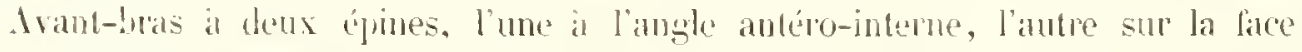
esterne. Main légèrenent ruguense, marifuée de carènes pen saillantes portant en dessus deux épuns courtes. l'une au-dessus de l'articulation de l'avant-bras. l'antre an-dessus el un peu en arriere de la base du proure. Palles ambulatoires de lat deavieme jaire fres-longties et griles, celles de la quatrième paire courtes. Abdonen da natle régulièrement triansulaire.

Largent de la carapace. (1)", $\left(128\right.$; longueur, $00^{\mathrm{m}}, 019$.

Ilabitation. - Ile de France, mer lionge, mer des Indes, Java, Samankng. Japon? Arehipel Viti.

La formo lobée du front ou les denx dents médianes se confondent en une, Jes

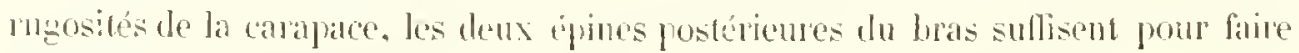
distinguer retle aspere de toutes les antres.

loblaction du Museman. 


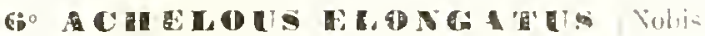

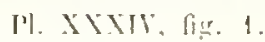

Carapare tris-longue, le diambro longitudinal sumpassant le diametre transver-

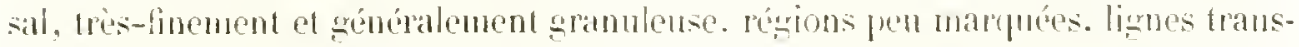
versales à peine visibles. Bords latéro-antérienrs prestue droits, découpés en neuf dents égales entre elles, très-petites el lirigées en arant. Front large et it six dents. les deur médianes rulimentaipes. les mitormmes plus grandes ot plus avanées. les externes ohnses ef rourtes. Burl sourcilier droit et divis: jar dens scissures. Pattes antéricures contes. Bras armé de trois éphes sur son hort anterieme de 1:ux sur son hord postérieur, l'une ferminale, l'antre submétiane. Arant-has a dem epines, l'mo ì l'angule antéro-interne, l'autresur la face externe. Main portant en tlessus trois épines, dens au-dessns de la base du ponce, la troisheme att-dessus de l'articulation de l'arant-hats. Pattes suivantes grêtrs. Ablomen miangularire.

Lat taille de cette espece est tris-pen considiable. Le liametre longitudinal est au diametre transversal comme $11: 8$.

Inubitulim. - Ambirinel Viti.

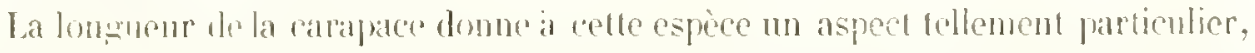
qu'it es imposible te la confondre avee ancume autre. L'. 1. gramulutus qui s'en rapprobe le plus est comparativement beatuoup plus ćlargi ; d'alleurs, la main

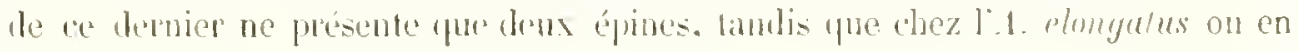
rompte trois.

Collection du Masée Brilamaigun

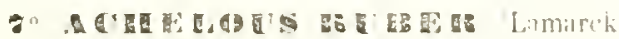

1\%. XIIII. fi: :

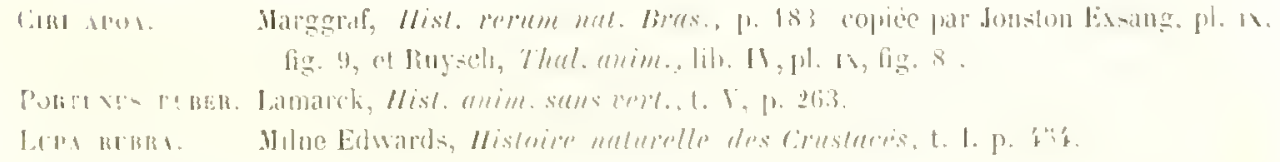

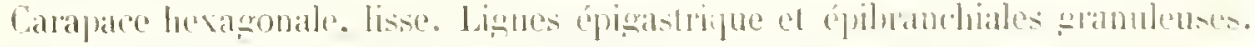

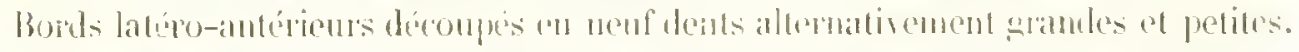

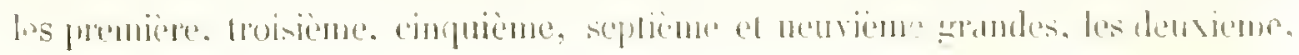


quatrième, sisième el huitième petiles; tontes acérés et dirigées en avant; la neuvieme dent dirige un peu phos en dehors, mais semblable a la septiene. Front

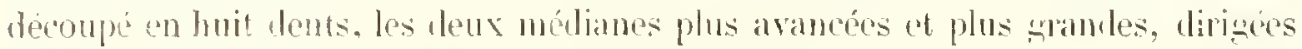
en avant, celles de la densieme paire aigues. dirigies mn pen en dehors ef separés de celles de la troistime paire par une éehancrure profonde, celles-ci aigutis, dirigées en avant et ì peine séprares de celles de la qualriène paire (ou angles orlilaires evternes) qui sont obuses. Bord sourelier droit et divisé par deux scissures. Article basilaire des antennes externes portant. en avant, an-ilessons de l'insertion

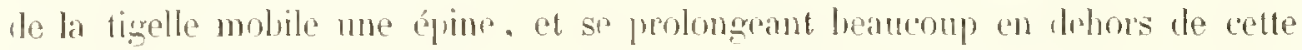
tigelle. Apophyse épistomienne à preine saillante et ne dépassant pas le front. Troisieme article les pattes-màchoires pen cehancré en dedans. Pattes antérieures robustes. Bras armé en arant de quatre à cimpépines larges ef fortes. un pen gratnuleux sur son borl pustérienr qui porte à son extrónite une tres-petile spinule. Arant-bras gami le cretes gramuleuses, et pursentant il son angle antéro-interne une ipine longue el arérie, el sur sa lace externe treis petiteséphes. Main tra-

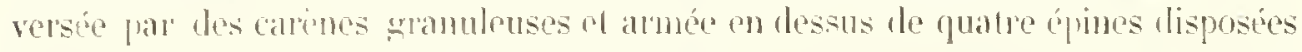
alternativenent, deux sur le hord inturne, deux sur le lorte exterme de la lace supérieure. Cinsse des pattes natatoires armée d’une épine à l'estrémité de son bord in lérieur. Aldumen du màle triangulaire.

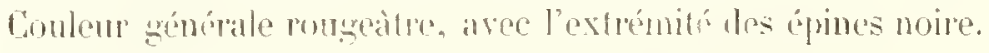

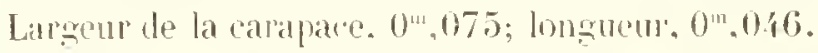

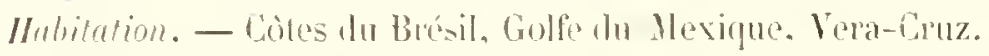

Cofte esprece est extrumement remarquable, paree qu'elle raltache les Lupéens anx Thalamitiens; en eftef, seule parni tous les Lupéens, elle présente huit dents au front; l'article bisilare de l'anteme externe porte une ápine et se prolonge beancoup en dehors de linsertion de la tigetle mobile, fous carnteres qui so retrouvent ilans le grompe des Thalamitions; pour completer les points te ressemblance, la cuisse porte une cipine sur son bord inférieur. disposition exceptionnelle chez les Lupáens, prisque le Teptumes Sebe et l'Achelous Whilei la présentent seuls. Il est anssi i noter que quatre des dents du lrord latéro-antérieur se sont beancoup réduites

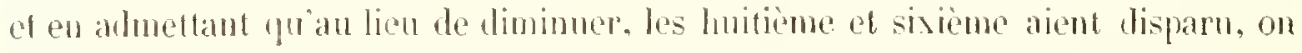
aurat exactement la mème disposition que l'on observe dhez le Goniosoma erythrodactylum. Enfun les pattes antériemres sont construites sur te mème plan que celles des Thalamiliens.

Collection du Muséum. 


\title{
ESPECES FOSSIIES:
}

\author{
ACHelors OBTting . E. Elw.
}

Alh. Hilne Edwards, loc. cil., p. 2i:, pl. m, lig. 2.

\section{TAHLESU DES ESPLCES REGLNTES DU GENRE MUHELOUS.}

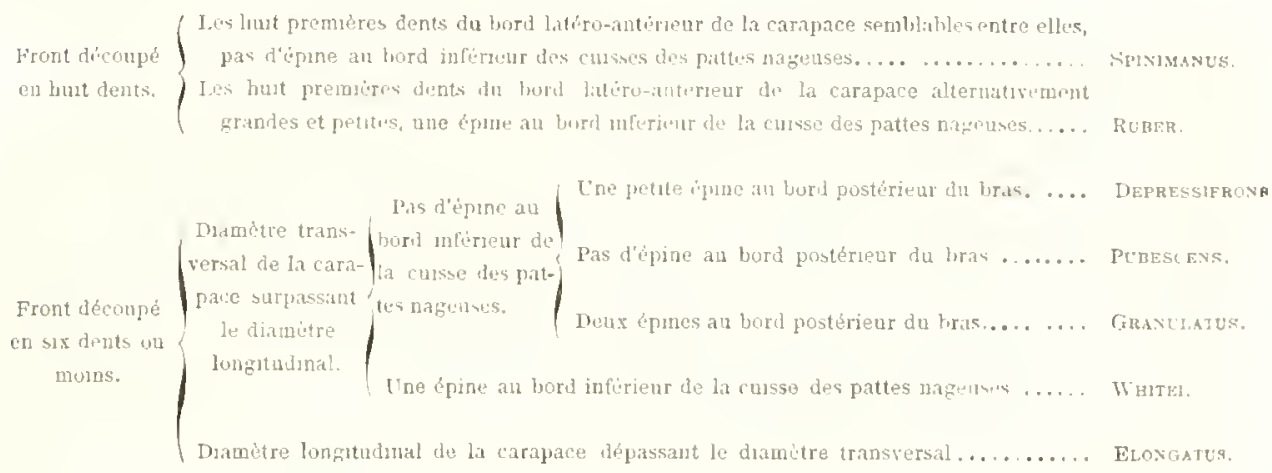

\section{Genre SGYLLA.}

Pontry - pars. Fabricius, Entomol. syst. viuppl. 11. 360.

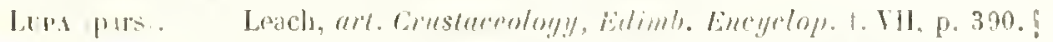

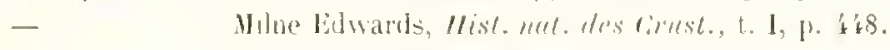

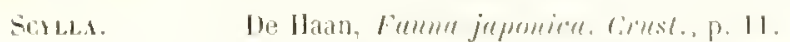

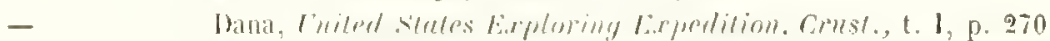

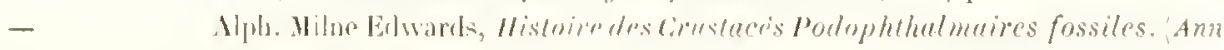
srime. nat., te sirie, t. XIt, P. 2.69,

Le genre Seyllu étalili par W. de Haan correspond exactement an sous-genre des dupées convexes de M. Milne Bhwards. Les caracteres que le célibre naturaliste hollandaris assignait à cette nouvelle division gémérigue, étalent tirés de la forme générale de la carapace ed de la disposition de la banche externe des piedsmichoires antírieurs. L'ádude altentive que j'al fatte de ce genre m'a permis d'y observer quelgues particularités de surucure qui, jointes à celles déjà indiejuées. me semblent autoriser plemenent le mantien de cette nouvelle division du grand genre Lupa.

La carapace est beauroup phus hombre ot phus épaisse que chez les autres Por- 
tuniens du mème groupe. Les bords latéro-antérienrs, beancoup plus obliques que chez les Neptunes, sont armés de neuf dents égales entre elles, caraclère qui se rencontre aussi chez les achelous.

Le front est découpé en six dents.

La région faciale qui s'étend du front au plastron sternal se relève beaucon:? moins que chez les icheluus et que chez les Viptumus, oì elle est presque verticale.

La cloison inter-antemulaire ne donne naissance ì ancun prolongement spiniforme. L'apophyse épistomienne est enchissée dans la fossette que le front présente pour la recevoir et ne se prolonge pas au dela.

Le plancher de l'orbite s'ilvance moins que chez les autres lupées, el en regardant la carapace en dessus. rest à peine si on roit son hord antérieur. La dent sous-orbitate interne présente à sa base et en dedans un sillon longitudinal ya la divise en deus parties. lune externe tres-sande el formant la dent proprement dite. lautre interne tres-petite, réduite a l'état te tubercule et appliquée contre la base de l'antemne externe. Cette dispusition n'existe chez ancun autre Lupre. L'épistone est biendéveloppé; le bord lahial, ou bord antérieur de la fosse huccale. est distinct du bond postéricur des fossettes antennaires, et il s'en trouve siparé par $u$ sillon transwersal qui se prolonge en arjiere des tubercules anditifs jusçu’au bon interne de la portion sous-ombitaire de la rarapace. Dans les gemres Achelous et Yeptumus on n'ajpergent jumais de traces de ce sillon.

Le plistron sternal est plus hombé. plus átroit el phus long que dans les genenres votsins. La suture médiune s'étend sur les trois terniers articles du thonax comme chez les lippunus el les dehelous.

Les pattes thoriciqunes de la prenière paire sont courtes ef robustes; la main notfe pas de cretes longitudinales analogues a celles qui se retrourent dez toules

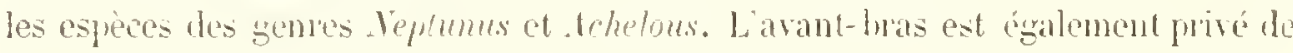
crètes.

De tous ces caracteres. le phus important, a mon aris, est cedui que fournit la région faciale, car sur les trente-quatre esjèces que comprennent les genres hephunus et Achelous. ancune ne frésente de silton transversal entre le bord labial et le bord protérieur des fossetles antennaires; ce n'est que dans le genre Soylla que celle particularité sobserve, tandis que la forme des pieds-maichoires, celle de la rarat pace et la disposition des pinces varient heaucoup en passant d'une esprece à l'autre.

Jusju'ici ce genre ne renferme quinne seule esperce récente qui habite les mers d'Asie el l'océan Pacilique. 
SCYIIA SEMEA'TA Forikial).

\begin{tabular}{|c|c|}
\hline CAXCER SERHTES. & 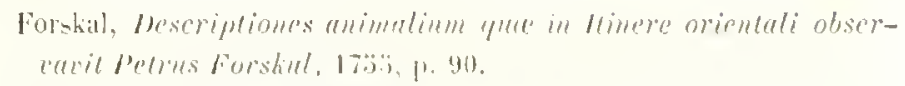 \\
\hline Giver HLAGES. & 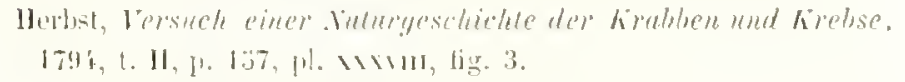 \\
\hline 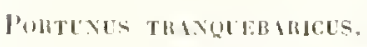 & Faluticina, supul. Eulume syst., 1798, p. 366. \\
\hline 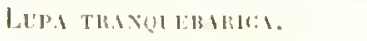 & 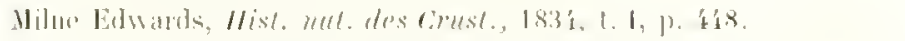 \\
\hline Lupl Lobritasia. & 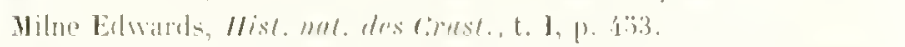 \\
\hline l'ohtoxt- SERHTLS. & 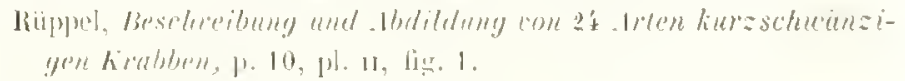 \\
\hline SCYLI, SERHTL. & 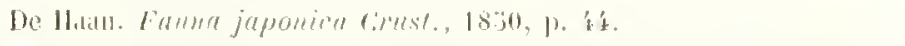 \\
\hline 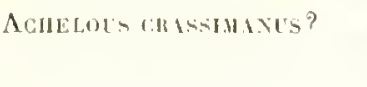 & 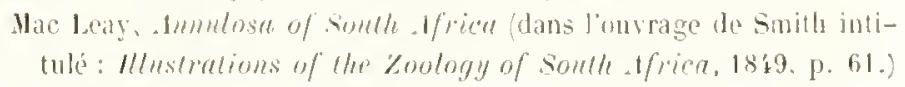 \\
\hline Scrlal Curassmaxus. & 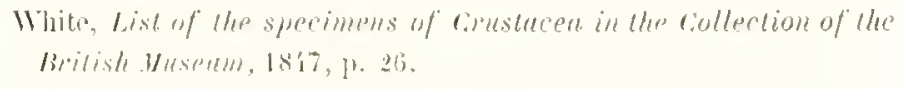 \\
\hline 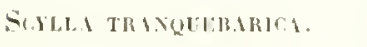 & 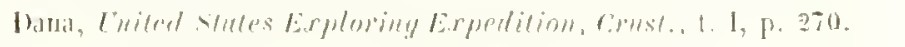 \\
\hline C.MCER PETREFICTHS. & 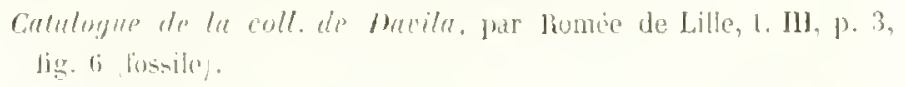 \\
\hline boRTINIS LEVRODOX. & Desmatest, crust. foss., 1822, p. 86, pl. 11 , fig. 1, 2 ot 3 (ossilej. \\
\hline LEP Liscolrox. & 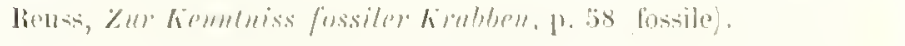 \\
\hline Platicibaices Bervela. & 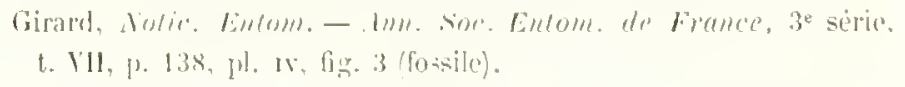 \\
\hline 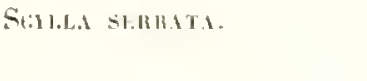 & 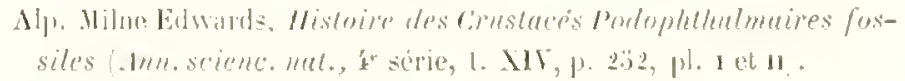 \\
\hline
\end{tabular}

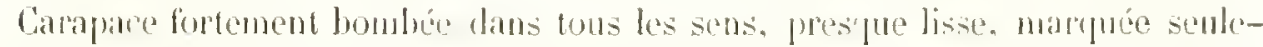
ment de gramulations très-fintes. Rhigions peu distinctes, lignes eprigatrique of épi-

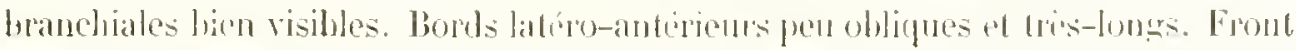
dénugé an sis dents larges ef plates, les deus mélianes en grénéral un peu plus

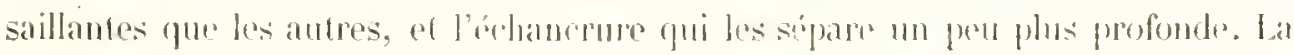
forme des drals frontales varie notablement aree l'atge : cle\% les jeumes elles sont

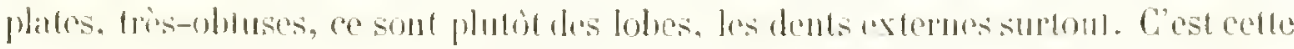

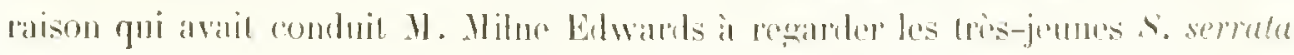

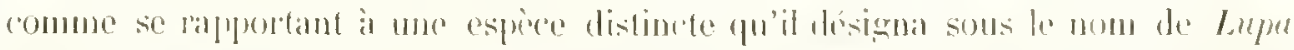

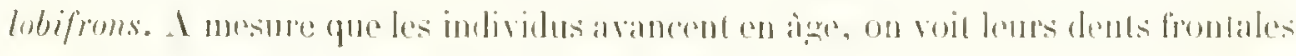

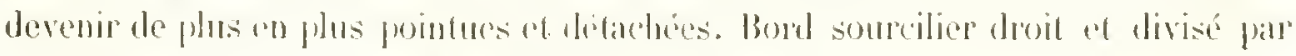
denx scissures dont l'interne est la plus probonde. 
Pattes anterteures tres-robustes. Bras prismatique trianghulaire arme de trois epines sur son antérieur, et de denx sur son hord postérieur. l'une terminale, l'autre subméliane. Ivaut-bras portant whe épime acérec ì son angle antérointerne, et deus petites epines sur la face externe le long du bord anterieur. Main très-grosse, atteignant des proportions énormes dhez les vieux indivilus, armée en dessus de trois épines, l'une au-dessus de l'articulation de l'araul-Jras, les deux autres an-dessus de la hase du pouce. Doigh forts et armes de tulerentes puissants. Alulomen du mite large et triangulaire.

Couleur de lat carapace d'un vert brun on olive, aree les pattes ambulatoires et nageuses marbries de taches plus claires.

Celte espece peut atteindre une taille frès-considerable. et daus ce cas la quosseur des pinces devient monstrueuse. Largeur de la carapace, 16 cent.; longueur 10 cent.

Mabitation. - La mer Rouge, les còles des lndes, de la Chine el du Japon. les iles de la Somle, la Tourelle-Hollande, l'ile Maurice, el fossitr dans les depouts quaternaires des mèmes rivages.

Le grand nombre de points sur lesquels on rencontre cette aspece, les.-rantess variations de taille qu'elle presente, puisfu'on en trouve depuis quelques millimetres jusqu'à près de 2 décimeres. ont ete canse de la multiplication des divisions: spécifiques que l'on a cru deroir former pour ce Portmien; mais en suitant pas a pas les modifiontions que les progrès de l'ige peuvent apporter dans les formes exterieures, on peut facilenent s'assurer que toml co qui a ćlé donné soil comme variété. soil comme espece voisine de s.. servata, ne peut en ètre siparte.

Collecion du Muséum.

\section{ESPECE FOSSILE.}

SCYLL MIUHLixi (A. Edw.).

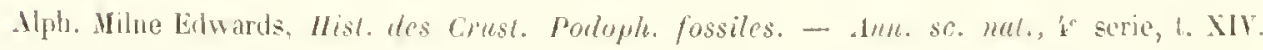
[1. $26 ?, \mathrm{pl}, \mathrm{IH}, \mathrm{fig} .3$. 


\section{Genre LUPA.}

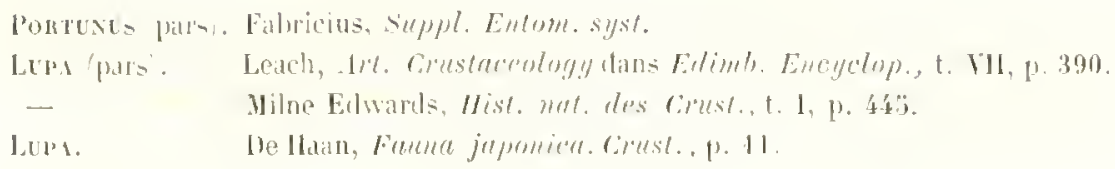

W. de Hatan réserva le nom de Lupa à un démembrement des Lupions de Leaded

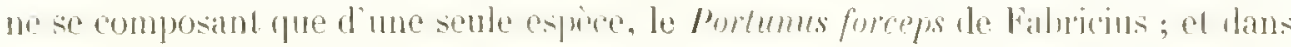
la reation de a gente il se lassa sur la forme du trobieme article des paltes-

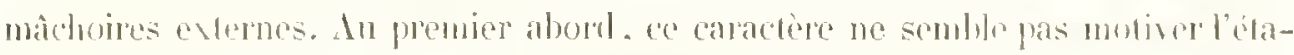

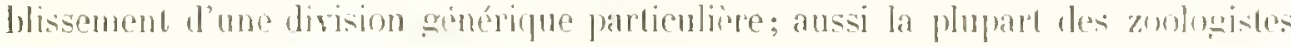
n'ont pats ardopte l'innovation proposée par le célebre carcinologiste loblindais.

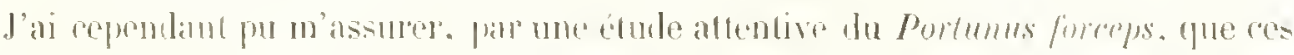
particularitio de forme des pieds-màchoires externes coüncibaient arec d'autres caracteres zoologiques tres-remarcpualules.

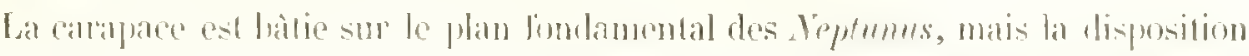

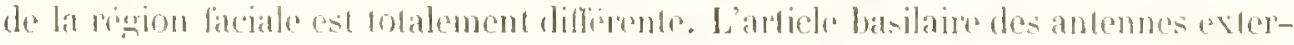

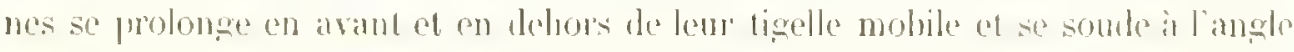

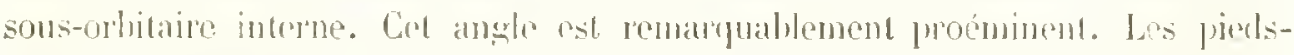

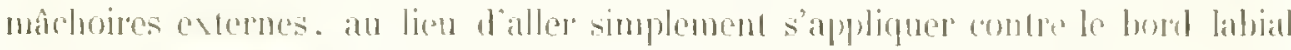

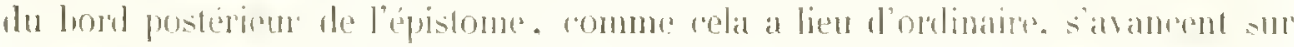

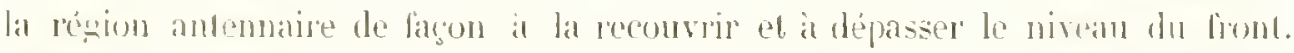

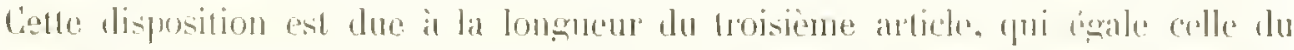

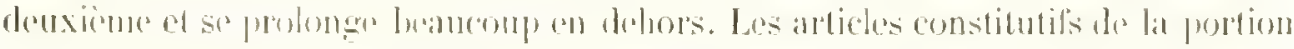

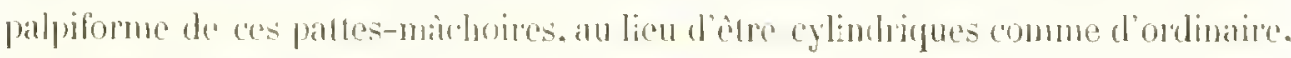
sont comprimes el lamelleux.

Les apodimes transversales de la portion postericure du thorax ne s'itemtent

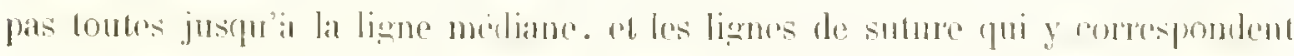

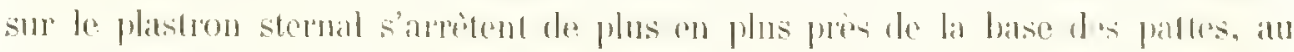

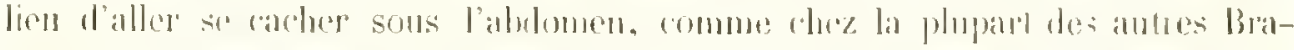

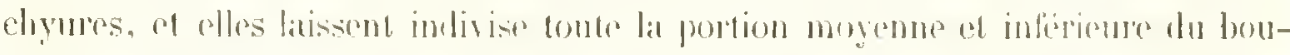

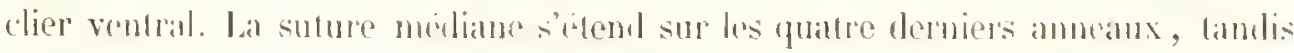

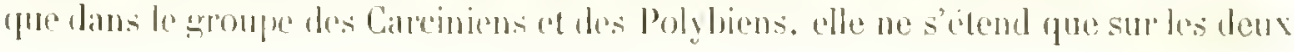


derniers. Dans le groupe des Thahamitiens, ainsi que chez les autres Lupéens, elle se prolonge sur les trois demiers sentement. Les pattes sont remarquablement grêtes; mais ce caraclère ne peut ète donné comme faractéristique du genre, car si fon trowait des Yephumus dont les pattes-màchoires el le plastron slemal fussent construits sur le plan que je viens d'exposer, on derrait les ranger à còté de la Lupa foreops, quand bien mime ils a!naient les palles forles et trapues.

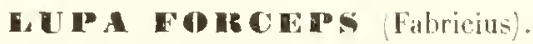

Pl. I, fig. I.

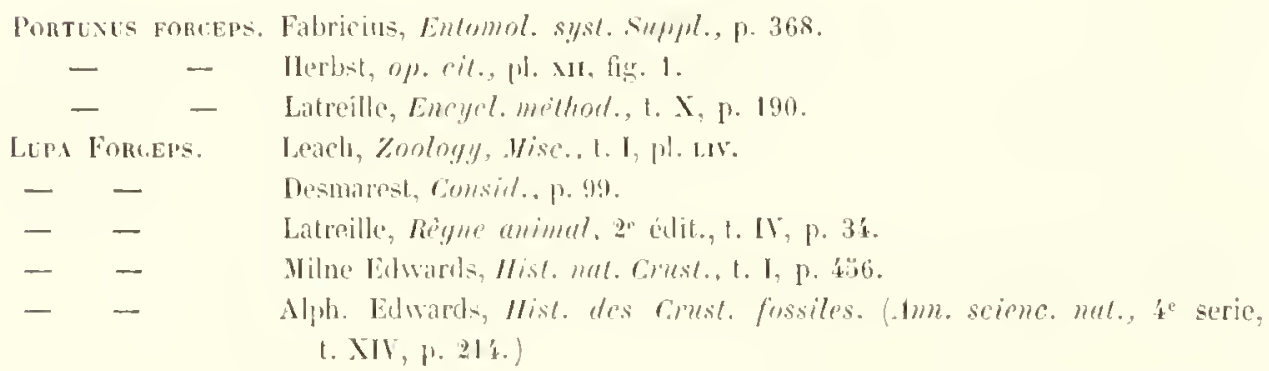

Carapace Irès-aphatie, légerement hevagonale, tres-finement granulense, lignes epigastrique el épiluandhiales pen visibles. Bonl postérieur très-large. Bords latiro-antirienrs armés de huit dents très-petites et pointues. Corne latlirale trèslongue ef elfiles. Front derompí en huit dents, les deux medianes courtes et aiguës, les miloyennes plus longues, les externes courtes el un peu olmuses. Bord sourcilier droit et divise par leux scissures. Apophyse épistomienne peu saillante et ne dépassint pas le front.

Pattes antérieures lisses ef remarquahlement quêles ef longues. Chez le màle. la longueur du bras égale le diamètre transiersal de la carapace pres de la hase des colnes latérales et la main égale deux fois ce dianètre. Bord anterien du loras armé de quatre à six épines, une épine à l'extrémité du hord posterieur. Avauttras portant deux cipines. l'une à l'angle antero-interne. l'autre sur la face externe. Main grile. cylindrique et arnee de doigh presque filiformes qui sont heancoup troy fables pour servir is la caphure d'une proie solide. Poignet tres-court ofliant deux émes en dessus. l'une au-dessus de l'anticulation de l'avant-bras, l'autre audessus de la hase du ponce. 
Chez la femelle, les pinces s'èloignent beaucoup moins de la lorme ordinaire. lat longueur des doights ne dépassant pas leatronp celle du poignel, et res appendices sont comprimés lateralement. earenes ef garnis de petites dents sur lenr hord tranchant.

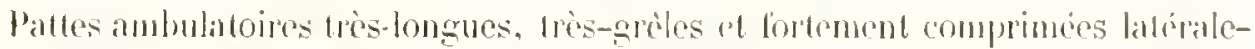

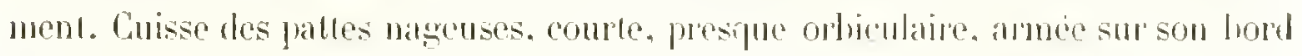
inférieur d'une epine anatogne à celle fui existe chez les lhatanitiens el chez

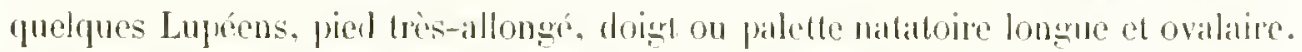
Ablomen du màle rélreci a parlir du quatrieme arlicle.

Larecur de la carapace, $0^{\prime \prime}, 067$; longueur, $0^{\mathrm{m}}, 033$.

Inabitation. - Les Antilles, Itaili.

Collection dlu Husénm.

\section{Genre ENOPLONOTUS.}

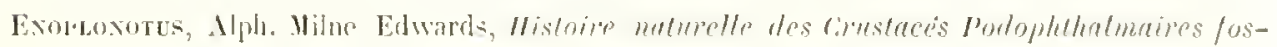

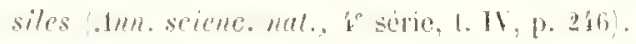

Ce petit genre a ché etabli prour un Portunion fossile du terrain nummulitique de Montr-Bolea. Il est caracterise far l'morme developjement des cornes larirales de la campace dont te lowl antricur est dente. de telle sorte que he bord

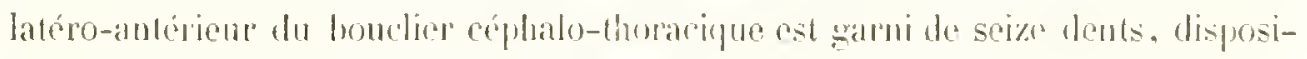
tion unique lans toat le groupe tes latrens.

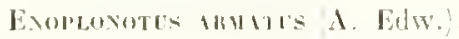

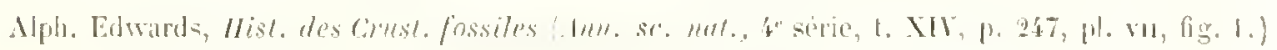

\section{GROUPE DES THALA.UTHEXS.}

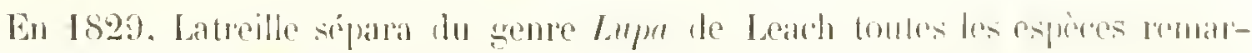

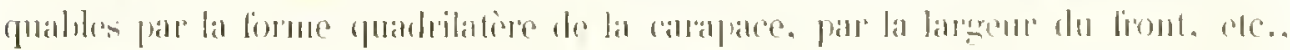

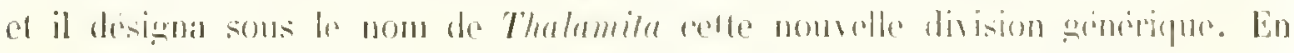

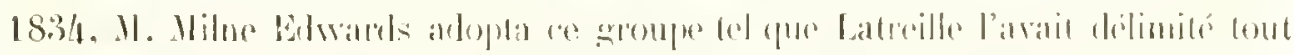
en y renonnatsiant denc lormes distinctes dont il lit des sons-genres. 
Vers la mème époque. W. de llaan crut nécessaire de multiplier les groupes génériques, et du genre Thalamitu il fit les gentes Thalumila Ocramus et Charyblis. Le premier correspondail an sons-zente des Thalamites quadrilateres de

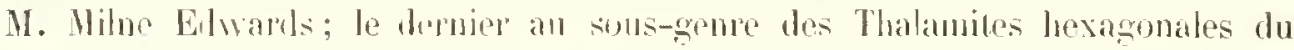
même auteur. Quant au ğtnre Oceamus, il ne comprenail yu'me seule esprèce. to Th. rrucifera (liab.). J'ai dúja en l'ocrasion de faire comanille mon opinion sur la valem de cette division gínériquo; elle n’est fondée que sur la forme de l'extrémité de la hranche inferne des piuls-màchorires antérients, calractire qui ne peut

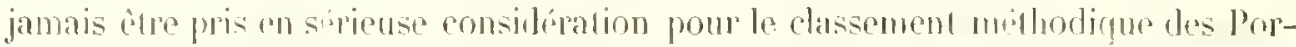

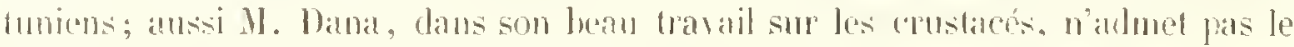

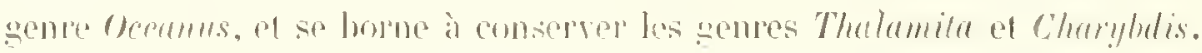

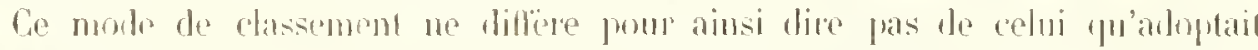
11. Nilne Ehwards; ses sous-genres sont simplement élevés au rang de cemres.

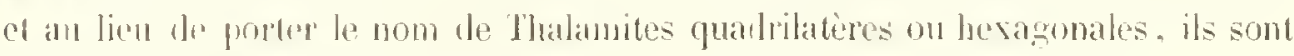
appoles Thalumile on Ciluarybulis.

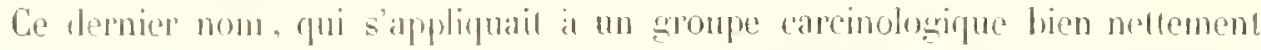
délinilé, ne jouvait inte employé ici. puisqu’il avail déjà servi a Peron el Lesnemp

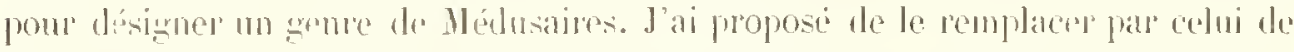
Coniosomn, qui rappeite la forme la la carapare de ees crustaces. Les Thatamitrs proprement dits sp séparent trè-nellement des Gonosomes. Arec un pen d'habi-

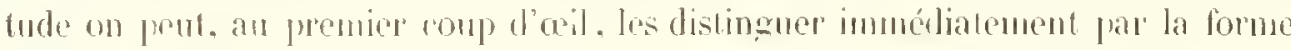
de la carapace. qui. chez les Thalanites, est presque quadriatiere, et tont le

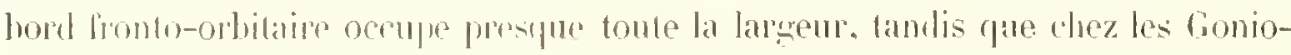

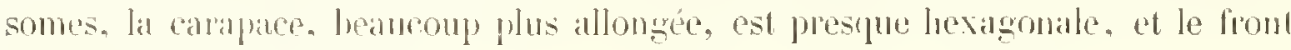
beancoup moins fitemulu.

\section{Genre TIALAMITA.}

La carapaes des Thalamites, tronquéc en avant oì le front s'ítend en ligne droite

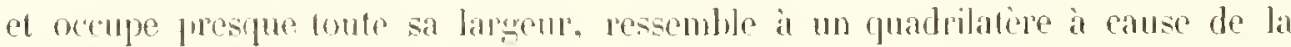

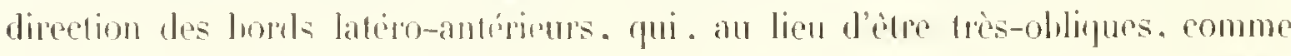
cela s'obserw dro la phupld des Portuniens. sont prestue droits. Son diandre transversal sur]asse d'emviron un liers son diamètre antéro-postérieur. Le front, divise tentót en lobes, lankit en dents, est plus avancé que l'angle orbitaire 
externe. Les orbites sont dirigées un pen en dehors; le bord sourcitier présente denx tissures. et le hord inférieur de l'ordite une seute. Les borls latiro-antérieurs ne som janais garnis de phus de aing dents. el encore il y un a quelguelojs

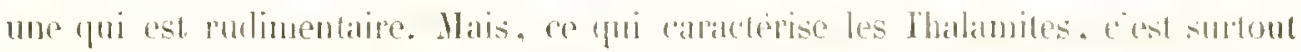
la dismosition de la région antennaire. La fissefte destince a loger la tigedle mothite des petites antennes est tris-allongre lransversatemeut, el la cloison infer-anten-

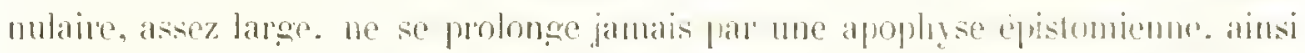

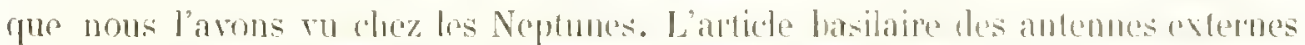

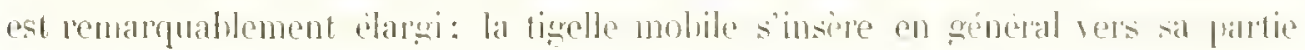

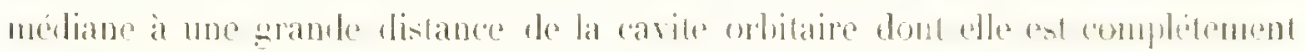

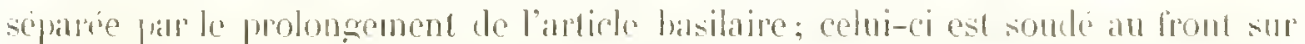

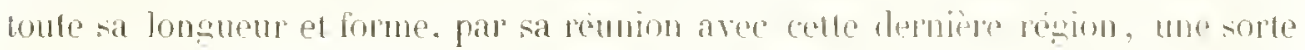

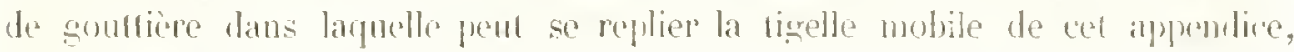

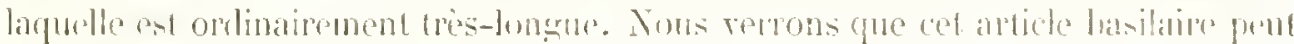

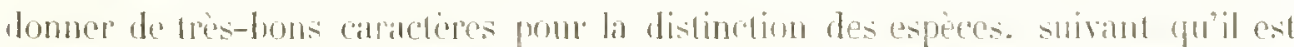
lisse ou granulenx, qu’il porte une crite ou des protongements spliniformes. elu.

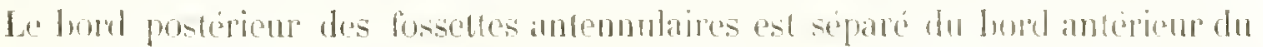

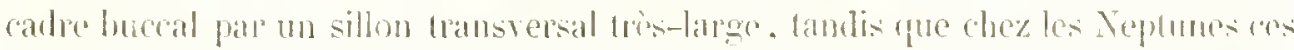

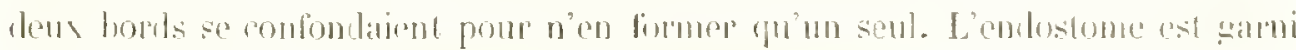

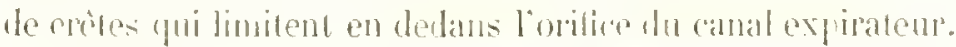

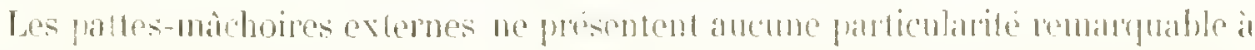

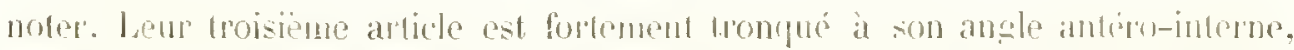
animi yue cela se voit chez la phupart des Portuniens. Ie plastron sternal est en

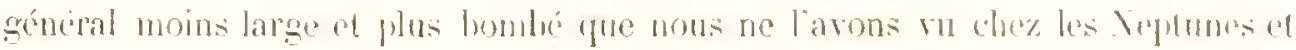

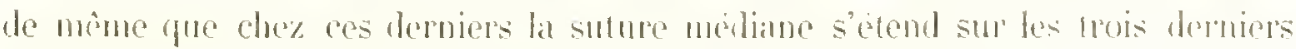

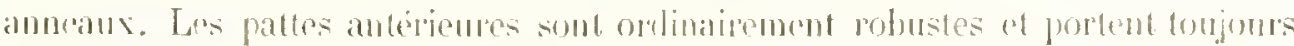
des epines plus on moins aceries. Los antres palles sont assez combles. surtont

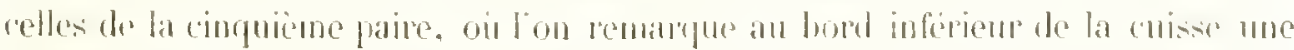
ípine que mons retrourerons chez les Goniosomes. mais ipui manyue chez les l'oplumes, les Carrins. les Platyonyques. les scylla, ele. et qui no se rencontre

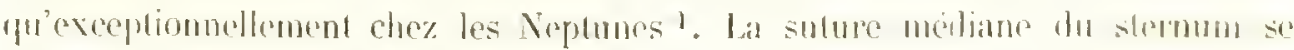

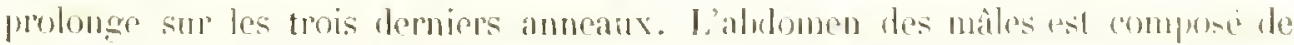

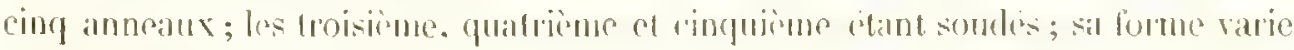
pen, de sorte qu’il ne pent fournir ancm bon caractere specitirue.

1. Ex, Viplunus Sober. de. 
Il est peu de genres qui soient anssi faciles à reconnaitre. La disposition du front et des antennes externes. ainsi que le nonbre des dents qui arment les bords latéro-antérieurs de la earapace. suflisent el au dela pour séparer les 'Thabautes de tous les autres groupes de la mîme famille.

Ce sont en géneral des emstacis de petite taille : le diamietre transversal de quelques espèces atteint somvent 10 centimetres envirun, mais la plupart des autres sont plus petites. On ne connait aucun representant de ce type dans les mers de nos climats; ils se tromvent principalement dans le volinige des tropiptues.

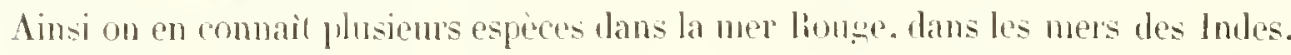
de Chine, du Japen. ele.

On peut. pour la facilité des déterminations. les diviser en deur groupes:

1 Les Thalamites a frout découpé en quatre lobes;

2 Les Thalamites it front découpé en lunit lobes.

\section{S Ier. THalamtes a floyt Quadilobé.}

A. Espèces it lobes fromtun.x égaux.

\section{IOTIILAMITANATE.}

C.iver idmete. Jerbst, op. cil., pl. wh, fig. 1.

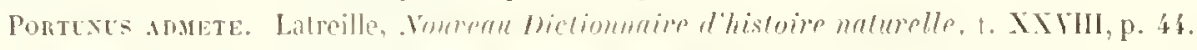

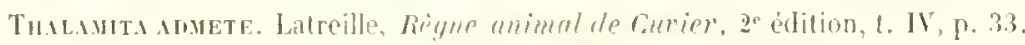

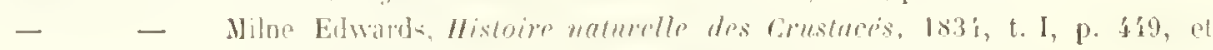

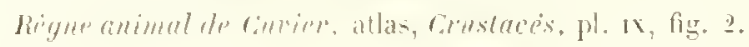

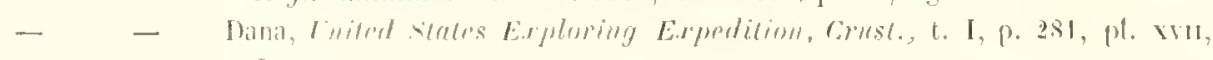
fice. $i$.

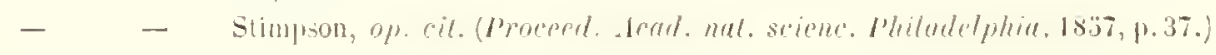

Carapace trie-blargie. lignes transversales à peine granuleuses et pen marquées. Bords latéro-anterients presque droits et antes de cing dents dont la quatrieme est mulimentaire. Bords latero-posterienrs tres-obliques. Front occupant presque toute la largem de la carapace, presque droil et dixisé à peu près dyalement en quatre bobes; les deux meilians flus avancés que les autres ot sur une ligne droite, les lateranx très-legirement coubles. Orbites dirigées un pen en dehors. Bord sourcilier divise par deux scissures peu profondes; plancher le l'orbite séparé 
par we fissure, angle sous-orbitaire interne tris-obtus. Article basilatire de l'antenne externe garni en avant d'une petite crête deuticulée qui se roit an-dessons et en avant des lobes latéraux du front. Pattes antérinures rolustes. Bras garni sur son borl antérisur de trois fopines. drant-luras armé à son angra antéru-interne d'une forte épine légèrement recomrbée. el de deux éphines rudimentaires sur sa face externe. Main portant sur elacun des borts de sa face supérieure trois épines. celles d'une rangere attenant aree celles de l'autre. sur la face exterme. dous cretes peu maryuces ot lisses. Patles suivantes courtes. le thight plutot styliforme que lamelleus. Pattes de la cincunieme paire portant sur

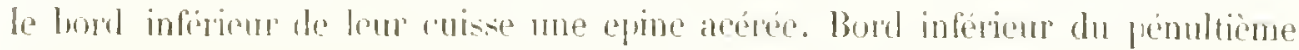
article denticule. Dongt matatoire large et armé d'un ongle bies marifué. Mastron stemal bombe. Abdonen du male compose de cing articles; le ternier petit ef pointu, les siviome et rinquiène sont à peu pris égaus, et ce n'est que le quatrième fui commence ì s'alargir.

IIabitution. - Letle espice. qui n’atteint jamais une taille consiléralle (4 rentimetres de large environ). lrabite les mers d'A tie et le grand Océin.

M. Dana l'a rencontréc anx iles Sandwich, anx iles Samaan, à l'ile Wakes. a) la meer Soolno. amx Indes-Orientales.

1. Stimpson l'a tronvée à l'ile Ousinar. Le muséum de Paris en posside un individu rapporté des illes. Iluzoleu par M. Jacquinot.

Collection rtu Jusium.

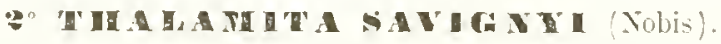

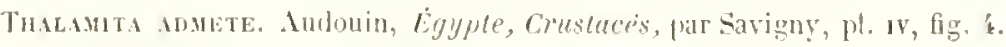

Celte espece ressemble beauconp à la préédente, et jusqu'ici parait avoir étés confondue aver elle; mais ethe s'en distingur par les lignes saillantes et granulées qui traversent a caraparee. et les lobes moyens du front qui sont plus avancés el très-légèrement ŕchanerés vers leur partie moyenne.

Les mains sont très-gramuleuses et hérissées te nombrenx tubereutes antre les crêtes longitudinales qui grantuissent ses faces externe et supérieure; lit lace interne est rgalument granuleuse. tamtis que chez lo Thulumitu admete la main est lisse ou du moins ne préserste que de très-rares stamulations.

Du reste. semblable a l'espere précédente avec larpuelte Audoun l'avait confon-

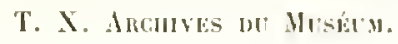


due dans la détermination des Crustacés d’Ézyple que Savigny avait fail fignurer. mais sans les décrire ni les nommer. Hême taille que la précédente.

Ilabitation. - La mer liouge.

Coilection du Museium.

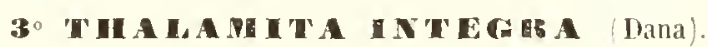

Thalanita integht. Dana, Cnited States Erploring Expedltion, Crustacea, t. I, p. 281, pl. xviI, fig. 6.

- - Stimpson. op. cit. (Proceerl. Acad. nal. srienc. Phitad., 18.37, p. 37.)

Carapace plus renthée que chez les espreses prócúdentes. ligunes transversales

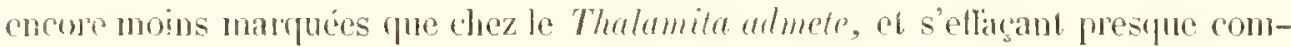
plétement sur lit lique médiane. Bonds labromantériems de la carapace armés de ring dents dont la quatrième est rudimentaire. Front prestue semblable à relui des esperces précélentes, si ce n’est que le hord des lobes latéranx est tout it fait droit. Larticle hasilaire des antennes exten nes est lisse ef porte une crête proéminente éralement lisse. Aandis que duez le Thulumita admete et le T. Sarignyi. cette mime crèle ćlait remplacés par une ligne de denticulations.

Les pattes antérieures sont trés-rolustes; la main est connpétement lisse ef dépourvue de crètes longitulinales evternes. Lu's borts supérieurs enx-mèmes sont lisses, tandis fue chez le Thulamita admete ils sont toujours granulés. Les épines qui arment les borts sont rudimentaires; on put cepentant en rompter trois. deux sur le bord interne et me sur le bord externe, au-dessus de l'articulation de l'avant-bras. Cet article. complétement lisse, ne porte futune seule epine à l'angle antéro-interne; le hord antérieur du bras porte trois épiues pen acerées. Cuisse rles pattes natatoires longue, tres-perl élargie el déponrue de extes. Bord infírieur du pénuttieme article denticulé. Le plastron sternal el l'alulomen ne présontent rien de remarpualile.

Ilabitation. - Iles Sandwich, les îles Tahiti, l'archipel des îles Basses (Paumatou), ainsi que l'ìle Ousima.

Collection du Inséum. 
B. - Thalamites à lobes frontan.r inéganx.

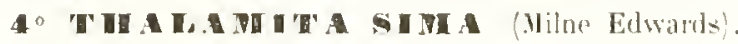

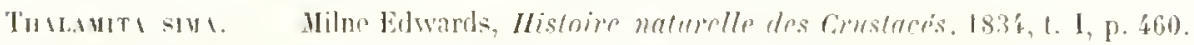

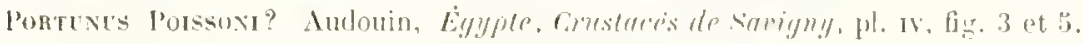

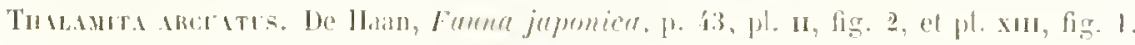

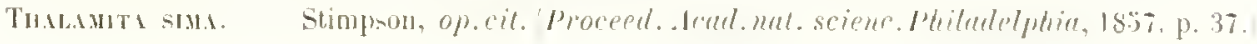

Caralqace moins élargie que dans les esjerces que nous venons d'examiner assez fortoment bombe et traversce de ligntes sillantes. Bords latero-antérieurs sannis de cing dents ; la cinquiome est plus fortur que les autros. tandis que la quatribme est presque égale aux premieres. Front beancoup noins large que chez les espires precédentes, divisi en quatre lohes; les derr médians dispreses sur une

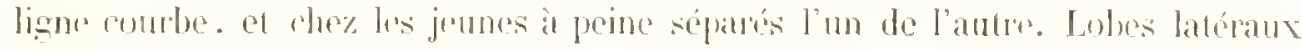

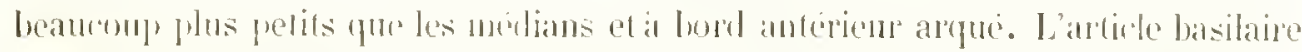
des antemes extermes, muparativement peu developpe, présente, de même que chez le Thulumila integra (Dana), une crite lisse. Liangle sons-onthitaire interne

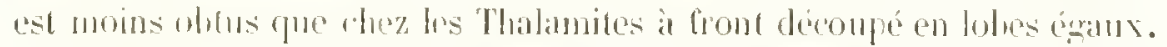

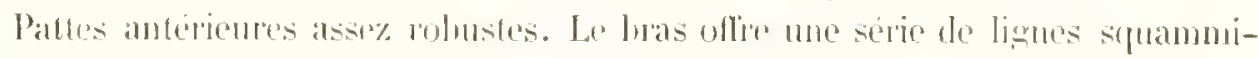
formes thansiversales; son hom anterieur est amé de trois éphues. Carpe granu-

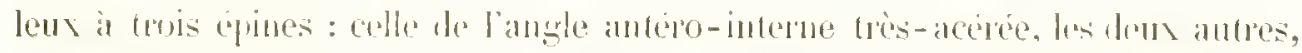
phacés. sur la litee extrome, sont rulimentaires. Main granuleuse portant en dessus cinc épines, trois sur te borl externe de la face supérieure, deus sur le hord

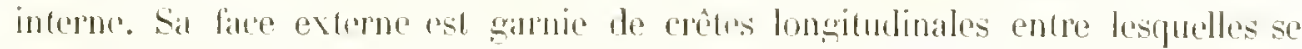
voient quelpues granulations qui, dhez les vieux individus, se remandquent aussi sur la face interne.

Ciniss des pattes natatoires aplatie, large et portant une eôte. Pémultime article lisse ef dépourvo sur son bord inférien de la série de denticulations qui se

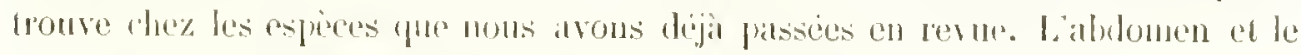
plastron sternat ne presentent ancune particulanite importante i noter.

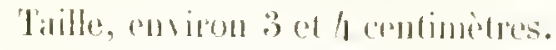

Mabilation. - Mer Liouge, Jara, mers du Japon et dr la Chine. Coltoction du lluséum. 


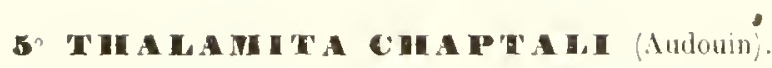

Tulamita Giaptal. Audouin, Égyple, Crusluce's, par Savigny, pl. w, fig. 1.

Carapace peu élargie. marquée de lignes transtersales saillantes. Borls latéroantérieurs arués de cinq dents tronquées, obtuses, presque carrées au bout et presque semblibles; la cinquieme ef la quatrime paraissent cependant un pen moins grosses. Front à quatre lobes; les deux medians disposés sup une ligne régulièrenent courbe et ì peine séparée sur la ligne meeliane; les lobes latéraux heaucoup phis petits et un peu arqués en avant. Pattes anterieures très-robustes. Bras portant sur son hord anterieur trois grosses cipines peu acépes. Carpe à une seule épine, placée à l'angle antéro-interne. Main lisse el nobliant sur sa face supérieure que des rudiments d'épines.

Larzemu de 4 à à centinitres.

Habilation. - Her Ronge.

Cetle espèce parail extrènement rare ; elle n'existe lans aucum muséc. soit de France, soil d'Angletere, soil de Ilollande. et depuis que Savigny l'a fait connaitre, aucun auteur ne l'a jamais citre dans ses ourrages.

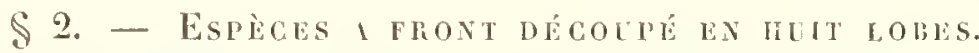

A. Guatrième dent du bord lalérn-anlérieur plus petite que les autres.

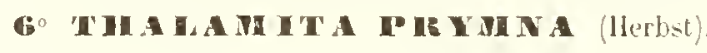

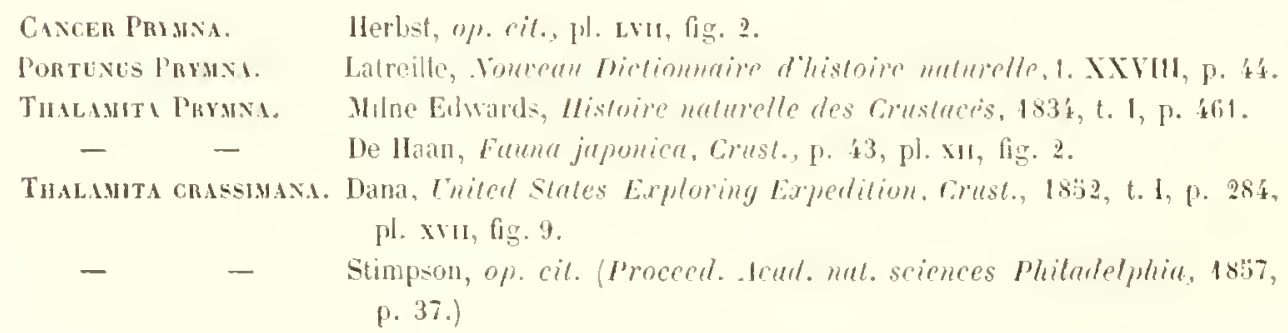
pl. xrit, fig. 9.

- - Stimpson, op. cit. (Procect. Acul. nut. scionces Phitndelphia, 1857, p. 37.)

Dans la description du Thalamita prymna que M. Milne Edwards publia dans son Ilistoire des Crustucés, il se lit dans le texte une transposition de phrases qui 
rendit inevacts certains points de refte description. Iussi lotsque V. Dana, on I859, étudia cette espece. et la compara arec la diagnose donnée dans l’ourrage que je viens de citer. if y troura quelques différences qui l'autorisiont à errou me espèce nouvelle a laquelle il donna le nom de Th. cressimana. Hais conme depuis longtemps de Haan avait publici de honnes figures ef une honne description du Th. prymma, e'est ce nom qui doit itre conservé. Quant a la ligure que IJerbst en a donné, cllo était trop imparlate pour pouvoir servir te terme te comparaison.

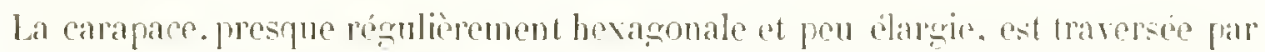
des lignes saillantes bien marquées; les lomls latero-antérieurs sont ames de cinq dents, la quatrieme est molimentaire. et la cinquieme un peu plus petite que les

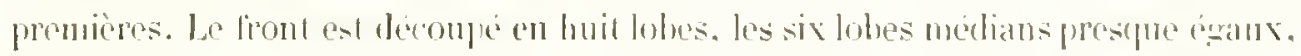
lamelleux. coupés carrement au sommet, el les échmerures qui les séparent ont a peu près la mème profondenr; les loles externes qui forment les angles orbilaires externes sont heancoup plus larges, tres-arpues en arant of separes des précédens par une echancrure profonde et brgement ouverte. an fond wa laphelle se voil l'insertion de la tigelle molite de l'antenne evterne. Liarticte hasilaire de rette antenne porte une petite crète armée do dewx ou trois épines aignes qui s'aperobirent anssi dans l'échancrure dont nous venons de parler.

Les pattes de ha première paire sont robustes. Le bras porte sur son hord anterieur environ trois épines fortes el pointues. L'arant-bras, létremement gramulom. présente a son angle antéro-interne me forte epine. ot sur sil face evterme deux tubercules spiniformes. La main. dont hes thigts sont tres-tigonrens. porte en

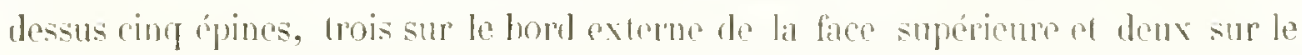
bort interne; ces épines alternent entre olles. La face evterne presente des erdes fongitudinales granuleuses; entre ces crites la main est comrerte sur toutes ses faces de granulations plus ou moins nombreuses, suivant les indivilus. Les pattes nagruses sont larges; leur pinulliene article porte sur son bord infericur une sarie de denticulations. Le plastron sternal fortement honbé. n'oltre ancune pardicularite remarquable. L'abulomen du màtrest estroit.

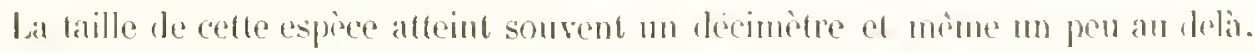

Mabilution. - Ile Iayolte, Tor. Jaran, Sumatro. mers de Chine. Japon, ile de Loo-Choo, Vanikoro, Instralie. 
PI. XXXY, fig. 4 .

Celte espince présente heamcoup d'analogie aver la précédente. Elle s'en dislingue nianmoins par un certain nombre de caractioses laciles à saisir. La carapace, ornée rle ligntes transrersates lien marquées, est très-ibargie. Le front est découpe en Inuil lohes séparés par des échancrures moins frotondes que chez le Th. prymmu: lenr disposition est dillirente; les deux medians ne sunt séparés sur la ligne méHane que par une étroite seissure; les deux mitogrns, siturs sur un flan un peu

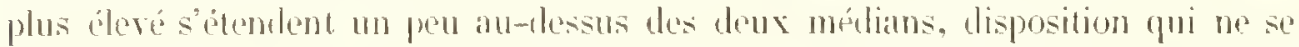
voit jamais chez le Th. Hrymma; enlin, les lobes suivants, an lieu te se terminer brusfunentent du coité externe, s'arrondissent un pen en tehors, de sorte que l'choncrure qui sépare ces lohes des angles orbitaires esternes n'est pas à beauconp pres aussi profonde que chez le Th. prymme. Enling ars lobes orbitaires externes soml heancoup plus larges el moins arpués. L'article hasilaire des antennes externos. an lieu de prisenter une crète épineuse, cst garnie d'une simple ligne de glanulations.

Les falles de la premiere paire sont semblables à celles de l'esperce précétente. Il en est de mème pour le plastron sternal.

Cotte espece présente miron 10 à 11 centimètres de largeur.

Inbitation. - Mers Il Isie.

Collection du lluseum.

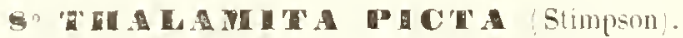

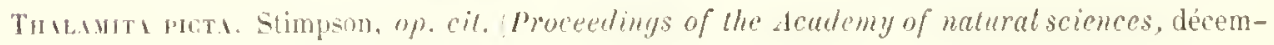
bre $18.3 \%$, p. $3 \%$

Carapace pubsecente, marquée de lignes transversales ćlevées. Bords latéro-antépienrs sarnis de cinq dents, dont la cinquieme est un peu plus petite que la troisième. et lat quatriòme est rulimentaire. Front un peu phus proéminent au milien; ses tohes séparés par des inhancrures profondes; les deux médians petits el ronds, les mitoyens élargis, Jes suivants aigus. Article basilaire des antennes externes portant 
une trète courte, lamelliforme, lisse, proúminente. et pui s'étend an arant du front. Pinces squammeuses en dessus, épineuses ef pulescentes. Face averne de la main garnie de crètes longitulinales. Carpe pourvo a son angle antéro-interne d'un ćpine longue et acérée. Le pénultieme article des pattes natatoires flentelé à son bord inferieur.

Couleur jaunatre, aree des behes d'un jaune phus clair.

Longucur de la caralance, $0^{\mathrm{m}}, 470$; laregeur. $0^{\mathrm{m}}$, 7/5.

Ilabitation. - A été trowvé sur la côtr de l'ile Gusina, entre les pierres at les rochers.

Cetle esprece, que je n'ai jamais etre entre les mains. Hoit se placor a roté des Th. prymna et Th. Stimpsoni auxqueds elle ressomble par la disprosition des épines des bords latéro-antérieurs; mais delle s'en distingue par les opnenents de lanticle Liwiliare des antennes externes gui. whez le Th. prymmu, se compusent dine crête poptement cipinense, chez le Th. Strimpsoni, d'une ligne de stanulations, et dans lespere qui nous ocupe d'une crite lisise et lamelleuse.

\section{B. - Chatrieme dent du bord latero-menticur égule and autres.}

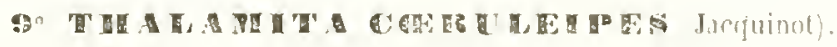

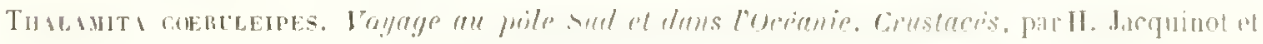
H. Lucids, pl. B. lis. 6.

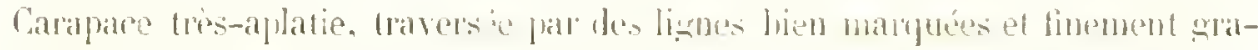

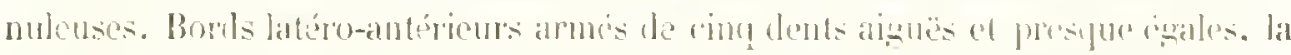

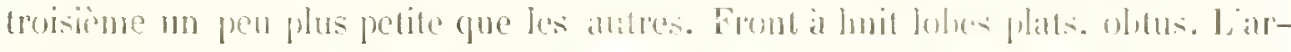

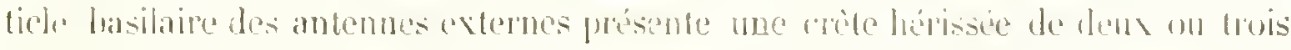

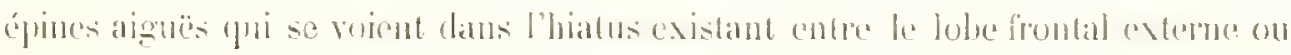

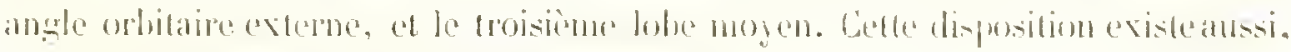
comme mous l'avons vir aliez le 7h. pryma.

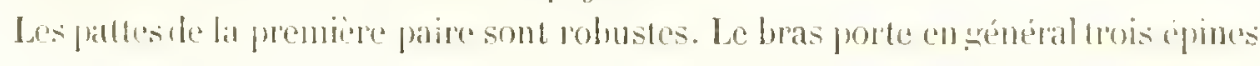

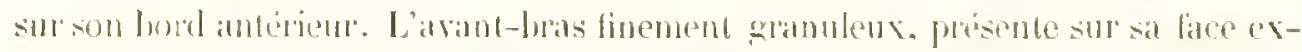

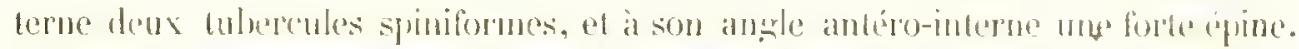
La main un peu gramulemse en dessus, est herisse de cind rpines sur les deus bord: de la face supgrieure; celles d'un hord alternant avec celles de l'antre; il? 
en a trois du còté externe, deux du còté interne. la face exterue présente deus crîtes dont la supérieure est fortement indiquée et se termine en arant par une sorte de tubercule. La cuisse des pattes natatoires est longrue. cylindrique plutùt qu'aplatie. el porte en dessous une épine acérée. Le pénultième anticle est denticuté à son brorl inférieur.

La conlent de cette espece est rosée, avec des laches blenâtres, principalement sur le's paltes.

Largenr, 5 à 6 centimètres; longneur. 3 a 4 centimètres.

Inubiation. - Ile Mangavira (océan Pacilique).

Cefte espece présente une grande ressemblance aved te Th. mymno, mais elle sen distingue facilentent d'ahord par sa couleur; ensulte par ses dents lateroanterienres gui sont tontes eigales, tandis que doez le T. prymma, la yuatrieme est rulimentaire.

Collection du Musćum.

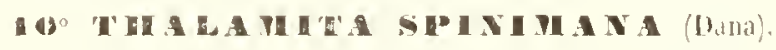

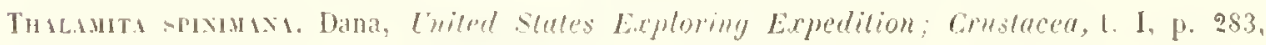
pl. wirl, fig. 8 .

Cintrapace traverséc par des lignes derées. Bords latéro-antérieurs à cinq dents ¿́gales, Ionques, aiguës, coubées. Front proéninent, divisé en huit lobes, les deuxiemes plus larges que los premiers, les trobièmes allongés el proéminents.

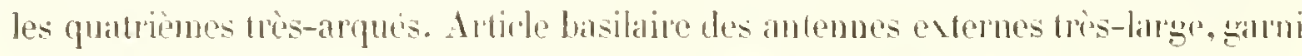
d'une crète épineuse comme dans l'espèce précente. l'attes antérieures très-épiueuses. Le loras porte trois ou quatre épines a son hord antérieur; l'avant-lias sis, al en ontre quelques spinules. La main est hérissée de sept a neuf epines, quatre ou cinq en dessus; sa lince externe porte deux còtes garnies d'une séric de spimules.

Le pénultiène article des pattes natatoires est denticulé à son bord inférieur.

Longueur de la carapace, $0^{\mathrm{m}}, 035$; largeur, $0^{\mathrm{m}}, 055$.

Mabilation. - Irchipel Viti (océan Pacifique).

Cette espece présente beancoup de rapports arec le Th. creruleipes, et ne paraît s'en distinguer que par le nombre d'épines dont les pattes antérieures sont hérissées. 


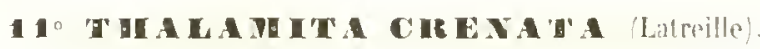

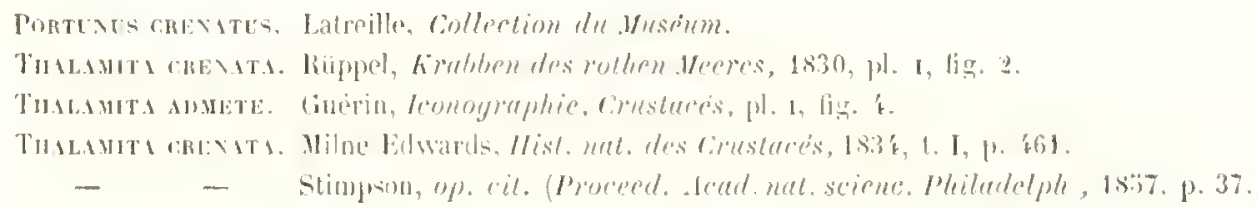

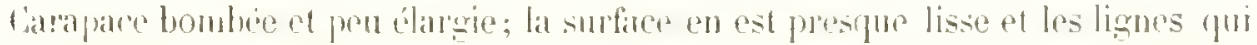

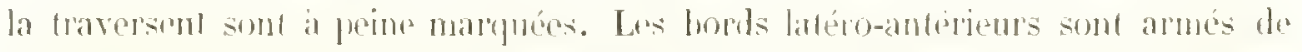

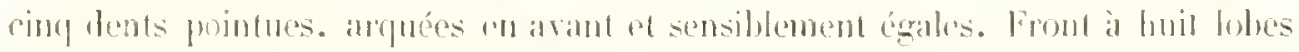
plats. trompues. beancoup moins saillants que dans les espices que nous arous examinées; les six lobes mitoyens sont presifue figaux; les externes sonit larezes rt fortemont arefués. Article hasilaire des antennes externes garni d'une cride de gratnulations disposées en sílic.

Palles anterienres rolustes. Bias portant sur son hord antérieur en chéméal trois

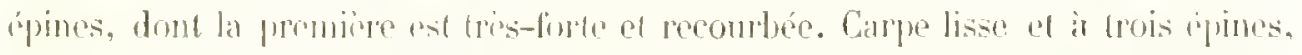

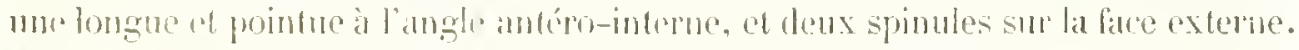
Main renthere. arméc de cinq b́pines ordinatrement peu saillantes. qualquefois

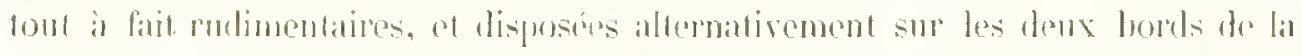

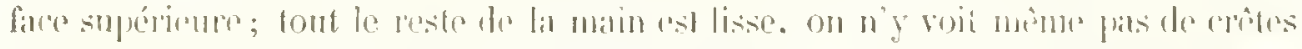

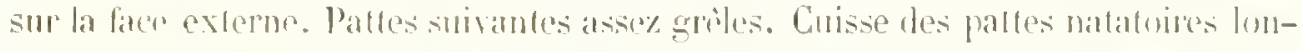

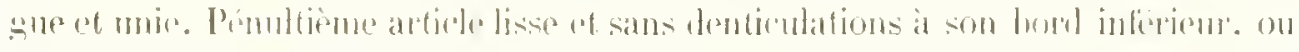
du moins n'y ofirant des dentirulations que trés-rarement. Le cinquirme articte de l'ablomen ies mâles plus útroit au sommet que le sivième, de façon que cot organe pardait pincé an milieu.

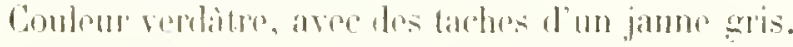

Cofte risece alteint de 7 a 8 conlimetres de latge sur 5 de long.

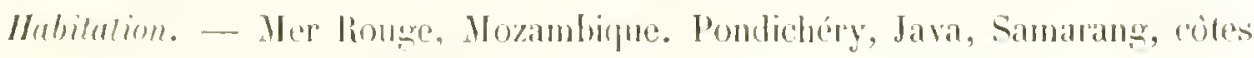
de Chine, ile Lon-Chon, iles Marquises, Hogolen.

Collection dis vuseum. 


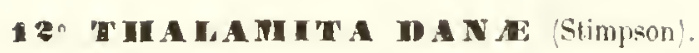

\author{
Pl. XXX, fig. 1.
}

Thalamita Dase. Stumpson, op. cit. (Proceedings of the Academy of matural sciences of Philadelphia, decembre 1857, 1. 37.)

Thabamita crexata. Dana, Enited States Exploring Edyedtion. Crustacea, t. I, p. 282, pl. xvil, fig. 7 .

Carapace aplatie, très-élargie et marquée de lig̣nos transversales fortement sail-

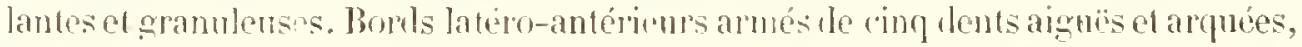
les quatrième et cinquième un peu plus petitus que les autres. Front découpé en huit lolies et presque semblable ì colui do The crenata. Article hasilaire des antennes externes portant unc rite de gramulations.

Patles antirientes assez grèles. Brats gantui orlinairement de trois épines sur son bord antérjeur. Avant-bras ligirement gramulens et portant, outre sa grande épine de l'angle antéro-interne, deur ou trois spinules sur sa face externe. Main luérissée sur sa face supérienre de cinq épines disposiess alternativement sur les dem bords de cette face; sa face extermiz garnie dre crtes longitudinales saillantes ef granuleuses. Sourent meme on roil des granulations sur la lace interne.

Cuisse des pattes natatoires largen. aplatir el cannelée. Pénultione article ordinairement dentieulé ì son bond inférieur. Dernier article de l'abdomen long et très-grêle; sixième article étargi an sommet, de facon à présenter un aspect spatuliforme; cinquieme article mu pen resserré.

Conleur d'un jaune faure et rongeàtre.

Taille. - 6 i 7 centimètres de large sur 4 de long.

Ilabilation. - Les cotes te la Chine (1Long-Kong), Java, Samarang.

Cette copèce avait jusqu’à juésent été confondue avec le Thalamita crenata, mais olle s'en distingue ficilenent par plusieurs caracteres très-apparents. tels que la forme élargie de liz carapace. les lisnes saillantes qui le traversent, el surtout les crêtes et les granulations qui ornent la main.

Collection du Museum. 


\section{TABLEAU DES ESPECES DU GENRE THALAMITA.}

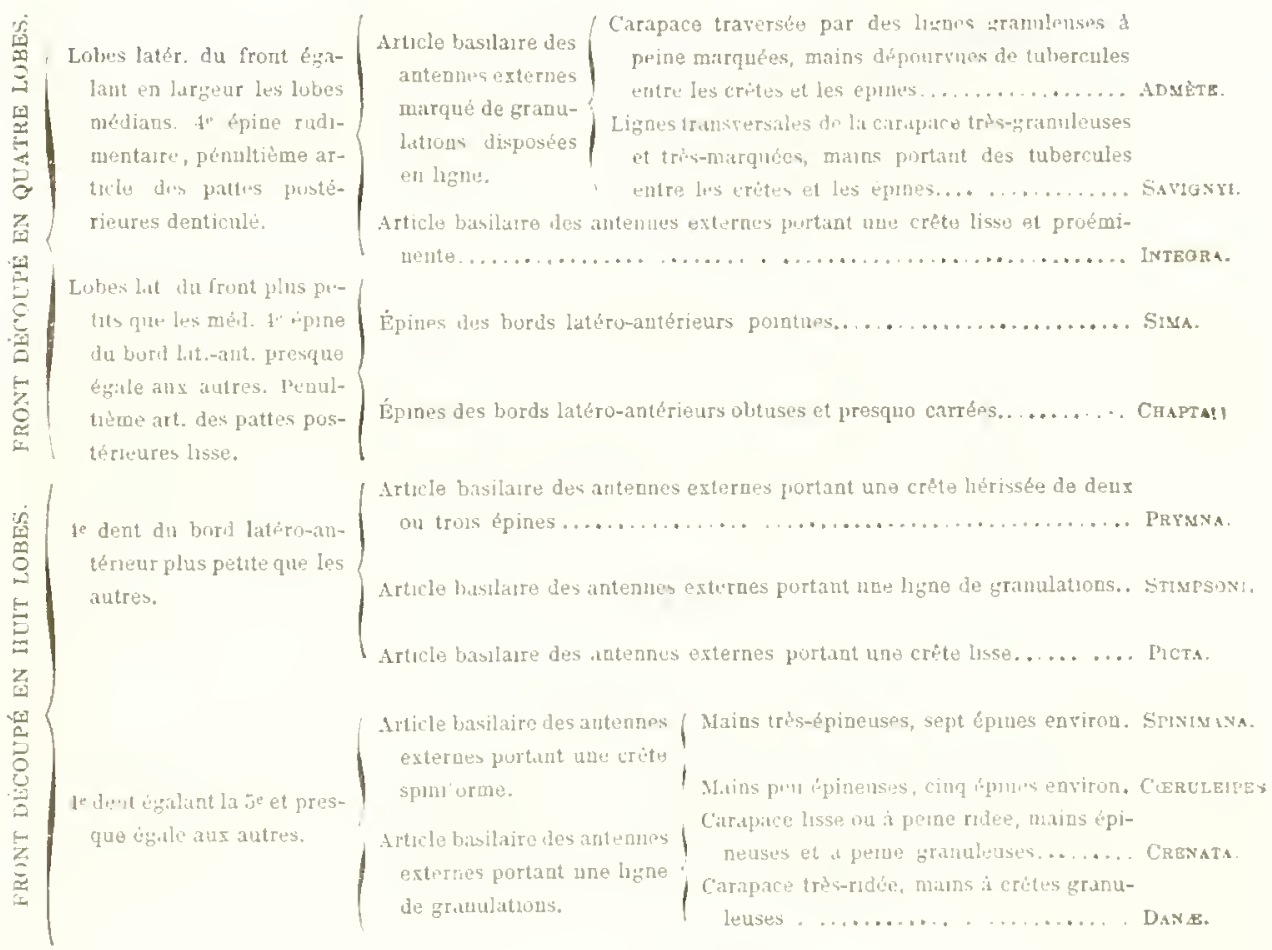

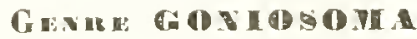

Pontexes prits. Fabricins, sipml. Entomesyst.

Tustumts (pars), Latreille, Rigne animul, de Cuvier, 2e edition, 1. IV, p. $33: 1829$,

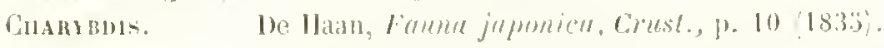

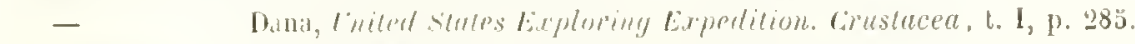

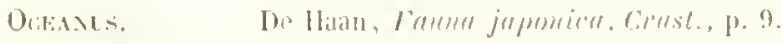

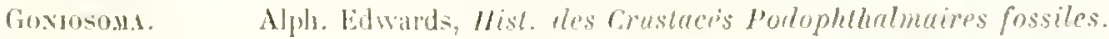

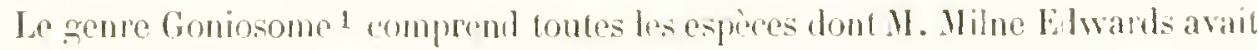
formé son sous-grinte des Thalamites hexagonales ${ }^{2}$; il rorrespond par conséquent

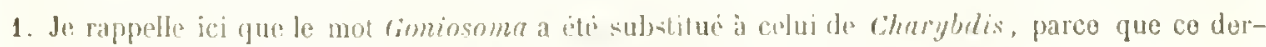

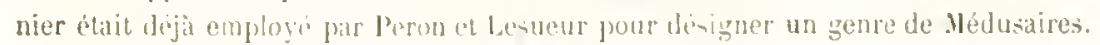

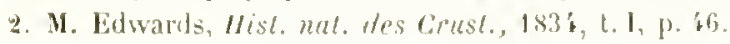


anx genres Oceamus et Charybulis de de IIan. Le prenter ne renfermant qu"une senle espece. le G. cruciferum, n'était etabli que dapres quelques particularités d'une importance minime dans la conformation drs anpremlices masticatores, ef it cst impossible daus un rangenrent meihodique de le séparer des especes qui formaient le genre Churybdis do de IIaan, genre tris-naturel et parfailement délimité,

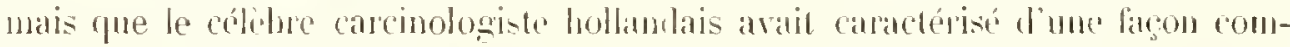
plétement insullisante en y assignant, l'ipres sa méthorle, comme carartère essemtiel, la forme ales pieds-mâchoires antérieurs.

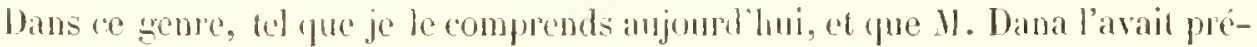
rédemment adopté, la carapace, au lien d'alfecter une forme quadrilatere. est an

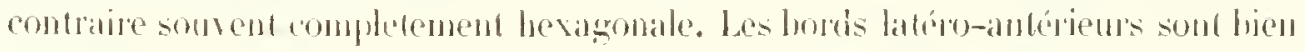
développes at obliques. Le monture des dents qui deompent res bords varle de einy a sept. Les orbites regandent directement an avant an lien l'itre dirigress

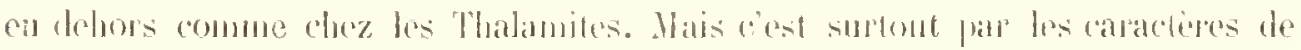

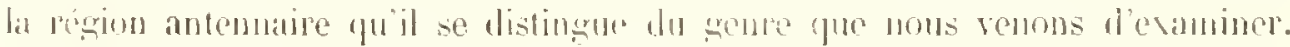

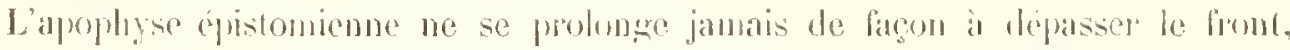
comme cela se voil hez tes Neptunes. Liartide basibire des antemnes extermes se

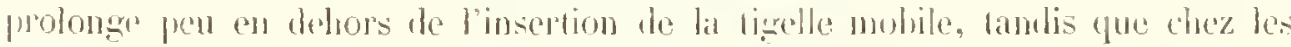

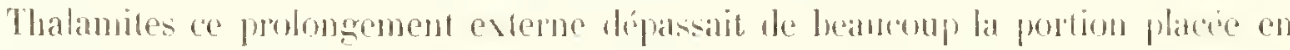

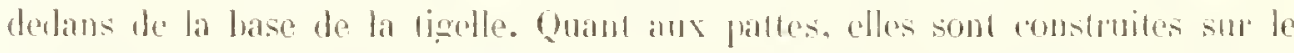

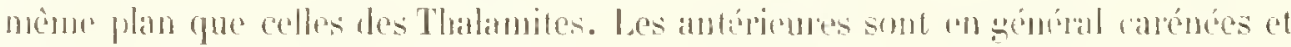

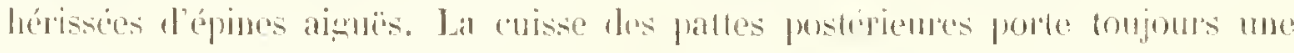

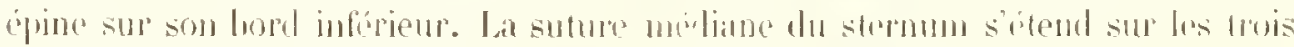

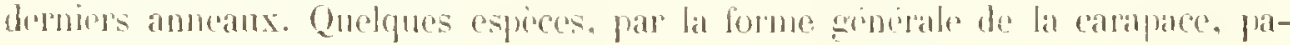
raissem élablir le pasiage entre les demx genres. comme nous le verrons an étudiant le G. ormatum. Matis bes caracteres tirés de ba brieveté de l'article lasilane do lamtonne exterme ne manquent jamais.

Aucunce espere dr re gonre ne vit lans nos murs. Elles sunt répandues en abourlance an volsinage des tropriques, vin quelpues-mes alteignent une taille considérable. 


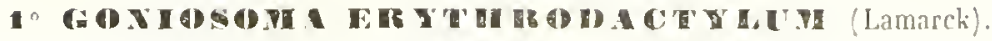

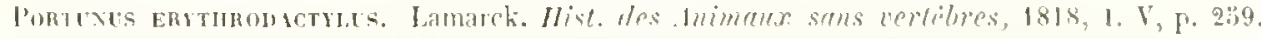

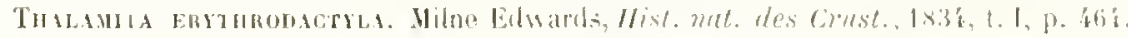

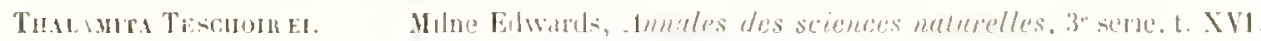

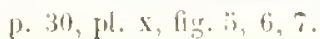 \\ Chinvens Dera. \\ White, Zuologie of the vaynge of H. W.S. sumurang. Comeste- \\ cees, 10. 48 .
}

Carapace peu rifee en dessus, of lisse entre les lignes qui la traversent. Bords

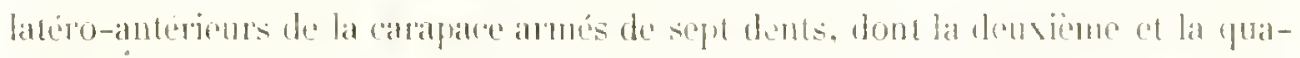

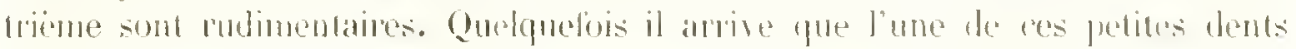

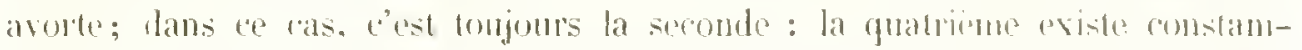

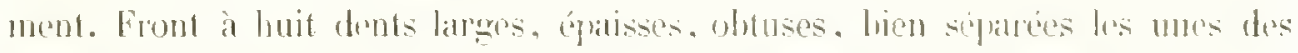
autres et presique somblables entre elles. Dans l'achanerure qui sópare les demb

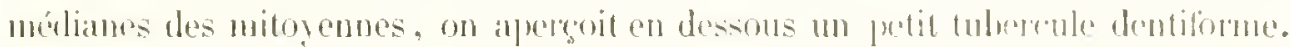

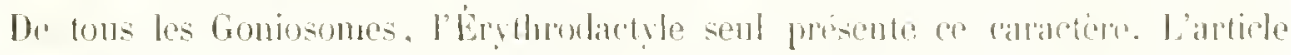

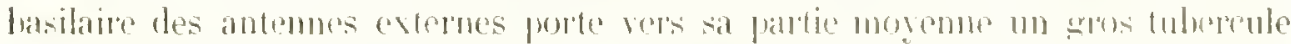

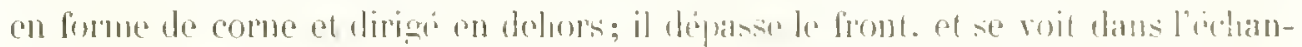
crule que larisont entre elles les troisieme of quatriome dents fombales.

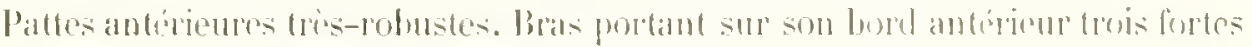

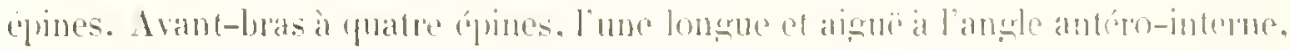

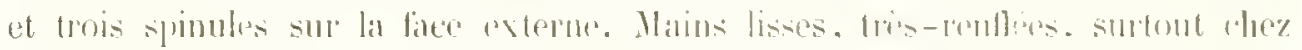

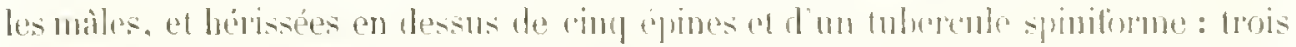

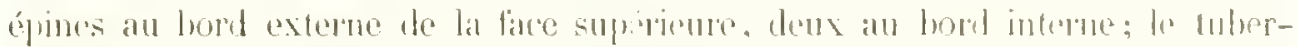

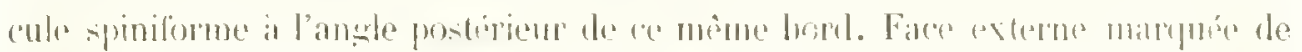

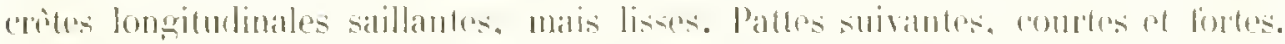

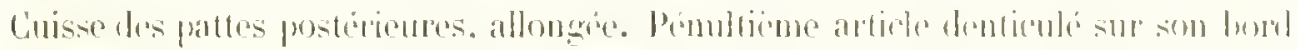

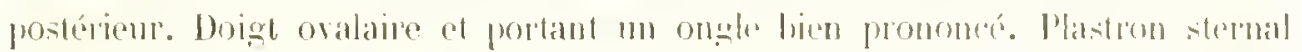

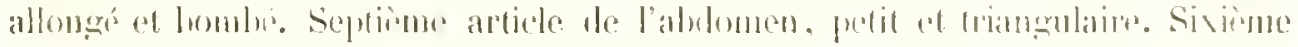

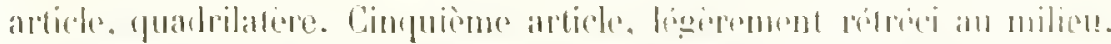

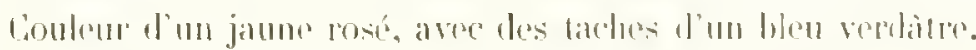

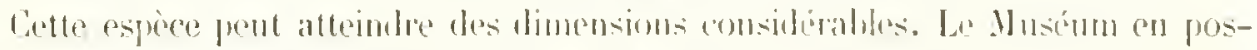

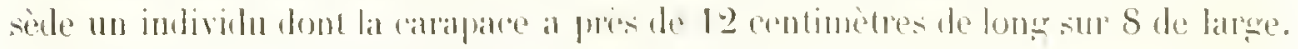

Ilabilation. - Les iles Marpuises. Iles Nolugues. 
M. Milne Elwards arait décrit. sous le nom de Th. Teschoircei, un mâle de cette espece dont la première dent rudimentaire avait avorté; mais ce n'ètait qu'un accident, qui arrive assez souvent, comme j'ai pu m'en assurer en étudiant un grand nombre d'individus de cette mème espèce.

Collection du suséum.

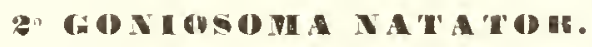

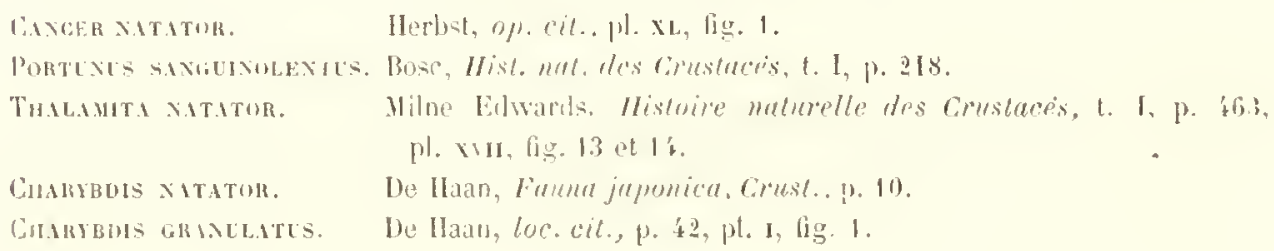

Carapace très-hevag̣onale, pen bombée, traversée par des lignes saillantes et granuleuses; quelques granulations a la base des dents des bords latéro-antérieurs. Ces dents, au nombre le six, larges à leur hase, un peu tronquées, et spiniformes a leur angle anterieur : les deux premières sont courtes, obtuses ef phus étroites que les autres. Front découpé en huit dents aplaties et lamelleuses. Les deux paires médianes à peu pries écales et séparées entre elles par des échancrures peu profondes, mais séparées de la troisième par une échancrure beancoup plus forte. Article basilaire des antennes externes portant une petite crète de fines gramulations.

Palles anterieures très-gobustes et fortenent tuberculenses. Bras hérissé de tubercules el portant sur son hort antérieur hrois épines longues et acérées : on voit quelyuefois entre elles des spinules. Avant-bras tubereuleux et i quatre épines, l'une grande ct aiguë à son angle antéro-interne. ef les lrois autres trèspetites sur sil fice externe. Main comverte d'un nombre considérable de tubercules, et arméc en dessus de quatre épines. Sur sa face externe existent de gros tubereules placés en série et formant des crètes long̣iludinales. Cuisse des pattes postérieures largen, courte el traversée par une crète. Pénultième article denticule à son hord inférieur.

L'aludomen ef le plastron sle!nal ne présentent ancune particularité intéressante à noter.

Couleur d'un jaune fauve, arec de nombreuses taches rouges. 
Cette espèce atteint des dimensions considéraliles, ef les faltes antricicures sont alors extrumement volumineuses. Lareur do ba carapaer. 12 centimètres; longneur. 8.

Ilabilation. - Ibe Mayotte. Java. Mes Philippines. Hers de la Chine. He HonsKongr. Hers du Japon. Hes Moluques.

collection du Musium.

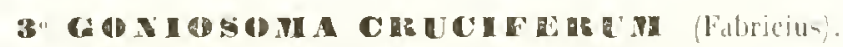

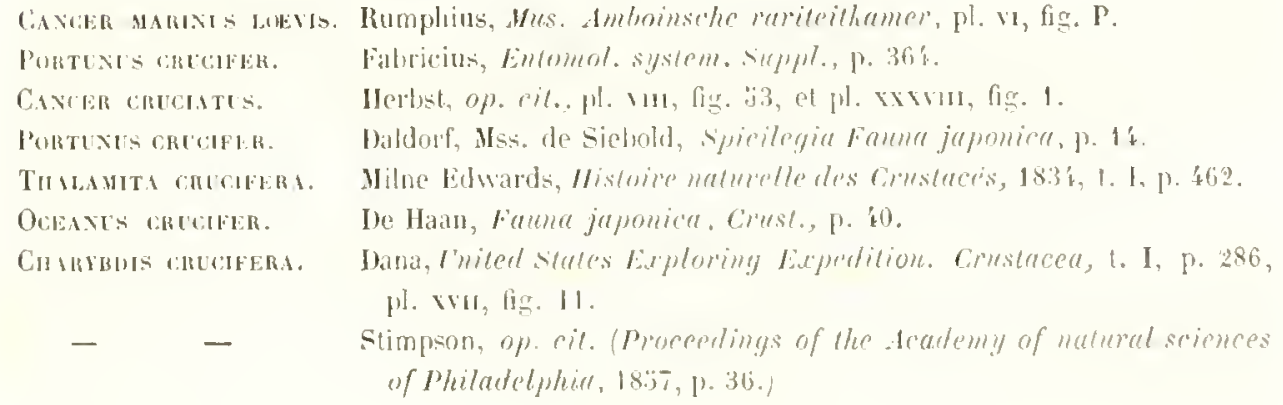

Carapace tros-hevagonale. complétement lisse en desus duez les vieux individus; trawersée par des lignes ligrement granuleuses of peu saillantes dhez les

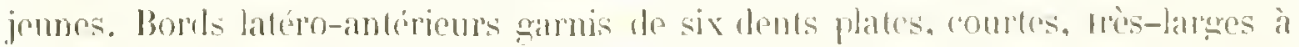
leur hase el peintues a leur anghe anterieur. La première. qui constitue l'angle

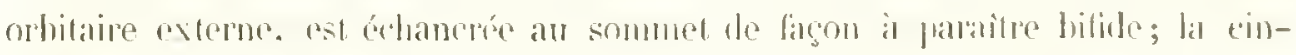
quième est plus mince et un peu plus longue quo les autres. surtout chro fre jeunes

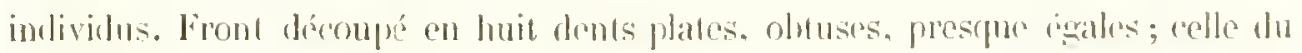

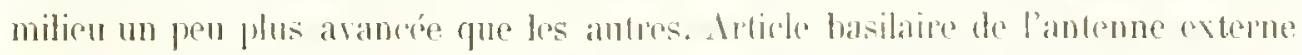

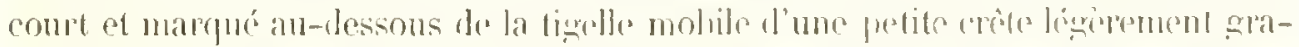

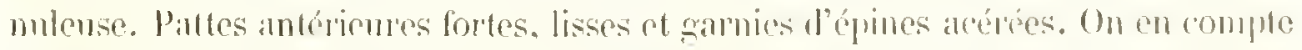

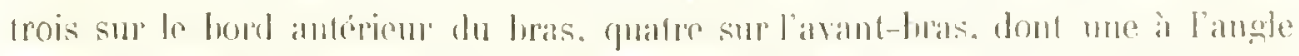

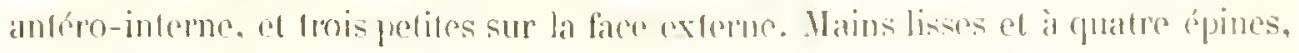

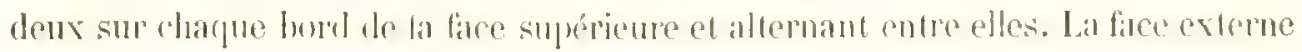

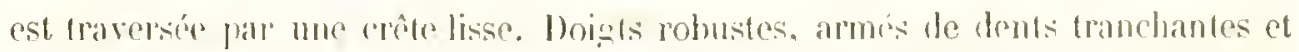
s'engrenant exadement. Cuisse des palles postórieures large. courte el ajlatie.

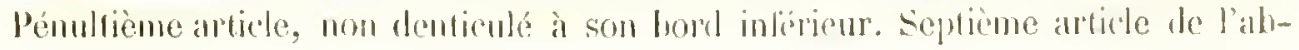


domen du màle, large el court. Sixieme arlicle, phus large à sa lase qu’à son extrémité. Quatrième article, légèrement rétréci.

Conlenr roureàle, avec des laches fauves, dont une, placée sur la région stomacale, est disposée en forme de arois.

Cette espece pent atleindre des dimensions considérables. On roit des individus

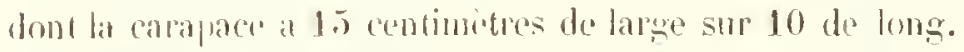

Ilabitalion. - Les mers de l'Inde: Bombay, Pondichery, Singipore, Sumatra.

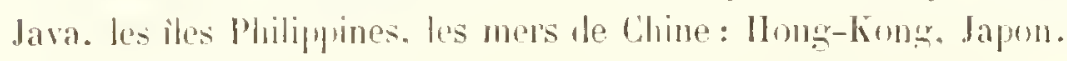

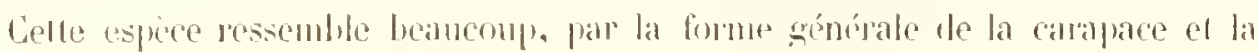

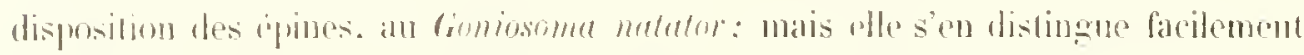

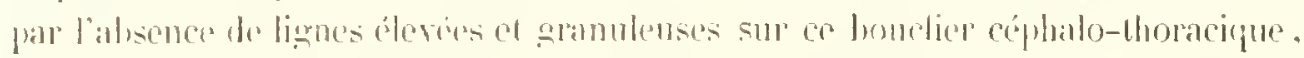
ainsi que far l'abseme de gros tubereutes sur les pathes anterienres.

Conlection du Mastrum.

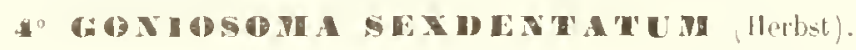

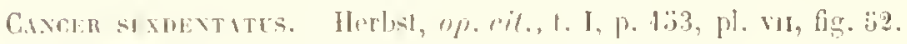

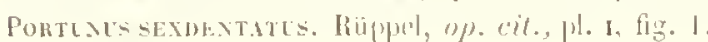

Camapace álargic, traversée par des lignes saillantes et granulenses. Bords

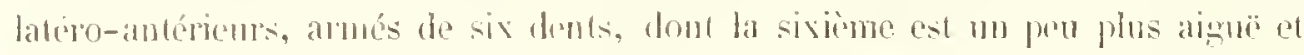

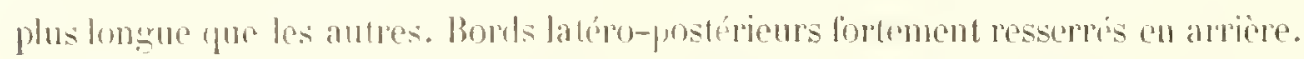

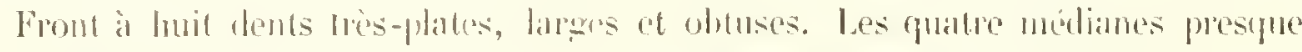

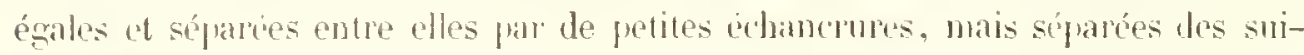

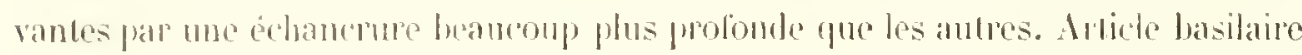
des antemnes exterues ponlant une pelite crête saillante et tres-linement granu-

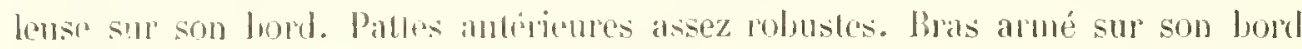
antérieur d'environ trois épines aćéées. Arant-bras traverse par des lignes saillantes granuleuses. entre lesquelles sont disposées quetques petites granulations, ef locisisz de guatre épines: l'une longue ef pointue a l’angle antéro-interne, les trois autres tres-rourtes sur la face exterme. Main arme en dessus de rind épines : trois sur le borl externe, dems sur le bord interne de ba face supérienre; crètes saillantes et granuleuses sur sa lace 'xterme; les lignes squammeuses sur sa lace inférieure. Pattes suirantes assez grèles. Cuises des pattes postérieures 


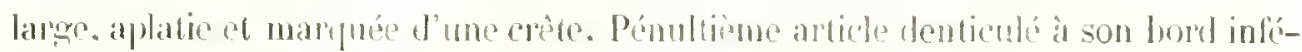
rienr. Mblomen du màle un peu pincé vers sal partie moyenne.

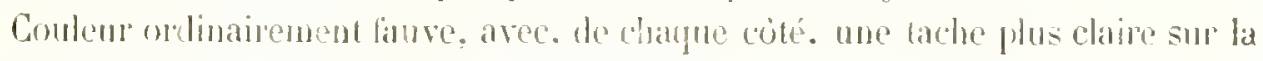
région luranchiale.

Largour de la carapace, $0{ }^{m}, 045$; longueur. $0^{\text {nn }}, 065$.

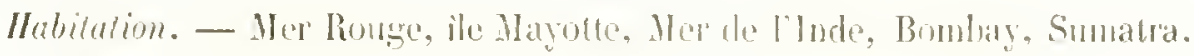
Cotlection du tluséum.

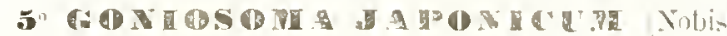

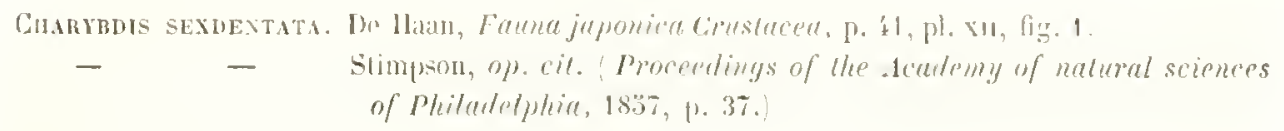

Ce Portunien a éti figurré par W. de llan, qui l'a appedé Chorybdis sexden-

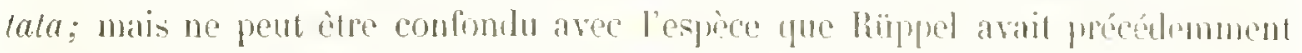
figurée sous le mòme nom spécilique ot pror consécunent il a falln te dégigner d'une maniere diflérente.

Canapace hevagonale et bontrée, margnée de lignes transwersales saillantes.

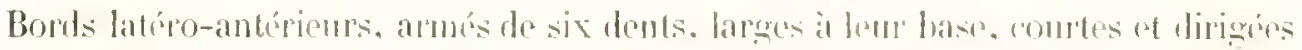

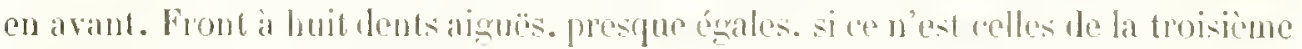

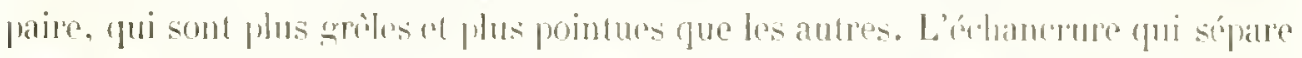
ces dents de celle de la quatrieme est phus profonde gore bes autres. tandis que

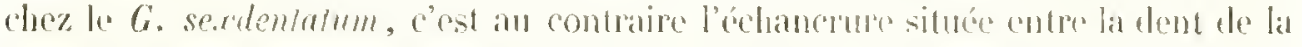
densieme paire et colle de ha troisieme qui ast de heancomp la plus profonde. Article basilaire des antennes externes. garni d'une pretite crite lógerement granulée. Pattes antérienres très-longues. Bras portant trois ápines il sin hord anté-

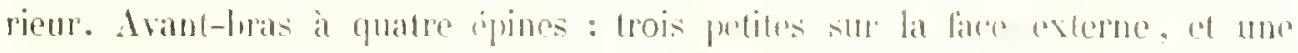

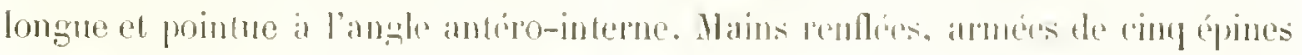
en dessus, trois sur le hord externe of dens sur le borel interme de la faee

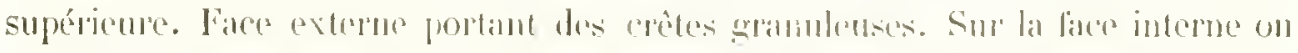

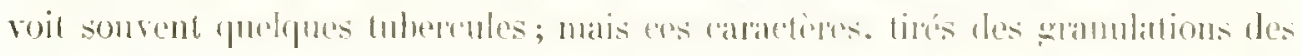
pinces, disparassent un pen dho\% les vieux intividus. Les pattes postorienres sont

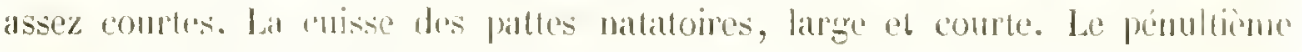
article, won dentienté a son bord inférieur. 
Couleur d'un ronge lie de vin, avec des lackes jaunattros.

Largeur de la carapare. $0^{\mathrm{m}}, \mathrm{d1}$; longuenr. $0^{\mathrm{m}}, 07$.

Ifabitation. - Mer du dapon, mer de Chine, Mong-Kong, Macao. Collection du Museium.

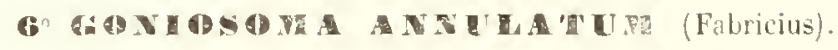

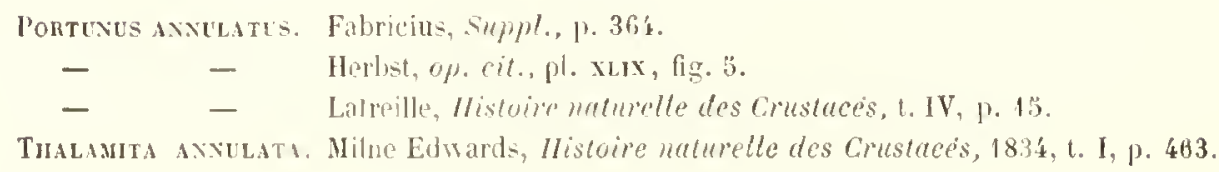

Carapace légórement lombíe et presque lisse; les lignes qui la travorsent sont a peine saillantes et lisparaissent a mesure que les individus avancent en àge. Bords latéro-anterienr's armés de six dents courbées en avant et à peu près écales. Dans le jenne igre, la sivieme dent rst un peu plus longue que les autres; mais par les progrés du déreloppenent elle reste stationnaire ef linit par devenir plus petite que les antres. Les bords latéro-postérieurs sont pentlés. Front à lunit dents disposies comme chez le G. serdentatum. Artirle basilaire des antennes externes garni d'une pelite crête un peu granuleuse. Pattes antériemes très-robustes et lisses. Bras armé sur son bord antírienr de trois dents aigues. drant-bras à quatre épines reliées entre elles par des crètes : celle de l'angle antéro-interne longue et aigüü, les trois de lit face externe rudimentaires. Mains portant sur sa lace supérieure truis épines hien hiveloppées: l'me au-dessus de l'amiculation du carpe, les deus autres vers le milien de dhacun des bonts de cotte lace, ot de plus deux tubercules spiniformes au-dessus de l'articulation dn pouce; lace externe presque lisse, ou traversée par des rutes pren saillantes, mais janais granulenses. Pattes snivantes fortes. contes et terminées par un article styliforme. Cuise des pattes postérieures allongée el peu aplatie; leur pémultième article, denticulé sur son bord inférienr.

Conteur d'un jaune rosé, avee des taches plus claires. Doigts roses, avec le hord tranchant et l'extrómité noire.

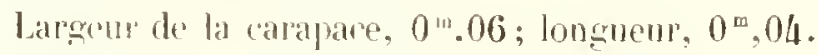

Hebitation. - Oeran Indion: Jasa, Bataria.

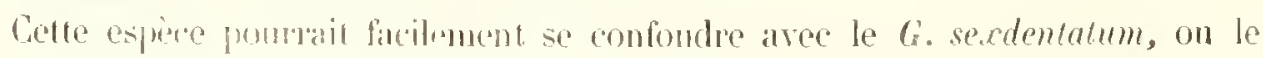


Japmicum; mais alle differe du secom frar la forme de son front, et des deux uspèces par la forme renllée des régions luandhates, par le pen te lignes yni traversent la carapace, et enfin par la conformation de la main. qui ne présente jamatis de sranulations.

Collection du Muséum.

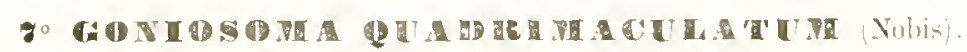

Pl. XXXI, fig. 3.

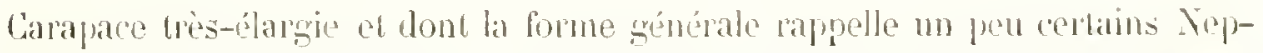
tunes; marquée de lignes transversales peu saillantes. Burds latero-antérieus armés de six dents à pen pres semblahles. Front à huit dents : les deux médianes (ou de la preniepre paire) un peu plus avancées que les autres ef droiles; celle de la seconde paite ligiement dirigées en dehors; celles de la troisième paire droites. Article hasibine des antemes externes portant une petite crête légèrenent granulée. P’alles antérieures rohusles el lisses. Bras portant sur son bord antérieur trois épines courtes el fortes. Nrant-bras à quatre fónes dont les trois de la face externe tres-courtes. Mais lisse et armée en desous de qualle

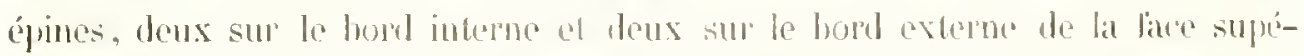

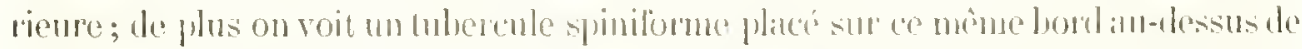

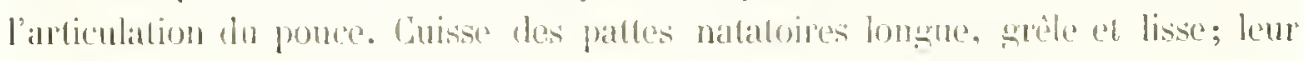
pénultiène arlicle denticulé sur son lond infiriene. Plastron sternal large ef plat. Aldomen resserré res's sal parlie médiane.

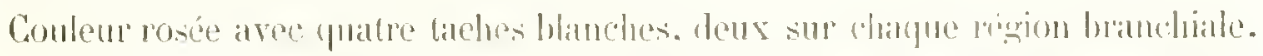

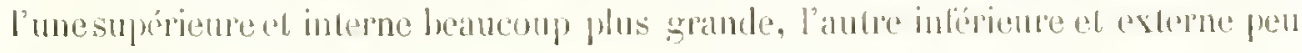
considérable.

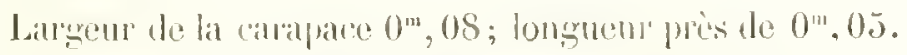

Mabitation. - Les coles du Malabar el de Jara.

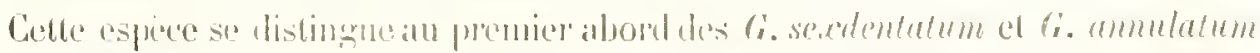

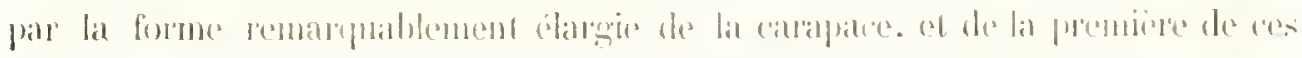

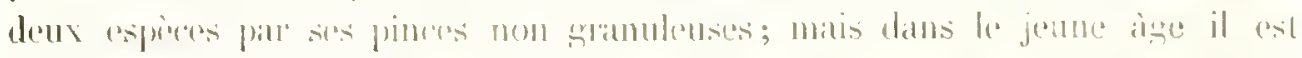

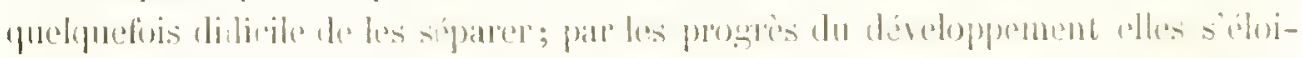

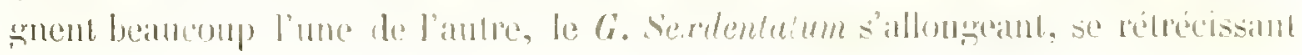


et se garnissant de tubreules sur les crêtes des mains, landis que le ri. Quudri-

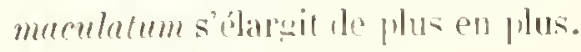

Collection du Museum.

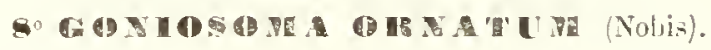

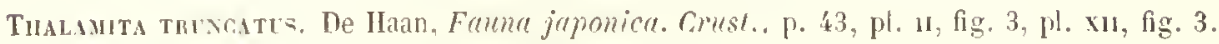

Carapace large ot courte, marqué de lignes traversales médiocrement saillantes.

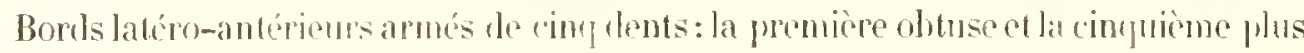
pelite que les autres. Bords latipo-postriens prespue droits ef tres-pen resserrés; angles postépleurs de la carajace aigus an lieu d'ètre arrondis. Front découpé en huit lents. les quatre mádianes prespue semhlibles of sépráes entro ellis seulement par des scisures flents de la troisieme paire très-rétrécies. ot séparées des précédentes far une édaume plus profonde; dents de la quatrieme paire (ou angles orbitaires intornes) prites. aiguës ot séparécs des précédentes par une échancrure tris-peu profonde. Arlicle basibaire des antennes externes portant une petite crète tris-linement granulée.

Pattes antérienres trè-epranuleuses. Bras rouvert de lignes syummenses et armé sur son bord antérieur d'environ trois épines, et d'une très-petite épine à son hord postérienr an-dessus de lanticulation de favant-bras. Ce dernier granuleus et il quatre épines, dont trois petites à sa fare externe, et une grande à son borl antéro-interne. Nains très-inégales portant en llessus quatre épines pen diveloppres: dens a la partie antérienre du borl interne, une à la partie moyenne du bort externe dir la lace supérienre, el me au-dessus de l'articulation de l'avant-bras. Face externe traverséc par des crêtes granuleuses. Toures les faces. l'externe. l'inférieure et linterne sont également hérissécs de gramulations. Les fattes suirantes longues et grêles. Cuisse des pattes de la cinquième paire aplatie et garnie d'une rote; lemr pénultième article denticulé à son borl inférieur; leur doigt long et ovalaire. Plastron sternal large et aplati. Septiene article de l'aldomen très-cont. Sixiène article extrömement renllé, landis que le cinquième rst an contraire tres-rétréci à son extrémité.

Couleur d'un rouge lauve.

Largenr" de la carajace $0^{\mathrm{m}}, 004$; longucur. $0^{\mathrm{m}} .003$.

llabilation. - Mer du Japon. 


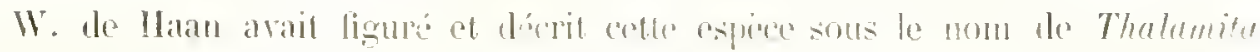
Truncatus, mais alle diffère complétement de celle dernière; il n'existe aucum.

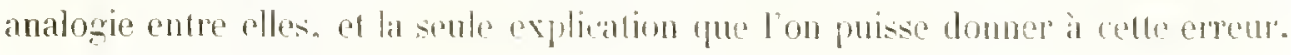
c'est que le Gominsoma Truncatum n’avait janlais été figuré.

Coltection du Musium.

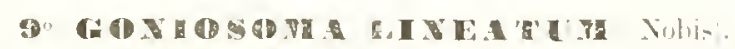

Pl. XXXY, fị. I.

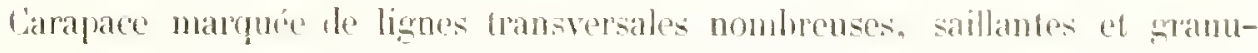
leuses. Borls latéro-antérieurs garnis de einq dents : la quatrieme est rudimentaire.

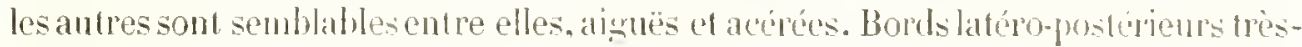
obliques. Angles postérieurs de la carapace arrondis au lien d'ètre aligrí conme chez le G. ornatum. Front découpé en huit dents plates et obtuses: les deus médianes bien séprarés entre elles, droites et difrassant un pen celles de la seconde paire qui sont plus larges et dirigees en dehors; les dents de la troisiome paire. séparées des suivantes jar uno échancpure profonde. sont beaucoup plus petites; celles de la quatrieme paire sont larges el arquéc. Article basilatre des antennes externes court et portant une rrote lisse et tris-saillante. Palles antirienres très-

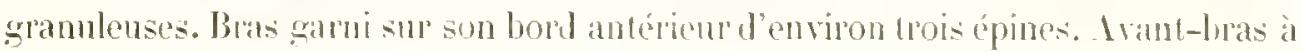
quatre épines. Main converte de nombreuses granulations of atruére de quatre épines peu développées qui sont disposées sur lés deus bords de sat fince superieure; Mblomen du màle resserre ress sa partie mojenne.

Couleur jaunître.

Largeur de la carapace, 0 w, 025 ; longueur, $0^{\text {m }} .020$.

IIabitation. - Ile Touhahiva.

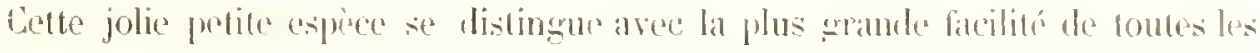

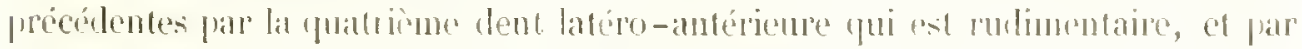

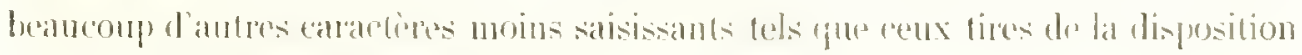
du fromt. des paltes antirientes. ete.

Collecolion du Museum. 


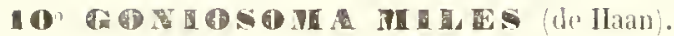

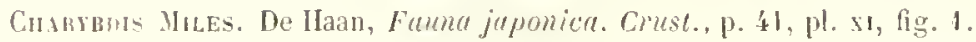

Carapace traversée par des lignes granulenses et maryuée sur chaque région branchialed'une tache ronde de conlenr banche. Bords latero-antérieurs armés de six dents à peu près égales. Front découpé en huil dents aiguës; l'échancerure qui séfrare refles de la deuxiène de celles de la Iroisiène paire duancoup plus profonde que les autres. Pattes antérieures remarqualulement longues et grôles. un peu plus courteschezles femelles que chez les miles. lipas lisse et portant sur snn borl antérieur quatre ou cinq épines aiguës. Avant-bras à quatre épines : colle de l'angle antéro-interne conrte et fortr; les trois de la face externe très-petiles. Main hérissée de quatre éphes: deux trés-aiguës sur le hord interne de sa face supérieure, les deux autres plus courtes sur son bord interne. l'mne an-dessus de l'articulation de l'avint-liras, l'autre à la partie médiane. Fäe externe fraversée par des crètes et légrement sufuanmense entre ces lignes. Pattes suivantes longues ot grêles. Cuisse des pattes postérienres large ct conrte; leur pénuliène article dentieulé sur son hord inférieur. Aldonen du màle rétréci vers sa partie mojenne.

Couleur d'un jaune rośa aree des taches plus claires.

Larrgeur de la caraluare. $0^{\mathrm{m}}$. 070 ; longueur $0^{\mathrm{m}}, 055$.

Habilution. - Mer du Japon.

Cullection du ytusinm.

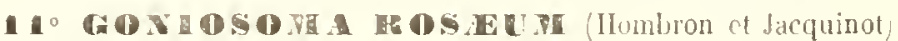

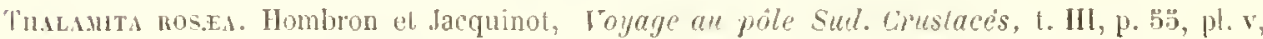
fig. 11 .

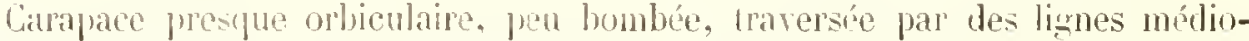
crement saillantes. Bords latéro-antérieurs peu obliqgues et tress-longs, garnis de sis dents larges a leur labe et pointues à leur angle antérieur. Front avancé. un peu arqué el hicoupi en huit dents triangulaires aplaties. assez profondément échancrées ef dont cultes de la troisieme paire sont les phos petiles. Pattes de la 


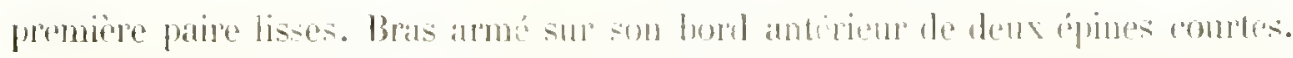
Arant-bras ì quatre epiurs: celle de l'angle antró-interme est pelativement courte.

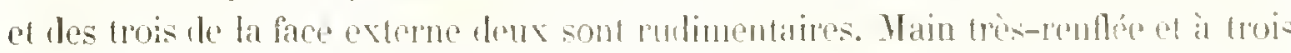
ápines, une sur ta jartie nogenne de tharm des bords de sa face superiente de

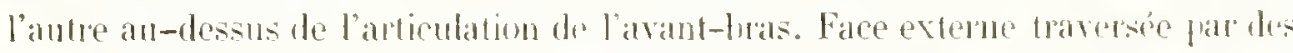

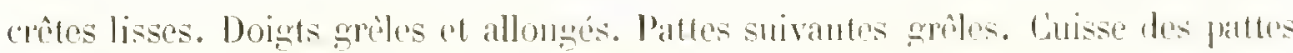

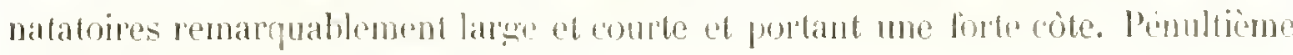
articte tros-lar:are et non denticuté.

Couleur d'un rose jàle.

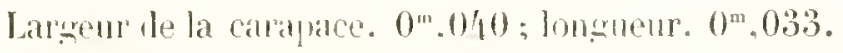

Habitation. - Cotes de la Nourelle-Gumé

Coltection du Muséum.

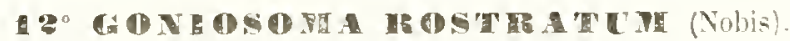

P. XXXY, fig. 2.

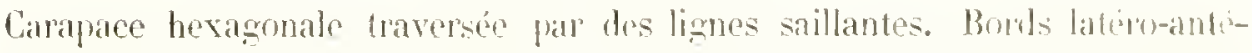
rieurs armés de sic dents larges ot pointurs. la dernière est un pen phu forte eque les antres. Front déconjé en lunit dents, les denx midimes. aptaties el ohuses. somt

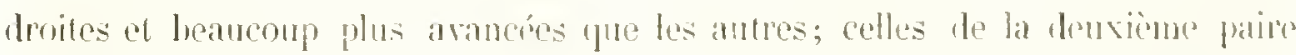

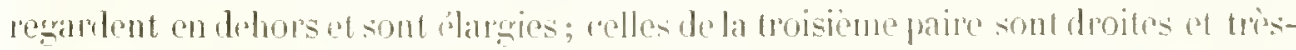
minces; celles de la quat rieme paire sont pointues ot encole fus petites. Palles ant -

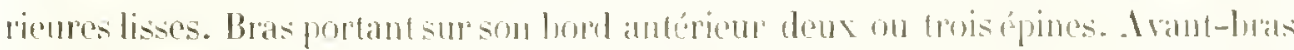

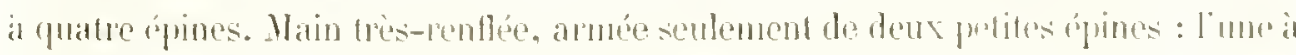

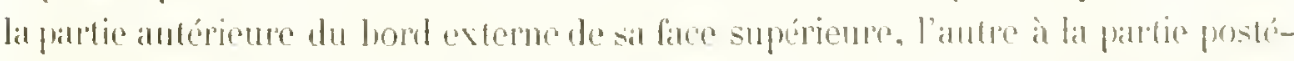

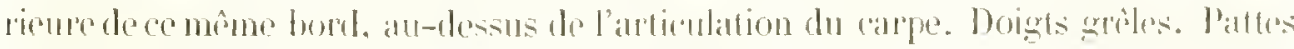

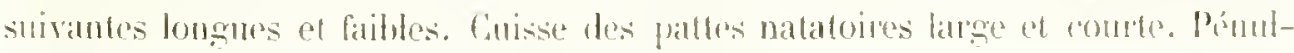
tieme article non denticulé a son bond inférienr.

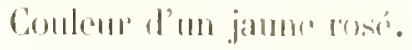

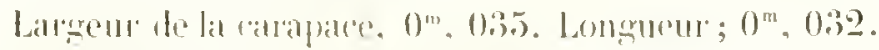

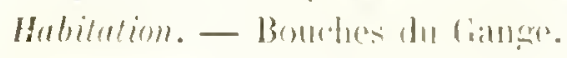

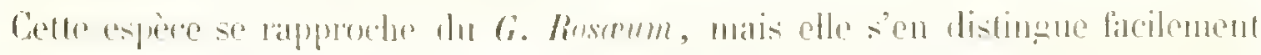

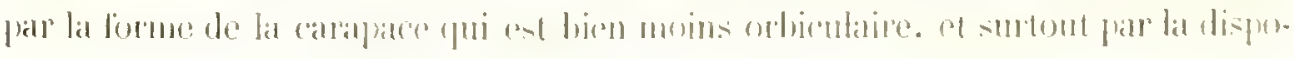


sition llu front oì les deux dents médianes s'arancent beaucoup plus que leśs autres, de lacon i constituer une sorte le rostre. Enfin. la main, an lieu de porter trois épines, n’en présente que denx.

Collection du Muséum

-3 4 A

Pl. 3i, fig. it.

Portunes trucicates. Fabricius, Sumpl. Entomol. syst., p. 363.

Latlreille, Mist. nut. de's Crust., t. VI, 1. 16.

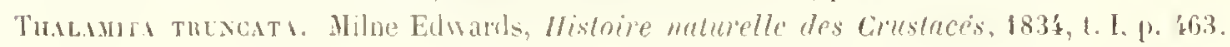

Carapace peu hombée. lisse, sans lignes saillantes transversales. Bords latéruantérieurs de la carapace gandus de six lents laryes a lenr base el tellement tronquées quon les croirat carrées du bout; la densiène est très-petile, et la

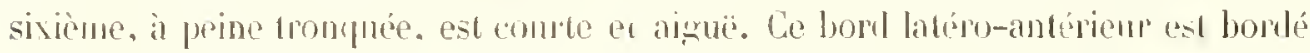
d'une ligne tinement granulemse. Hront large, découpé en huil pedites dents pointues, remaryublement courtes of presque égales entre eltes. Apticle lasilaire des antennes externes portant me petite trète. Pattes antérieures longues el grềles. Bras zarni sur son lond antérieur de deux on trois très-petiles épines ot de nom-

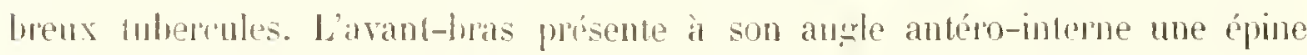
ronrte el larye, et a sa face everne trois tuberctiles spiniformes. Mains très-allongeees. anmées en dessus de trois épines : deux smr le bord interne de la face supé-

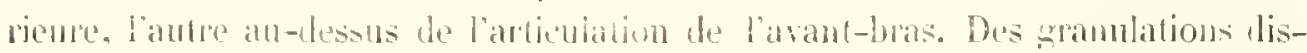
posies ('n serries forment des crites sur ses fices interne th eqterne. Doigts longs et spriles. Puttes suivantes grồles. Cuisse des paltes postérieures lingre, courte et renflée. présentant une forme discoülale. Pénultieme article non denticulé sur son bord postérieur. Plastron stemal large et apdati. Adomen du mâle triangulaire quoiqu'un peu rétréci atu-dessons du sivième article.

largent de la carapace, $0^{\mathrm{m}}, 055$; longueur. $0^{\mathrm{m}}, 050$.

Mabitution. - Cote du Malaluar et Port Natal.

La forme des dents latéro-intérieures, celle du front ainsi que les granulations des épines. sulfisent pour empêcher de confondre cette espècé avec les autres du mime genre.

Coliection du Husenm. 


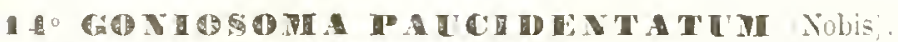

\author{
Pl. XXXY, fig. 3.
}

Carapace peu bombée. presgue lisse; les lignes qui la traversent sont tris-peu saillantes; enfin elle est peu álargie el son diamètre longitudinal égale presque son diamitre transversal. Bords latéro-antérieurs garnis de six dents: la deuxiène et la ruatrième l'udimentaires ct placées dans les échancrures que laissent entre clles les autres dents; les premiere. Iroisieme el cinquième fortement dirigées en arant. acúpes el semblables entre clles; la sisième plus courte que les précidentes. Front it huit dents larges; plates et obuses, celles te la troisiome paire plus longues que les autres. Article basilaire des antennes externes portant une épine a son borl antéricur. Ingle sous-orbitaire interne pointu. el lord sous-othilaire linement lenticulé. Thígions ptérygostoniennes lisses. Cuisse des pattes natatoires longrue el crêle; leur pénulliène article denticulé sur son bord inférieur.

Couleur d'un janne rosé avec des taches plus claires.

Lomguever de la carapace, $0^{\mathrm{m}}, 04 \mathrm{~s}$; largeur, $0^{\mathrm{m}}, 062$.

Mabitution. - Ile Nanrice.

de ne connais justrà présent rue la femelle de cetle espece. el encore est-elle

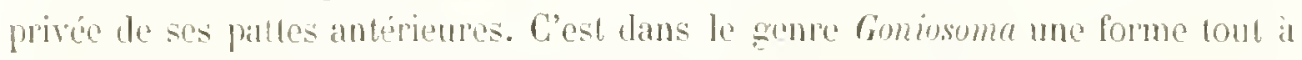
hail nouvelle. On ne connarisait encope aucune espèce n’ayant sur le bord lattérnantérieur que quatre dents bien developlées et deux dents alvorlées.

Collection du Muscum.

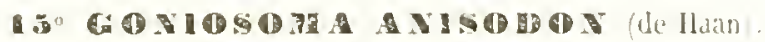

Pl. XXXIII, lig.

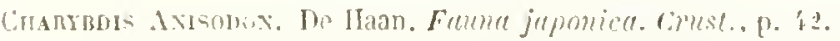

- - Stimpison, op. rit. Pronerotings of the dratemy of naturat sciences

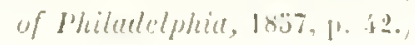

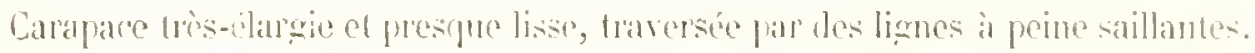

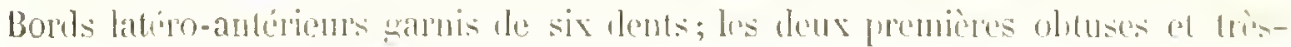
Amontrs ot M!tsicu. T. L. 
courtes; la troisième large à sa base el peu acérée; la quatrième ut la rinquiène arfuées, pointues et égales entre elles; la sixième très-longue et mince. Front divisć en luit dents très-plates. obuses et à peine découpées, les quatre múdianes sur un même plan, égales entre elles et séparées de celles de la troisiòne pairo par une échancrure plus profonde que les autres. Arlicle basilaire des antemnes externes garni d'une très-petite crète lisse. Pattes antérieures longues el assez robustes. Bras lisse et armé sur son hord antérieur de deux ćpines seulement. Arant-hras lisse portant sur son angle antéro-interne une épline longue el arérée ol sur sa face exteme trois tubercules spiniformes. Main lisse et à leux épines situées, l'une vers la partie mojenne du hord interne de la face supérieure, l'autre an-dessis de l'articulation de l'avant-hras. Face externe lisse et sans crites saitlantes. Palles suivantes longues el grètes. Cuisse des paltes natatoires plate et élargie. Pénultiène article garni dr guelgues rares denticulations. Doigl large el ovalaire.

Longucur de la carapace, $00^{m} .040$; largeur, $0^{\mathrm{m}}, 075$.

Mubilation. - Coites de Chine, Jara, Nonvelle-Calédonie.

collenion du Wuscum.

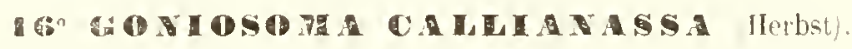

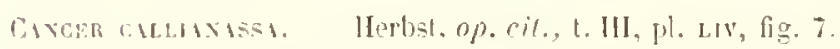

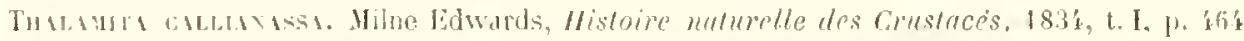

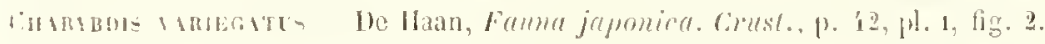

stimpson, op. cit. Prosendings of the trademy of nutural scieners of Philatelphiat, $18: 3$, , 13.36i.)

tharapa te te-shargie, maryuce de ligues transversales saillantes et nombreuses. Bonts latero-antérien's garmis de six dents. les prenières bien sćparées les unes les autres. arquées, pointues et semblables entre elles, la sixionne plus fine el rnviron denx fois plus longue que les autres. Front dérompé en huit dents qui sont obuses chez les jemes et plus aiguës chez tes vieux indivilus; les quatre médianes presque semblables entre elles et séparées de celles de la troisiome paire par une

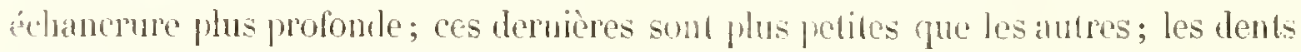
d: la quatrieme paire aiguës. Pattes antirieures longues. Bras garni sur son hord anterieur de deux ou trois ápines. Arant-lyas sillonné de crites saillantes el gra- 
muleuses, el andmé i son angle antéro-interne d'une grmonde ejone et sur sa face externe de trois tuhercules spiniformes. Main renflée. portant en dessus trois ou quatre ćpines. une vers la partie moyenne de son bond interne, quelquefois une seconde à la partie antericure de ce même bord, et deux autres sur le bord externe de sa falce supérieure; sa face externe el sa face interne sont traversées de whes le plus en plus saillantes et pranuleuses, à unesure que les individus avancent en àge. Pattes suivantes grèles. Cuisse des patten natatoires large et thaverséte par une còtesaillante. Pénultième article non denticulé à son bord inférieur. Doigt ovalaire et allongé. Abdomen du mâle un jeu resserré à la jartie moyenne.

Longueur de la calrapace, $0^{\mathrm{m}} .01 \mathrm{~s}$; Jargeur. $0^{\mathrm{m}}, 030$.

Ilabitation. - La mer des Indes, Bombay, la mer du Japon.

Collection du yuséum.

Cette esprece, par la forme générale, se rapprodhe du $G$. Anisodon (de Ilaan). mais elle s'en distingue facilement par la disposition des dents des bords latéroantérieurs dont les deux premieres sont égales aus troisième, quatrième el cinqquème. ainsi que par la forme du front et les erêtes qui garnissent la main.

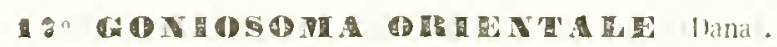

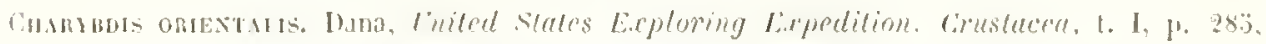
1.. 1 in, fig. 10.

Ginapace lisse. traversée par des lignes lérèement granuleuses. Bords lateroanterieurs armés de six dents; les deux premieres plus petites que les autres; lat terniere ézale ans trobieme, quatriène et cinquieme. Font légerement arqué. à huit dents langres, limelleuses. oltuses et sensiblenent égales.

llabilation. - Les ìles Philipines.

Cette espèce, dont II. Dana parail n aroir pu examiner que la carapare, se rajtproche du Ci. anisoton, mais en diflere cependant par lit sixieme dent. (qui, che\% refte derniere espece. cist beancoup plus longue que les andres. 


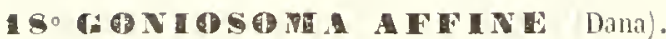

Cilartbds afrixis. Dana, Cnited states E.rploring Erpedition. Crustucea, 1. I, p. 286, pl. xw1, fig. 12.

Caripace traversée par des lignes élevies. Borls latéro-antéricurs armés de six dents. dont la demière dépasse de beaucoup les autres. Front étroit, arancé, déroupé en huil dents petiles, aiguës, sensiblement égales. Pattes antérieures courtes. Bras armé de trois épines sur son bord antérieur. Main garuie en dessus de cinq épines.

Ilubitution. - Singapous.

Celte espece parait assez voisine du G. cullianassa, mais s'en distingue par le tront heaucoup plus avancé, par la brièveté du bras, ainsi que par les cinf épines 'pui arment la main.

Hac leay a kicril sons le nom de Charyblis smithii une espèce du genre qui nous oceupe, tronvée sur les cotes sud de J'Afrique 1. Mais la description qu'il en donne et qui n'est pas aecompagnée de figures est trop rague el peut s'appliquer rigalement à un reptain nombre d'especes connues du mène gempr.

\section{ESPECES FOSSILES.

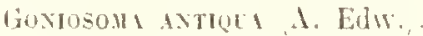

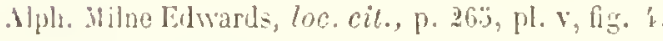

1. Vac Leay, Illustrutions of the . Immelosa of Sonth .1frien, 1838, dans l'ouvrage de Smith, intilule: Illustrations of the Zoology of south afriea. 
ETUDES ZOOLOGLOUES SUR LES PORTLNIEXS RECEXTS.

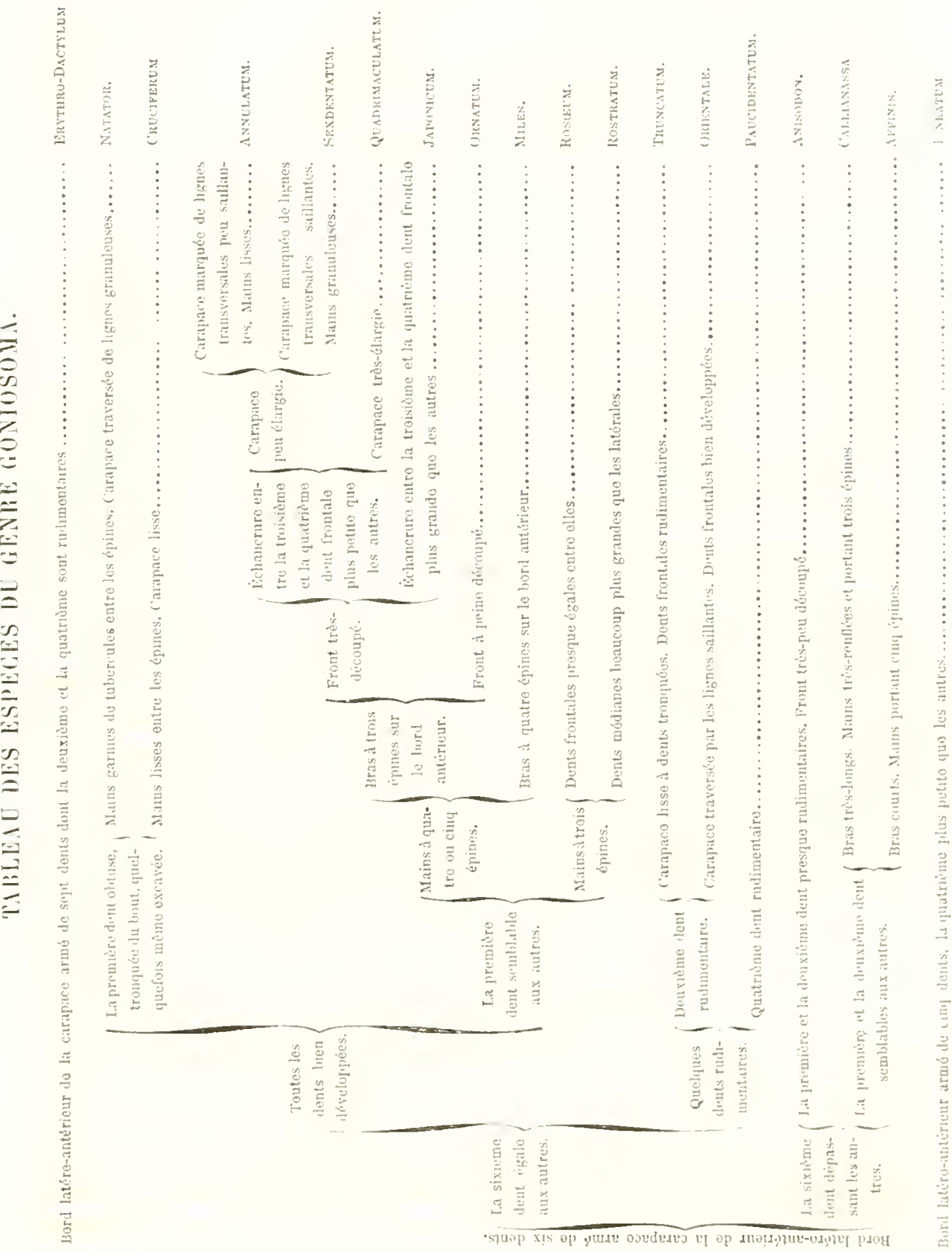




\section{GROUPE DES CARUPIENS.}

\section{Genre CARUPA.}

LArups. Dana, L'nited States Erploring Expedition. Crustacea, p. 279.

Ce genre a été étalhi par M. Dana pour une petite espèce de Portunien qui, par la forme générale de la rarapace, ressemble beancoup aux Thahamitiens, mais s'en distingue nettement par la disposition des antennes externes et des pattes.

I a carapace est large et presque quatrilatère. Les hords latéro-antérieurs sont découpés en sept dents. Le front très-large. Larticle basilaire des antemes externes cot grèle, cylindrique, et ne présentant pas de prolongement externe comme drez les Goniosomes. La ligrelle mobile s'insère lans le canthus interne de l'œil. L'endostome est pourvu de crêtes olliques latérales. L'apophyse épistomienne nest pas saillante. Les pattes ambulatoires sont longues et grèles, les pattes natatuires terminées par une palette ovalaire. 11 . Dana indique également parmi les caractires de ce genre la risposition de l'abdonen qu'il a trouvé composé senlement de quatre articles, mais comme il u'a eu it sa disposition qu'm seul indivilu très-jeune ot de très-petite taille, je suis porté à croire que celle particularité de structure na pas la valeur qu'il y assigne. On la rencontre d'ordinaire ehez les femelles jemes dont l'abkomen n'est pas encore bien développé et offre une forme triangulaire. Ce nest que phe tard que les diflérents articles deriement mobiles. de sorte qu'il me parail probable que l'individu observé par M. Dana etait me june femelle et non un mâle comme le suppose re naturaliste.

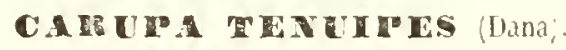

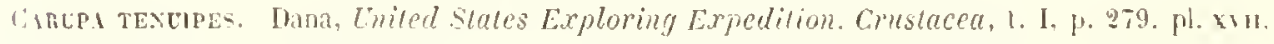
fig. 1 .

Cirrapace élargie, un pen quadrilatère. lisse et ne présentant pas de lignes trausrersales saillantes. Bords latéro-antérieurs garnis de sept dents aignès et dirigées en arant; la cinquième plus petite que les autres. Front large, entier et légèrement 


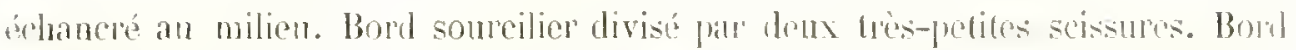
orbitaire in lërienr' lécoupé en quatre petites crénelures. Paltes anthienres courtes.

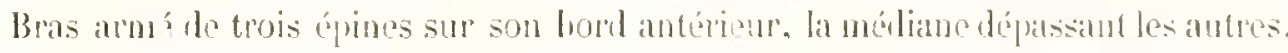

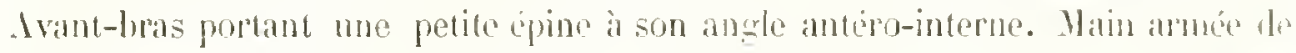

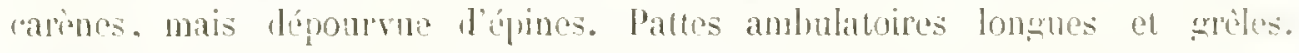
Pattes natatoires contes of pen dargies; leur cuise presque cylindricue of allonsééc; leur dernier artide ovalaire.

Ilabitation. - Arehipel Pomotou.

Celte espiece n'est connue jusqu'ici que flar un seut individu de très-petite taille et jeune recueilli par H. Dana.

\section{GROUPE DES LUPOCYCLIENS.}

\section{Genre LUPOGYGLU.}

Lupocreus. Adams et White. Zoology of the royage of M. .M. S. Samarang, Crustacen, 46.

Ce grenre. qui jusqu ici ne se compose que d'une senle espece, se reconnatit ans caracteres suivants. Carapace sub-orbiculaire. Bords latéro-antérieurs dentés. Front très-avancé. Bond sourcilier divisé far dens scissures linédres. Irtide basilaire des antennes externes grèle, libre et entrant dans la composition de la tigrelle nolite qui se logre dans l'hiatus interne de l'opbite. Endostome mescontant des crêtes latérales olliques. Pattes longues et grobles.

Ce genre parait devoir, par la forme grénérale de la carapace se rapprother dre rertains Goniosomes, tandis que. par la structure de ses antennes evernes. il présente beaucoup d'analogic avec les Platyongyues.

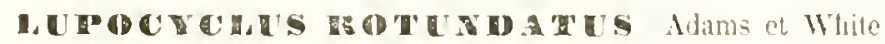

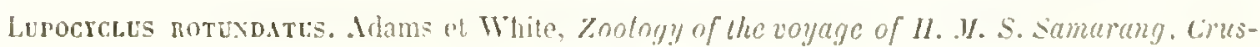
lacea, $x^{2}$, pl. xir, fig. i.

Carapace rugueuse. finement granuleuse surtout sur les parties saillantes. Lignes épigastrique et ípiluanchiales bien marquées. Bords latéro-antérieursarmés. 
d'apres HII. Alams el White, de cint spandes épines et de cinq petites, intermúliaires; mais ce caractere ne doit pas ètre constant. car, sur mo jeune indiviılu appartenant an Muséum d'histoire naturelte, le nombre des dents est de six, ef

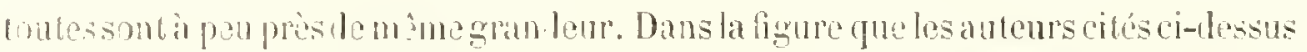
cont donnée de cette espece. le froat, bien a ancé el un peu lamellenx, est dícoupe en six dents dont les deux mádianes sont phus avancées que les mitoyennes, el

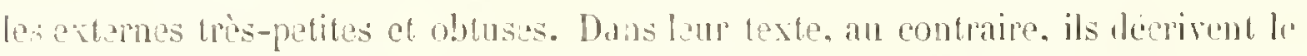
front comme divisé en cinf lobes íganx et dentiformes. Malheureusement, sur l'individu que j"ai entre les mains, le front est lopisé, el je n’ai pu savoir quelle est en ríalité la conformation de cette réxion. Les pattes antéricures sunt longues ef

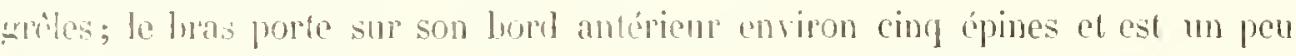

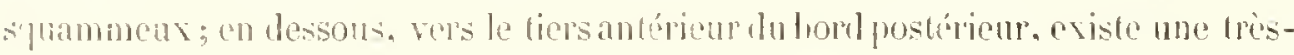
petite épine. On en roit quelyuefois une rullimentaire it l'extrémité de ce lord.

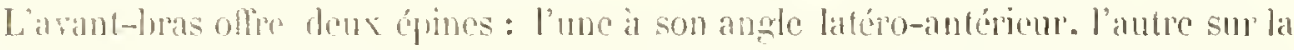
face externe. Hain longue. carénée, portant trois épines en dessus, l'une an-dessus de l'articulation du carpe. les leur antres vers le tiers antérieur de dhacune des carines de la face simpéiteure. Doigts longs ef grites. Pattes ambulatoires lonpues of spêtes; celles de la denxione paire dépassant les autres; celles de la cinquieme paire larges et aptaties, et terminées par un doigt ovalaire. Aldomen du mâle sultriangulaire.

Coukear jaumitre, avee une larye hande rougreâtre átendue longitudinalement surr la partie médiane de la carapace. Pattes annelées de jaune ef de rouge.

Larrentr de ha carapace, $0^{\mathrm{m}}, 020$; longrueur, $0^{\mathrm{m}}, 019$.

Unbitation. - lle Balambangenn (au nod de Bornén).

\section{GROUPE DES CARCINIENS.}

Le groupe des Careiniens comprend les gempes Portunnset Carcinns. que Leach avait étaluli au dépens de la division des Portunes a cing dents de Falnicius, te genre Portunites de 11 . Th. Bell el mon grenre Nectocarcinus. Ce spoupe. ansi ronstitué, ne correspond à ancune des divisions de W. de Haan el de H. Dana. En

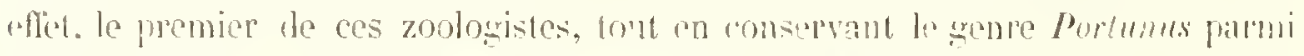

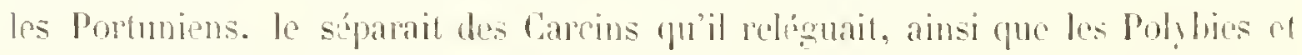

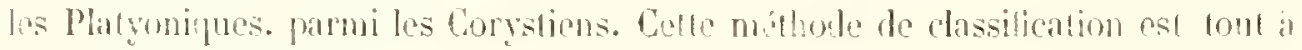


fait artificielle; clle réunit des espeeces dont le plan fondamental d'organisation est complétement différent, et elle en éloigne d'autres dont les affinités zoolugiques sont, aur contraire, étroites.

M. Dana a mieux saisi le lien qui existe entre les différents genres de la famille des Portuniens. Cependant il en sépare les Carcins, les Platyonyques et les Polybies. non pas pour les ranger comme de Jaan à coté des Corystiens, mais jour en faire une famille particulière de mene valeur que celle des Portuniens. Je erois qu'il est impossille de séparer autant les Portunes proprement dits des Carcins; leur organisation est trop analogue pour ne pas les placer à còté les uns des autres daus un système de classification naturelle qui ne doit pas se baser sur l'application empirifue d'un scul taratere tiré soit de la forme des appendiees mastieatoires. soit de celle de la carapace. mais bien sur l'ensemble de l'organisation soit cxtérieure. soit intérieure.

Le genre Portunite de M. Th. Bell, bien qu'imparfaitement connu, parait devoir se placer à còté des Careins.

Enfin le genre Nectocarcinus présente beaucoup d'analogie avec les Portunes parmi lesfucls on rangeait anciennement quelques-unes des espèces dont j'ai eru devoir former cette nourelle division.

Dans le sroupe des Carciniens, la carapace est médiocrement élargie; ses hords latéro-antérieurs forment, avee le bord fronto-orbitaire, une courlure réguliere à petit rayon, et ils sont armés de quatre ou cinq dents et jamais plus. La suture médiane, au lien de s'étendre sur les quatre dernier's anneaux du plastron sternal, comme dans le gene Lupa, ou sur Jes trois lerniers, comme chez les autres Lupécns et les Thalamitiens, noccupe que les deux dernicrs anneaux thoracigues. La tige mobile des antennes externes nait sur sur un gros article basilaire dans l'hiatus de l'orbite. Les pattes antérieures sont généralenent courtes. Les mains ne jréseutcut que rarement les carènes saillantes hérissées d'épines qui se trouvent presque toujours chez les Lupéens et les Thalamitiens. 


\section{Genre Gargiñs.}

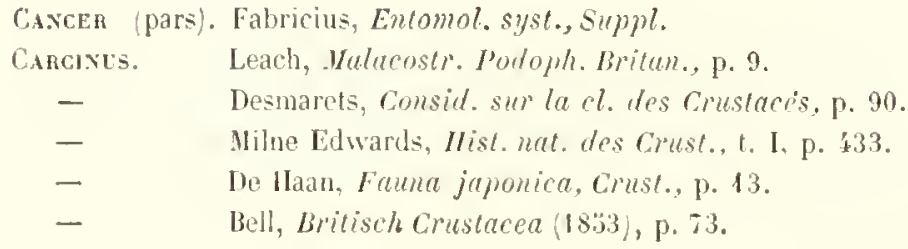

Ce genre, étahli en 1815 par Leach, semble relier entre elles les deux familles tes Cancériens et tes Portuniens, dont les formes typiques paraissent au premier ahord si dilférentes. Il n'est plus exclusivement conformé pour la natation, et desliné à habiter la lıante mer comme tous ceux que nous avons examinés jusqu'a présent; il peul vive trìs-longtemps hors de l'eau, et ses pattes postérieures, au lieu de former de larges palettes, ressemblent beaucoup aux pattes ambulatoires. Le pénultieme article en est cependant encore très-large et comprimé, mais le dernier est très-citroit, aplati ct lancéolí. Quant a la cuisse, elle est semblable à celle des pattes précédentes. Au premier abort, la carapace ressemble à celle de certains Lancériens, les Panopés et les Pirimèles, par exemple. Nais, en l'examinant attentivement, on y retrouve les principaux traits de l'organisation du type Portunien. Elle est plus large que longue, peu bonhée, mais épaisse. Les bords latéro-antérieurs sont decoupés en cinq dents et forment avec le front une courbure régulière. Les bords latéro-postérienr's sont très-longs et présentent en arrière une B́chancrure, hien accusée et destinée à recevoir la base des pattes postérieures. Celte dehancerure qui se retroure chez tous les Portuniens manque ou est trés-rare chez les Cancériens où les pattes postérieures, presque tonjours grèles, n'ont pas besoin l'une excavation pour recevoir leur article hasilaire. Les ordjites sont dirigées en avant, et lemp hord sonreilier est divisé en deus lobes par une scissure. Le front est arancé, horizontal et jeu élargi. Larticle hasilaire des antennes externes se soude au front. L’apophyse éfistomienne n'est pas saillante et est recue daus une fossette creusée sous le front. Eutre ho bord inférieur des "fosses antennaires et le bord lahial, il existe un sillon transversal; l'endostone est marque de chaque côté par une crite oblique et saillante. Les pattes-mìchoires externes sont lonzrues. Le plastron sternal est plus étroit que chez la plupart des autres Portu- 
niens, à l'exception des Platyonyques. La suture médiane en occupe les deux derniers segments. Les pattes antérieures noflrent aucun caractère générique important à noter. On ne connaît encore qu'ume senle espèce de ce genre.

\section{CARCIIUS VIUNAS.}

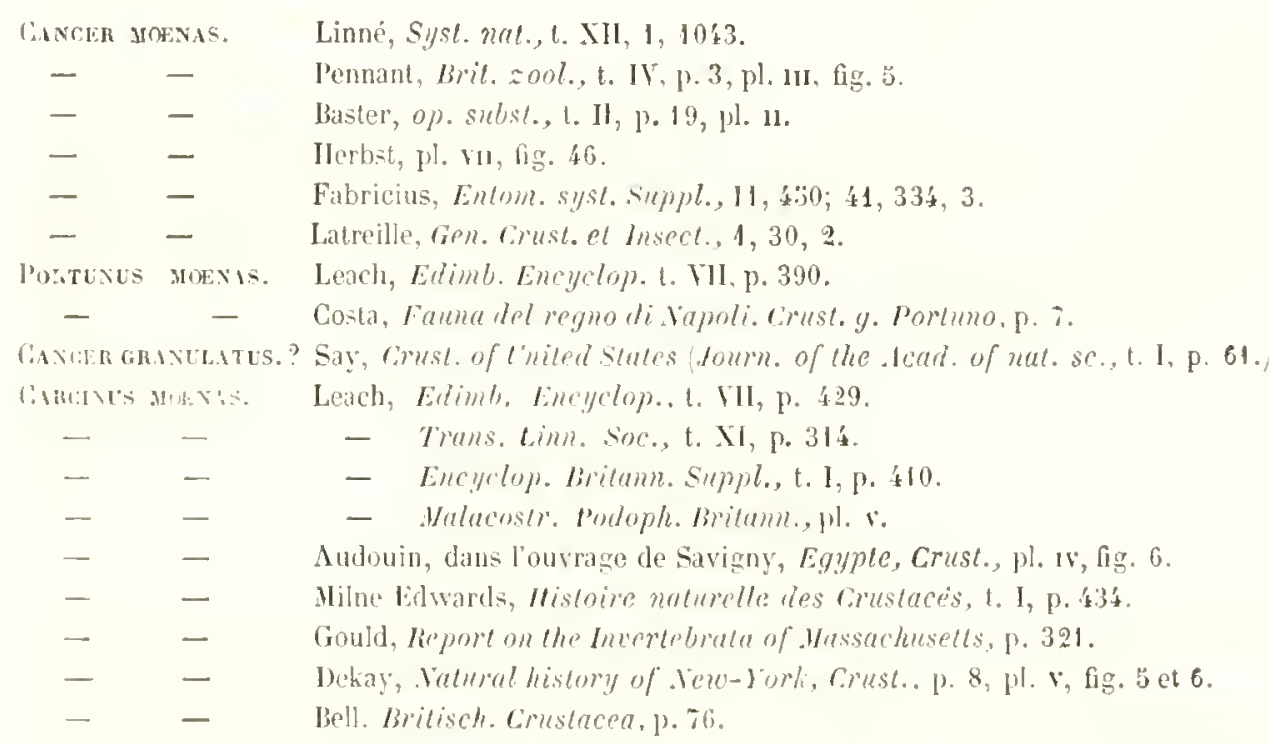

Rugions de la rarapace bien distinctes. Pas de lignes gramulenses fraversant ce bouclier. Surlace granuleuse. surtout en arant. Front lamelleux et divisé en trois loles flus on moins tronqués. Le lobe mélian un peu plus proćminest que les autres. Paltes antérieures conrtes et furtes. Bras ne dépassant pas le lord latéroantírieur de la carapace et non épineux. Mrant-bras aruné à son angle latérointerne d'une épine aplatie, lisse sur sa face externe. Main présentant deux carenes en dessus. l'interme phos marquée et terminée par mu tubercule spiniforme. Doighs armés sur leur bord tranchant de petits tubereules dentiformes tris-rapprochés. Pattes suivantes robustes et peu comprimées. Dernier article de celles des deux. trois et quatre premières jaires styliforme. Abdomen du male large. courl en triangulaire.

La couleur de cette espèce est ordinairemeut verdàtre, quelquefois lie de vin. 
l'autres fois jaunâtre. Les jeunes présentent sourent sur la carapace des taches blanches.

Largeur de la carapace, $0^{\mathrm{m}}, 070$; longueur, $0^{\mathrm{m}}, 055$. Il est rare qu'ils dépassent cette tiille.

Ilabilation. - Cette espèce vit en grand nombre sur les côtes de France el d'Angleterre. On la rencontre sur tout le littoral de la Múditerranée, pent-être mème jusque dans la mer Rouge. Les Carcins Ménades se trouvent sur les côtes des Élat-Unis d'Amérique. Au nord, ils remontent jusqu”à la mer Glaciale. Ils se liennent sous des rochers on enfouis dans le salule, et à la marée hasse on les voit courir sur la plage. Quand on les poursuit, ils creusent rapidement un trou dans le sable à l'aide de leurs pattes ambulatoires, pendant qu'ils se défendent avec leurs pinces. Aussi les connait-on sur nos côtes sous le nom de Crabes enrazés. On les vend sur les marchés.

Collection dı Huséum.

\section{ESPECE FOSSILE.}

CARCINUS PERUVIANUS (d'Orbigny).

Portuxes penuvianus. D'Orbigny, loyage dans lismérique mérilionale, 1842, $\mathrm{t}$. V, p. $10 \pi$, Praleonlologie, pl. vi, fig. 17.

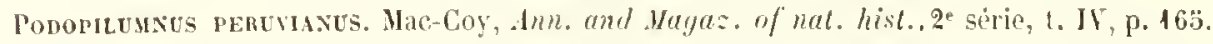

Carcrves peruvianes. Mph. Milne Edwards, Mistoire des crust. fossiles (1 $\mathrm{m} n$. des scienc. nat., í série, 1. XI1, p. 269, l. vi11).

\section{Genre PORTONOS.}

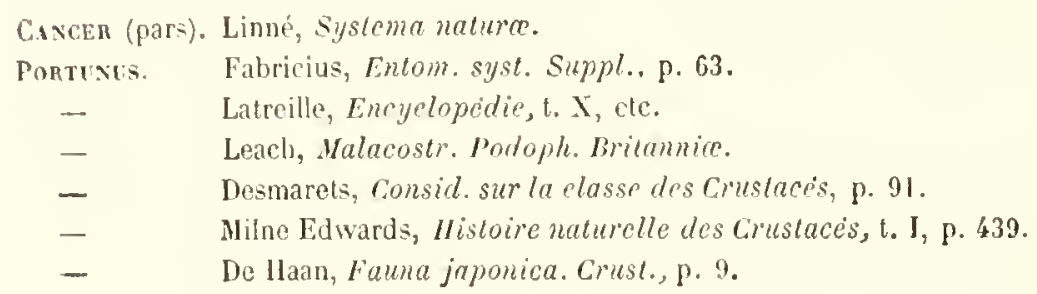

Le genre Porlumus avait été formé par Fabricius pour recevoir tous les Portuviens connus alors, à l'exception du Carcimus mœnas. Mais peu à peu ses limites 
se restreignirent, et anjourd'hui il ne comprend plus qu'un petit groupe de Cýclométopes nageurs. Les espèces qui le composent sont mienx conformées pour la natation que les Carcins et les Nectocarcins; mais clles sont bien moins douces sous ee rapport que les Thalamitiens et les Lupéens. La carapace des Portunes proprement dits est un peu plus large que longue : la différence dans ces rapports est an plus d'un tiers. Les bords latero-antérieur's forment avee le front une ligne fortement coumb. Ces bords sont divisés en ciup dents, en général dirigées en avant et aigurs. Le front est peut élargri ot proćminent; il dépasse les angles orbitaires externes. Les fossettes mtenmulaires sont placées sur le mème niveau que les yeux. L'apophyse épistomienne ne fait jamais saillic. L'article hasilaire des antennes extermes est étroit et somér au front, de facon ì clore complétement l'orbite en dedans. Les pattes-mâchoires externes sont allongées; leur troisieme article est tronqué à son angle antéro-interne. Les paltes antérieures sont assez courtes et inćgales. l'une étant plus robuste que l'autre. Le liras est lisse. L'arantbras armé d’une forte épine à son angle antéro-interne. La main carénée. et lécérement excaréc à sa face interne, pour pouvoir s'appliquer exactement eontre les llanes. Le doigt des jattes ambulatoires est styliforme, allongé el camnelé. Les paltes nageuses sout conformées sur le même plan que eelles des Lupéens; leurs deux derniers articles étant trés-larges el trés-aplatis. Le plastron sternal est étroit et long; la suture médiane en oceupe les deux derniers articles. L'alulomen du màle se compose de cinq anneaux ot est en général triang̣ulaire.

La plupart des espèces de ce genre vivent dans nos mers. Quelques-unes habitent cependaut les còtes de l'Amérique et la mer du Japon. Elles ne fréquentent pas la haute ner comme les Lupéens, ni la còte, comme les Carcins; elles se tiennent au-dessous du niveau des basses marées. Aussi, à l'époque de l'équinose, en trouve-t-on souvent dans les llaques d'eau et sur les rocher's que le rellux a laissés à déconvert. Les picheurs en prennent souvent en péchant prìs des còtes; quelques-unes sont comestibles.

10 POATUNUS HOHAMTS (Fabricius).

Portexus notsates. Fabricius, Entomol. syst. Suppl., p. 366.

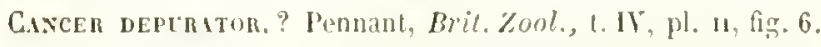

Pontuxis unines. Leach, Edimb. Eneyel., t. V'II, p. 390.

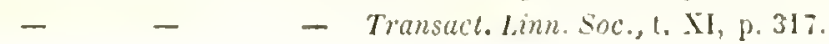


Portinus uninus. Leach, Walacostr. Podoph. Britam., pl. ix, fig. 3 et 4.

- - Thompon, Crust. of treland. (Inm. of nat. hist., 18 3, 1. X, P. $28 \%$.

Pontuxus molsatus. Milne Edwards, Hist. nat. des Crust., t. I, p. $4 \mathbf{k} 3$.

- - Costa, Fuma del regno di Vapoli. Crostacei, g. Porturo. p. 4.

- $\quad$ - Bell, Brilisch. Cruslacea, p. 109.

Carapace aphatie. Surface comverte de granulations visibles à la loupe seulement. Bords laféro-antérieurs formant avec le front une courbure régulière (1) arm s de cinc deuts, dont les quatre premieres sont tres-larges ì leur base; la cinquieme est an contraire aiguë. Front divisé en cinq dents : les trois médianes triangulaires, aigness. régulierenent espacies el sensillement égales entre elles; les dents externes sont complétenent obtuses. Bord sourcilier divisé par deux seissures. Endostome garni de crìtes latérales obliques. Pattes antérieures courtes. Bras lisse. Arant-bras portant une longue el forte épine à son angle antéro-inlerne. Main 'arénée en dessus et en dehors, el portant au-dessus de la base du ponce. du côtú interne, une petite épine. Pattes ambulatoires longues et fortement cannelées il jartir de la jambe jusqu'au doigh. Dernier article des pattes nageuses tres-bargi. Mylomen du màle pointu et triangulaire.

Couleur d'un rert slauque; la partie antérieure de la carapace plus foncée que le reste.

Largenr de la carapace, $0^{\mathrm{nz}}, 053$; longueur, $0^{\mathrm{m}}, 040$.

Mubitation. - Les còtes de France et d'Angleterre, où elle vit à quelque dislance du rivage.

Collection du Muséum.

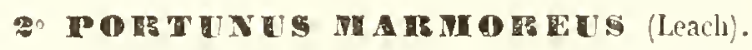

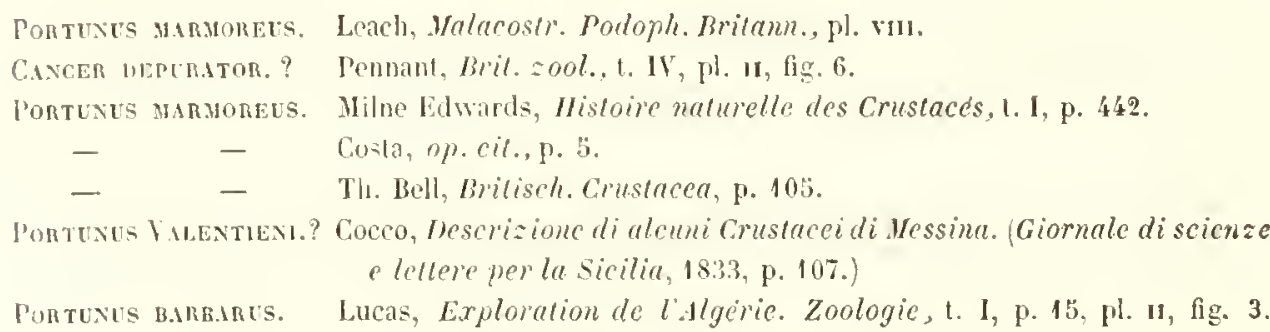

Il est très-difficile d'indiquer les différences qui séparent cette espèce de la précédente; car tous les caraclères principaux qui s'appliquent à l'une peurent servir 
à l'autre. Il est vrai. cependant que dans l'aspect grénéral, dans l'ensemble de l’animal, il y a queleques légìres différenees. Linsi la carapace est plus rélrécie postérieurement chez le: $P$. holsatus que chez le $P$. marmorens; les doigts des pattes natatoires de ce dernier sont moins álarọis. Il me semblerait cependant préférable de ne regarder cette espice que comme une variété du Portumus holsatus, ou peut-être comme le jaune ağe de ce dernier; car on ne rencontre jamais de $P$. marmoreus d'une taille aussi considérable que dans l'espece roisine. Cejendant. commo à la rigueur on peut les séparer par l'examen des palettes natatoires. comme le Portunus marmoreus a été aduis par tous les auteur's depuis Leach, je n'oserais le supprimer des cadres carcinologiques.

M. Lucas a décrit, sous le nom de l'. berbarus, une variété de llarmorens à 'arapace un peu plus bombée et plus granuleuse ${ }^{1}$.

Couleur d'un vert houteille, avec les pattes plus claires.

Largeur de la carapace, environ $0{ }^{\mathrm{m}}, 030$; longueur, $0^{\mathrm{m}}, 022$.

Ilabitation. - Les còtes de France. d'Angleterre, et toute la Héditerrance. Collection du .lluséum.

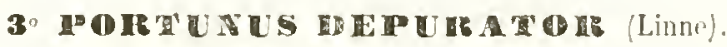

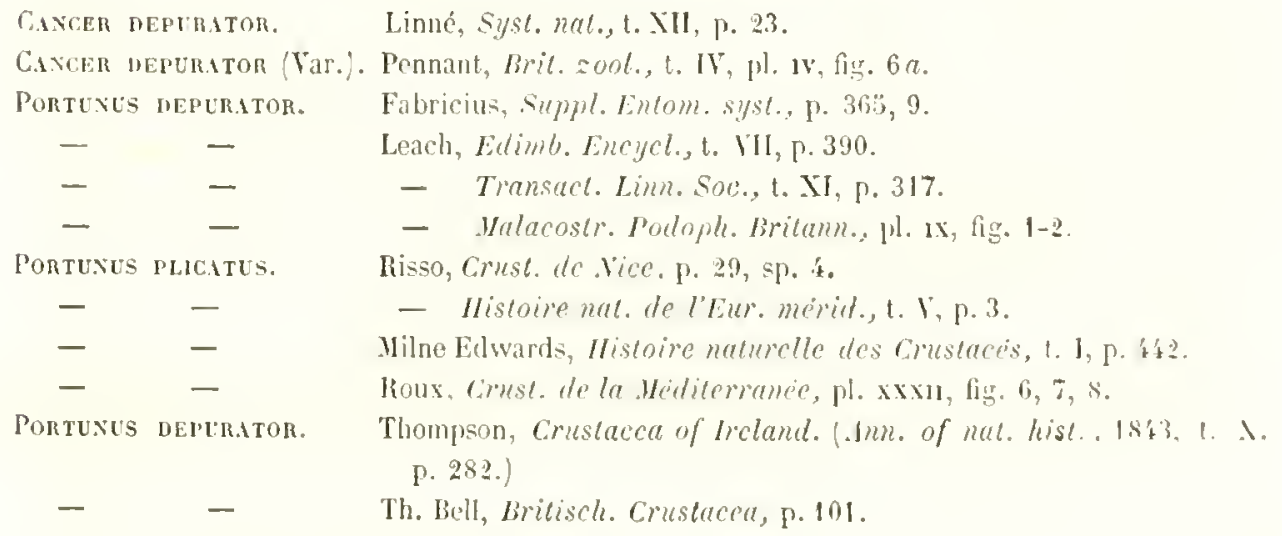

Carapace aplatic, bosselée, courerte de rides et très-pubescente. Rigions hien

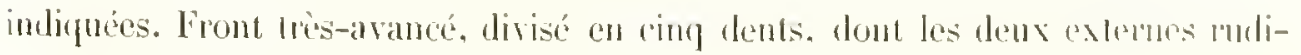

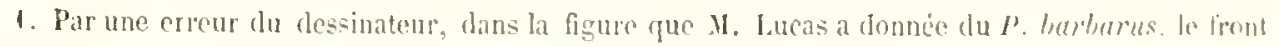
pressente deux dents médianes, tindis qu'il n'y en a jamais qu'une seule. 
mentaires, les trois médianes à peu près éçales, profondément séparées, aiguës ef un peu relevées. Bord sourcilier divisé par denx scissures. Bords latéro-antérieur's garnis de cinq dents aiguës et dirigées en avant. Pattes antérieures un peu ridées. Bras lisse. Arant-bras armé à son angle latéro-interne d'une forte épine, et an hord antérieur de sa face externe d'une petite dent rudimentaire. Main fortement carénée et portant une épine du còté interne, au-dessus le la lase du pouce. Pattes ambulatoires carénées et très-longues. Dernier article des paltes nageuses très-large. Abdomen du mâle triangulaire.

Couleur d'un rose jaune el quelquefois roussatre.

La carapace des grands individus a 6 centimètres de large sur 4 de long.

IIabilation. - Mer Méliterranée.

La forme du front, la longueur des pattes et les rides qui ornent la carapace sont pour cette espèce d'excellents caractères distinctils.

Collection du Muséum.

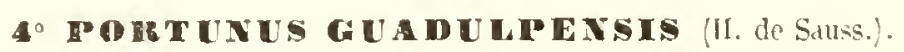

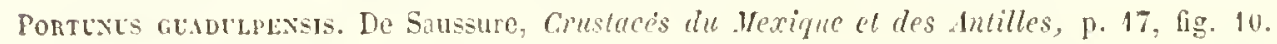

Carapace lionbéc et longue. régions à peine indiquées. Bords latéro-antérieurs dicouprs chacun en cinq épines aiguës. Front à cinq dents, dont les deux externes rudimentaires, les trois autres également avancées; la médiane aiguë, les mitoyennes plus arrondies. Bras court et lisse. Avant-bras armé d'une seule épine à son angle antéro-interne. Mains fortement carénées portant une petite é/ine audessus de la base du pouce. Palles suivantes grêles.

Largeur de la carapace, $0^{\mathrm{m}}, 023$; longueur, $0^{\mathrm{m}}, 019$.

Ilabilation. - La mer des Antilles, la Guadeloupe.

La forme bombée de la carapace, oì les régions sont à peine visibles, suffit pour faire distinguer cette espece de tous les autres Portunes.

Collection du Musium.

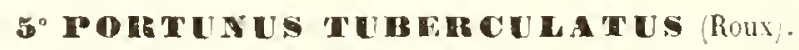

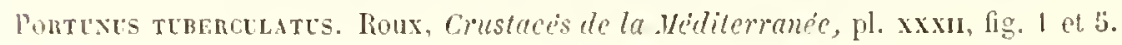

Carapace très-bosselée, surtout sur la région cardiaque. Bords latéro-antérieur: 
tris-obliques et découpés en ciny dents, dont la deruière est plus du double des autres, rlisposition qui donne à cette espèce de la ressemblance arec certains Neptunes. Front à cinq dents, dont les deux externes sont rudimentaires. les trots médianes stillantes, aiguis et sensibiement égales. Pattes antérieures assez lonsnues. Arant-lias armé de deux épines: l'une très-longue à l'angle antéro-interne, l'autre plus petite sur la lace externe. Main carénée el portant du cotio interne, au-dessus de la base du pouce, une épine très-longue. Pattes suivante: longues al gribles.

Conleur d'un roux jauntitre, aree les pinces un peu plus claires det un peu tachetées de rouge.

Largeur de la carapace. $0^{\mathrm{m}}, 048$; longuene, $0^{\mathrm{m}}, 026$.

Habitation. - Baic de Naples (tris-rare).

Ce Portune est jusqüici le seul dont la dernière dent du bord latéro-antérieur dépasse les autres.

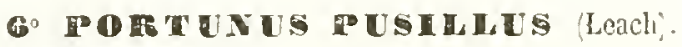

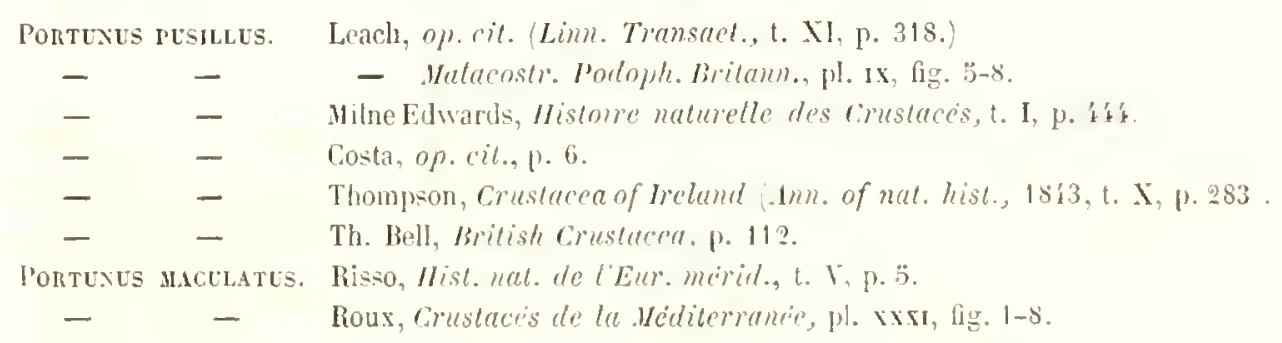

Carapace glabre. allongée, très-bosselée, surtout sur la réggion cardiayue; te lobe mísogastrique se prolonge jusqu'aupres du front, disposition rare chez les Portunes. Bords latéro-antérieurs à trois dents aigruës. Front très-avancé, lamelleux et terminé par trois larges dents, la médiane un peu plus proćminente que les deux latérales. Pattes antérieures robustes. Bras lisse. Avant-bras armé d'une úpine acérée à son angle antéro-interne. Main courte et grosise, assez fortement carénée, armée d'une petite épine an-dessus de la hase du pouce. du còté interne. Pattes suivantes gröles. Dernier article des pattes nageuses allongré.

Conleur l'un rose clair, avec des taches d'un rouge plus foncé.

Ce Portune n’atteint jannais que quelques millimitres. Largeur de la calrapace. $0^{\mathrm{m}}, 017$; longruenr, $0^{\mathrm{m}}, 019$. 
Mabilation. - La Méditerranće et les còtes d'Angleterre, à une assez grande profondeur.

La forme avancíe lu front, les bosselures nombreuses, ainsi que la longueur de la carapace. permeltent de distinguer facilement cette petite espece.

Collection du Muséum.

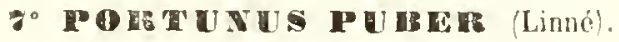

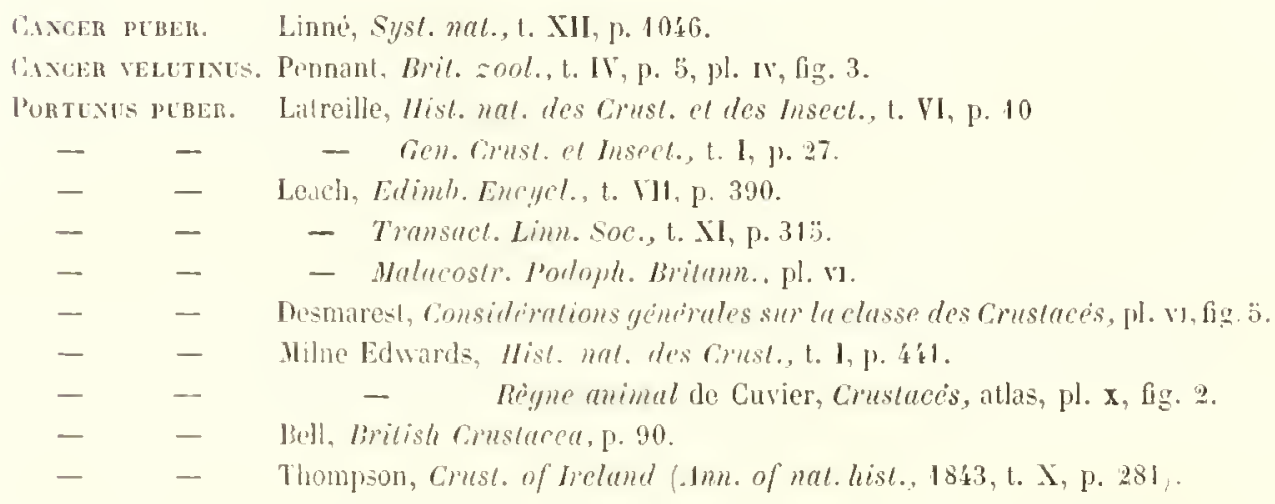

Carapace aplatie, très-large. velue, marquée de lignes transrersales saillantes. Burds latéro-antérieurs courts et régulièrement courbés, découpés en cinq dents acées. Front large armé de deux dents medianes saillantes et dirigées en dehors. suivies de charque côté de deux ou trois dents, petites et aiguës, et d'un lobe saillant denticulé. formant l'angle orbitaire interne. Bras lisse. Avant-bras granuleux. portant deux épiues, l'une grande à son angle antéro-interne, l'autre petite sur sa face exterue; le borl antérieur, faisant suite it la grande épine, est profonfément denticulé. Mains à côtes granuleuses, armées d'une épine an-dlessus de l'articulation du pouce, du còté interne. Pattes suivantes médioeres el compriunées. Dernier article des palles nagreuses très-allongé.

Couleur brunàtre, avec des taches bleues disposées en série sur les pattes.

Cette espèce peut atteindre une taille assez considérable. On en voil dont la arapace a 8 centimetres de largeur sur 6 de longueur.

Habilation. - Nos còtes ocćaniques el la mer Méditerranée.

La forme du front de ce Portune suffit pour le faire reconnaitre aut prenier ahort; cest le seul dont le borl frontal soit ainsi découpé. Cette espèce se mange 
sur nos cotes, où on la connait sous le nom de Crabe à laine. Crabe espagnol. étrille, etc. Elle rit à quelque distance du riraže, el meurt aussilòt retirée de l'eaur. Collection du lluséum.

\section{So POIRTINUS A IRCUATE.}

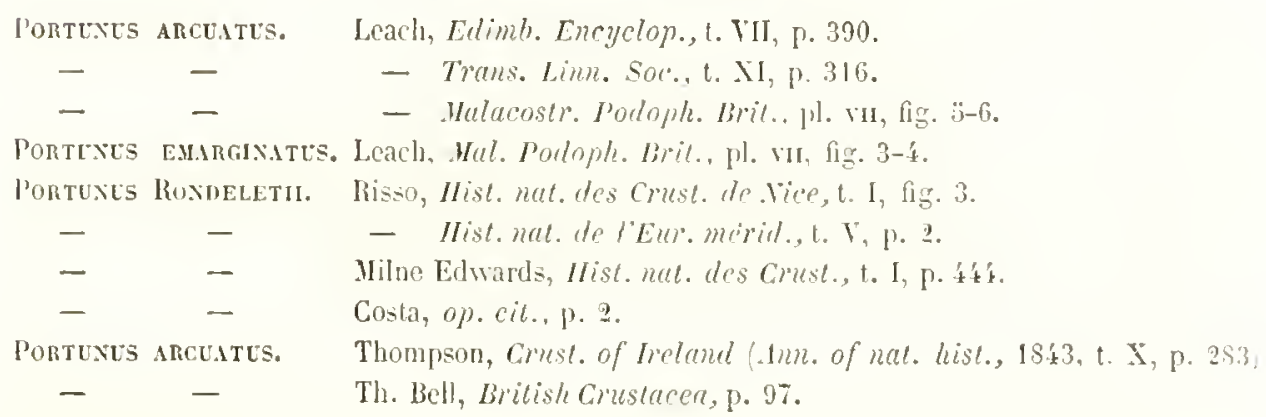

Carapace bombée, légìrement squammeuse et granulée. Régions distinctes. Lobe mésogatstrique se continuant jusqu'auprès du front. Borls latéro-antérieurs découpés en einq dents, petites et aigueis, la quatrième plus petite que les autres. et formant aree le front une courbure régulière; celui-ci ondinairement arrué et non découpé; quelquefois il présente la trace de trois lobes peu distinets; d'autre: fois, mais plus rarement, i] est excavé au milieu : c'est cette variúté dont Leanth avait fait une espèce sous le nom de P. emarginatus. Pattes antérienres infúcales. très-fortes chez le mâle, moins chez la femelle. Blas lisse. Avant-bras armé d'une épine à son angle antéro-interne. Nain carénée et portant une petite épine autlessus de la base du ponce, du còté interne. La denxième paire de pattes courte. la quatrième très-longue, la troisième intermédiaire. Cuisse des pattes postérieure: longue et étroite. Dernier article lancéolé. Abdomen du màle pointu et triangulaire.

Couleur d'un brun jamnâtre, quelquefois parsemé de taches violettes ou rougeîtres.

Largeur de la carapace, $0^{\mathrm{m}}, 0.30$; longueur, $0^{\mathrm{m}}, 02 \%$.

IIabitation. - Cette espece, asse\% rare dams l'Océan, est commune dans la Méditerranée, oì elle se tient dans des fonds vaseux et peu profonds qui avoisinent l'embouchure des ports. 
La forme du front et la brièveté de la quatrième dent du bord latéro-antérieur suffisent pour faire distinguer cette espèce.

Collection du Muséum.

\section{g' POIETUNUS LONGIRES〈Risso).}

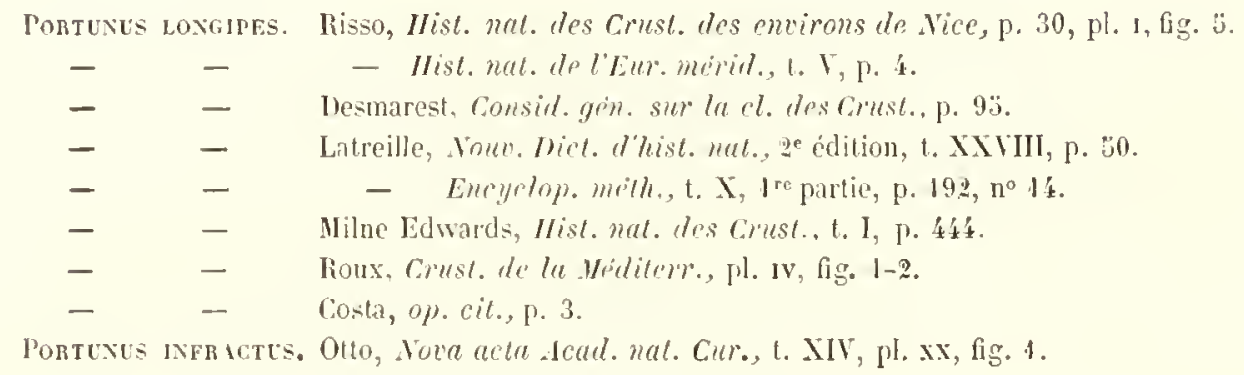

Carapace un peu quadrilatere, lisse postérieurement, finement granuleuse sur la partie antéricure, diviste en deux parties presque égales par une impression saillante qui s'étend d'une des dents postéricures à l'autre. Bords latéro-antéricurs il cinq dents; la cinquieme, dirigée en tehors, plus gramde et plus aiguë que les antres. Front enticr indistinctement quadrilobé. Pattes antérieures tris-inégales. la droite, en général, près du double de l'autre. Bras lisse. Arant-liras portant une large épine à l’angle antéro-interne. Nains à peine carénées; armées d'un tubercule spiniforme au-dessus de la base du pouce du côté interne. Paltes suivantes très-grêles et très-longnes; celles des troisième et quatrième paires dépassant heaucoup les autres. Pattes nageuses longrues et peu ćlargies. Dernier article lanréolé. Abdomen du màle triangulaire.

Couleur d'un ronge foncé brillant, légìrement tacheté de jaune.

Largeur de la rarapace, $0^{\mathrm{m}}, 030$; longueur, $0^{\mathrm{m}}, 020$.

Ilabitation. - La Méditerranée. Il se tient dans des trous de rochers, à une assez grande profondeur, et vit solitaire.

Liextrème allongement des pattes des troisième el quatriène paires uni à la forme un peu quadrilatère de la carapace, ainsi que la disprosition indistinctement 'juadrilohée du front, caractérisent suffisamment cette espice.

Collection du Muséum. 


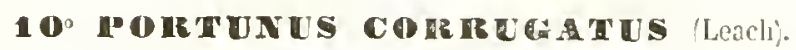

\author{
Pl. XXX円1, fig. 3.
}

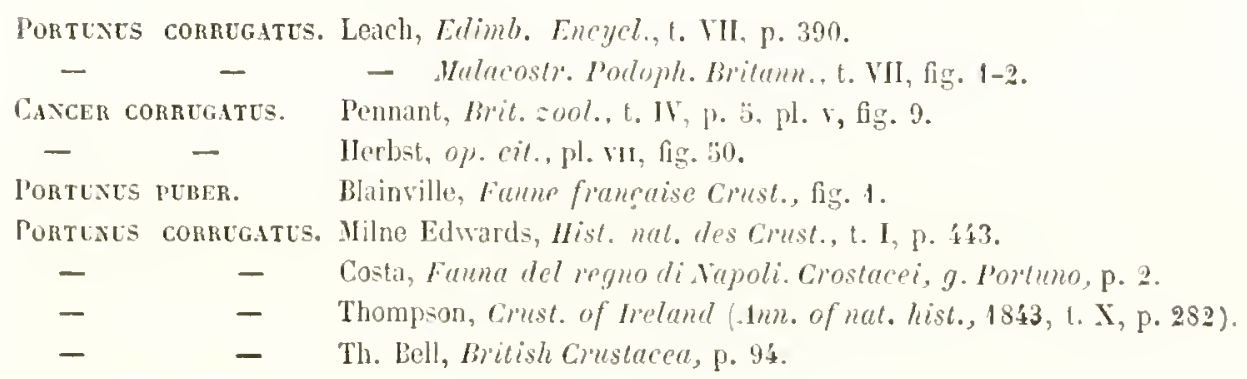

Carapace bombée, courerte de lignes transrersales granuleuses dlonnant insertion à des poils. Régions distinctes. Lohe mésogastrique se prolongeant jusqu'an roisinage du front. Bords latéro-antérieurs découpés chacun en cinq dents égales. aignës et fortement dirigées en arant. Bords latéro-postérieurs longs et resserrés. Front découpé en trois lobes aigus, surtout les deux latéraux. Pattes antérieures courtes, très-ridées, comme la carapace. Avant-bras armé d'une épine à son angle antéro-interne. Main portant une épine aiguë vers le tiers antérieur du bord interne de la face supérieure. Pattes suivantes conrtes et fortes. Abdomen subtriangulaire traversé par des crètes saillantes. Dernier article très-étroit.

Conleur rouge, aree des taches d'un jame rlair.

Largeur de la carapace, $0^{\mathrm{m}}, 055$; lougueur. $0^{\mathrm{m}}, 042$.

Ihabitation. - Tris-commun dans la Héditerranée; plus rare dans l'Ocćan.

Les rides nombreuses qui courrent la carapace et les pattes antérieures, la forme trilobée du front, ne permettent de confondre cette espèce avec aucune de celles que nous avons exanninées.

Collection du IIuséum. 


\section{H TRTUNUS SUECORREGATE (Nobis).}

Pl. XXXYI, fig. 2.

Purtuxes conrcg.tess? De Ilaan, Fama juponica; Crust., p. 40.

Portuxus hoxdetetu? Audouin (Savigny, Égypte, Crust., pl, w, fig. 2).

Cette espèce, très-roisine de la précédente, s’en distingue par sa carapace moins ridéce el par la forme du front, qui est à peine divisé; c'est à peine si on apercoit la trace des trois lohes. Il est probable que c'est cette espèce que de IIaan indique comme le P. corrugatus du Japon, que Savigny arait fait représenter dans l'ouvage sur l'Égypte, et qu'Aulouin avait rapportée an $P$. arcuatus, avec lequel de ne peut cependant ètre confondue, puisque les dents des loords latéro-antérieurs sont toutes égales, que la taille est beancoup plus tonsidérable, et enfin que la carapace est beaucoup plus rilée. Le front ne présente, il est vrai, aucune trace de trilobation; mais il est possible que par les progrès do l’âge ces traces disparaissent de plus en plus : c'est ce que je n'ai pu coustater, n'en ayant qu'un seul individu entre les mains.

Couleur rongecitre.

Largeur de la carapace, $0^{\mathrm{m}}, 045$; longueur, $0^{\mathrm{m}}, 037$.

Ilubitation. - Ce Portune a été étiqueté comme provenant de la mer Rouge. Collection du Muséum.

\section{PITUNUS STRETIIS (Stimpsou).}

Portexus stricilis. Stimpson, op. cit. (Proceed. of the Ae. of mat. scienc. of Phitadelph., 1857, p. 35.)

Carapace pubescente, un peu bombée, marquée de lignes transvercales ondulenses et rapprochées. Bords latéro-antéricurs à cinq dents de longueur médiocre. Front large, avancé, à peine convert, indistinctement trilolú. Pattes antérieures rugneuses. Main courte, carénée, avec une petite épine an-dessus te la base du pouce. Carpe portant une épine aiguè à l'angle antéro-interne. Pattes natatoires à doigt lancéolé at bordé de cils très-longs. 
Habitution. - Ner du Japon.

Cette espice n'a janais été figurée et n'est connue que par la courte description qui précède; il est assez dillicile d'établir ses véritabtes aflinités; clle paraît cependant se rapprocher de I'. corrugatus, mais en différer par l'épine de la main qui. chez ce dernier', an lieu d'être courte et situéc au-dessus de la base du jouce, est longue et placée plus en arrière.

Je crois devoir regarder le Portumus carcinoides des côtes d'Irlande (Kinhan.

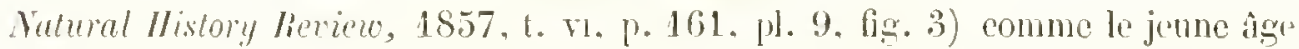
du Carcinus Honas; la figure qui l'accompagne peut parfatement se rapporter it cette dernière espèce. el on ne peut recourir à la descriplion. qui n’a pas élí donnée.

D'ajrès M. Prestandrea, i] existerait sur les còtes de la sicile deux antres espèces de Portunes qu'il désigne sous les noms de $P$ '. macropipus et de $P$. mararigne (Effemeridiscientifiche e litterarie per la sicilia, 1833). Mais ces observalions, qui datent de près de trente ans, n'ont été confurntées par aucun des naturalistes qui depuis ont étudié la Faune maritime de cette ile, et il me semble bien probalste que cet auteur a considéré comme étant des formes spécifiques nouvelles de simples variétés d'espèces déjà connues. Cependant. n’ayant pu me procurer le travait de 1. Prestandrea, je n'ose me prononcer à cet égard d'une manière absoluc.

\section{Genre PORTUUTES.}

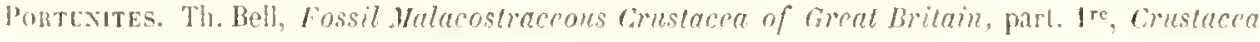
of the Lomdon citay P'alerontograph. viacirty. 18:56, 1). 20).

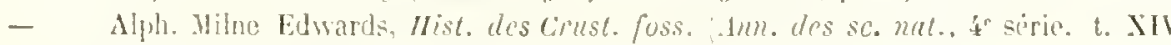
1). 273.$)$

1. Elocullus. Reuss, Zur Lembiss fossiler Kräbben, 18.59 , p. 56.

Ce genre a étéćtablien $\mathbf{8 5 9}$ par 11. Th. Bell ponr un Crustacé fossile le l'argilk the Londres dont les allinités zoologinues ne sont pas encore parfintement connues. C'est aver tes Carrins el les l'ortunes que ce clabe présente le plus d'analogie; il s'en distingue cependant par te reliel des diverses régrions de la camapace. 
PORTUNITAS INCERTA (Th, Bell).

Portcnites incerta. Th. Bell, op. cil., p. 20, pl. vill, fig. 1 à 5.

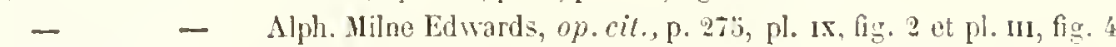

Leiochlets Morrisi. Reuss, op. cit., p. 36 , pl. xrin, fig. 7.

\section{Genre NEGTOGARGINUS.}

Pontcies (pars). Mitno Edwards, IIist. nat. des Crust., t. I, p. 440.

Nectocarcincs. Alph. Milne Edwards, IIist. nat. des Crust. foss. (Anm. des sc. nat., $4^{e}$ série. i. XIT, p. 220.)

J'ai cru devoir créer cette nouvelle division générique pour y placer toutes les espèces de Portuniens dont le bord latéro-antérieur de la carapace est découpé en quatre dents au lieu de cinf. Le bouelier céphalo-thoracique est peu élarģi, peu bombé, mais épais. Les bords latéro-antérieurs forment avee le front une courhure régulière à petit rajon dont le centre serait sur la ligne médiane à la partie antérieure de la régrion cardiaque. Les régions sont hien marquées. Le front est avincé, tantòt découpé en dents, tantôt indivis. Les orthites sont petites et enfonrées. L'article basilaire des antennes externes est droit, étroit et soudé au front. L'arlicle basilaire des antennes internes est très-Jarge. L'apoplyse épistomienne est reçue dans une fossette ereusée sous le front, et ne fait pas saillie au dehors. Les pattes-màchoires externes sont allongées; leur troisieme article échancré en ledans. Les pattes antéricures sont courtes et robustes. Les pattes postérieures sont en général moins favoralılement disposées pour la natation que thez les Portunes, mais plus élargies que chez les Carcins. La suture médiane occupe seulenent les deux derniers articles du plastron sternal, comme chez les Carcins. les Portunes et les Polybiens. L'ablonen du mâle est construit sur le même type que celui des antres Portuniens, e'est-à-dire qu'il se compose de quatre articles seulement, les cinquième, quatrième et troisième étant soudés entre eux.

Ce grenre ne comprend que des espèces exotiques.

IIabitation. - Les mer's de l'Océanie. 


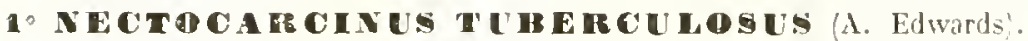

\author{
Pt. XxxiI.
}

Siectocarcines tuberclosus. Alph. Milne Edwards, Ilist. des Crust. foss. Imo des se. nat 4' série, t, XIV, p. 2.20.)

Larapace très-ćpaisse, peu bombée en dessous. Régrions bien distinctes. Le lobe mésogastrique se proionge en avant jusqu'auprès du front. Les lobes ćpig̨astriques sont saillants et couverts de tubercules. Les lobes protogastriques sont également tuberculeux. Les régions hépatiques, petites, mais bien nettement circonscrites. sont hérissées de tubercules. Toute la partic postérieure de la carapace est lisse. Les borls latéro-antérienrs régulièrement courbes sont découpés en quatre dents couvertes de tubercules: la première est la plus large; la dernière est au contraire petite et aiguë. Le front peu élargi présente deux lobes presque confondus sur lit ligne médiane et bordés en avant de deux rangées de tubercules serrés les uns contro les autres; ces lobes sont séparés des angles orbitaires externes par une échanceure peu profonde. Le bord soureilier n'oftre presque ancune trace de seissures. L'angle sous-oldhitaire interne est long et bien détaché. L'épistome est également granuleux sur son borl antérieur. Entre le horl lithial et le bord postérieur des fossettes antennaires eviste un sillon transversal très-large. Les paltes antériemes sont fortes. courtes et très-tuberculenses. Le bras ne dépasse pas le hord latéral de la carapace, el offre sur son bord postérieur une courte épine sulmédiane. L'arant-bra. est armé à son angrle antéro-interne d'une épine forte el courte. La main earéncin ne présente aucune trace d'épines, et les tuberentes qui l'olnent sont régonlieresurent disposés en séries longitudinales; les doiggts également tulverculeux sont bortement carénés. Les pattes ambulatoires sont robustes et eomprimées lateralement. La cuisse des pattes nageuses est presigue semblalide anx autres. Le deruier article de ces pattes est lancéolé et comprimé latéralement. L'abdomen présernte unt. forme quadrilatere allongée. Les lignes de somdue des cinquiome, quatrième en troisième articles sont hien distinetes.

Couleur rougeâtre avec quelques taches jaunes sur les pattes el des tubercules noirs sur les mains. 
Largenr de la carapace, $0^{\mathrm{m}}, 075$; longueur, $0^{\mathrm{m}}, 060$.

Inabitution. - La Tasmanie.

Collection du Huséum.

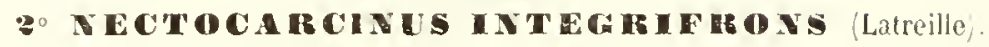

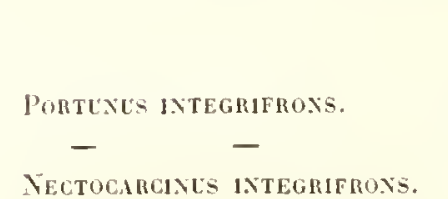

YECTOCARCINLS INTEGRERONS.

\section{Pl. XXXYlII.}

Latreille, Encycl, méth., t. X, p. 192.

Milne Edwards, Histoire nalurelle des Crustaces, t. I, p. fí $\mathrm{Al}_{\mathrm{l}}$.. Milne Edwards, Mistoire des Crust. foss. Amr. des scienc. nat., 4e série, t. XIT, p. 220.

Nectocarcinus aelaxob.ctrues. Alph. Milne Edwards, op. cit., p. 220.

Carapace peu lombée, légèrement granuleuse. Granulations disposées par petits groupes. Régions nettement circonscrites. Lobe mésogastrique se prolongeant jusqu’auprès du front. Bords latéro-antérieurs découpés en quatre dents, dont la première est la plus large, et la dernière petite et pointue. Front large, argué et non livisé. Bord sourcilier divisé par denx seissures linéaires. Orbites petites et probondes. Angle sous-orbitaire peu avancé. Apophyse épistomienne courte. Bord litial séparé du bord postérien des fossettes antennaires par un large sillon. Pattes antérieures convertes de lignes squammeuses et de granulations rapprochées. Bras court armé sur la partie moyenne de son bord postérieur d'une courte épine. Ivant-bras portant à son angle antéro-interne ume épine pointue. Main non carénée, armée en dessus du còté interne, au-dessus de la hase du pouce, d'une petite épine. Doigrts fortement carénés; leur bord tranchant, leur extrémité et leurs carènes noires. Pattes suivantes comprimées et à ternier article styliforme. Cuisse les pattes nageuses presque semblable anx autres. Pémultième article élarọgi. Doig̨t plat et lancéolé. Ablonen du màle subquadrilatère.

Conlenr d'un jaune rougeàtre.

Largeur de la carapace, $0^{\mathrm{m}}, 050$; longuemr, $0^{\mathrm{m}}, 036$.

Uabitation. - La Nouvelle-Hollande, la Tasmanie, la Nonvelle-Zélande.

J'avais mentiomné, sous le nom te $\lambda$. melanodaclylus, une espèce qui me paraissait se distinguer du $N$. integrifrons par le prolongement sur le poignet de la conleur noire de l'inder. A cette époque, je n'avais pu la comparer qu'avec de jeunes individus du . Y. inlegrifrons qui ne présentent pas ce caractère; mais depuis 
jai pu n’assurer que la coloration noire des doigts s'étendait de plus en plus à mesure que les individus vieillissaient, de telle sorte que les jeunes ont seulement l'extrémité de la pince noire, tandis que chez les vienx individus la hase du poiwnet voisin du doigt immobile est noire en dehors aussi bien qu'en dedans. La distinction établie de la sorte doit done être abandonnée. De plus, l'individı qui m'avait servi de type pour la description du N. melanodactylus avait été vendu comme provenant de la mer Rouge, tandis que les $\mathrm{N}$. integrifrons habitent l'Océanie. Il est probable qu'il y aura en erreur de localité.

Collection du Muséum.

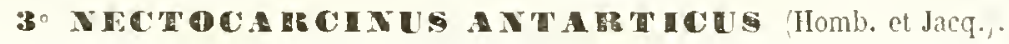

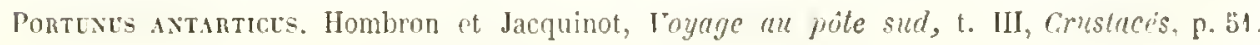
pl. v, fig. 1.

Carapace peu bombée, très-arrondie, ridée et traversée par des lignes granuleuses. Dents du bord latéro-antérieur très-courtes; la première plus largée, la quatrième petite et pointue. Front étroit, saillant, découpé en six dents : les deux médianes pointues et courtes; les mitoyennes larges, triangulaires et plus longues; les externes très-contes et obtuses. Bord somrilier divisé par une scissure linéaire. Angle sous-orhitaire court et pointu. Apophry se épistomienne courte. Bort labial séparé du bord postérien des fossettes antemnaires par m sillon transversal átroit. Pattes-mâchoires externes longues. Pattes antérieures courtes et granuleuses. Bras portant sur le milieu de son hord postérieur une épine courte. Irant-bras artnéde deux épines : l'une à l'angle antéro-interne. l'autre sur la face externe. Main peu carénéc, portant en dessus da pouce, du còté interne, une courte śpine. Ponce armé sur son bord supérieur de quatre ou cinq petites épines acérées. Pattes ambulatoires, grêles, assez allongées. Pattes de la cinquième paire s'éloignant par leur forme en palette de celles des espèces préédentes pour se papprocher de celles des Portunes. Cuisse courte et large. Pénultième article aplati. Doing ovalaire et lantelleux. Abdomen dı mâle subquadrilatère.

Conlenr d'un boun ferimginemx.

Largeur te la carapace, $0^{\mathrm{m}}, 060$; longueur, 0 "'015.

Ilabitation. - Iles Auchland. Collection du Muséum. 


\section{GROUPE DES POLYBIENS.}

Leach, en se fondant sur la structure du bord sourcilier et de l'orbite, ainsi que sur la forme des pattes, étahlit le genre Portummus aux dépens des Portunes à cinq dents de Fabricins; mais ce dernier nom ne différait pas assez de cetni de Portumus, dont il est synonyme, pour que l'on pùt l'adopter, el quetque temps après Latreille Ini suhstitua celui miens choisi de Platyomychus.

Bientò apreses, Leach, ayant cu l'occasion d'étudier un Portunien de nos còtes qui avait échappé à l'attention des zoologistes, y reconnut un mode d'organisation particulier, et le prit pour type d'un nouveau genre, auquel it donna le nom de Polybius.

W. de llaan sépara complútement ces deux derniers genres de la famille les Portuniens, et les relégua parmi les Corystiens, dont ils different sous tous les rapports l'organisation tant extérieure qu'intérieure; et, aux dépens du genre Platyonychus, il forma le genre Anisopus, semblable au précédent par la plupart des caractires, mais en dillérant par la forme des appendices masticatoires. Aussi. M. Dana, dans son beau travail sur les Crustacés, ne crut pas devoir conserver cette nouvelle division générique.

M. Mac-Leay forma une noureau genre, sous le nom de Xaira, pour une petite espece qui, à mon avis, a trop d'analogie avec les Platyonyques pour pouvoir en ètre séparée.

Enfin, j'ai cru deroir former le genre Psammocarcinus pour une espèce fossite connue depuis fort longtemps et décrite par Desmarest sous le nom de Porturus hericarti.

De telle sorte que, dans l'état actuet de nos connaissances, le groupe des Polybiens ne comprendrait que les trois genres Polybius, Platyonychus et Psammocurcimus, l'ecomaissables à leur carapace orbiculaire, ou plus longue que large, dont les bords latéro-antérieurs sont armés de cinq dents. La suture médiane dı plastron sternal, de mème que chez les Carciniens, ne s'étend que sur les deux derniers articles du sternum. L'article basilaire des antennes externes est grèle. libre, et ne lerme pas complétement la cavité orbitaire en dedans. Les pattes antérieures sont courtes et robustes. 


\section{Genre POLYBIOS.}

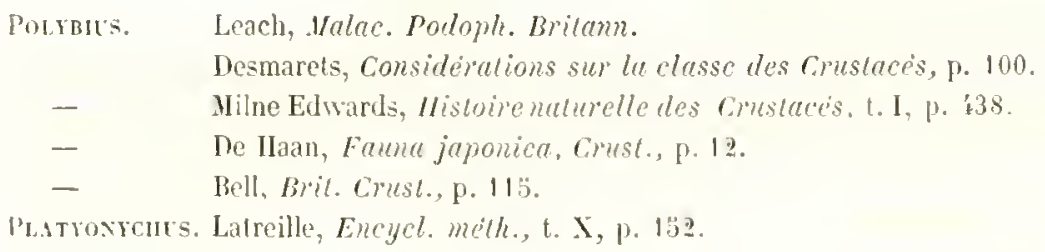

Le genre Polybius, établi en 1815 par Leach, ne comprend jusqu'à présent qu'une seule espèce qui halite nos còtes. Il se reconnait anx caracteres suivants. Carapace orbiculaire. Bords latéro-antérienrs découpés en cinq dents sensilhement écrales. Fissures du bord sourcilier à peine visibles. Article basilaire des antennes externes grềle et ne fermant pas la cavité orbitaire en dedans. Pattes-màchoires externes lonģues. Troisième article peu échaneré en dedans. Endostome présentant des crètes obliques latérales. Pattes des deuxième, troisième, quatrième et cinquième paires natatoires; celles des troisième, quatrième el cinquième aplaties el terminées par un doigh comprimé et lancéolé. Abdomen du mâle sulıriangthaire et composé de cinq articles.

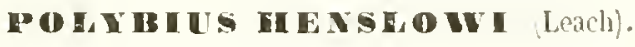

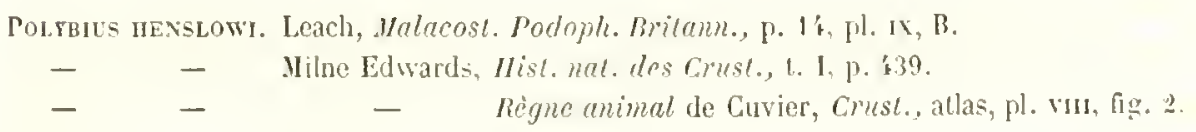

Lette espèce représente à elle seule le genre Polybius, et on peut dire que de tous les Portuniens cest le mieux organisé pour la natation. La carapace. presque orbiculaire, est plane en dessus et complétement lisse. Les dents des bords latéro-antérieurs sont courtes et larges; la cimquième est plus petile que les précédentes. Le front est découpé en cind dents, dont la médiane est la seule qui soit pointue; les autres sont oltuses. Les paltes antérienres sont courtes ot de force médiocre. Le bras est lisse; l'avant-bras porte une b́line à son angle antérointerne. La main, faillement carénce, est almée du còte interne, au-dessus de 
l'articulation du pouce, d'un tubereule spiniforme. Les doights sont larges et armés de dents tranchantes s'engrenant exactement. Le plastron sternal est plat et allongé.

Couleur d'un lnun rosître.

Largeur de la carapace, $0^{\mathrm{m}}, 055$; longueur, $0^{\mathrm{m}}, 048$.

Habilation. - Cette espèce vit à une assez grande distance de nos côtes, dans l'océan Mllantique. On l'a rencontréc sur les rivages d'Angleterre, de France et d'Espagne.

Collection du Muséum.

\section{Genre PLATYONYGHOS.}

Cincer (pars). Linné.

Portcius (pars). Fabricius, Entomol. syst. suppl.

Pontumses. Leach, Malacost. Podoph. Britann., p. 7.

Putroxicnts. Latreille, art. Platyonyque du voleveau dict. d'hist.nat., t. XVII, p. 27.

Milne Edwards, Hist. nat. des Crust., t. I, p. 435.

Pontuñus (pars). Bell, Bril. Crusl., p. 82.

P'latrosichus, Axisopls. De Haan, Fama japonica. Crust., p. 12.

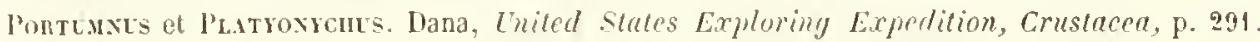

Xiva. Inc Leay, Anmulosa of Soulh Africa (dans l'ourage de Smith, intitulé Zoology of south . 1 rica, p. 62).

Le genre Platyonyque, tel que Lcach l'arait établi sous le nom de Portumuus, ne comprenait qu'une seule espèce, Ic $P$. latipes. Mais les recherches des carcinologistes plus modernes ont fait connaitre d'autres Portuniens, qui, tout en ayant avec celui-ci les plus étroites affinités, s'en distinguaicnt par quelques particularités de structure d'une importance sccondaire. Il a donc été nécessaire de modifier légèrement les caractères distinctifs que Leach avait assignés à son genre. Chez les Platyonycjues, la carapace est, en général, plus longue que cluez les autres Portuniens. Le front est très-étroit et denté. Les bords latéro-antérieurs sont divisés en cinq dents à pen près égales. Les fossettes des antennes internes sont petites et imparfaitement séparées des orbites. L'article basilaire des antennes extemes cst très-petit et n'occupe pas tout l'espace compris entre l'angle sousonhitaire interne et le front, mais est libre et ne peut pas clore complétement en dedans la fosse orbitaire. Les pattes-machoires externes sont longucs. L'endostome est garni en général de crêtes obliques latérales. Le plastron sternal est 
allongé et étroit. La suture meliaire n'oceupe que ses deux derniers articles. L'abdomen présente tantòt cinq, tantòt sept articles mobiles. Les pattes n'olfrent rien de caracléristique.

\section{IDATYOYYCHLS LATHED.}

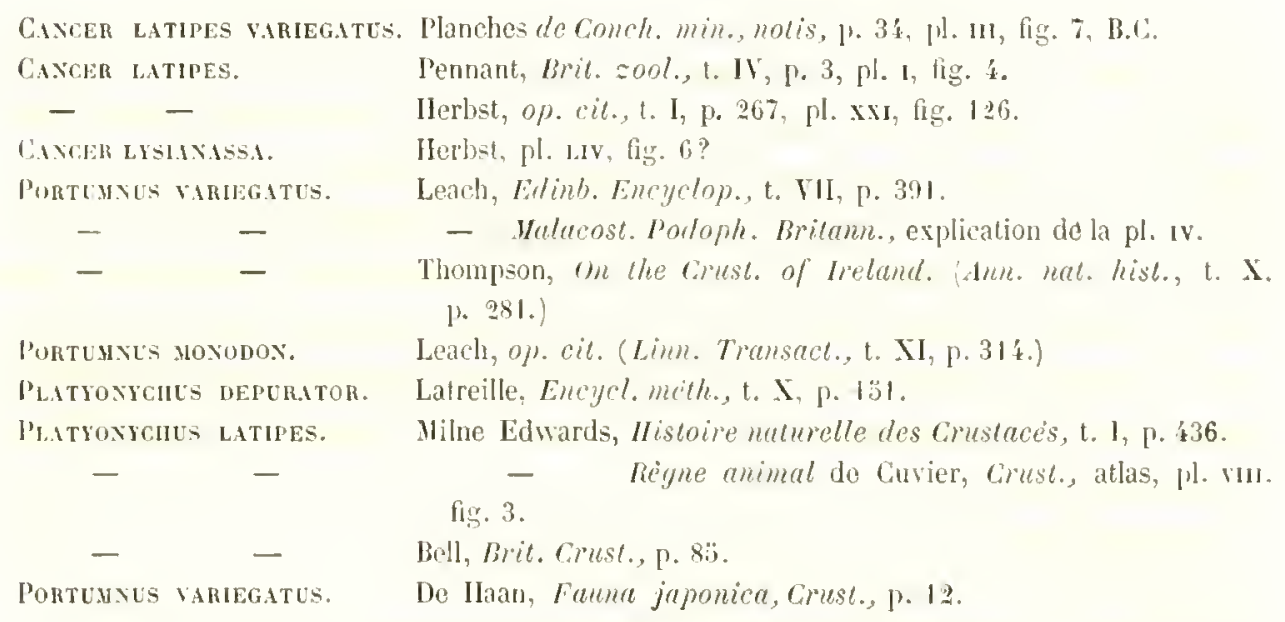

Carapace très-allongée. Fortement rétrécie postérieurement. Complétement lisse. Bords latéro-antérieurs dirigés jresque directement en arrière et armés de cinq dents très-petites et à hase très-latrge. Front avancé et découpé en cincy dents, la médiane plus avancée, les evternes olutuses. Pattes-màchoires allongres. Pattes antéricures tourtes et disposécs de faron ì s'appliquer exactenent contre la région faciale. Bras lisse; avant-lras armé d'une épine ì son anghe antero-interne. Hain lisse en dehors et dépourvue d'épine. Doights courts. larges et comprimés latéralement. Pattes suivantes élargies. Pied comprimé, doigt lanréolé. Dernier article des pattes-nageoires long et pointu. Ablomen du màte romposé de énq anneaux, et remarquahle par sa forme de languette tres-allongín.

Couleur grise marbrée de taches verlitres.

Laryeur de la carapace $0^{\mathrm{m}}, 022$, longueur $0^{\mathrm{m}}, 022$.

Mabilntion. - La Manche, nos rótes oríanipues, la Héditerranée. Cette espèce. très-bien conformće pour la natation, vit cnfouie dans le sable, au niveau ules basses matrées.

Colleclion du huscum. 


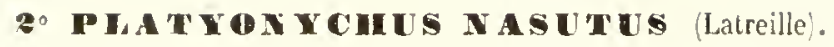

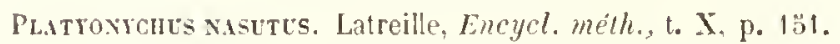

- - Milne Edwards, Hist. nut. des Crust., t. I, p. 438.

- - Lucas. Exploration de l'Algeric, Crust., p. 1', pl. 11, fig. 3.

Carapace très-élargie en avant, très-rétrécie postérieurement. Régions bien risibles. Bords latéro-antéricurs arqués et découpés en cinq dents assez standes; la première est large et échancrée au sommet de façon à représenter un lobe bifide. Front très-avancé et divisé en trois lobes, dont le médian est beaucoup plus proéminent que les autres. Pattes antérieures très-courtes. Bras lisse. Arant-bras armé d'une épine ì son angle antéro-interne. Main petite, carénée en dehors et dépourvue d'épine. Pattes suivantes comprimées latéralement. Dernier article des pattes-nageoires long et très-pointu. Abdomen du màle allongé et en forme de languette.

Couleur brune.

Largeur de la carajace, $0^{\mathrm{m}}, 025$, longmeur $0^{\mathrm{m}}, 022$.

Habitalion. - Mer Méditerranée, où il est assez rare.

La forme de la carapace, renflée antérieurement, la disposition de la premiere dent du Lord latéro-antérieur, et celle du front suflisent pour faire facilement distinguer cette espèce de la précédente.

Collection du Muséum.

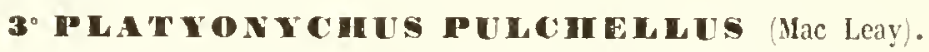

Xalia pulcielca. Mac Leay Ammulosa of South Africa (dans l'ourrage de Smith, Zoology of South Africa), p. 62, pl. In.

Carapace très-renflée antérieurement, rétrécie postérieurement: très-bosselée. surtout sur la région gastrique, à la partie antérienre de la région cardiaque et sur la ligne épibranchiale. Bords latéro-antérieurs courbes divisés en cinq dents, dont la première, obtuse, est échancréc au sommet, de façon à paraître bifide. Front très-avancé et dirisé d'une manière peu distincte en trois lobes, dont l'antérieur est le plus proéminent. Pattes antérieures courtes. Bras lisse. Arant-bras armé 
d'une épine à son anĝ̣e antéro-interne. Main courte et carénée. Pattes suirantes flargies. Doigt lancéolé.

Conleur d'un rose clair, avee des reflets verdâtres.

Largeur te la carapace. $0^{\text {ma }}, 018$, longueur $0^{\text {ma }}, 016$.

Ilabitation. - Cote sud de I Afrique.

Cette espece, lont Mac'-Lay arait formé le genre Xaiva. présente l'anatogie la plus grande avee le Platyonychus nasutus, dont il ne dillère que par les bossehures de la carapace. Le front, les dents des bords latéro-antérieur's étant exactement semblables dans ces deux espèces.

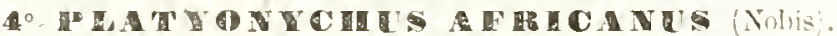

Pl. XXXI, fig. 2.

Carapace très-allongée, presque lisse. Bords latúro-antépleurs se réuniscint anx latéro-postérieurs par un angle très-obtus. Les premiers, découpés ro cinct petites dents dirigées en arant et sensiblement égales. Front peu arancé di jeente hécoupé en quatre dents oltuses; les deux médianes très-putites et très-rapprochies; les latérales sur lo même plan et beaucoup plus larges. Orbites larges. Bortl sourcilier dreoupé par tenx scissures linéares. Pattes antérleures faibles el courtes. Bras lisse. Arant-lias portant une épine à son angle antéro-interne. Nain carénée en dessus, mais lisse en dehors. Pattes suirantes grètes.

Cette espice est tonjours de tris-petite taille, quelques millimitres seulement.

Ilabitation. - Baie de Simon, còte d'Afrique.

La forme du front ne permet de confondre cette espece arec ancune antle du mème grenre.

Collection du llusce Britannique.

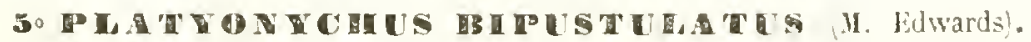

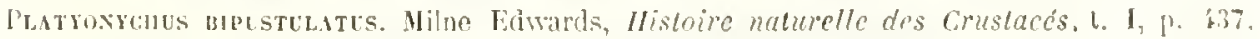
נ). xint, fig. $7-10$.

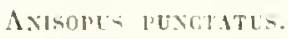

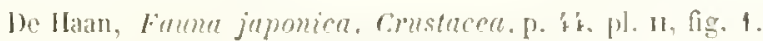

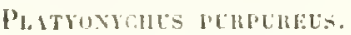

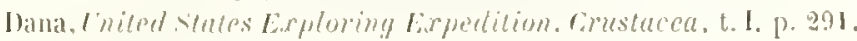
pl. xust, fig. 3 .

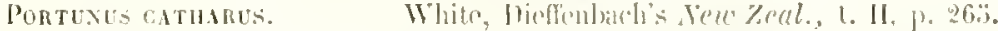

Carapare élargie, prespue circulaire, tres-finement granulense. liégions à peine

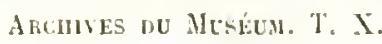


marquées. Bords latéro-antérieurs régulièrement arqués et déconpés en cinq dents grandes et fortement dirigées en arant. Front peu arancé, armé de quatre petites dents, les médianes plus saillantes que les latérales. Bord somreilier divisé en trois lobes par deux scissures, lobe médian épineux. Pattes antérieures médiocres. Bras lisse. Irant-Iras armé d'une épine à son angle antéro-interne. Main fortement carénée, à carènes granuleuses, et portant une petite épine au-dessus de la base du pouce, du côté interne. Pattes de la deuxième paire très-longues et très-rolustes, surtout chez le mâle. Au-dessus de l'articulation de la jambe, le bord de la cuisse se relève en forme de crète. Pied falciforme et a bord supérieur fortement cannelé. Pattes des troisième et quatrième paires ordinaires. Pattes nageuses, larges et trapues. Doigt large et arrondi. Abdomen du mâle composé de sept segrments distinets.

Cette espece peut atteindre une taille considérable; on rencontre des individus qui n'ont que quelques millimètres, ef d'autres dont la carapace a près de 10 cent. de large sur 7 de long.

Couleur jaunâtre avec un pointillé pourpre très-seré à la partie postéricure des réçons branchiales et de la réǵgion lrépatique.

IIabitation. - Les còtes du Chili et les mers de l'Océanie et des Indes.

Les différences de taille et de coloration que l'on remarque chez les divers individus de cette espèce ont amené plusieurs auteurs à considérer comme distinctes certaines formes qui ne sont que des passages l'un seul et même type spécifique. C'est ainsi que l'on laissait le nom de P. bipustulatus aux jeunes individus dont la forme était plus allongée et la coloration à peine indiquée; on appelait D. purpureus les rieux individus dont les couleurs étaient brillantes et la carapace très-large ; on réservait le nom de Punctutus ì ceus dont le bouclier céphalo-tlıracilpue était un peu plus granuleux et les dents médianes du front un peu plus avancées. Nais, eràce aux richesses accumulées dans la collection du Muséun , jai pu, en examinant près de trente individus de tont âge, me convaincre que toutes ces différences n'étaient que transitoires, et que l'on n'arait affaire qu ì une senle et même espèce.

De tous les Portuniens, le Platyonychus bipustulatus est le seul dont l'abdomen présente sept anneaux distinets. Aussi quelques autenrs ont-ils roulu be prendre pour le type d'une nouvelle division générique à laquelle ils appliquaient le nom de Platyonychus, réservant celui de Portumnus pour les $P$. latipes et $P$. nasutus; mais la disposition de la région antennaire étant la mème chez tous ces 
Crustacés, il me parait phus ronforme à leurs aflinités véritables de les grouper ensemble; d'ailleurs la forme de la caraface, qui est plus élargie chez le l'. bipuslulatus que dims les autres espèces que nous avons examinées, varie aree l'ticre: chez les jeunes, en effet, elle est beauroup phus allongée.

Collection du \luséum.

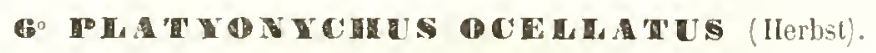

PI. XXYiI, fig. 4.

Caxcer ocellates. Herbst, op. ril.,pl. xux, fig, 4.

Pontuxs metus. Say, crust. of Thiled Stales acad. of Philad., t. I, p. 62, p]. Iv. fig. 4 .

P'Latrowiches ocellatis. Latreille, Encyct. méth., t. XYI, P. 132.

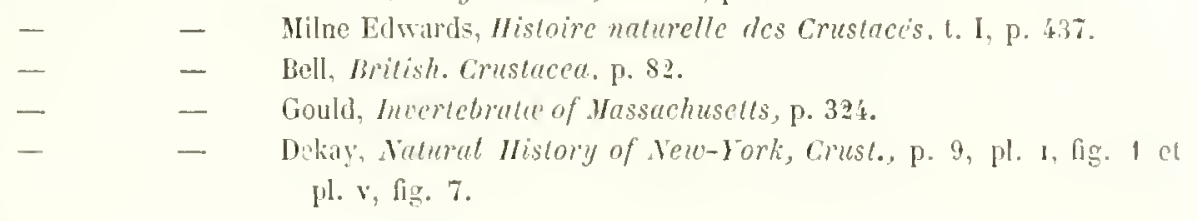

Carapace élargie, très-finement granuleuse el à régions à peine marquécs. Bords latéro-antérieurs découpés en cing dents bien séparées. aighës et dirigrées en avant. Front étroit el divisé en trois dents; la médiane longue et aiguë, les litérales plus courtes. Bord sourcilier droit el divisé par une seule scissure. Pattes-màchoires externes longues, leur troisième article profoudénent échaneré en dedans pour l'insertion de la tiggelle mobile. Endostome lisse. Pattes antériemes médiocres. Bris portant de fines denticulations à son bord antérient. Avant-bris armé de deux épines, l’une à son angle antéro-interne. l’autre sur sal face externe. Hain traversée longitudinalement par des carenes un peu grannleuses, el portant une épine au-dessus de la base du pouce du còté interne. Pattes ambulatoires courtes et grềles. Dernier article des pattes-nageoires lare et ovalaire. Abdomen du mâte en forme de languette. comjosé de cinq anneaux, le sepptième très-petit et comme enclaré dans le sixiène.

Coulenr jaunitre, avec de petites tikdes ronges.

Largenerr de la carapace, $0^{\mathrm{m}}, 05_{1}$; lonģueur, $0^{\mathrm{m}}, 042$.

Habitation. Cồtes des Etats-Unis, golle dı Mesique. 
Cette espèce a, par sa forme générale, de yrandes analogies avec le $P$. bipusurlatus; elle en differe cependant par la forme du front, oì existe une dent médiane. par l'aḷsence d'épine sur le bord sourcilier, et par le nombre des anneaux de l'abdomen, qui est de cinq au lieu de sept.

Collection du Mluséum.

\section{Gente PSAMMOGARGINUS.}

Pontuxis 'pars. Desmarest, Crusluces fossiles. p. 87.

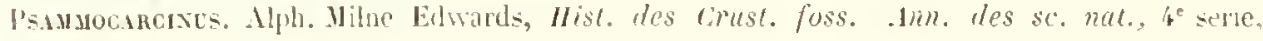
1. XIV, 1). 975 .)

Cette nouvelle division générique ne comprend qu'une seule espèce fossile. comnue déjà depuis fort longtemps et décrite par Desmatrest sous le nom de Portumus hericurti. Ce genre se distingue facilement des Platyonyques par l'existence de chaque còte de la carapace d'une longne corne latérale, portant elle-mène une ou deux petites dents. A ce caractère, d'une très-grande importance. viennent s’en ajouter plusieurs autres. Le bord sourcilier est continu, droit, et ne présente ancune trace de scissure linéaire. Les orbites sont d'une profondeur considérable. Les bords latéro-postérieurs de la carapace, au lien d'ùtre échancrés en arrière pour recevoir la base des pattes de la cinquième paire, sont droits et se réunissen! carrément au bord postérieur.

\section{ESPECE FOSSILE.}

Psamiocincixus inericanti Desmarest).

Portexts hencinti. Desmarest, Cirust. foss., p. 87, pl. v, Gg.

Psampocarcints ienicarti. Alph. Milne Euwards, op.cil., p. 279 , pl. 1x, fig. 1 el pl. x. 


\title{
GROUPE DES LISSOC.IRCINIENS.
}

\section{Genre LISSOGARGINUS.}

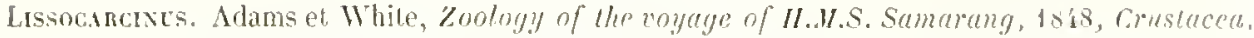 \\ p. 40 . \\ - Wana, Iniled stutes Exploring Lirped., Crust., t. I, p. 2ss.
}

Ce grenre a été établi en 18/s, pro MII. Arlams et White, pour me petite espèce de Portuniens nouvelle pour la science. Mais M. Dana ayant découvert un autre représentant du même type, qui, par l'ensemble de ses caracteres. ne pourait en être séparé géneriquement, fut oldig̣é de modifier légèrement les linites de re petit grouje.

La carapace est orbiculaire ou mème phus longue que large, et léxè̀rement unvexe. Les bords latéro-antérieurs sont armés de eing dents. Le front est lamelleux ef très-arancé. L'article hasilaire des antennes internes est allongé. el se prolongere un peu dans le eanthus interne de l'orbitr. La tigedle mobile est insérée sous le front et exclue do l'orbite. Pattes antérieures tries-courtes et trapues. Paltes antbulatoires conrtes, à doigt étroit el pointu.

Par leur forme sémérale, les Lissocarcinicns se rapprochent beaucoup des Platyonyques, mais ils en dillèrent par la disposition de la région antemaire.

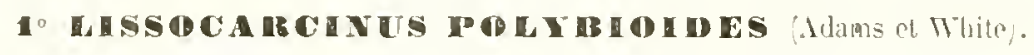

Lissocincixus pourbioldes. Adams et White, Zoology of the royage of 11 . . . s. Samaramy. crustacea. 1. iti, pl, xi, fig. ¿..

Carapace allongre, lisse, traversée pall une liçne épibranchiale saillante et presque droite. Bords latéro-antérieurs se rémnissant par un angle à peine marqué. armes de cinq dents petites, à base large, dirigées en arant et sensiblement rigales entre elles. Front lamellens, tress-avanéé, réçulièrement arqué, presentant sur la ligne médiane une échancrure étroite et triangulaire. Angle sus-orbitaire interne constituant une dent froutale petite et aiguë. Onbite étroite et pen profonde. Bord 
sourcilier divisé par deux scissures étroites. Pattes antérieures courtes. Bras lisse et court. Avant-bras portant deux très-petites épines: l'une à l'angle antérointerne, l’antre sur la face externe. Main courte, renflée, carénée en dessus. excavée en dedans de façon à s'appliquer exactement contre la région buecale armée de deux épines an-dessus de la base du ponce. Pattes ambula toires courtes et comprimées latéralement. Pattes natatoires longues. Cuisse large et aplatie. Dernier article ovalaire.

Largeur de la carapace $0^{\mathrm{m}}, 013$; longueur $0^{\mathrm{nd}}, 013$.

Ilabitation. - Trouvé sur bambou flottant en pleine mer dans l'océan Indien.

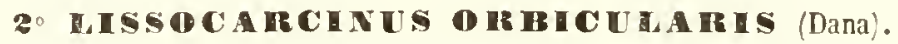

Lissocarcines orbicularis. Dana, L'nited Slates Exploring Expedition, Crustacea, t. , p. 288, pl. xyın, fig. 1.

Carapace presque orbiculaire, un peu plus large que longue, complétement lisse. Bords Jatéro-antérieurs se continuant par une courbure régulière avee les bords latéraux postérieurs et plutôt lobés que dentés. Front lamelleux arancé, non divisé, arqué et se prolongeant un peu en pointe sur la liggne médiane. Cavités orlitaires profondes et très-étroites. Pattes antérieures courtes et trapues. Bras lisse. Avant-bras portant un tubereule spiniforme ì son angle antéro-interne. Main hicarénée en dessus et non épineuse; pouce garni en dessus d'une petite crète tranchante. Pattes ambulatoires très-courtes et très-grêles. Pattes natatoires également petiles. Cuisse cylindrique el presque semblable aux précédentes. Dernier article aigu et lancéolé.

Conleur jannâtre avec de grandes taches d'un rouge brun sur la carapace et les pattes.

largeur de la carapace $0^{\mathrm{m}}, 012$; longueur $0^{\mathrm{m}}, 010$.

Ilabitation. - Récifs madréporiques de l'arehipel Viti.

Cette espèce se distingue facilement de la précédente par la forme orbiculaire de la carapace, l'absence d'échancrure médiane sur le front, et la gracilité des paltes. 


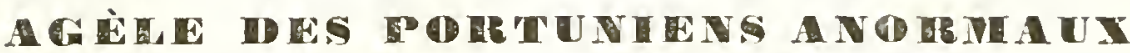

Front spatuliforme et inlléchi. Orbites et pélonentes oculaires longs et occupant presque toute la largeur de la carapace. Angles orbitaires se prolongeant beaucoup plus en dehors que la portion suivante du bord latiral et suivis seulement d'une petite épine.

\section{Genre PODOPHTHALMUS.}

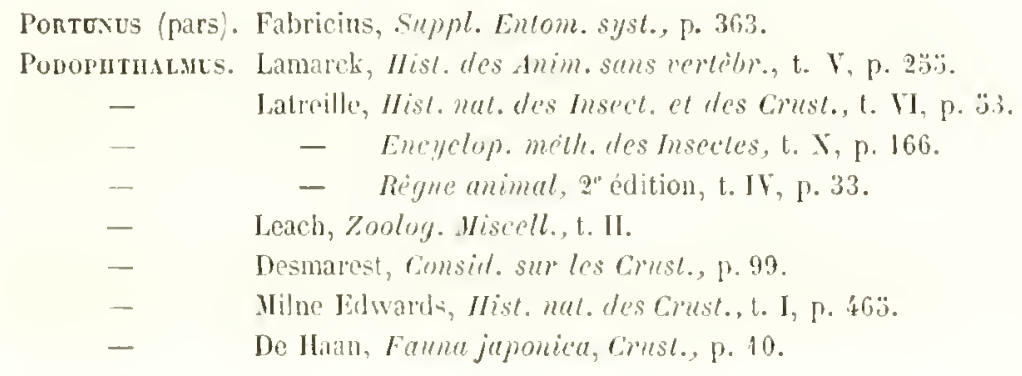

Ce grenre, conme son nom l'indigute, est caractérisé par l'énorme développement des pédoncules oculaires qui égülent chacun la moitié de la largeur te la carapace.

Ia carapace se termine en avant, non plus far un hord arqué, mais par un bord droit on presque droit, formé en majeure partic par les parois supérieures des orbites. Le bouclier céphalo-thoracique semble alors avoir été brusquenent tronqué en arant el ressemble à celui d'un Teptunus qui serai brisé suivant une lizne qui réunirait les deux cornes latérales. De chaque còté de la carapace exisme une épine très-aigué, diriguée en arant è au-dessous de laquelle est loggé l’ocil propremsent dit quand son pédoncule est replié dans la grouttière orhitaire. Les récrions sont peu marquées. Le front, constitué par le bord anterieur de la carapace. ollre vers sa partie médiane, entre la base des pédoncules aculaires, un prolongentent presque linéare qui s'álargit heanconp en dessons, de firgon à former la paroi supéricure des fossettes amtenmulaires, lesquedles se frourent situées sunt: la base des púdonoules orulaires, disposition complétement difrérente de celle qui existe chez les Portuniens normanx. Lia tigette mobile de ces atppendices est bean- 
couj plus longue que la fossette antennulaire. el ne peut s'y reployer. L'article basilaire des antennes externes occupe tout l'espace compris entre l'angle sousorlutiare interne et l'angle externe du prolongement supéricur du front contre lequel il s'appuie. Les orbites sont formées par une gouttière qui s'étend du prolongement frontal à l'extrémité de la corne latérale, et. par consépuent, elles uccupent toute la largeur de la carapace. Les pédoncules oculaires, extrèmement longs el grềles, sont susceptibles d'exćcuter des mourements très-étendus. L'endostome fort large, mais court, est clépourvu des crêtes ohliques qui servent à limiter en dedans l'orifice du canal expirateur. Les pattes-màchoires externes n'necupent pas toute la largeur du cadre buceal. et ne peurent se joindre sur la ligne médiane. Leur article basilaire très-court est álargi à sa base; le troisième article présente une forme presque triangulaire à eause de la profondeur de l'echancrure destinée à l'insertion de la tigehle molile formée d'articles remarquablement gros et longs. Les pattes sont conformées sur le nème plan que celles des Neptunes. Comme chez ces derniers. la suture médiane du sternum en ocupe les trois Jemiers articles Thoraciques.

Entre le genre Podophthalmus et Je genre Neptunus, les points de similitude sont si nonthrenx qu'on pourrait considérer celui-ci comme un Neptune anormal.

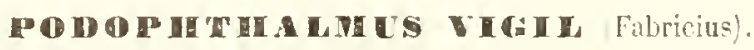

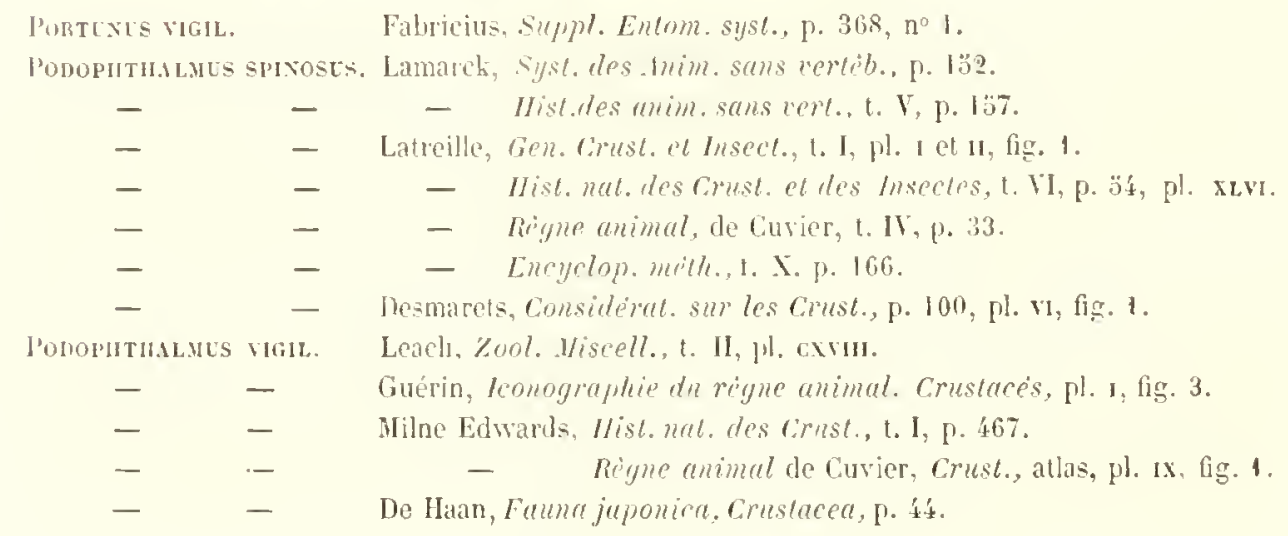

Carapace aplatie. un peu sranuleuse sur son hord anterieur. sur la ligne épibranchiale el sur les réçuons branchiales. En arrière de la corne latérale destincé 


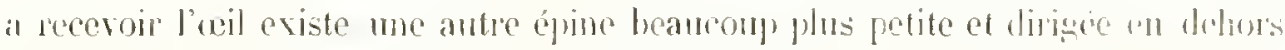
ot en arrière. Bord postérieur de la caripare droil et large. Patter antérieurce trés-longues. Bras anmé de trois épines sur son bord anterienr et de deur sur son borl postéreur, l'une a l'extrémité, l'autre subméliane. Avant-hras portant denx éphes. l'une ì son angle antéro-interne, l'antre un peu plus petite au bord antérieur de sa face exterme. Main allongée. carénée. la carene de la face

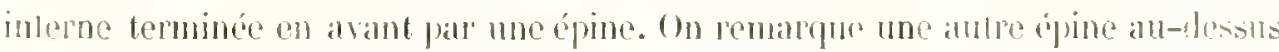

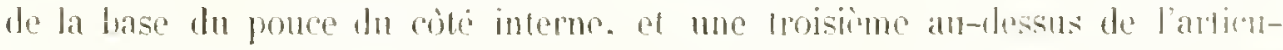
lattioil de l'avant-bras. Doigts forts, cammeles of armés de dente tamehantes qui s'engrencent exactement. Pattes ambubatoires longres et comprimés.

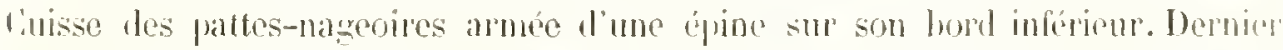

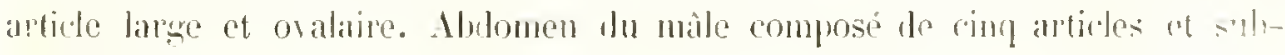
triangolaire.

Couleur brin rougeâtre.

Largeur de la carapace, $0^{\mathrm{m}} .110$; longueur, $0^{\mathrm{m}}, 042$.

Ilabitation. - Lîle de France, l'ile Bombon, la mer des Indes. Jara, les iles Philippines, la mer du Jalpon.

\section{ESPECE FOSSILE.}

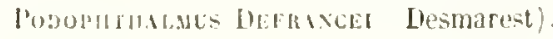

Desmareat, Crusturess fossiles, 1.,88, 11. 1. fig. 6, 7,8 .

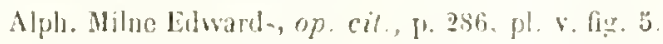




\section{LISTE DES ESPECES CITÉES DANS CE MÉMORE}

\begin{tabular}{|c|c|c|c|c|}
\hline lehelous & $\ldots \ldots \ldots$ & & & \\
\hline 1. & 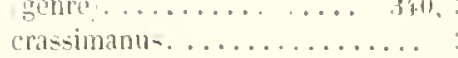 & 311 & Cancer vedhatus.... & \\
\hline 1. & 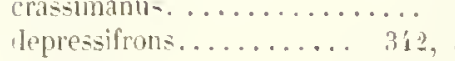 & 319 & C. & \\
\hline . 1. & tus........... & 31. & C. & \\
\hline 1. & 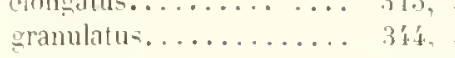 & $3+4$ & ar & \\
\hline 1. & $\ldots \ldots \ldots \ldots \ldots \ldots \ldots \ldots$ & $34 i$ & $\cdots \ldots \ldots \ldots \ldots \ldots$ & \\
\hline 1. & pubesecns.............. 3in, & 3 & $\ldots \ldots \ldots \ldots \ldots \ldots$ & \\
\hline 1. & ruber. . . . . . . . . 3 & : & $\ldots \ldots \ldots \ldots \ldots \ldots \ldots$ & \\
\hline 1. & spinimanus............ & 3 & ntus............. . & \\
\hline 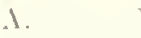 & Whitri............ 3i3. & 31 & $\ldots \ldots \ldots \ldots \ldots$ & \\
\hline mplituite & 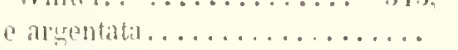 & 31 & $13 \ldots \ldots \ldots \ldots \ldots \ldots$ & \\
\hline . & 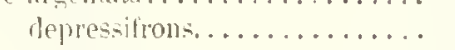 & $\begin{array}{l}332 \\
342\end{array}$ & $\ldots \ldots \ldots \ldots \ldots \ldots$ & \\
\hline & gladialor............ 330 & 342 & onpe des. ............... & \\
\hline 1. & uricillimi................. & $33 \%$ & 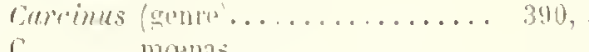 & \\
\hline . & Ilaanii.................. & 330 & $\cdots \ldots \ldots \ldots \ldots \ldots$ & \\
\hline & hastatoides............... & 332 & 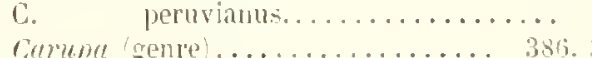 & \\
\hline & 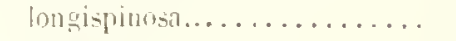 & 337 & $\begin{array}{l}\text { Corupe gente } \ldots \ldots \ldots \ldots \ldots \ldots \ldots \\
\text { C. }\end{array}$ & \\
\hline & 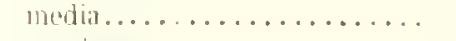 & 331 & $\begin{array}{l}\cdots \cdots \ldots \ldots \ldots \ldots \\
e-\ldots \ldots \ldots \ldots \ldots\end{array}$ & \\
\hline & speciosil............... & $3+4$ & (es.............. & \\
\hline & tenuipes................. & $33 \ddot{3}$ & $\begin{array}{l}\cdots \cdots \cdots \cdots \cdots \cdots \\
\cdots \cdots \cdots \cdots \cdots\end{array}$ & \\
\hline . & vigilans................. & 336 & $\cdots \cdots \cdots \cdots \cdots$ & \\
\hline nisolus i & punctatis.................. & 113 & $\cdots \cdots \cdots \cdots \cdots \cdots$ & \\
\hline e! & $\ldots \ldots \ldots \ldots \ldots \ldots \ldots$ & 329 & $\begin{array}{l}\cdots \cdots \cdots \cdots \cdots \\
\cdots \cdots \cdots \cdots \cdots\end{array}$ & \\
\hline int & $\ldots \ldots \ldots \ldots \ldots$ & 3.36 & s......... & \\
\hline & $\ldots \ldots \ldots \ldots \ldots$ & 393 & ( & \\
\hline & $\ldots \ldots \ldots \ldots \ldots \ldots$ & 320 & $\cdots \cdots$ & \\
\hline & $\ldots \ldots \ldots \ldots \ldots \ldots$ & 401 & C. & \\
\hline & $\ldots \ldots \ldots \ldots \ldots \ldots$ & $3 \pi$ & $\begin{array}{l}\text { sexd } \\
\text { smit }\end{array}$ & \\
\hline & .......... & $39: 3$ & $\begin{array}{l}\cdots \cdots \\
\cdots \cdots\end{array}$ & \\
\hline gra & $\ldots \ldots \ldots \ldots \ldots \ldots$ & 391 & $\begin{array}{l}\text { C. varlega } \\
\text { Enoplonolus / gen }\end{array}$ & \\
\hline & …… & 332 & 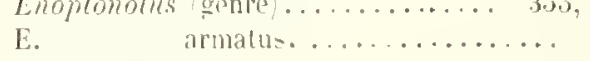 & \\
\hline & alipes..................... & औl & $\ldots \ldots \ldots \ldots \ldots$ & \\
\hline & tipes variegratus............ & 411 & $\ldots \ldots \ldots \ldots \ldots \ldots$ & \\
\hline s & sianassa.................. & ill & din. $\ldots \ldots \ldots \ldots \ldots \ldots$ & \\
\hline a. & ris............... & 371 & $\cdots \cdots \cdots \cdots \cdots$ & \\
\hline & nenestho.............. & 330 & $\ldots \ldots \ldots \ldots$ & \\
\hline & & 390 & $\begin{array}{l}\text { G. } \\
\text { G. }\end{array}$ & \\
\hline & $\ldots \ldots \ldots \ldots \ldots$ & 370 & $n \ldots \ldots \ldots \ldots \ldots$ & \\
\hline
\end{tabular}




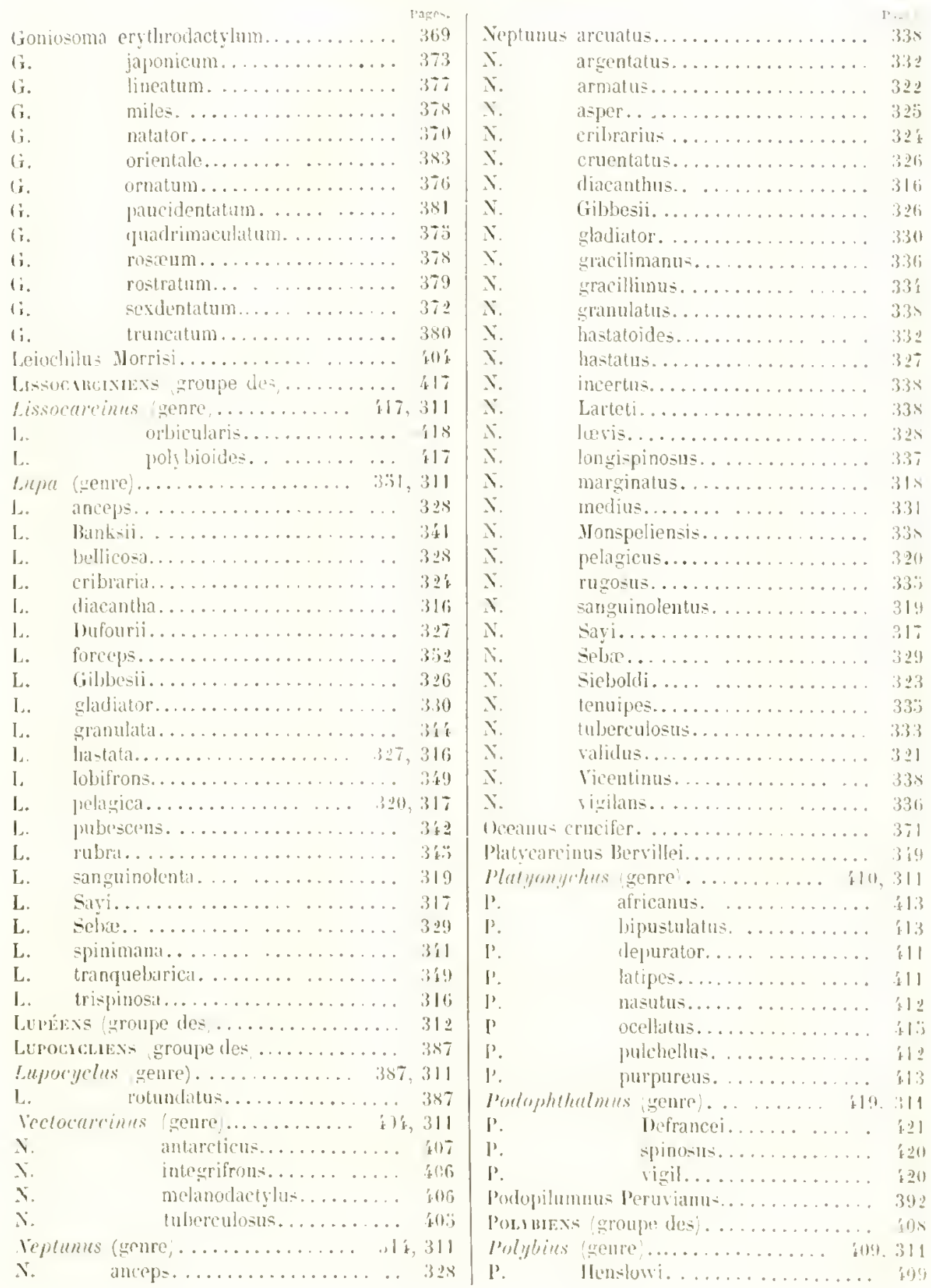




\begin{tabular}{|c|c|c|c|c|c|}
\hline & & & & & \\
\hline 3 & Ilomodoa.. . . . . . . . . . . & 411 & Portunus & 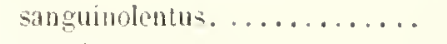 & 310 \\
\hline & variegatus............... & $\$ 11$ & P. & serratus. ................. & \\
\hline PORTLYII & ES ANORU IUX . .......... & 419 & l'. & sexdentatus.............. & \\
\hline ORTUXII & 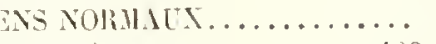 & 312 & l'. & manus. ............. & \\
\hline orluniles & (genre) . . . . . . & .311 & $\mathrm{P}$. & 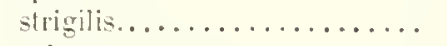 & \\
\hline & 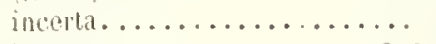 & fol i & P. & subcorrugalus............ & \\
\hline ortumes: & 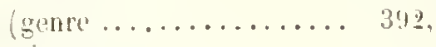 & 311 & P. & uebaricus. ............. & \\
\hline P. & 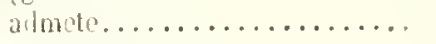 & 256 & P. & ............... & \\
\hline 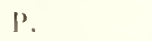 & $1{ }^{\prime} \ldots \ldots \ldots \ldots \ldots \ldots$ & $3 i$ & $l^{\prime}$. & latus................ & \\
\hline . & $u=\ldots \ldots \ldots \ldots \ldots$ & 107 & P. & 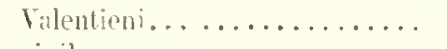 & \\
\hline & $u s \ldots \ldots \ldots \ldots \ldots \ldots$ & 399 & l. & 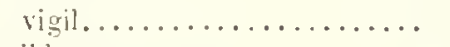 & \\
\hline ?. & 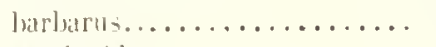 & 394 & Posidon । & ralidus.................... & \\
\hline 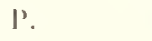 & des................ & 403 & Istemmoc & arcines genre ....... \$16, & \\
\hline & $\ldots \ldots \ldots \ldots \ldots$ & $\$ 13$ & & Ilericirti......... . & \\
\hline 1. & $11=\ldots \ldots \ldots \ldots \ldots$ & 101 & Srylla (g & gente) $\ldots \ldots \ldots \ldots \ldots \ldots$. 347 & \\
\hline P. & $\ldots \ldots \ldots \ldots \ldots \ldots$ & $36 \%$ & $\therefore$ & 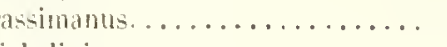 & \\
\hline ?. & $\ldots \ldots \ldots \ldots \ldots$ & 321 & $\therefore$ & ..................... & \\
\hline P. & . . . . . . . . . & 371 & S. & .................... & \\
\hline P. & $r \ldots \ldots \ldots \ldots \ldots \ldots$ & $39 \ddot{2}$ & s. & rica................ & \\
\hline 13. & $111=\ldots \ldots \ldots \ldots \ldots \ldots$ & 316 & Therelemite & a (quenre)............. 334 , & \\
\hline 1) & $119 \ldots \ldots \ldots \ldots \ldots$ & $39 !$ & $\mathrm{T}$ & allmete................ & \\
\hline ?. & yylus. $\ldots \ldots \ldots \ldots$ & $36 ; 9$ & $\mathrm{~T}$. & ta................... & 37 \\
\hline & $\ldots \ldots \ldots \ldots \ldots \ldots$ & $\because \because 3$ & 1 . & $=\ldots \ldots \ldots \ldots \ldots \ldots$ & . \\
\hline 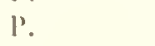 & $\ldots \ldots \ldots \ldots \ldots \ldots$ & 330 & 1 . & al. . . . . . . . . . & \\
\hline l'. & $i{ }^{\prime} \ldots \ldots \ldots \ldots \ldots$ & 396 & ' & $\ldots \ldots \ldots \ldots \ldots \ldots$ & $\sin$ \\
\hline P. & $\therefore \ldots \ldots \ldots \ldots \ldots$ & 332 & $\mathrm{~T}$ & ripip................ & \\
\hline , & $\ldots \ldots \ldots \ldots \ldots \quad 32 i$ & 316 & 1. & nia............... & (ii) \\
\hline 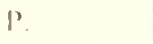 & $\ldots \ldots \ldots \ldots \ldots$ & .393 & ' & ................... & \\
\hline 1.. & $\ldots \ldots \ldots \ldots \ldots \ldots$ & 190 & T. & a........... 36.0 & .360 \\
\hline 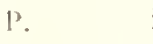 & . . . . . . . & 406 & $\%$. & 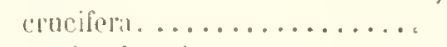 & $3 i \mid$ \\
\hline 1 & $\ldots \ldots \ldots \ldots \ldots$ & $3\{9$ & $\mathrm{T}$. & laclyla.............. & $36 !$ \\
\hline 1 & n............. & $3 !$ & T. & $\ldots \ldots \ldots \ldots \ldots \ldots \ldots$ & 3.58 \\
\hline . & $\ldots \ldots \ldots \ldots \ldots \ldots$ & 100 & $\mathrm{~T}$. & $\ldots \ldots \ldots \ldots \ldots \ldots$ & 370 \\
\hline 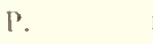 & $11 ; \ldots \ldots \ldots \ldots . .$. & 403 & T. & $\ldots \ldots \ldots \ldots \ldots \ldots \ldots$ & 362 \\
\hline 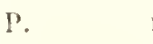 & .............. & $3 ! 17$ & $\mathrm{~T}$. & $i \ldots \ldots \ldots \ldots \ldots \ldots$ & 3,7 \\
\hline 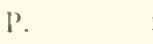 & $\ldots \ldots \ldots \ldots$ & 201.3 & $\mathrm{r}$. & $\ldots \ldots \ldots \ldots \ldots \ldots$ & 360 \\
\hline & $\ldots \ldots \ldots \ldots \ldots \ldots$ & $39 \dot{x}$ & $\mathrm{l}$. & $\ldots \ldots \ldots \ldots \ldots \ldots \ldots$ & $3: 8$ \\
\hline & $\ldots \ldots \ldots \ldots \ldots$ & 390 & l'. & $i \ldots \ldots \ldots \ldots \ldots \ldots$ & $3 \% \pi$ \\
\hline & $\ldots \ldots \ldots .320,: 317$ & $3 i l$ & $\mathrm{l}$. & $\ldots \ldots \ldots \ldots \ldots \ldots$ & 359 \\
\hline & $\ldots \ldots \ldots \ldots \ldots \ldots$ & 342 & $\mathrm{~T}$. & $\ldots \ldots \ldots \ldots \ldots \ldots$ & $36 t^{\prime}$ \\
\hline & $\ldots \ldots \ldots \ldots \ldots \ldots$ & $11: ;$ & $1 ?$ & $\ldots \ldots \ldots \ldots \ldots$ & $6 \pm$ \\
\hline & & $39: 3$ & $\mathrm{~T}$. & rei................ & 364 \\
\hline & $\cdots \ldots \ldots \ldots \ldots \ldots$ & $31 ; 0$ & $\mathrm{l}$. & $\ldots \ldots \ldots \ldots \ldots$ & \\
\hline & $\ldots \ldots \ldots \ldots \ldots \ldots$ & $3 !$ & 1 . & $s \ldots \ldots \ldots \ldots \ldots$ & \\
\hline & . & 39 & & onje des . . . . . . . & \\
\hline & tii. ............... & 399 & Xaiva julle & 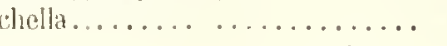 & \\
\hline . & 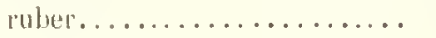 & $3 \%$ & & & \\
\hline
\end{tabular}




\title{
EXPLICATION DES PLANGHES
}

\author{
PL. XXYHI
}

1. Lips ronseps. Individu mile, de grandeur naturelle, rapporte de llaiti.

4 a. Region antemaire du mème, grossie.

1h. Riegion faciale du méme grossie, de faron à montrer les pattes-máchoires externes yut sa pulongent jusquen avant du front.

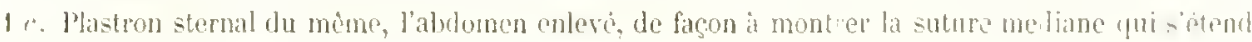
sur les quatre derniers articles.

11. Alidomen du mème.

1/. l'ince d'um femelle de la mitne espice vesur sa face interne.

$1 g$. La meme vue en dehors.

2. Neptcres SEB. Individu mile de grandeur naturelle, rapporte du Bré-il.

2a. Aldomen du mème.

\section{PL. XXIX.}

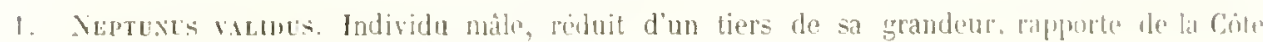
d'Or difique oecidentale,

11/. Mistron sternal et aldomen du mime.

1). Patte-nuchoire exterue, grosisic.

2. Neptexes sim. Individu male de gramleur naturelle, rapporte des cótes d's burrique.

2ul. Ilistron sternal at abdomen du minc.

2b. Pittr-machoire evterne, grosite.

PL. IXX.

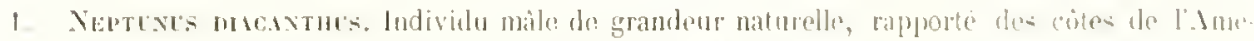
rique septentrionale. Viriste a front quallibilob.

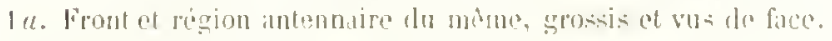

1h. Partie antirienre de la carapace du meme, grossie.

1\%. Plastion sternal et aldomen da nutme. 
14. Partie anterieure de la carapace dlun .r. diacanthus ordinaire, grossle.

te. Front et région antennaire du mème, grossis et vus de face.

1f. Pattemâchoire d'un N. lincamelus, grossie.

2. Neptuxus manovites. Individu mâle de grandeur naturelle, rapporté des cötes du liabrin

2u. Partie antérieure de la carapace du mème, grossie.

21. Plistron sternal el abdomen du méme.

2. Patte-mâcloire externe du même, grossie.

3. Neptryus asper. Individu male de grandeur naturelle, mporte res cotes ilu chili

3ı. Partie anterieure de la carapace dı même, grossie.

3. Plastron sternal du mime (l'abdomen manque en partie).

3i. Patte-mâchoire externe du mème, grossie.

\section{PL. XXXI.}

1 Neptixus Gibbesu. Individu miln, grossi, rapporte des cotes la la Laroline alu sul

i $\%$. Carapace de grandeur naturelle.

16. Plastron stemal et aljomen.

2. Neptus cru extatus. Individu màle de grandenr naturelle, rapporlé des Antille-.

211. Contour du front du mème, srosisi.

3. Neptuxus Lovis. Individu màle de grandeur naturelle, provenant de l'océan Inlien.

3a. Contour du front du meme, grossi.

3l. Jlistron sternal et abdomen du mème.

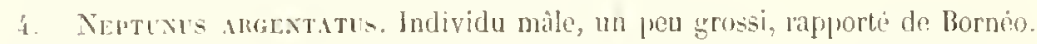

in. Contour du front du même, grosei.

ih. Aldomen du mime.

;. Neptuxis nerosts. Individu mảle, grossi, rapporté de l'Australie.

; $\iota$. Carapace du mène de srandeur naturehle.

ab. Plastron stemal et abilomen du même.

"i. Pince du mème, wo en dehors et grossie.

fi. Acherous Writer. Individu mảle de grandeur naturelle, rapporte de Bornéo

till. Contour da front, grosis.

fil. Pince du mème, vue en dehors.

fic. Abdomen alu mime.

\section{I'L. XXNH}

1. Achelous sprimaxus. Individu mâle de grandeur naturelle, rapporté des cutes du Chili. 1\%. Mastron strernal et abdomen du meme.

1\%. Jeune individu de la meme espece.

\section{PL. XXXIII.}

1. Acincoús nuber. Individu male do grandeur naturelle, rapporté des còtes du Bresil.

1 1. Région antennaire du meme. grossie. 
11. . 11,doman du mème.

2. Nevtuxts anmıtrs. Individu mâle, très-légèrement grossi, rapporte d'dustralie.

212. Abdomen du même.

3. Nertuxes nugoses. Indivitu mále, un peu srosit, rapporté d'Australie.

3a. Carajace de grandeur naturelle.

4. Goxiosoma Avizonox. Individu mâlo de grandeur naturelle, rapporti de la Youralle-Caledonte.

\& 2 . Pince du mème, voue en dehors.

\section{PL. XIXH.}

1. Achelors elozgates. Intividu mâle, un peu grossi, rapporté de l'archipel Viti.

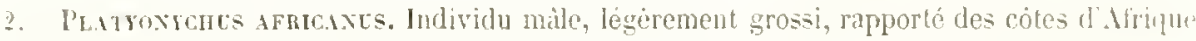

2) Contour du front du mème. grossi.

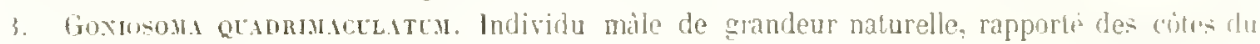
Ilalahar.

3u. Platron sternal et abdomen du mème.

4. Goxionom troxcitux. Individu màle de grandeur naturelle, des mers de l'Inde.

fu. Plastron sternal et ahdomen du mime.

\section{PL. SXYl.}

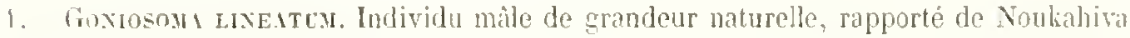

1\%. Fiont du mème, grossi.

11. Abdomen du mime.

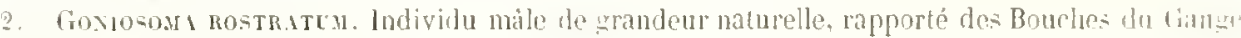

?u. Front du mème, grossi.

26. Abdomen du meme.

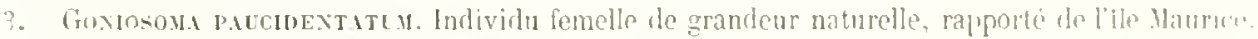

311. Reigion antennaire du menze, gronsice.

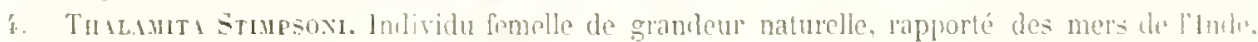

4h. Region antennaire du méme, grossie pour montrer l'article basilaire de l'antenne extrene winn! d'une linne de granulation:

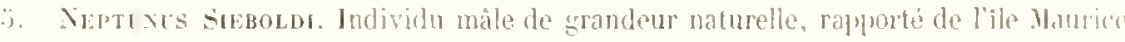

.j. Abdomen du mème.

\section{I'. IYXY.}

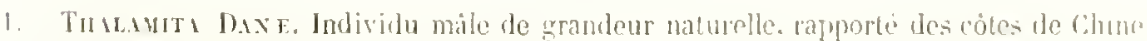

1 u. Hisitron strmal el abdomen du merme.

b. Pilte-micherire esterne, srositir.

Ic. Pince de granteur naturefle, vie on dolor:

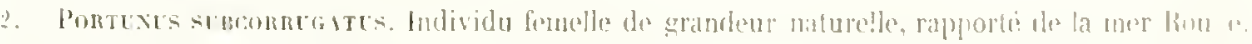

2u. Contour du front, grmsis.

21). Palto-matiolre externe, orosits.

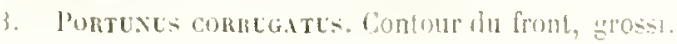


i. I'Litroxraus oceldatus. Individu mâle de grandeur naturefle, rapporte des côtes de l'Amrrique septentrionale.

i.

sh. Palte-máchoire externe, grossie.

\section{PL. XXXVII}

1. Vectochrcinus tebercllosts. Individu màlo de grandeur naturelle, rapporte de la Tismani: 11. liégion antennaire, grossie.

11. P'ince, vue dn còté externe.

1 $\because$. Iastron slernal et abdomen.

11. Plastron sternal, sans l'abdomen, de façon a montrer la suture merdiane qui s'étend sur to. deux derniers anneaux.

1/. Patte-mâchoire externe.

\section{PL. XYXVIII.}

1. Vectocinchis ixtegrifroxs. Individu màle de grandeur naturelle, maporte des mers it focéanie.

1". Kégion antennaire, grosisie.

16. Pince, vue du còte externe.

Ir. Ilastron sternal sans l'ahdomen, de facon à montrer la suture médhane qui s'etend sur less denx derniers anneaux.

1. Mlastron sternal et abdomen.

1/. Patte-màchoire externe. 


\section{ADDENDA}

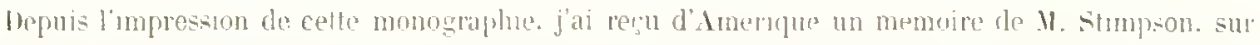
les rustacis du musée de l'institution smithsonnienne, dans lequel ce sarant fait connajtre un coptain nombre d'especes nouvelles de portuniens; el afin de rendre mon travail alu-si complet que posihle, je pense nécesaire d'indiquer les principaus faits introduits aim-i dans la science.

M. Stimpson a eru devoir établir, sons le nom de CALLIXECTEs, un genre noureau pour lo Teptmms tracanthus loy. p. 3fi), se fondant sur ce que l'angle antéro-externe du troisicme anticle de pattes-màchoires externes, est pointu et recourbé en dehors, et sur la forme particulierer de l'aldomen du màie. Mais, comme le dit lui-mene cet habile obserrateur, le lippl. Diarenthas. par sa forme genérale et ses antres caracteres, ne differe en rien des autres. Yeplumus. Et quant it li valeur que l'on doit assigner à la forme de l'abdomen du màle, elle ne me parait pas sullicante pour moliver l'utablissement d'une nouvello eaupe greniripue, puisque chez les jeunes individus dle n'es que tris-imparfaitement indiquée. Jajouterai que les caracteres tires de ligieres diflerences dans lal forme du troisieme article des pattes-michoires externes conduirait a faire parmi les Portunicns presque autant le genres qu'il y a l'mpreces.

Les formes nouvelles que .H. stimpion rupporte au genre . lelelous doivent prendre place dans in senre veptume, tel que je lai délimite ci-dessus. Je ne hornerai à indiquer les princifaux carac-

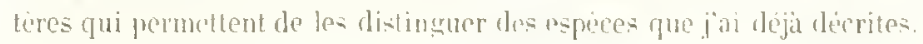

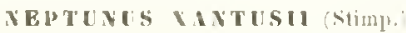

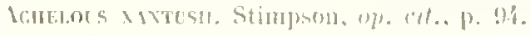

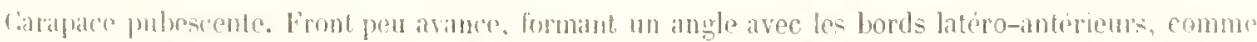

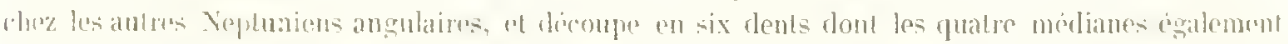

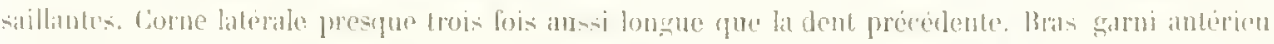

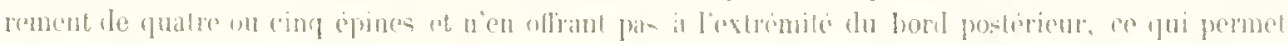

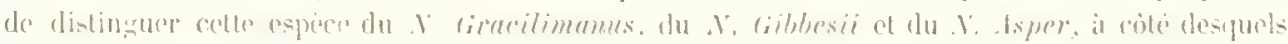

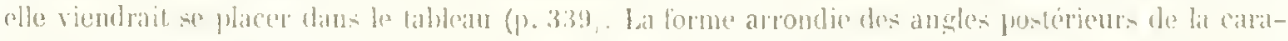

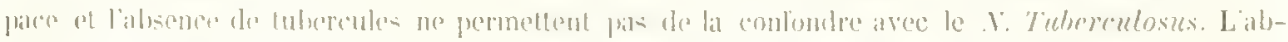

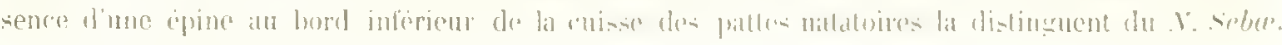

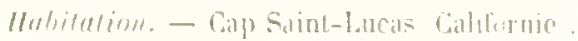

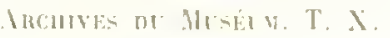




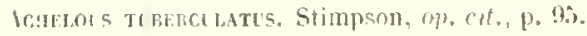

Cette espiece parait ètre estrèmement voisine de mon $X$. Tuberculosus. Cependant, d'apres la description que II. Stimpson en a flonnée, elle s’en distinguerait par la gracilité des pinces el par l'ah. sence d'épine a l'extrimite do bord posterienor du bras; de plus, la disposition des tubercules do la

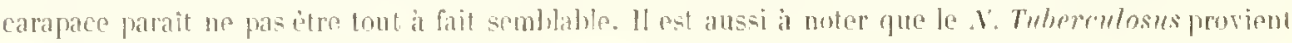

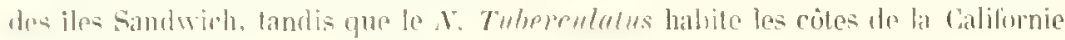

\section{NEPTUNUS OBDW AY: SHEM.}

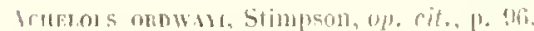

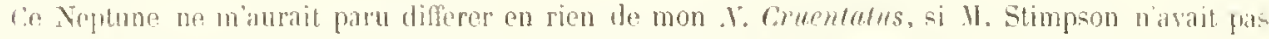
undique les granulations de la earapace comme existant seulement pres des bords latero-interieurs.

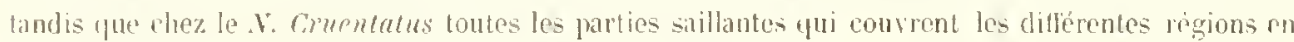
sunt hérisses. Liun el l'autre proviennent des Antilles.

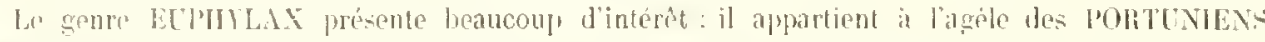

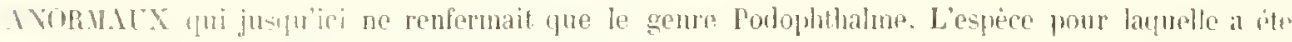

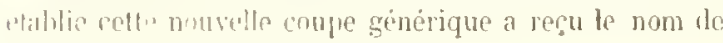

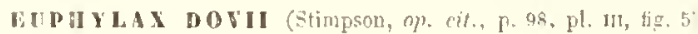

Carapace ovalaire, moitie plus large que longue, glabre et finement ponctuée. Front étroit entre

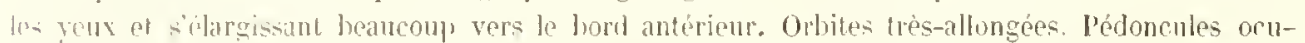

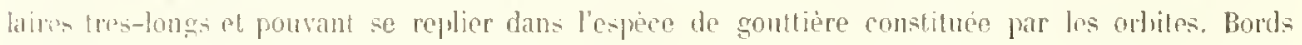
latero-anterieurs de la carajace plus courts que les bords Jatero-postérieurs, et olscurement disisés (1) cimp dents, la premiere, constituant langle orbitaire axterne, est beaucoup phus grande et phas saillante yue les iutres, qui sont spiniformes ot peu distinctes. Iras armés antérieurement ule truis ou fuatre petites duines. Arant-l)ras portant une épine sur son angle antéro-interne. Main traverséc par des carrines faillew, gramulers ou spinulemes. On ruit deux on truis tubercules allongés sur la fice interne du poigned, rerrière la base du pown. Doigt des pattes ambulatoires large et lancéolé. Cette Pipece provient the la cóte oupst de l'A nérique centrale.

le genre CRONuts a été propose par M. Stimpson pour recevoir l'. ichelous Ruber, espèco qui,

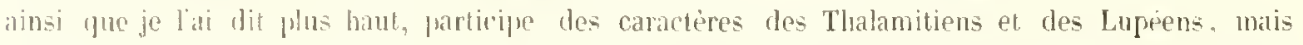
(qui cependant. ne me parail pas devoir ètre séparèe des autres dchelous. Elle relie ceux-ci aux Coniosomea, fonme le genre dehelous, consideré daus son ensemble. relie les Neptunes aux Thalaunitiens. 

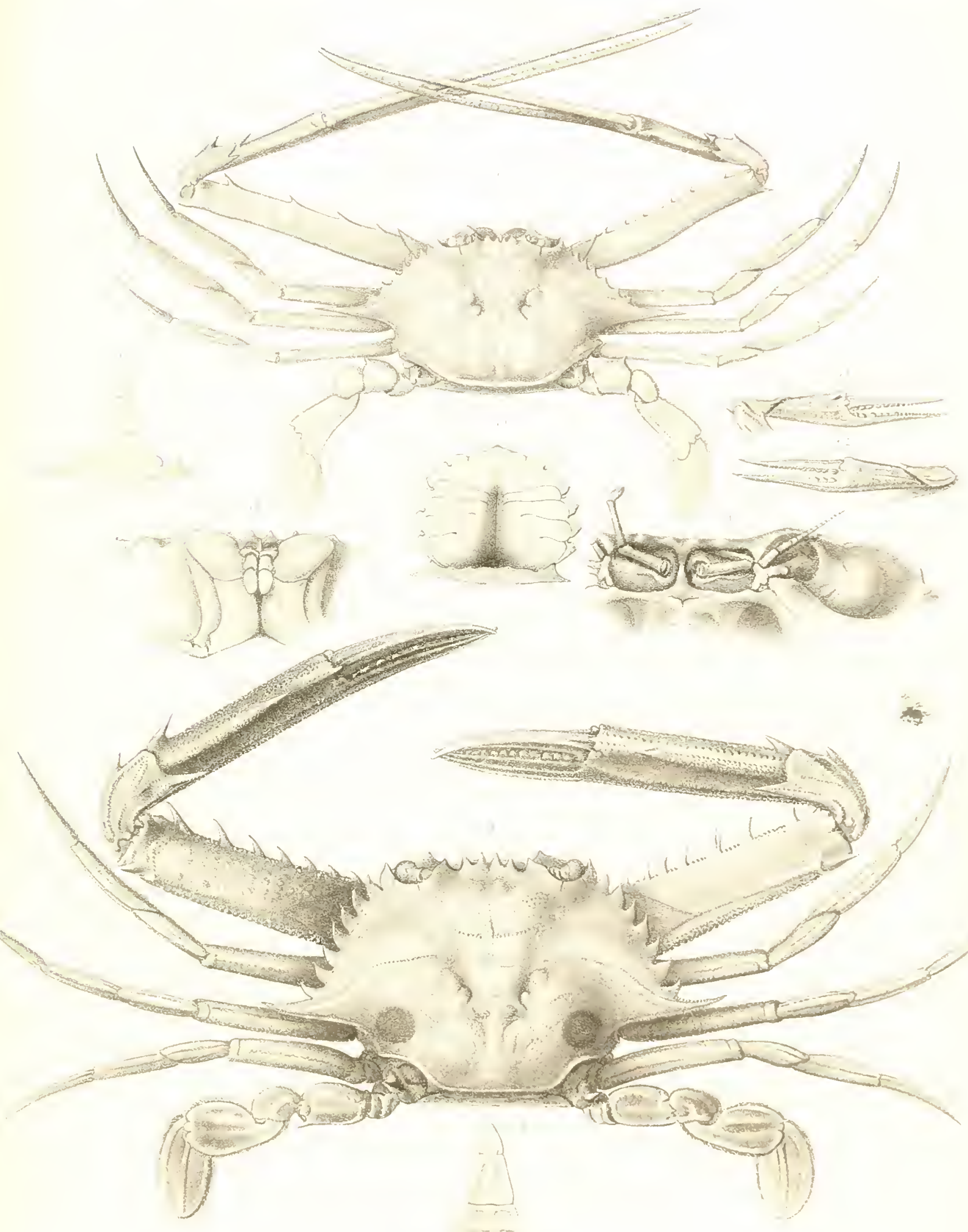



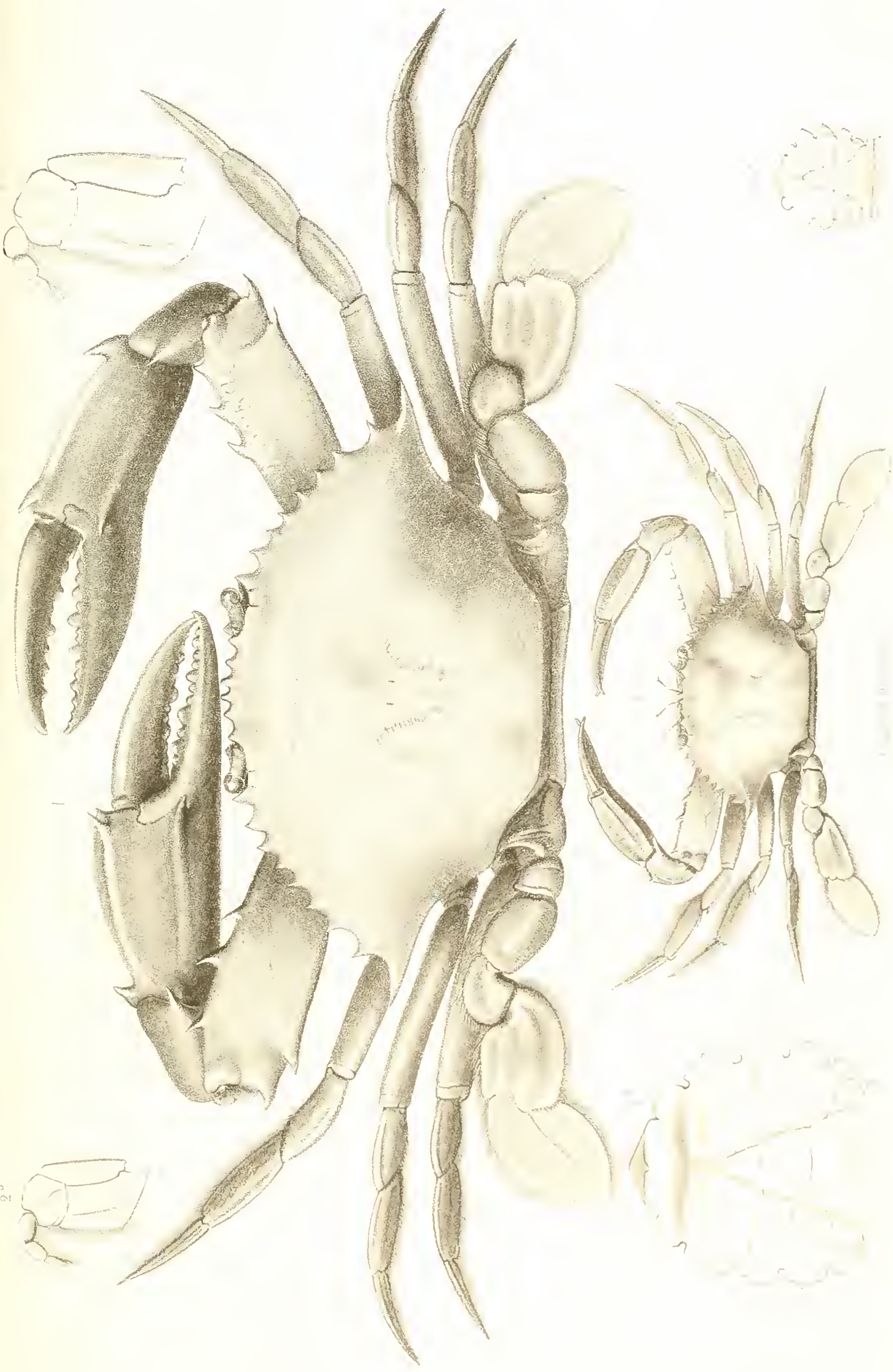




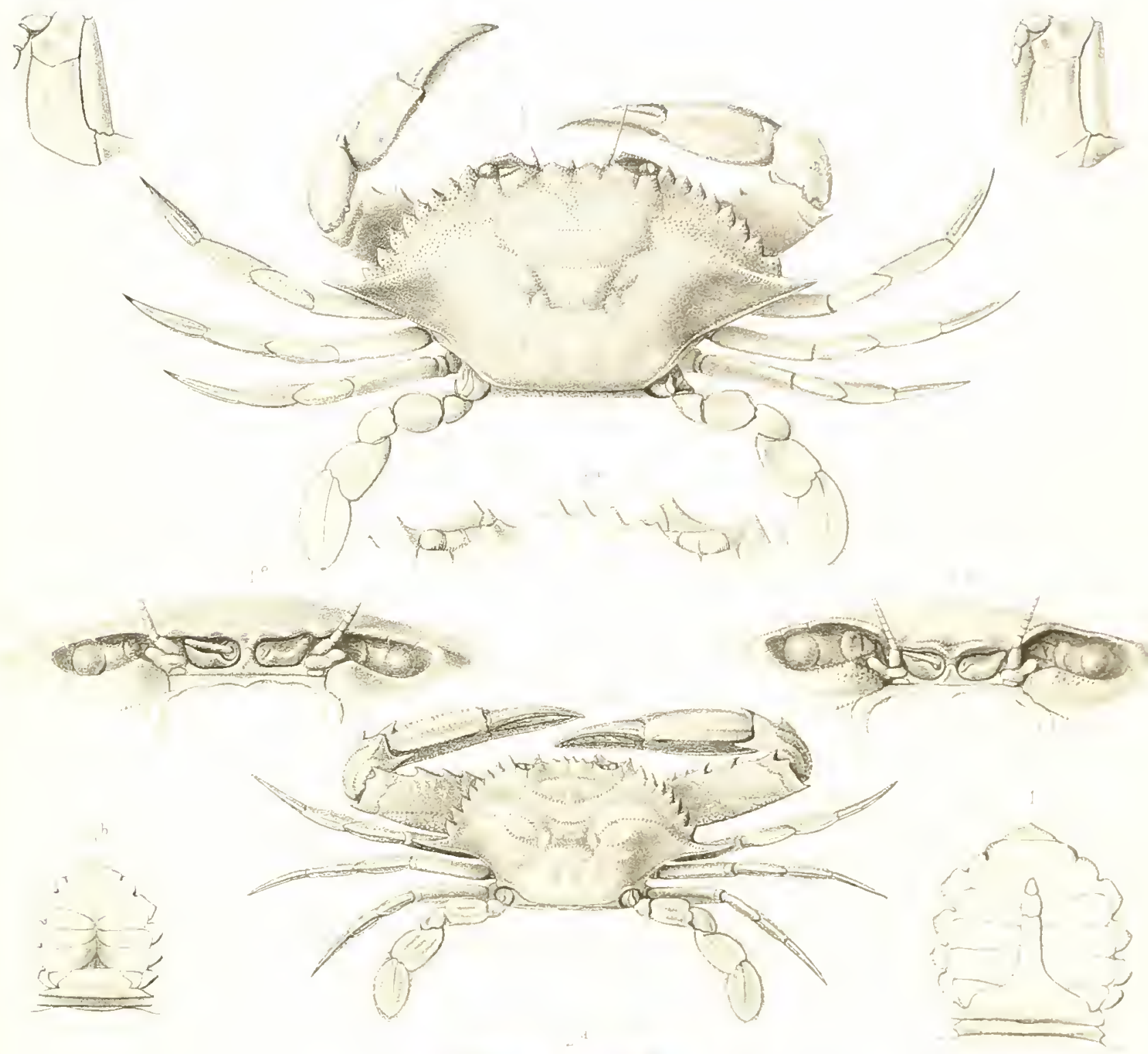

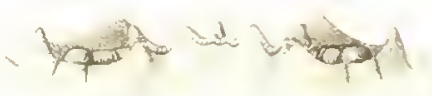

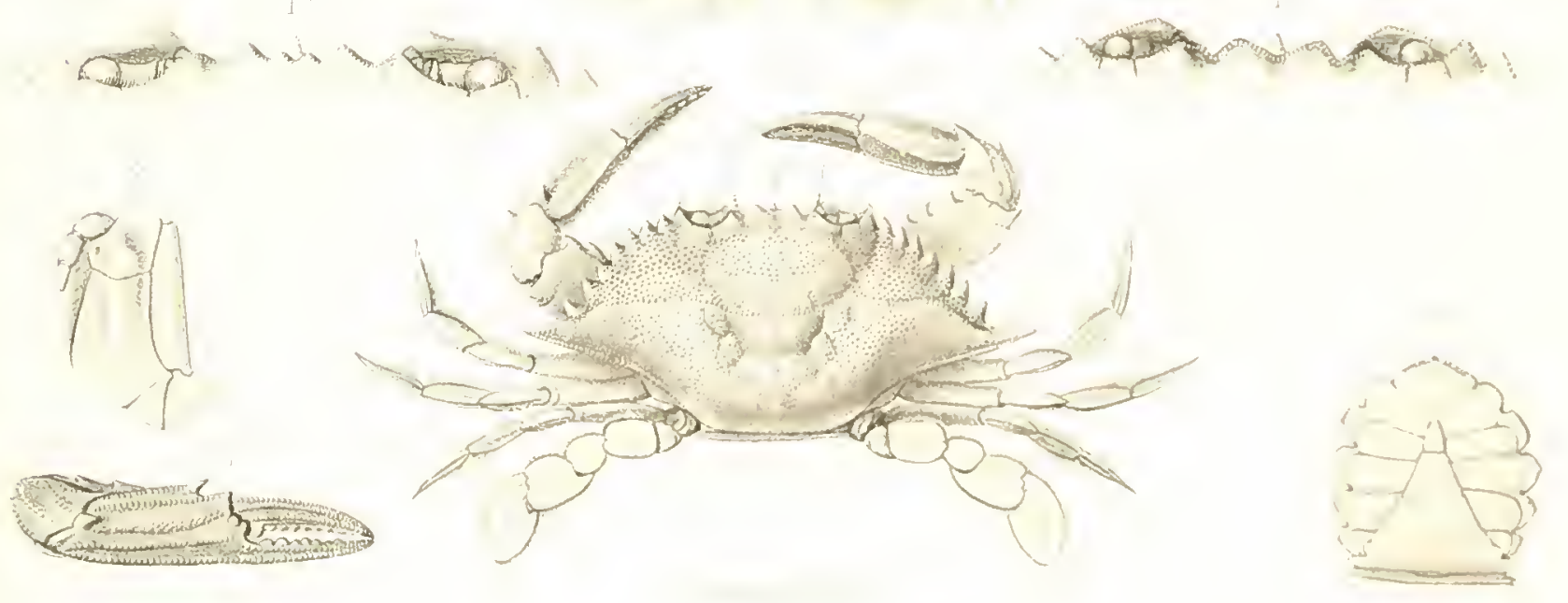





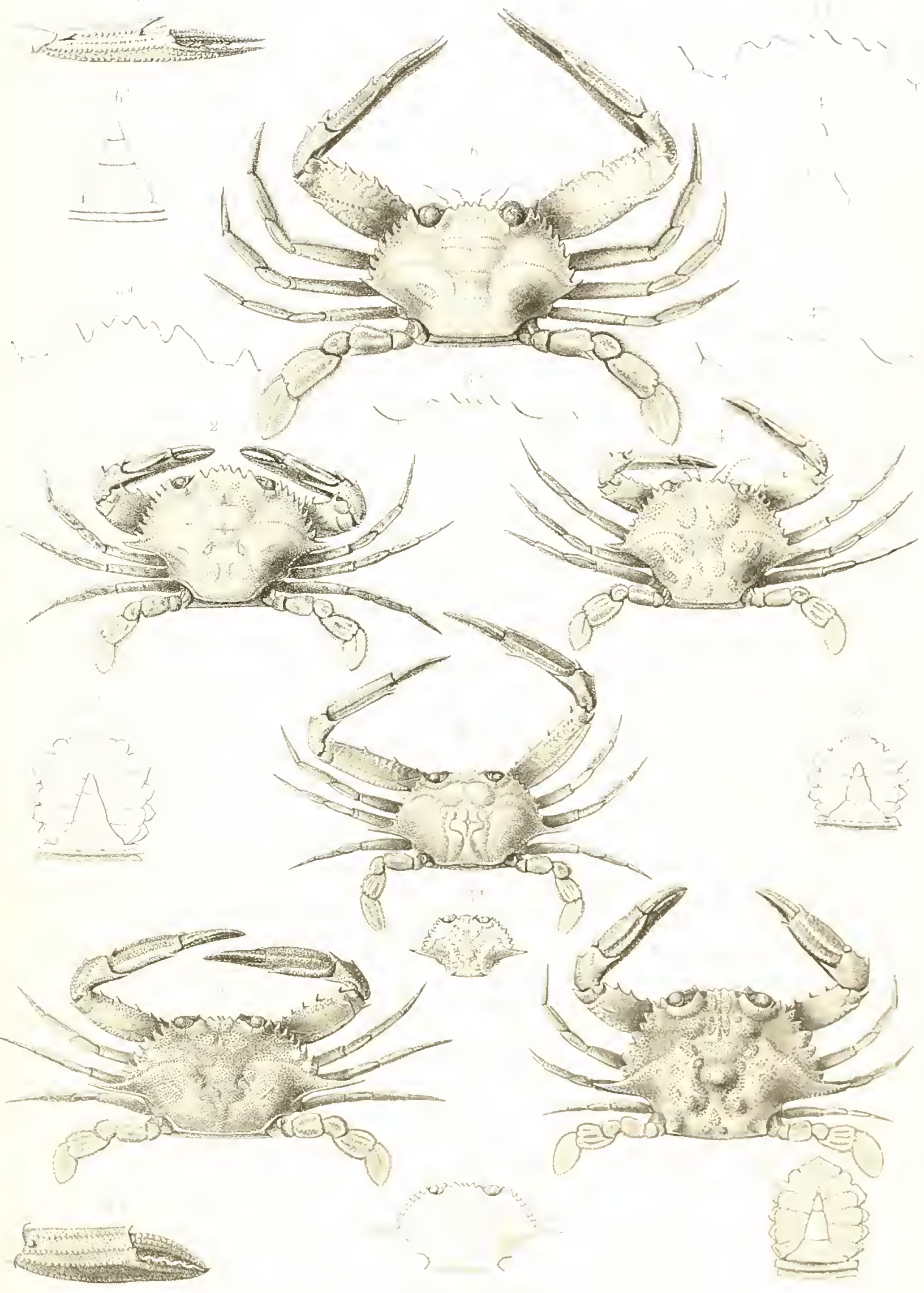





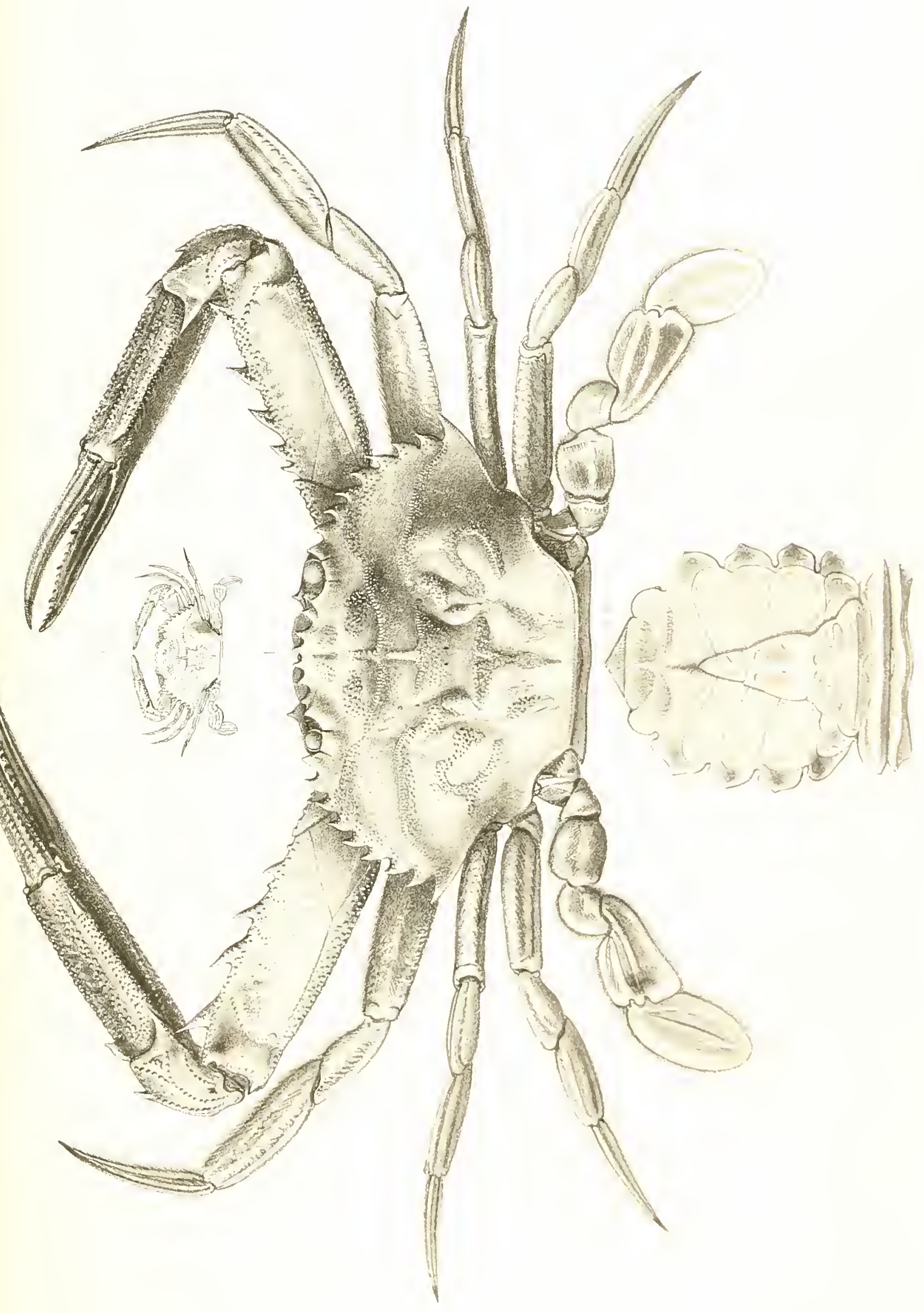





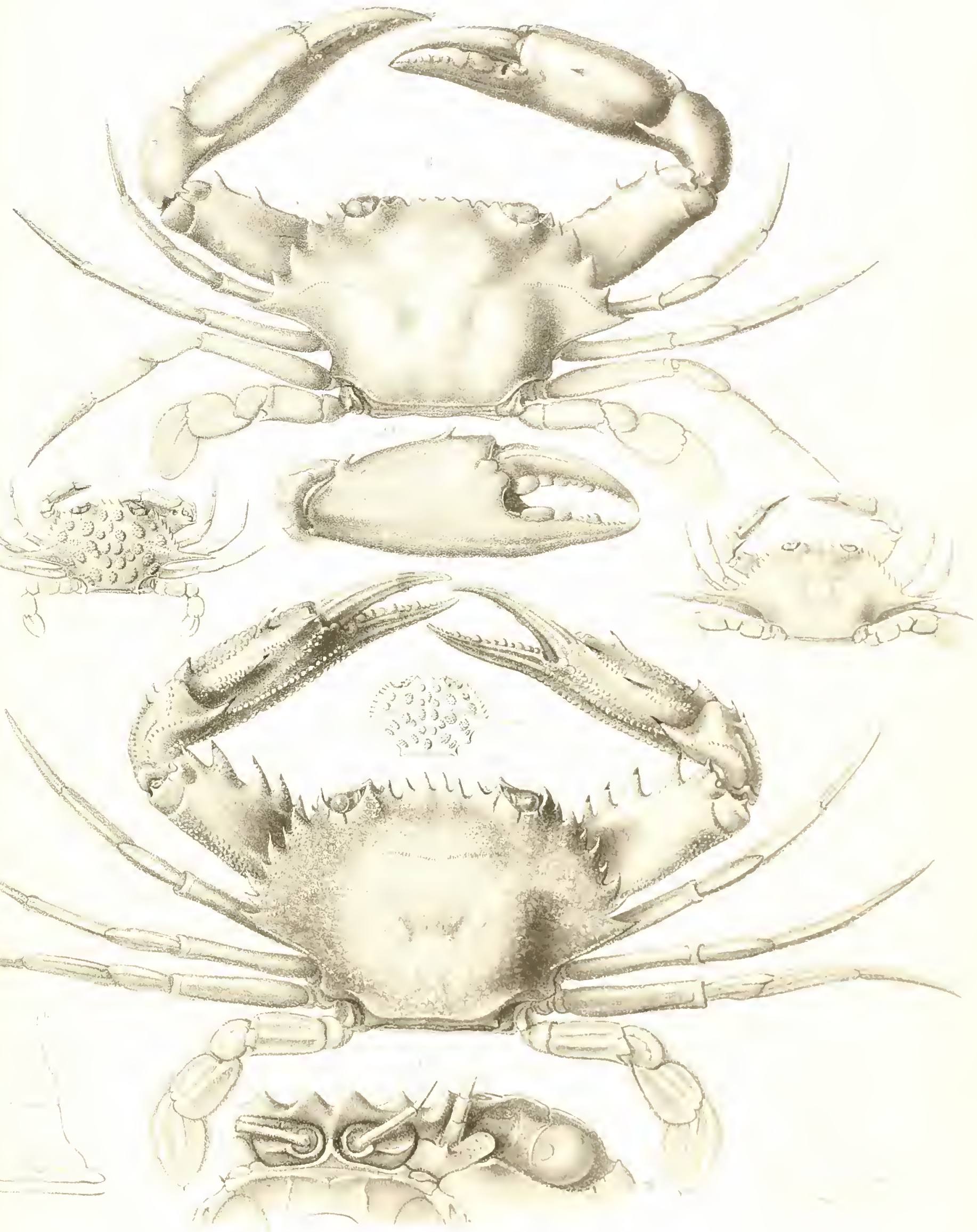





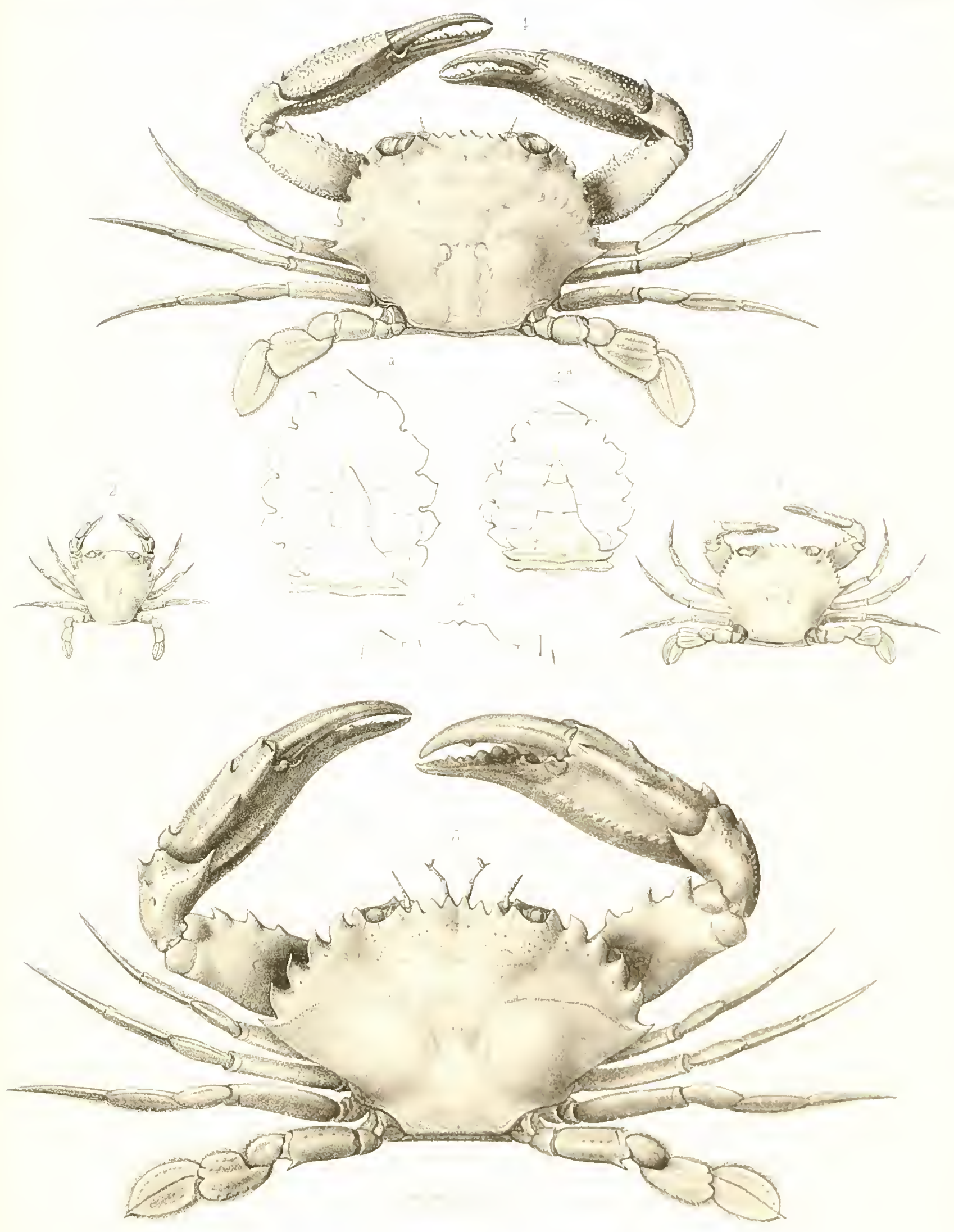





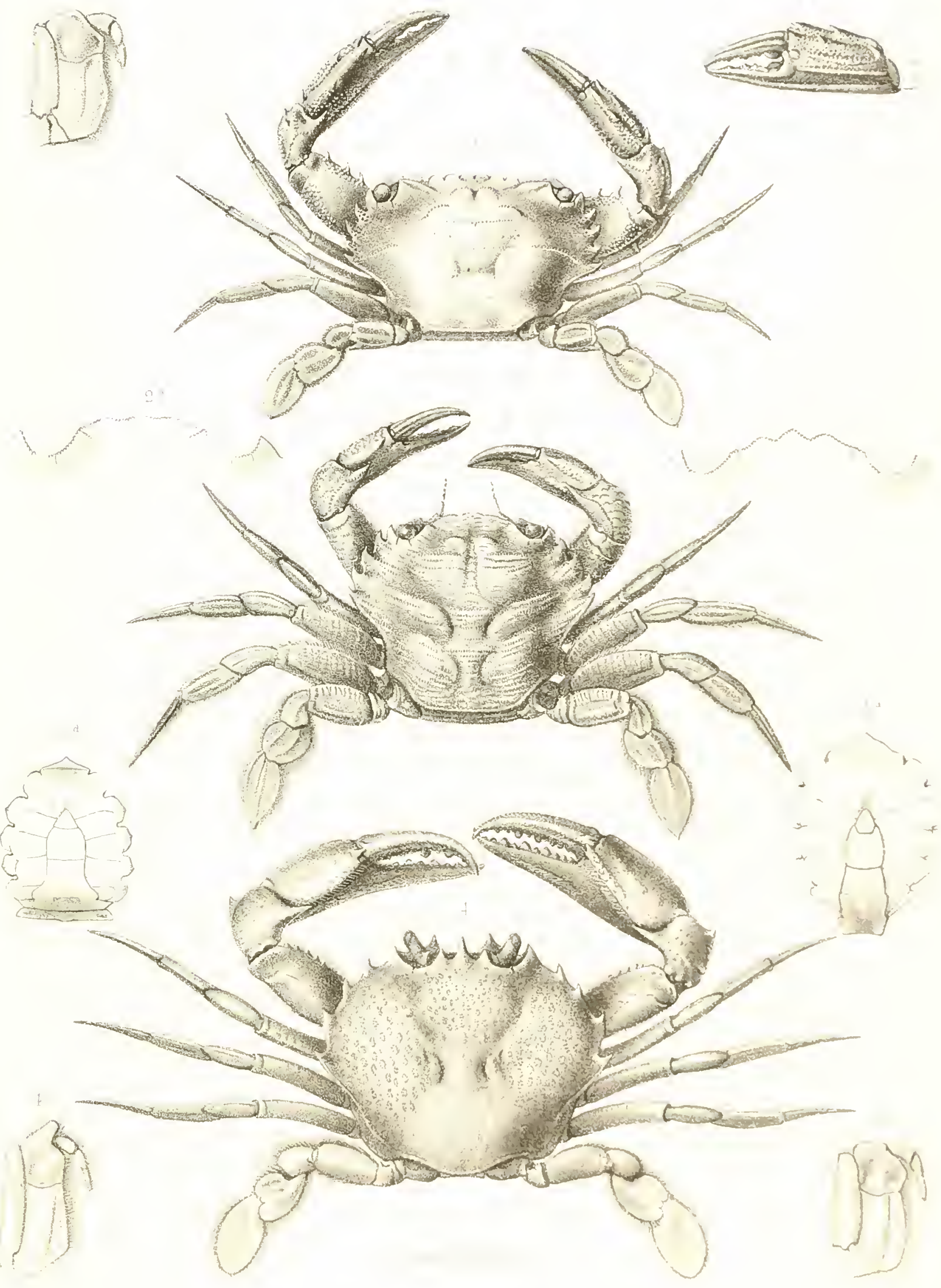





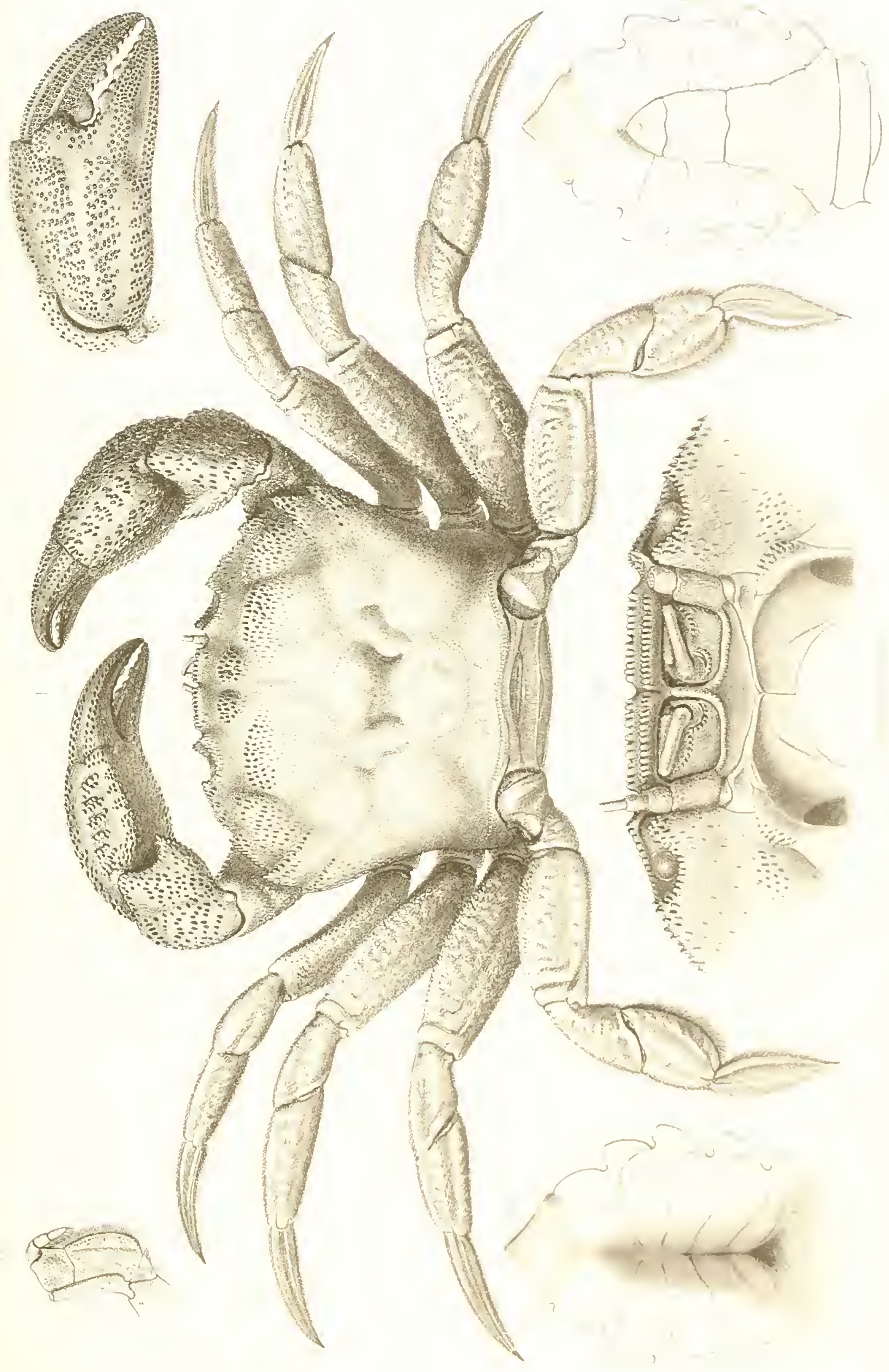





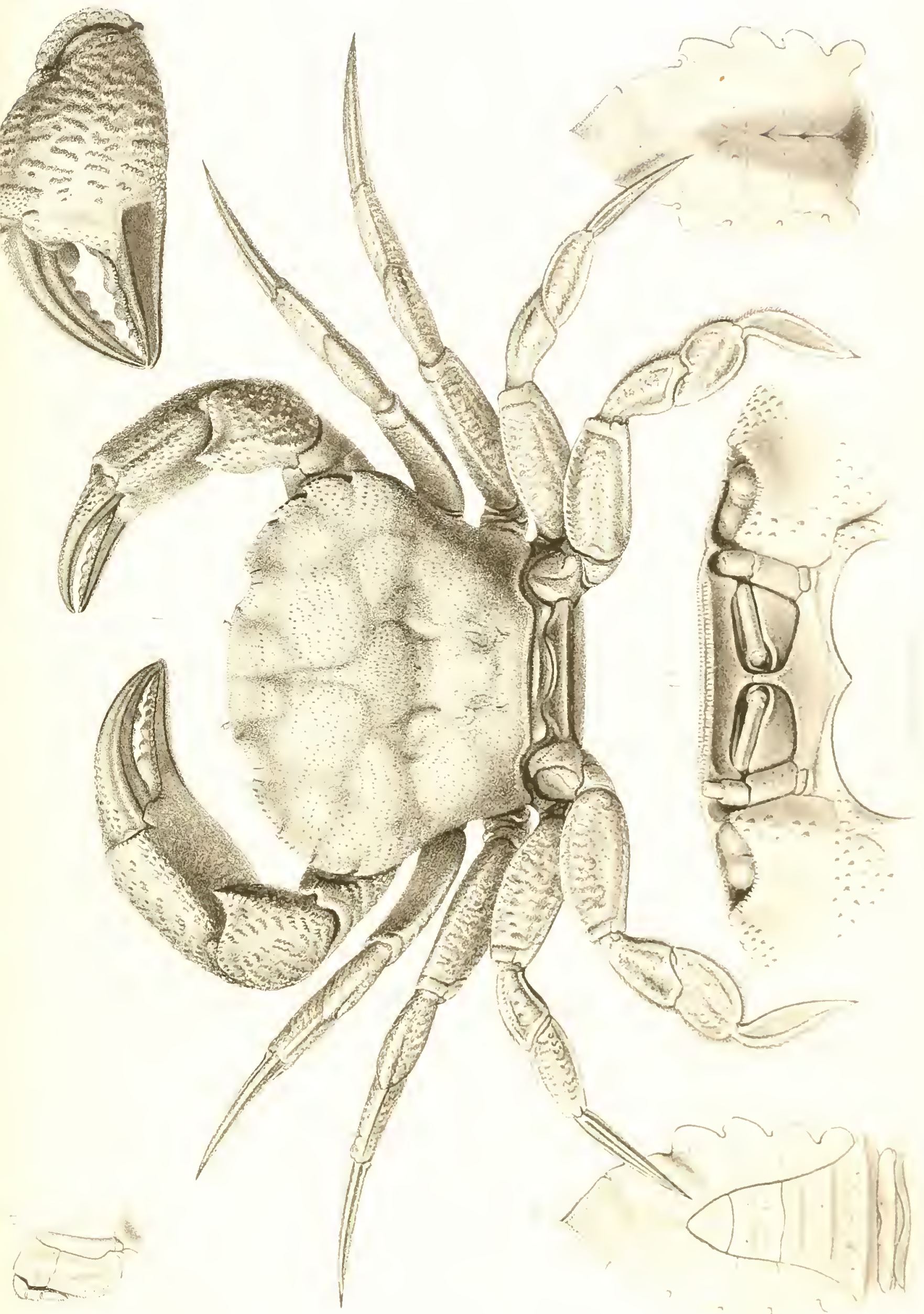


, 



(5)

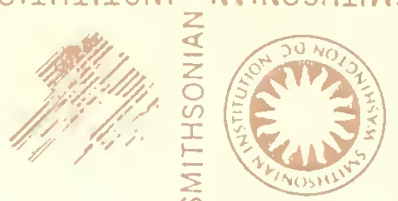

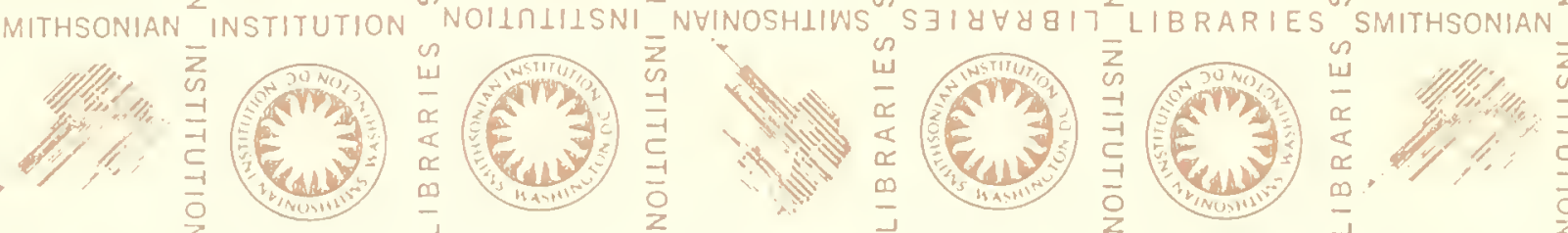

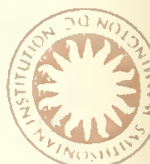

(2)

3

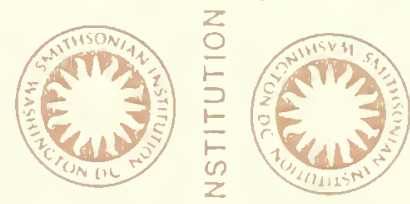

(3)

is.

(n)

E. (N)

,

(2)

(a)

)

(n)

(n)

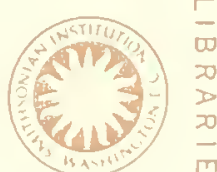

NINOSHIIWS
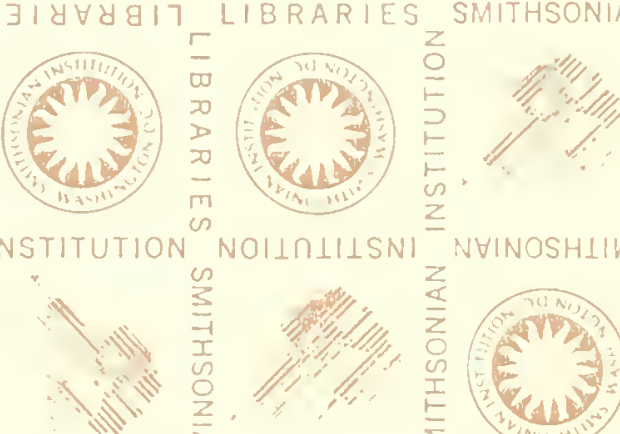

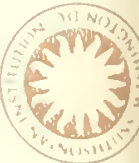
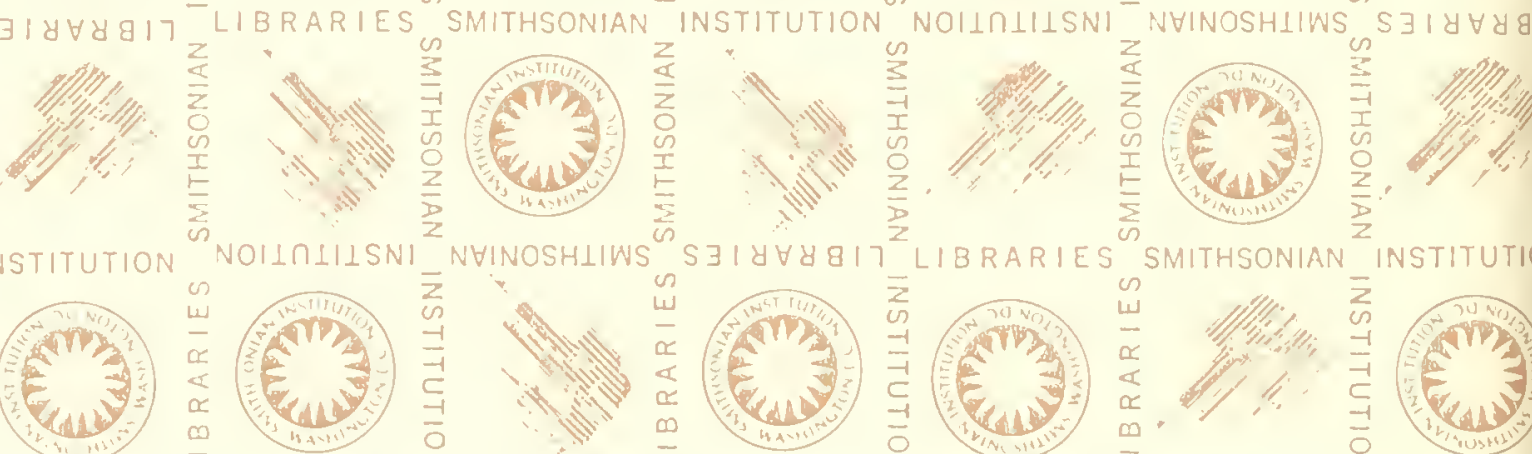

SMITHSONIAN
US:":
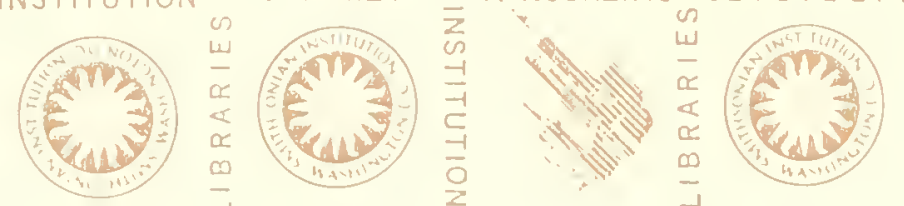

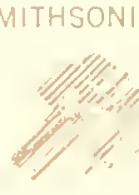

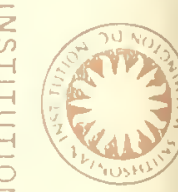

(y)<smiles></smiles>

(n)

(․․
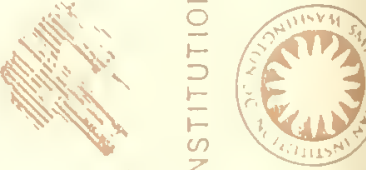

NOI $\perp \perp I \perp S N I$
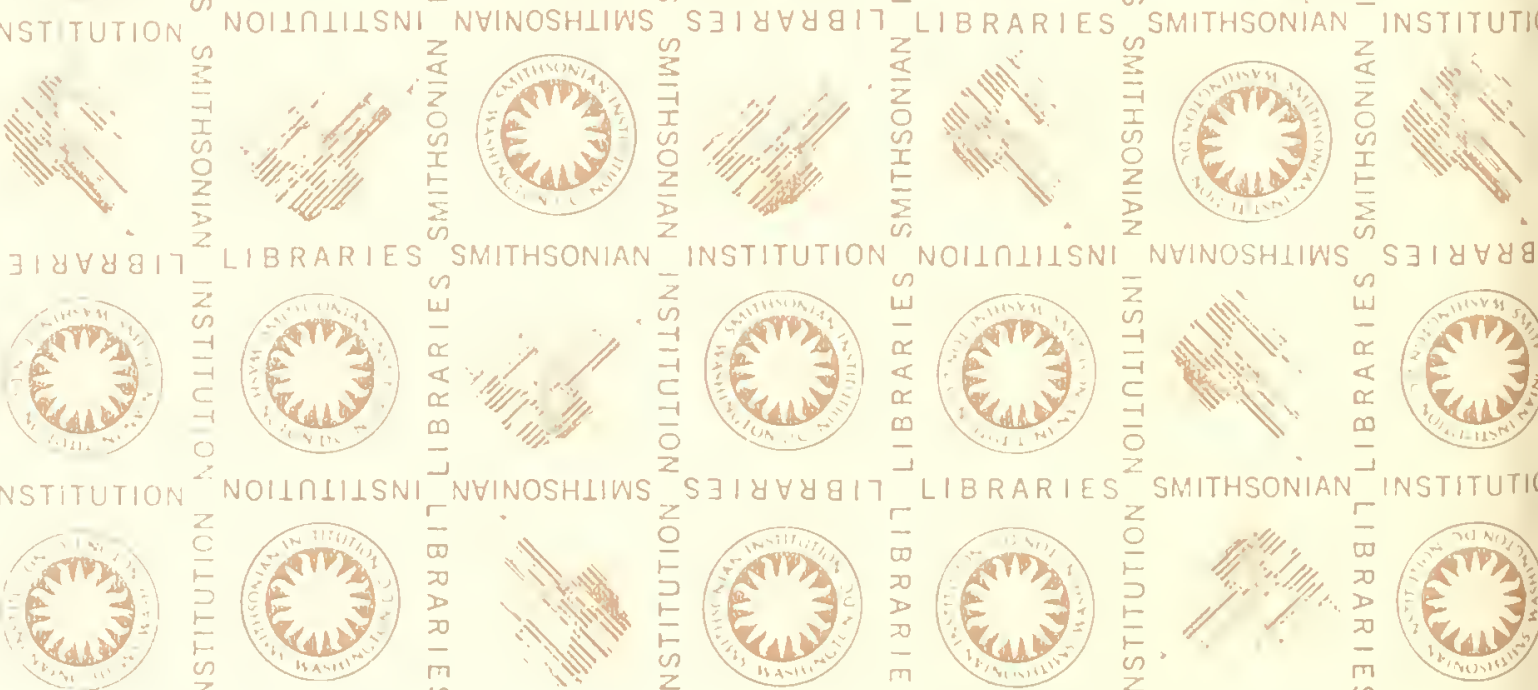


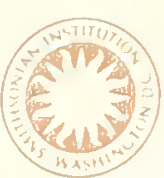

V,
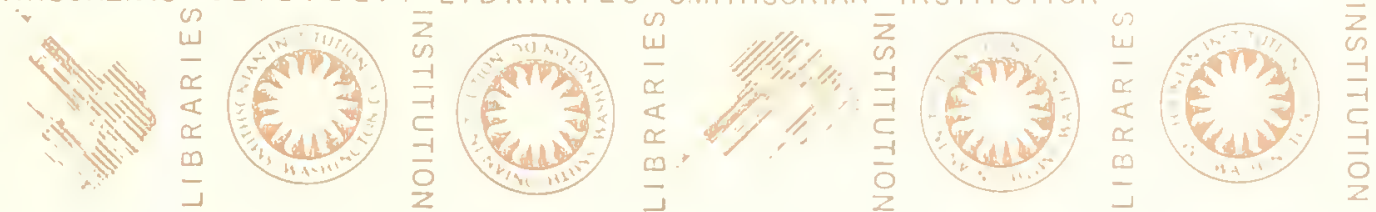

hitive

E 3

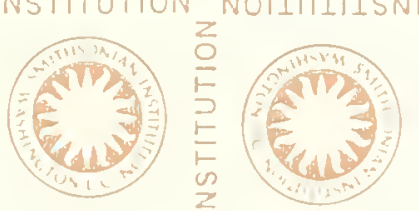

(a)

$=\frac{1}{2}$

(a)
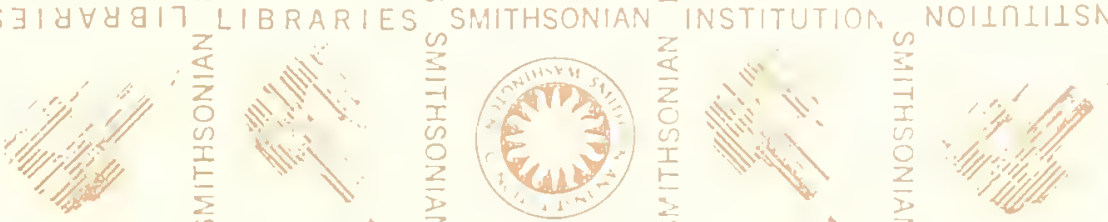

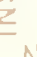

NINOSHIIWS

$\exists \mid$ y $\forall$ व

"ys

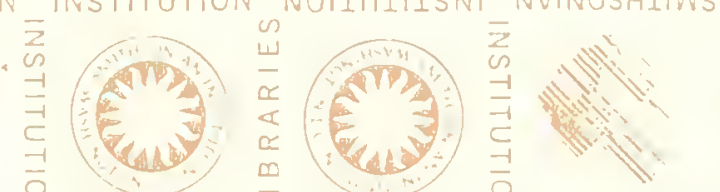

(ain

(in)

Ens?

(and

Anv

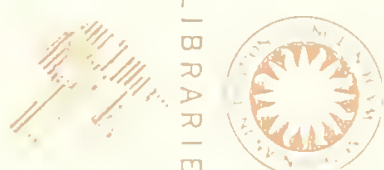

(m)

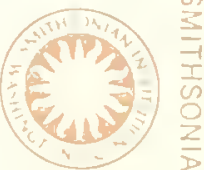

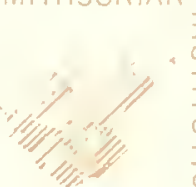

E

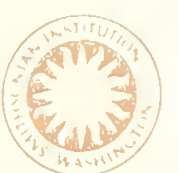
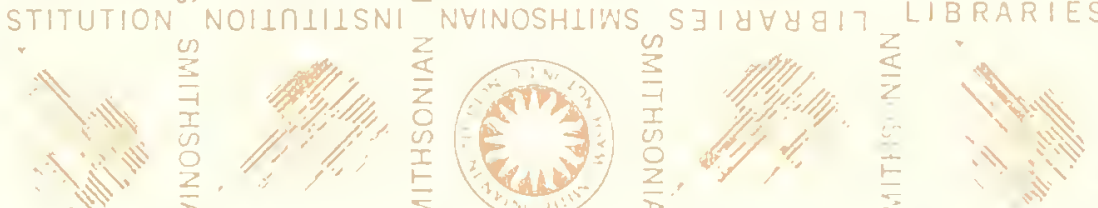

Evis

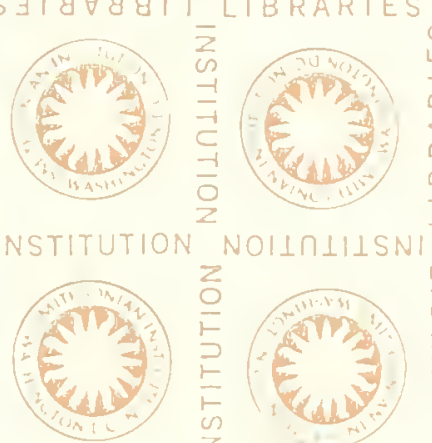

.

(a)

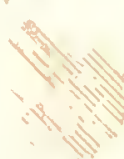

E

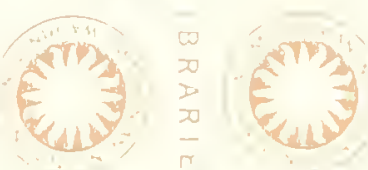

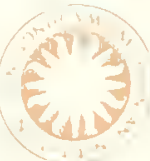

NSTITUT

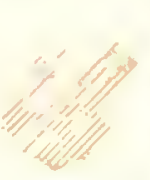

$E_{(1)}$

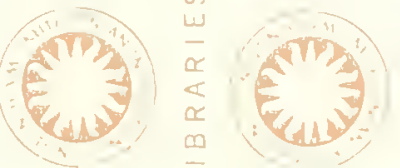

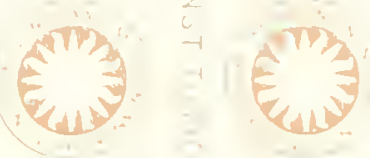

anvis
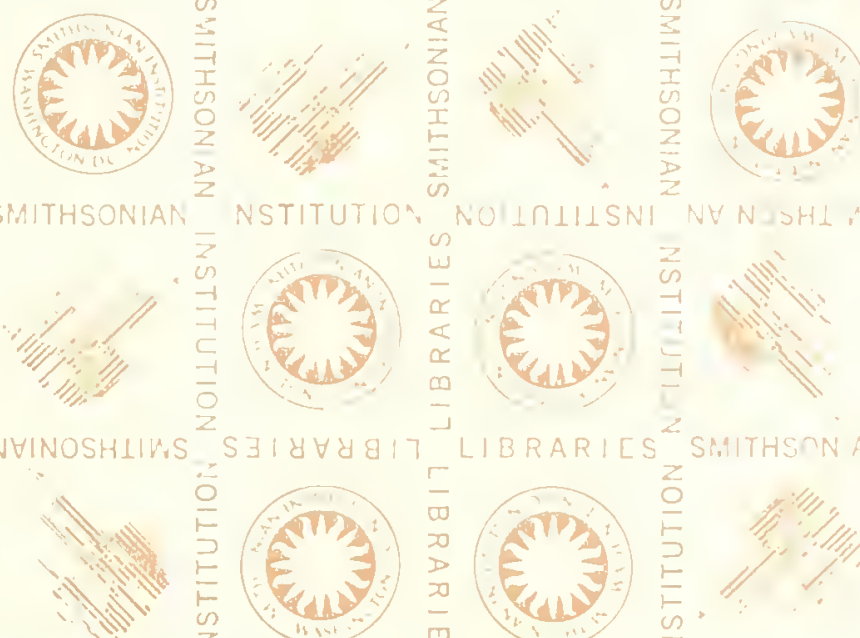

$$
\text { (1) }
$$


